Virginia

\author{
William J. Greathouse
}

Follow this and additional works at: https://researchrepository.wvu.edu/etd

\author{
Recommended Citation \\ Greathouse, William J., "Development of a conservation action plan for the eastern hellbender \\ (Cryptobranchus alleganiensis alleganiensis) in West Virginia" (2015). Graduate Theses, Dissertations, \\ and Problem Reports. 5707. \\ https://researchrepository.wvu.edu/etd/5707
}

This Dissertation is protected by copyright and/or related rights. It has been brought to you by the The Research Repository @ WVU with permission from the rights-holder(s). You are free to use this Dissertation in any way that is permitted by the copyright and related rights legislation that applies to your use. For other uses you must obtain permission from the rights-holder(s) directly, unless additional rights are indicated by a Creative Commons license in the record and/ or on the work itself. This Dissertation has been accepted for inclusion in WVU Graduate Theses, Dissertations, and Problem Reports collection by an authorized administrator of The Research Repository @ WVU.

For more information, please contact researchrepository@mail.wvu.edu. 


\title{
DEVELOPMENT OF A CONSERVATION ACTION PLAN FOR THE EASTERN \\ HELLBENDER (CRYPTOBRANCHUS ALLEGANIENSIS ALLEGANIENSIS) IN WEST VIRGINIA
}

\author{
William J. Greathouse
}

Dissertation submitted to the

Davis College of Agriculture, Natural Resources, and Design

at West Virginia University

in partial fulfillment of the requirements

for the degree of

Doctor of Philosophy

in

Animal Science

Eugene E. Felton, Ph.D., Committee Chairperson

Robert Dailey, Ph.D.

Margaret Minch, DVM

Thomas K. Pauley, Ph.D..

J. Todd Petty, Ph.D.

Division of Animal and Nutrition Sciences

Morgantown, West Virginia

2015

Keywords: hellbender, Cryptobranchus, salamander, head-started, reintroduction, translocation Copyright 2015 William J. Greathouse 


\title{
ABSTRACT
}

\section{DEVELOPMENT OF A CONSERVATION ACTION PLAN FOR THE EASTERN HELLBENDER (CRYPTOBRANCHUS ALLEGANIENSIS ALLEGANIENSIS) IN WEST VIRGINIA}

\author{
William J. Greathouse
}

The Eastern hellbender (Cryptobranchus alleganiensis alleganiensis) is the largest salamander in North America growing to 75 centimeters in length. This fully aquatic species is an indicator of good stream and river quality and has been considered to be in decline or rare throughout its range. This study focused on the current distribution of the Eastern hellbender at sites of historic occurrence in West Virginia in order to determine the species' current range and factors impacting its distribution in order to facilitate planned reintroductions and translocations of hellbenders reared in human care. The success of the reintroduction and translocation efforts were also a key focus of this study to determine if the release of individuals raised in human care could contribute to the conservation of this species in West Virginia.

Results of this study have indicated that hellbenders were only detected at 12 of 23 $(52 \%)$ surveyed sites of historic occurrence, and the habitat variables most strongly associated with the presence of this species at historic sites was the presence of forested landscape within the watershed and increased dissolved oxygen concentration within streams and rivers.

Key data from diet intake studies showed that $84 \%$ of hellbenders collected in West Virginia during periods of feeding had consumed crayfish with fish species being the second most frequently observed item consumed. In addition, no (39 of 39) hellbenders captured from July 8th - August 29th in West Virginia had any food items present in their stomach during surveys. The greatest factor associated with the lack of prey consumption was water temperatures in excess of $23^{\circ} \mathrm{C}$. These findings were confirmed with individuals in human care with individuals maintained at these temperatures not eating and losing an average of 15.33 grams during the 86 day trial period.

Finally, we created predictive models based on sites of hellbender presence during our surveys to identify high probability of occurrence sites for translocation of head-started hellbenders. We then released 14 individuals at a reintroduction site where head-started hellbender eggs were collected as well as 15 individuals at a translocation site that was previously occupied by hellbenders. Survival rates through 6 months of tracking during this study did not differ statistically between sites. Movement and home range were greater at the reintroduction site than at the translocation site, and stream bank shelters were used more frequently than stone shelters at the reintroduction site than at the translocation site. Increased movement and alternative shelter use are believed to be due to reduced shelter availability due to fewer boulders and the presence of adult hellbenders at the reintroduction site as opposed to conditions at the translocation site. 
Future hellbender conservation efforts in West Virginia should include preservation of forest habitat near current hellbender populations and surveillance of historic sites based upon predictive model results. Reintroductions and translocations of head-started juveniles or subadults should be conducted at sites of greatest predicted occurrence with long-term monitoring for detection of reproductively sustainable populations. 


\section{ACKNOWLEDGEMENTS}

This dissertation and the research associated with it have been made possible by the sacrifice of my wife, Susan, and my daughters, Caroline, Bethany, Emma, and Hannah. Their sacrifice of time with me over the past several years has enabled me the opportunity to complete this study and to enjoy my passion of studying this magnificent species. I also must acknowledge the impetus of pursuing this degree to my parents, Bill and Sally, who have always instilled the importance of education in spite of not having the opportunity to attend college themselves.

I would like to thank my graduate research advisor, Dr. Eugene Felton, as well as the rest of my graduate committee members, Dr. Robert Dailey, Dr. Margaret Minch, Dr. Thomas Pauley, and Dr. Todd Petty, who have provided their time, guidance, expertise, patience, and understanding to enable me to complete this research. I would also like to thank Penny Miller, the director of Oglebay's Good Zoo, Dr. Michael Miller, the zoo's former veterinarian, and Dr. Barbara Wolfe of the Wilds for their support and encouragement of me to pursue this degree. Without the support and encouragement of all of these individuals, I would not have been able to have managed a full-time career, my studies, and my family in the manner that they facilitated.

Furthermore, I would like to thank the West Virginia Division of Wildlife for funding this study through the State Wildlife Grant Program and Walt Kordek and Michael Welch of the West Virginia Division of Wildlife for guidance and assistance with completion of these studies 
as well as Barbara Sargent for assistance with collection permit guidance. I would also like to thank the Columbus Zoo and Aquarium Conservation Fund for partial funding of the telemetry equipment utilized during this study.

Finally, the activities associated with the completion of this research were not possible without the support of many co-workers, interns, and volunteers from Oglebay's Good Zoo who assisted with several of the activities carried out during this project including field surveys for hellbender presence - Susan Greathouse, Mindi White, Kala Bassa, Troy Quick, Bryan Blawut, James DeNucci, Sid Jacobs, Dan Martin, Kyle Jones, Amy Toman, Phillip Cahill, Mike Adams, Kanyon McClean, Kyleigh Garberson, Rebecca Spear, Kortney Jaworski, Daniel Caron, and Stan Myers; caring for hellbenders in human care during rearing - Susan Greathouse, Mindi White, Kala Bassa, Troy Quick, Melanie Hengler, and Katie Marino; surgical implantation of radio telemetry transmitters - Dr. Paige Stoehr and Dr. Todd Moores; and radio telemetry survey assistance - Susan Greathouse and Derek Zagort.

I greatly appreciate the support and the effort of all of the aforementioned individuals who have supported my endeavors and these efforts to conserve such a fascinating species in our state. 


\section{TABLE OF CONTENTS}

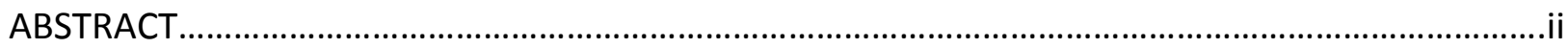

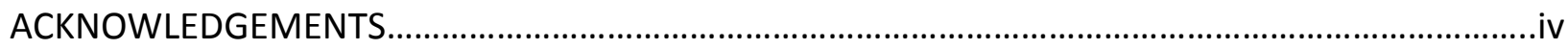

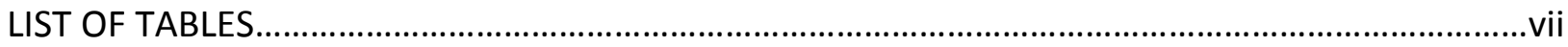

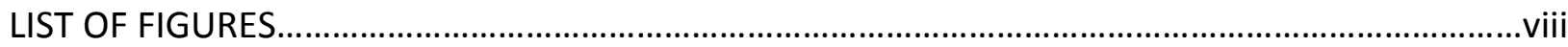

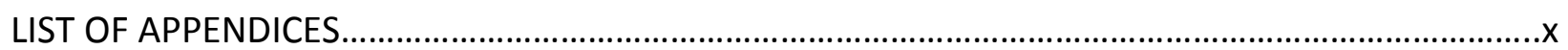

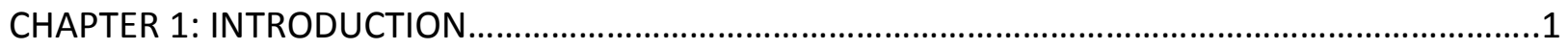

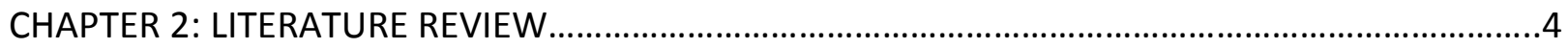

CHAPTER 3: LANDSCAPE AND MICROHABITAT VARIABLES ASSOCIATED WITH THE DISTRIBUTION OF THE EASTERN HELLBENDER (CRYPTOBRANCHUS ALLEGANIENSIS ALLEGANIENSIS) IN WEST

VIRGINIA.

CHAPTER 4: INCREASED WATER TEMPERATURES ASSOCIATED WITH FASTING IN THE EASTERN HELLBENDER (CRYPTOBRANCHUS ALLEGANIENSIS ALLEGANIENSIS) ........................................74

CHAPTER 5: SURVIVAL, HOME RANGE, AND SHELTER SELECTION OF REINTRODUCED AND TRANSLOCATED HEAD-STARTED EASTERN HELLBENDERS (CRYPTOBRANCHUS ALLEGANIENSIS

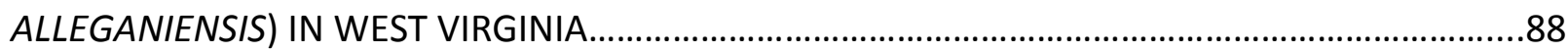

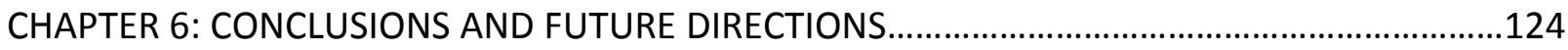

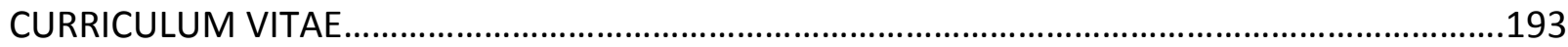




\section{List of Tables}

\section{Chapter 2}

Table 1. Historic sites of hellbender occurrence in West Virginia and the year of the last recorded hellbender observation prior to this study....

Table 2. Results of recent surveys of sites of known hellbender occurrence in West Virginia...50

\section{Chapter 3}

Table 1. Mean morphological measurements of captured hellbenders.

Table 2. Mean microhabitat and landscape variable values at sites where hellbenders were observed and not detected with Mann-Whitney test $p$-values

Table 3. Results of canonical discriminant analysis of environmental variables associated with sites of hellbender presence (positive values) and sites where hellbenders were not observed (negative values)

Table 4. Contribution of landscape variable importance of training data to MaxEnt model as well as permutation importance of each variable to the AUC.

\section{Chapter 4}

Table 1 - Mean length and mass changes of hellbenders reared in human care

\section{Chapter 5}

Table 4 - Translocation site rankings based upon models of in-stream and landscape-level environmental variables. The lowest sum value of rankings was utilized to select the translocation site. 


\section{List of Figures}

\section{Chapter 2}

Figure 1 - Map of the range of the hellbender. Illustration is courtesy of the Marshall University Herpetology Lab web site -

http://www.marshall.edu/herp/Salamanders/hellbender.htm. 39

Figure 2 - Gill slit opening on side of sub-adult hellbender

Figure 3 - Head of adult hellbender showing eyes without eyelids and open anterior nostrils.40

Figure 4 - Female hellbender with multiple bite wounds from other adult hellbenders

Figure 5 - Photo of adult hellbender with orange ventral pigmentation .41

Figure 6 - Lateral folds of the Eastern hellbender.

Figure 7 - Front and hind feet of the hellbender .42

Figure 8 - The tail of the hellbender. .43

Figure 9 - Swollen cloacal gland of the male hellbender....................................................43

Figure 10 - Male hellbender with bite from a conspecific.......................................................44

Figure 11 - Male hellbender with leg injury during breeding season. ......................................44

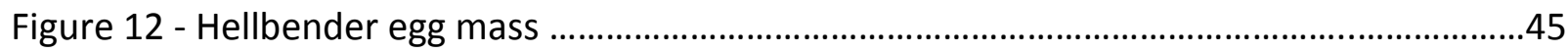

Figure 13 - Individual hellbender egg at approximately 2 weeks post-fertilization...................45

Figure 14 - Multiple hellbender larvae being reared in human care.......................................46

Figure 15 - Physical stone-lifting surveillance technique...................................................46

Figure 16 - Hellbender being measured in measuring tube................................................47

Figure 17 - Hellbender being implanted with PIT tag …........................................................47

Figure 18 - Whip transmitter being implanted in adult hellbender ........................................48

Figure 19 - Smaller loop transmitter being implanted in juvenile hellbender.........................48 


\section{Chapter 3}

Figure 1 - Map of hellbender survey sites........................................................................55

Figure 2 - Frequency distribution table of number of hellbenders captured per $5 \mathrm{~cm}$ size class......

Figure 3-Box plot indicating canonical discriminant analysis score for sites where hellbenders were present $(\mathrm{Y})$ and not observed $(\mathrm{N})$ as well as plot of vector magnitude associated with analyzed environmental variables

Figure 4-Plot of training and test area under curve (AUC) data of MaxEnt analysis for landscape level variables associated with prediction of Hellbender occurrence.

Figure 5 - Map of predicted rasters of hellbender probability greater than $73.6 \%$ .64

Figure 6-MaxEnt predictive map of Hellbender occurrence in West Virginia at the landscape level.

\section{Chapter 4}

Figure 1 - Classification and regression associated with hellbender prey consumption during summer months in West Virgnia.

Figure 2 - Boxplot indicating changes in mass of individuals housed at $20^{\circ} \mathrm{C}$ and $23^{\circ} \mathrm{C}$

\section{Chapter 5}

Figure 1-Kaplan-Meier survival estimates for Hellbenders released at the reintroduction and translocation sites

Figure 2-Chart of boulder shelter area $\left(\mathrm{cm}^{2}\right)$ occupied by Hellbenders at the reintroduction and translocation sites.

Figure 3-Chart of shelters selected during each season by individuals at the reintroduction site......

Figure 4-Photo of most boulder dense region of the translocation site.

Figure 5-Photo of most boulder dense region of the reintroduction site 122 


\section{List of Appendices}

Appendix 1 - Proposed conservation action plan for the hellbender in West Virginia...... .128

Appendix 2 - Morphometric measurements of hellbenders captured during 2010 surveys...133

Table 1 - Morphometric measurements of hellbenders captured during 2010 surveys

Appendix 3 - Environmental variables measured from 2010 survey sites and associated analysis values.

Table 1. In-stream habitat characteristics for each study site 134

Table 2. Wolman pebble count data for substrate composition at each study site...135

Table 3. Landscape level characteristics of study sites 136

Table 4 - Mann-Whitney test results of statistical comparisons of in-stream and landscape environmental variables at sites where hellbender presence was documented as opposed to sites where hellbenders were not observed.

Appendix 4 - Capture per unit effort abundance data from 2010 surveys and associated analyses.

Table 1 - Hellbender distribution and density table

Figure 1 - Map of survey sites by abundance level.

Table 2 - Average in-stream environmental variables by abundance level.

Figure 2 - Canonical discriminant analysis biplot of in-stream environmental variables at each site as a function of abundance

Table 3 - Table of eigenvectors $(\geq|0.4|$ ) associated with canonical discriminant analysis of in-stream environmental variables as a function of abundance.

Figure 3 - Canonical discriminant analysis biplot of in-stream and landscape variables at each site as a function of abundance.

Table 4 - Table of eigenvectors $(\geq|0.4|$ ) associated with canonical discriminant analysis of in-stream and landscape variables as a function of abundance. 144 
Table 5 - Kruskall-Wallis test results of statistical comparisons of in-stream and landscape environmental variables at sites as a function of hellbender abundance

Appendix 5 - Hellbender consumption and growth as a function of water temperature..146

Table 1 - Original and final masses $(\mathrm{g})$ and total lengths $(\mathrm{cm})$ as well as the changes in each individual observed during the lab portion of this study. 146

Figure 3 - Pie graph of food items consumed by percent of individuals studied in the wild that were observed to have consumed prey.

Table 2 - Table of prey items observed in captured wild hellbenders

Figure 4-Gastric lavage technique being utilized on adult hellbender......

Figure 5 - Stomach contents collected from adult female hellbender ID \#: 00-068D-9E7B at Buffalo Creek on May $1^{\text {st }}, 2010$.

Figure 6 - Stomach contents collected from adult male ID\#: 00-06FB-9CDA from the Back Fork of the Elk River on July $7^{\text {th }}, 2010$.

Figure 7 - Stomach contents collected from adult female ID\#: 00-06FB-8D5D from the Shavers Fork of the Cheat River on June $17^{\text {th }}, 2010$.

Figure 8 - Stomach contents collected from adult male ID\#: 00-068D-AAE3 from the West Fork of the Greenbrier River on June $12^{\text {th }}, 2010$.

Figure 9 - Stomach contents collected from adult male ID\#: 00-068D-BFBD from the Wheeling Creek on May 28th, 2010.

Appendix 6 - Models and maps utilized for determination of translocation site.

Table 1 - Calculated Bray-Curtis similarity index values of environmental variable values where Hellbenders were not observed during 2010 surveys.

Figure 1-Cluster dendrogram with Ward linkage from Bray-Curtis similarity index showing relationship of environmental variables at sites of historic occurrence where Hellbenders were not observed recently to sites of current observed Hellbender abundance ( $\geq 0.4$ Hellbender captures per person hour)..154 
Figure 2-NMDS biplot based upon Bray-Curtis similarity index of environmental variables at sites of historic occurrence where Hellbenders were not observed recently to sites of current observed Hellbender abundance ( $\geq 0.4$ Hellbender captures per person hour).

Table 2 - Relation between two dimensional nonmetric multidimensional scaling (NMDS) axes and in-stream and landscape variables at 23 survey sites of historic hellbender occurrence in West Virginia, summer 2010

Figure 3-Map of soil rasters utilized in MaxEnt prediction model 157

Figure 4 - Map of population density rasters per square mile utilized in MaxEnt prediction model .158

Figure 5 - Map of land cover rasters utilized in MaxEnt prediction model. .159

Figure 6 - Map of landscape integrity rasters utilized in MaxEnt prediction model

Figure 7 - Map of geology rasters removed from MaxEnt prediction model .161

Figure 8-Map of elevation rasters utilized in MaxEnt prediction model 162

Figure 9 - Map of predicted rasters of hellbender probability greater than $73.6 \%$. 163

Figure 10 - Cedar Creek MaxEnt probability projection. .164

Figure 11 - Cherry River MaxEnt probability projection. .165

Figure 12 - Fish Creek MaxEnt probability projection........................................166

Figure 13 - Glade Creek MaxEnt probability projection......................................167

Figure 14 - Greenbrier River MaxEnt probability projection...............................168

Figure 15 - Laurel Creek MaxEnt probability projection .169

Figure 16 - Little Kanawha River MaxEnt probability projection .170

Figure 17 - Mud River MaxEnt probability projection .171 
Figure 18 - North Fork Hughes River MaxEnt probability projection

Figure 19 - Second Creek MaxEnt probability projection

Figure 20 - Twelvepole Creek MaxEnt probability projection

Table 1 - Individual Hellbender transmitter numbers, telemetry transmitter frequency number, mass in grams (g), snout-to-vent length (SVL) in centimeters $(\mathrm{cm})$, result of individual during study, and days observed following release.

Table 2 - Individual Hellbender transmitter numbers, telemetry transmitter frequency number, minimum convex polygon (MCP) home range in square meters $\left(\mathrm{m}^{2}\right)$, linear home range (LHR) in meters $(\mathrm{m})$, result of individual during study, and days observed following release.

Figure 1 - Large boulders utilized by released hellbenders in this study at the Cherry River translocation site. Large boulder in center of top photo was and large boulder in foreground of bottom picture was inhabited regularly by released individuals

Figure 2 - Photo of deceased hellbender that was buried and removed from deep gravel bed after high water event.

Figure 3 - Hellbender tail observed coming out of crevice in stream 179

Figure 4 - Buffalo Creek 164.012 observed locations (red dots) during study........180 Figure 5 - Buffalo Creek 164.053 observed locations (blue dots) during study......181 Figure 6 - Buffalo Creek 164.093 observed locations (green dots) during study....182

Figure 7 - Buffalo Creek 164.255 observed locations (green dots) during study....183

Figure 8 - Buffalo Creek 164.263 observed locations (red dots) during study........184 Figure 9 - Buffalo Creek 164.304 observed locations (blue dots) during study......185 Figure 10 - Cherry River 164.032 observed locations (purple dots) during study..186 Figure 11 - Cherry River 164.043 observed locations (blue dots) during study......187 
Figure 12 - Cherry River 164.083 observed locations (purple dots) during study...188

Figure 13 - Cherry River 164.162 observed locations (blue dots) during study.......189

Figure 14 - Cherry River 164.183 observed locations (red dots) during study.........190

Figure 15 - Cherry River 164.214 observed locations (red dots) during study.........191

Figure 16 - Cherry River 164.222 observed locations (red dots) during study.........192

Figure 17 - Cherry River 95\% MCP's of translocated individuals tracked during study. 


\section{CHAPTER 1}

INTRODUCTION

Threats to amphibian biodiversity have resulted from a variety of factors including habitat loss and fragmentation, diseases such as the amphibian chytrid fungus

(Batrachochytrium dendrobatidis) and FV-3 ranavirus, chemical and non-point source pollution, collection for the pet and food trades, and the introduction of invasive species (Gibbons, 2000; LaMarca et al., 2005; Mendelson, 2006; and Norris, 2007). The International Union for the Conservation of Nature (IUCN) has noted that approximately one-third (32\%) of the world's 5,743 documented amphibian species have been classified as threatened with extinction, and at least 122 species went extinct between 1980 and 2005 (Gascon, 2005).

The Eastern hellbender (Cryptobranchus alleganiensis alleganiensis) is the largest salamander in North America growing to 75 centimeters in length (Conant and Collins, 1998). This fully aquatic species is considered an indicator of good stream and river quality and an important predator of crayfish within the systems that it inhabits (Petranka, 1998). Hellbender populations have been documented to be in decline throughout the species' range in terms of abundance as well as distribution, with the number of streams and rivers currently inhabited by this species being greatly reduced compared to historically documented observations (Prosen, 1999; Wheeler, 1999; Wheeler et al., 2003; Lipps and Sisson, 2008; and Burgmeier et al., 2011). Causes of hellbender declines have been attributed to a variety of factors including acid mine drainage, impoundment of streams and rivers, sedimentation, disease, over-collection and historic bounty hunts, and predation by invasive species (Mayasich et al., 2003). 
Relatively few studies of the Eastern hellbender have been undertaken in West Virginia, and poor baseline data exist on the historic abundance of this species throughout the state. At one point it was believed that West Virginia was the region of the United States with the most abundant populations of hellbenders (Green, 1934), but no survey data are published for this species between 1935 and 1999. A well-studied population of hellbenders in the West Fork of the Greenbrier River, Pocahontas County, has appeared to remain stable over recent decades (Humphries and Pauley, 2005; Horchler, 2010). However, surveys in southern West Virginia early in the $21^{\text {st }}$ century indicated that the species is in decline throughout this region (Makowsky, 2004; Keitzer, 2007; Keitzer et al., 2013).

I initiated studies of the hellbender on several streams of historic occurrence in the Northern Panhandle of West Virginia in 2005 with assistance from the West Virginia Division of Wildlife. Surveys on two streams have continued annually to maintain baseline data on the abundance and distribution of the species at these sites. During surveys in September, 2007, the author discovered a nest of hellbender eggs that had been infected by the water fungus, Saprolegnia (Buffalo Creek, Brooke County, West Virginia). With the permission of the WV DNR, these eggs were taken to Oglebay's Good Zoo and raised with the intention of future reintroduction back to the site after individuals had reached a size appropriate for reintroduction. For incubation purposes, infected eggs were discarded and eggs that were not visibly infected were separated from each other and maintained in 60 milliliters of water treated with sodium thiosulfate at a rate of $7.5 \mathrm{ml}$ per liter of water to remove chloramines and heavy metals. The water was also treated with methylene blue at a concentration of 3 parts per million to prevent or treat fungal infection. The hatching of this clutch of eggs and 
successful rearing was the first time that eggs from this species had been hatched successfully in any zoo or aquarium in the world.

This project was initiated to maximize the potential conservation benefit of the headstarting effort for these individuals and to prevent returning potentially too many individuals from the same clutch and age class to a reintroduction site than what would typically be observed with naturally-occurring recruitment. The goals of this project were to: 1) identify the distribution of current populations of hellbenders based upon surveillance of historic sites of occurrence; 2 ) identify habitat variables that may be most associated with hellbender presence; 3) collect data on the natural history of the hellbender throughout West Virginia including morphologic, demographic, and diet intake data; 4) identify appropriate sites based on habitat suitability models where hellbenders once occurred but were no longer able to be detected for translocation of hellbenders raised in human care; and 5) to assess the viability of reintroductions and translocations of hellbenders raised in human care. 


\section{CHAPTER 2}

\section{LITERATURE REVIEW}

The hellbender (Cryptobranchus alleganiensis Daudin 1803) is one of three extant members of the amphibian order Caudata and family Cryptobranchidae, along with the Chinese giant salamander (Andrias davidianus) and the Japanese giant salamander (Andrias japonicas) (Phillips and Humphries, 2005). The hellbender, also sometimes referred to as water dog, Allegheny alligator, snot otter, old lasagna sides, and grampas, is the only species of the family Cryptobranchidae extant in the Western Hemisphere with two subspecies currently recognized (Mayasich et al., 2003). The Eastern hellbender (Cryptobranchus alleganiensis alleganiensis) inhabits a current range from southern New York south through northwestern Georgia, northern Alabama, and northern Mississippi and west through western Tennessee, Kentucky, and southern Indiana as well as a disjunct population in central Missouri. The Ozark hellbender (Cryptobranchus alleganiensis bishopi) is isolated to streams and rivers in southern Missouri and northern Arkansas (Behler and King, 1998) (Figure 1). The Eastern hellbender has historically been documented from thirty two streams and rivers in twenty two counties in West Virginia (Table 1) (Mayasich et al., 2003).

The fossil record for this family places individuals from as early as the mid-Jurassic epoch in Asia (176-161 million years ago (mya)) and the Paleocene epoch (66-56 mya) in North America (Duellman and Trueb, 1994; Browne et al., 2012). Cryptobranchidae are believed to have expanded from Asia to North America in the Upper Paleocene (Milner, 2000), and cryptobranchid fossils have been observed in historic sites of North America distantly outside of 
the current range of the hellbender including sites near Charleston, South Carolina and in the states of Nebraska and Colorado (Meszoely, 1966). The origin of the Cryptobranchus genus in North America has been determined to have arisen from the southern Appalachians or southern Ozarks from either the New, Current, or Eleven Point River systems based upon mitochondrial DNA analyses (Sabatino and Routman, 2008). The oldest fossil remains of the hellbender to date have been identified from Cumberland Cave in the Potomac River Valley of Maryland, indicating that the historic range of this species did extend into the Eastern Panhandle of West Virginia at one time (Bredehoeft, 2010).

Genetic studies have indicated the origin of the hellbender in the United States to have arisen in either the Ozarks or the southern Appalachians from refugia populations after the Pleistocene glaciations (Routman, 1994; Sabatino and Routman, 2008). Mitochondrial DNA surveys across the hellbender's range indicate that there is minor geographic variation across the species' range as opposed to other vertebrates, reflecting a potential population bottleneck followed by mitochondrial DNA evolution (Merkle et al., 1977; Routman, 1993). Mitochondrial DNA surveys have indicated that individuals from the New River drainage are most similar genetically to individuals from the Tennessee River and the southern Ozark populations, and individuals from the Ohio River drainage are most similar to those from northern Ozark populations (Routman et al., 1994). Tonione et al. (2010) suggested that there are 8 distinct genetic groups of hellbenders in the United States composed of individuals from the Northern Ozarks, Ohio and Susquehanna River drainages, Tennessee River drainage, Copper Creek drainage, North Fork of the White River, Spring River, New River, and the Current and Eleven Point River drainages. However, recent microsatellite studies have also suggested that the 
Eastern hellbender can effectively be managed as two separate populations including the Ohio River drainage and the Tennessee River drainage (Unger et al., 2013a). This study as well as another recent study have indicated that there are minimal impacts to within stream genetic variation at scales of less than $100 \mathrm{~km}$, and in the case of the Unger study, it was reported that there was greater within stream variation in the Eastern study sites than was experienced across stream drainages or basins (Unger et al., 2013a; Feist et al., 2014).

The cryptobranchids are the largest extant amphibians with individuals of the Andrias genus growing up to nearly $1,520 \mathrm{~mm}$, and the hellbender, the third largest salamander in the world, growing to $740 \mathrm{~mm}$ (Fitch, 1947). All cryptobranchids are fully aquatic salamanders that inhabit fast-flowing streams or rivers with high dissolved oxygen concentrations (Browne et al., 2012b). These individuals were observed in streamside puddles or traversing land near streams but are rarely found out of the stream or river (Beck, 1965; Floyd et al., 2013). The root of the latin name Cryptobranchus (crypto - false, branchus - gills) refers to the lack of gills in adult members of these aquatic species, with only the hellbender retaining open gill slits into adulthood (Duellman and Trueb, 1994) (Figure 2). Adult hellbenders are most commonly observed utilizing stone slabs or bedrock for shelter as well as occasional observations under logs or in stream banks (Blais, 1996).

The hellbender has a strongly flattened head which enables excavation and entry of burrows underneath shelters. The eyes are small and without eyelids and a pair of nostrils opens to the anterior portion of the head (Figure 3). The premaxillary and maxillary bones of the skull contain 100 small, conical teeth, with 24 in the premaxillary region and 76 in the 
maxillary region, and an additional 50 bicuspid teeth are located on the vomer posterior to the buccal opening, with 64 teeth on the lower mandible (Reese, 1906; Lorenze Elwood and Cundall, 1994). This double row of teeth is readily recognizable upon conspecifics during aggression events and enables researchers to determine the origin of bite wounds from other hellbenders (Figure 4).

The integument of the hellbender is typically brown, gray, or either of these colors with black spots, with rare observations of reddish, slightly yellow, or albino individuals (Nickerson and Mays, 1973b). The Ozark hellbender is distinguishable from the Eastern hellbender by an increased amount of coloration in the form of black mottling on the dorsum as well as a smaller spiracle opening (Grobman, 1943; Dundee and Dundee, 1965). However, more reliable delineation including site of collection or genetic analysis is typically required to perform a subspecific identification of an individual in the field. The coloration of individuals in West Virginia is similar to those described through the remainder of the range. However, individuals from a portion of the range have ventral pigmentation similar to the dorsum in the lowland portion of the state, while individuals from montane sites routinely have bright orange ventrums (Figure 5).

The integument is highly vascularized and consists of loose waves, referred to as lateral folds, on the sides of the body in order to increase surface area to facilitate cutaneous respiration (Figure 6) (Noble, 1931). Respiration occurs through gills until the gills are absorbed by the juvenile at approximately 18 months of age in the wild (Smith, 1907). The hellbender does have lungs, but they appear to play little role in respiration, with blood oxygen saturation 
levels remaining similar in individuals with lungs and individuals that had lungs surgically extracted in experiments performed in the 1960's (Boutilier and Toews, 1981). Studies conducted by Guimond and Hutchinson (1970) indicated that $90 \%$ of the hellbender's gas exchange occurs through the skin. In anoxic conditions, the hellbender will increase movement and will perform a side to side rocking behavior to increase oxygen movement across the skin surface (Beffa, 1976). Increased movement of respiratory organs such as gills has been shown to be utilized by caudates such as mudpuppies (Necturus maculosus) in low oxygen conditions as well (Lenfant and and Johansen, 1967). Laboratory studies have shown that the aforementioned rocking behavior initiates at water oxygen saturation levels of $75 \%$, with rocking behaviors maintaining blood oxygen tensions until water saturations are dropped below the $25 \%$ level at $12^{\circ} \mathrm{C}$ (Harlan and Wilkinson, 1981).

The loss of gills following the larval stage and the presence of four toes on each of the front feet and five toes on each of the hind feet (Figure 7) enables the hellbender to be distinguished from the other fully aquatic salamander of West Virginia, the mudpuppy. The mudpuppy is paedomorphic, retaining gills throughout its life, and this species has four toes on each front foot and four toes on each hind foot (Green and Pauley, 1987; Behler and King, 1998). The hellbender also retains several paedomorphic traits such as lack of eyelids, retention of gill slits, utilization of buccophayrngeal suction feeding behavior, the retention of a lateral line along the side of the body, and the lack of posparietal, supratemporal, lacrimal, and septomaxillary bones (Reese, 1906). Hellbenders walk on stream or river bottoms on its feet or tuck them into its side when swimming short distances. Hellbenders also utilize a large laterally compressed tail to facilitate swimming (Figure 8). 
The hellbender is primarily predatory in nature, but the species has been observed to act as a scavenger at times as well (Green, 1934). The primary diet of the hellbender is crayfish, and the hellbender has been considered an important predator of this group in the streams and rivers that it inhabits (Dierenfeld et al., 2009; Humphries and Pauley, 2000). The second most frequently observed prey is fish with a variety of species being observed in stomach contents, including green-sided darters (Etheostoma blennioides), northern brook lampreys (Ichthyomyzon fossor), central stonerollers (Campostoma anomalum), freshwater sculpins (Cottus sp.), and rainbow trout (Salmo gairdneri). Other species that have been observed to be consumed by the hellbender in a far less consistent manner include macroinvertebrates and their larvae, such as hellgrammites (Corydalidae), stonefly nymphs (Pteronarcidae), damselfly nymphs (Calopterygidae), larval alderflies (Sialidae), horsehair worms (Gordioidea), and freshwater snails (Mesogastropoda); a bullfrog (Lithobates catesbeianus), an American toad (Anaxyrus americanus), fish eggs, hellbender skin and eggs, other hellbenders, mudpuppies, and Northern two-lined salamanders (Eurycea bislineata) (Netting, 1929; Nickerson et al., 1983; Peterson, 1989b; Pfingsten, 1990; Irwin et al., 2014; Groves and Williams, 2014; Greathouse et al., In Press.). The only documented studies of the diets of larval hellbenders have observed ingestion of larval and adult macroinvertebrates including Megaloptera, Ephemeroptera, and Diptera (Pitt and Nickerson, 2006).

The feeding mechanism of the hellbender is primarily accomplished through buccopharyngeal suction where the hellbender will cock the anterior portion of the head towards the ground at an approximately $45^{\circ}$ angle to facilitate the rapid downward opening of the lower mandible. This rapid opening enables water to be forced into the buccal cavity, while 
the prey item is sucked into the mouth (Deban and O'Reilly, 2005). Next, the mouth is closed and hyobranchial depression followed by hyobranchial elevation are induced to push the prey into the esophagus. Smaller items are ingested fully into the oral cavity before passing into the stomach, but large items are grabbed by the teeth after the prey item is ingested until the prey can be passed farther into the oral cavity and into the stomach. Once the prey is restrained, additional suction movements are made. Hellbenders are unique amongst salamanders in having the ability to asymmetrically provide jaw force on the right or left mandible to restrain prey, suggesting motor patterns and patterns of force generation that are most commonly associated with mammals (Lorenze Elwood and Cundall, 1994). I have captured several hellbenders that are restraining a crayfish in their mandibles with the anterior and claws of the crayfish remaining outside of the hellbender's mouth.

The only reliable technique for gender determination in the Eastern hellbender in the field currently is the identification of swollen cloacal glands in the male hellbender from May October (Figure 9) (Peterson, 1987). Several studies have indicated mean snout-to-vent length $(\mathrm{SVL})$, total length (TL), and or mass of females to be greater than males (Peterson et al., 1985; Humphries and Pauley, 2005; Burgmeier et al., 2011c). Makowsky and Pauley (2010) utilized museum specimens and determined a significant dimorphism of male and female hellbenders including increased SVL, thoracic girth, and mass of females as opposed to males, but these techniques cannot be utilized in the field with reliability. Female individuals of the Eastern hellbender have been observed to produce mature eggs at an age of 7-8 years and total length of approximately 408 mm (Taber et al., 1975; Topping and Ingersol, 1981), and males have been observed with spermatid presence at a minimum SVL of $166 \mathrm{~mm}$ (2-3 years based on Missouri 
growth rates) and with cloacal swelling at $300 \mathrm{~mm}$ (5 years based on Missouri growth rates) (Taber et al., 1975; Wikramanayake and Dryden, 1985). Spermatogenesis in males was observed from late June through early August with maximum measurements being achieved by mid-July and regression occurring in October, and vitellogenic activity being at its greatest from May through mid-September with maximum ovarian weights and oocyte diameter occurring in September prior to ovulation (Ingersol, 1982).

Reproduction of the Eastern hellbender can occur from mid-August through early October with Ozark hellbenders breeding in late October to as late as late January (Nickerson and Mays, 1973b; Peterson et al., 1989a). Breeding occurs typically in a nesting site that has been excavated underneath a boulder or flat slab of stone by the male, though nests have been observed in bedrock crevices as well as river banks (Nickerson and Tohulka, 1986; Peterson, 1988). I have observed male aggression increase in West Virginia during the last two weeks of August and the first week of September. During the breeding season, males protect nest sites from other males that would attempt to enter their den (Bishop, 1941; Briggler and Lohraff, 2014) (Figures 10 - 11). Upon the initiation of breeding, female hellbenders begin walking through the stream, even during daylight hours (Smith, 1907), searching for the male and the breeding den. Upon arriving at the nesting rock, the female will enter the den, or the male will grasp the female and pull her into the den. Once in the den, the female has the potential to lay up to 650 eggs measuring approximately $3.5 \mathrm{~mm}$ in diameter and attached to each other in a rosary formation (Altig and McDiarmid, 2007) (Figure 12). In spite of these large clutches, nearly $26 \%$ of individuals surveyed in one study in Missouri were shown to retain mature oocytes after breeding (Taber et al., 1975; Ingersol et al., 1991). The male then releases milt 
into the water in the den above the eggs. The hellbender is the only North American salamander capable of external fertilization. Genetic analyses and field observations have indicated that multiple males and females will enter a den rock at the time of a breeding event (Peterson, 1985; Crowhurst et al., 2011; Ettling et al., 2013). Following the breeding event, one male will remain at the entrance of the den rock to protect the eggs throughout development.

The author has observed twelve nest rocks in West Virginia via borescope or through physical inspection from September 2007 - September 2014 in six streams and rivers. Each rock has had a single, clearly excavated entrance that faces downstream or on the side to the thalweg of the stream and is typically (10 of 12 nests) covered on the upstream portion of the nest by stone or sediment. Each breeding event or nest observation has occurred from August $28^{\text {th }}-$ September $18^{\text {th }}$. Clutches of eggs collected and reared (7) in human care by the author for past and future reintroduction efforts have ranged from $48-286$ eggs per clutch with a mean of 139.7 eggs per nest. In human care, male and female hellbenders have been observed to take eggs away from the nest rock, and male hellbenders guarding the nest have been observed to consume some of the eggs that they are guarding (Pfingsten, 1990; Ettling et al., 2013).

Larval development within the egg has been documented to proceed for a range of 23 days in human care and approximately 58-65 days in the wild (Smith, 1907; Peterson, 1988), and metamorphosis has been documented to occur at a range of 18 months - two years after fertilization. In human care, the author has observed emergence from the egg to occur from 22 - 95 days depending upon incubation temperature, and metamorphosis has occurred in as 
rapid as 8 months in individuals maintained at $21^{\circ} \mathrm{C}$ and fed blackworms daily. Eggs are initially composed of a gelatinous outer membrane with a bright yellow embryo within the egg that develops into a gilled larvae that will survive strictly from the nutrition provided by its yolk sac for nearly 30 days until it is nearly absorbed (Figures 13-14). Time of dispersal from the guarded nest is not well known, nor is other information regarding larval and juvenile hellbender natural history.

The hellbender is primarily nocturnal in behavior, with diurnal observations only occurring during the breeding season (Smith, 1907). However, there have been rare accounts of diurnal activity from May through August, although only one of these sites has been documented in recent years in the mountains of North Carolina (Townsend, 1882; Nickerson and Mays, 1973b; Humphries, 2007). During a study on the West Fork of the Greenbrier River, nocturnal movement was observed to peak particularly in females in May and June with a decrease in activity from July through October with reduced summer activity being attributed to potential predator avoidance (Humphries and Pauley, 2000). Laboratory studies have indicated that hellbender activity increases nocturnally, following a biphasic circadian rhythm (Noeske and Nickerson, 1979).

In temperate regions of the range where stream and river temperatures decrease below $4.5^{\circ} \mathrm{C}$, hellbender activity will slow or cease in these cold temperatures with individuals taking substantial time to initiate movement following capture (Noble, 1931; Pfingsten, 1990). Feeding observations of hellbenders in Indiana increased with individuals being caught on baited hooks regularly several times from March - May (Minton, 1972), and this phenomena 
has been reported to the author by anglers in West Virginia and has even been reported in local media where individuals have caught hellbenders while fishing near dams in the Ohio River in early May (Oliver, 2008).

In addition to periods of inactivity when water temperatures increase, physiological studies have shown negative impacts of warm water on hellbender health. During laboratory experiments, increases in temperature indicated that hellbenders took four days to acclimate to temperature increases from $5^{\circ} \mathrm{C}-25^{\circ} \mathrm{C}$ and eight days to acclimate to temperature decreases from $25^{\circ} \mathrm{C}-5^{\circ} \mathrm{C}$. This was the poorest ability to adapt to temperature change of any amphibian that had been studied to that point (Hutchison et al., 1973). Laboratory studies also indicated that hellbenders acclimated to temperatures of $5^{\circ} \mathrm{C}, 15^{\circ} \mathrm{C}$, and $25^{\circ} \mathrm{C}$ moved to preferred temperatures of $11.6^{\circ} \mathrm{C}, 17.7^{\circ} \mathrm{C}$, and $21.7^{\circ} \mathrm{C}$ respectively. This study indicated that hellbenders as well as mudpuppies prefer cooler aquatic temperatures than most caudates when given an option (Hutchison and Hill, 1976). Critical thermal maxima (CTM) for the species at the aforementioned temperature treatments were $32.7^{\circ} \mathrm{C}, 33.0^{\circ} \mathrm{C}$, and $36.6^{\circ} \mathrm{C}$ respectively (Hutchison et al., 1973). The two lower CTM's in this study have been experienced by the author in streams in the Ohio River Valley in West Virginia during the month of August during previous surveys. The hellbender typically moves in slow walking movements or in short bursts of swimming. Studies have indicated that 30 minutes of strenuous activity in water temperatures of $25^{\circ} \mathrm{C}$ lead to metabolic and respiratory acidosis in the hellbender, requiring nearly 22 hours to recover as opposed to only 4-8 hours in marine toads (Bufo marinus) (Boutilier et al., 1980). 
Shelter for hellbenders throughout the range is primarily composed of boulders or large flat slabs of sandstone depending upon the region of the range. Less frequently utilized shelters include logs, stream banks, and bedrock crevices. A study in a North Carolina river indicated that larger boulders with larger cavities underneath for shelter on sand and gravel were preferred by hellbenders in order to provide more secure space for shelter under the stone (Rossell et al., 2013). Radio telemetry studies in Indiana indicated that adult hellbenders most frequently utilized shelter rocks in the range of $5,000-15,000 \mathrm{~cm}^{2}(60.16 \%$ of observations) with a range of size from $1,033.9-159,448.3 \mathrm{~cm}^{2}$, with the largest shelters being utilized in the fall, winter, and spring (Burgmeier et al., 2011a). Several researchers have hypothesized that stream or river bends and the associated surface geology associated with these sites produce boulder fields that are selected by hellbenders (Pfingsten, 1990; Quinn, 2009). Upon finding an appropriate shelter, hellbenders remain fairly sedentary.

Recapture studies of adult hellbenders without the use of telemetry have reported fairly minimal dispersal (Nickerson and Mays, 1973b) and substantially smaller home ranges than telemetric studies. This is possibly due to reduced incidences of recapture and failure to expand searches beyond the selected physical survey site. Recaptured hellbenders without the use of telemetry were documented to have mean linear recapture distances of 19 meters in a Pennsylvania stream, and in a separate study, 35.8 meters in a West Virginia river (Hillis and Bellis, 1971; Humphries and Pauley, 2005). Home ranges in similar studies have ranged from 28 square meters in a Missouri river up to 198 square meters in a West Virginia river, utilizing home range determination techniques including minimum convex polygon (MCP) and elliptical home range analysis (Coatney, 1982; Peterson and Wilkinson, 1996; Humphries and Pauley, 
2005). Adult hellbenders that have been displaced and moved within their own river system have shown the ability to home upstream and downstream. These studies have shown that a greater proportion of individuals were able to home upstream as opposed to downstream, that the greatest proportion of animals homing back to their original site of capture were larger animals, and that individuals could home upstream up to 880 meters in as few as seven days (Wiggs, 1976; Blais, 1989).

Radio telemetry studies of the activity of adult hellbenders have indicated that the period of greatest movement is during the spring and summer months with little movement in the winter (Blais, 1989; Burgmeier et al., 2011a). Mean linear movements in Indiana adults were similar to mark-recapture studies without telemetry at $27.5 \mathrm{~m}$ per movement, but MCP home range in this study was 2,211.9 $\mathrm{m}^{2}$ (Burgmeier et al., 2011a). A radio telemetry study of adults in a Maryland river also produced a larger mean home range $\left(1,026 \mathrm{~m}^{2}\right)$ than nontelemetry studies (Gates et al., 1985b). The Indiana telemetry study confirmed the sedentary nature of adults with a mean of 14.1 movements per individual (10.2 movements during summer months) from a sample of 21 tracked salamanders. Telemetry studies of adults in Indiana and New York have confirmed the use of alternate habitat not typically examined during physical surveillance including downed trees, root masses, stream banks, and bedrock (Blais, 1996; Burgmeier et al., 2011a).

A wide variety of techniques have been employed to survey for hellbenders, and several studies have focused on reviewing some of these methods (Williams et al., 1981; Nickerson and Krysko, 2003; Browne et al., 2012a). The most commonly employed technique, and the one 
considered most successful for capture throughout the species' range, involves lifting stones in hellbender habitat and searching for hellbenders underneath the stone (Figure 15). This technique is either employed by visual perception through the water, tactile nature in streams or rivers with increased turbidity, or accompanied by snorkeling at sites where depths permit wading or scuba diving at deep water sites. Many times nets will be placed downstream to capture individuals that swim from the rock (Browne et al., 2012a). To incorporate leverage for lifting large stones, several researchers have used rakes or log peaveys for lifting with success (Pfingsten, 1990; Soule and Lindberg, 1994; Humphries and Pauley, 2005). Some individuals have utilized noodling or hand investigation techniques where hands and arms are placed under stones, but inherent dangers of grabbing unidentified objects or getting a hand or arm stuck when underwater render this technique potentially dangerous (Nickerson and Krysko, 2003).

Nocturnal spotlighting of clear streams that are able to be waded has proved to be successful in the search of hellbenders as well as Japanese giant salamanders (Humphries and Pauley, 2000; Browne et al., 2012a). This technique is challenging in streams with increased turbidity, as the search light will typically not penetrate murky waters, but the technique prevents disruption of habitat as is seen with rock turning surveys. Bank lines with hooks and baited mesh minnow traps have been utilized in some studies with limited success (Dundee and Dundee, 1965; Nickerson and Krysko, 2003). Recent surveys in Missouri have utilized concrete nest boxes with accessible entry lids with some success (Browne et al., 2012a). However, utilization of these techniques in Indiana, Ohio, and West Virginia over the past year have failed to provide a capture to this point. Electrofishing was used with success in surveys in Maryland 
(Williams et al., 1991). However, this technique did not prove to be effective in subsequent surveys of sites in Missouri, New York, or for mudpuppy surveys in Ohio. Failure of this technique could be associated with the resulting electrotetany or electronarcosis that would disorient the hellbender, yet still not enable the individual(s) to float out from their shelter rocks (Nickerson and Krysko, 2003). No survey techniques have been successful at detection of juvenile or larval hellbenders throughout the species' range. However, several sites where larvae appear to be abundant have been surveyed by snorkeling and searching under small stones and amongst the interstices of gravel and cobble (Foster et al., 2009; Hecht-Kardasz et al., 2012)

The most recently investigated surveillance technique utilizes environmental DNA (eDNA) surveillance of populations by amplifying hellbender DNA samples extracted from filtered stream water samples (Browne et al., 2012a; Olson et al., 2012; Santas et al., 2013). This technique is relatively inexpensive and does not impact habitat. However, the only attribute of hellbender biology or ecology that can be studied at this point with this technique is distribution in the form of presence or absence. That being said, this is an effective technique for rapidly identifying and prioritizing sites for focused surveys utilizing some of the aforementioned techniques to study demographics, behavior, health, and natural history attributes.

Morphologic measurements on individuals in the field have included the use of balance scales or hanging scales for mass observations. The use of fish measuring boards, PVC pipes outfitted with measuring tapes (Figure 16), and novel items such as the bender board, a 
wooden box with an adjustable side for restraint with the hellbender situated on foam, have been incorporated for measurement of SVL and total length (Humphries and Pauley, 2000; Wheeler et al., 2003; Burgmeier et al., 2010; Horchler, 2010).

For surveys where individuals are physically captured and there is a desire to mark individuals for population or behavior studies, several marking techniques have been attempted. Early techniques that were attempted but have since been replaced included the utilization of toe clipping, mammal ear tags placed on the tail or on the hind leg, Floy T-tags through the tail, and anesthesia with tricaine methanesulfonate (MS-222) followed by branding (Nickerson and Mays, 1973a; Williams et al., 1991; Peterson and Wilkinson, 1996). The most effective of these techniques for maintenance of a long-term mark without loss of tag or ripping of skin or potential regeneration of amputated digit was branding with recaptures still being readily identifiable in Missouri from $10-28$ years after the initial branding (Prosen, 1999). However, recent studies have indicated that streamside utilization of MS-222 could have potential negative impacts on hellbenders with recovery times of up to two hours and negative impacts on the hellbender's behavior and physiology as well as that of accompanying parasites or microbes (Byram and Nickerson, 2009).

Recent studies have more commonly utilized passive integrated transponders (PIT tags) for identification of hellbenders (Humphries and Pauley, 2000; Nickerson et al., 2003; Burgmeier et al., 2011c). A study of previously marked populations in a West Virginia river indicated transponder retention in individuals for a minimum of at least 11 years at that site (Horchler, 2010). Transponders implanted intramuscularly in the lateral portion of the tail of 
hellbenders in Indiana (Figure 17) were accompanied by collection of tissue samples for creation of genetic markers for each individual to validate efficacy of transponder identification for this species, and follow-up surveys indicated a $100 \%$ retention rate of transponders within these individuals (Unger et al., 2012). For larval hellbenders, the use of visible implanted elastomers (VIE) in an arrangement of patterns on the ventrum of larvae has proven a successful technique for identifying these individuals (Hecht-Kardasz et al., 2012).

As mentioned previously, radio telemetry transmitters have been utilized to study hellbenders on several occasions, and these devices also provide an individual frequency for short-term identification (studies up to 1-2 years in length) without replacement upon battery failure. Until recently, these studies were primarily performed with adult hellbenders due to the available size of transmitters. Whip transmitters have been used with adult hellbenders that were immobilized in MS-222 until the righting reflex was lost. The transmitter was then placed inside of the coelomic cavity through an incision through the abdominal wall with the antenna of the transmitter trailing out through the abdomen after sutures had enclosed the incision (Figure 18) (Stouffer et al., 1983; Heyer et al., 1994). The whip antenna transmitter proved effective for tracking during studies, but antennas have been caught and caused the transmitter to pull free from the body in rare cases (Blais, 1996). External transmitters as well as subcutaneous implantation of transmitters have been attempted but have failed to stay on hellbenders due to falling off or necrosis of the skin tissue (Coatney, 1982; Blais, 1996). Recent studies have utilized transmitters with loop antennas to fully contain the transmitter within the coelomic cavity (Burgmeier et al., 2011a), and advances in transmitter technology have enabled the employment of smaller transmitters (Figure 19) for tracking juvenile hellbenders (Bodinof et 
al., 2012a). Head-started hellbenders that were raised at the St. Louis Zoo and reintroduced to their site of collection in Missouri showed mean dispersal distances greater than those observed in adult telemetry studies, with mean dispersals of $318.28 \mathrm{~m}$ and $121.95 \mathrm{~m}$ in two separate sections of the release site and maintained MCP home ranges of up to $986 \mathrm{~m}^{2}$ during the first year post-release with reduced movement during the second year following release (MCP range $=31.33 \mathrm{~m}^{2}$ at site 1 and $11.08 \mathrm{~m}^{2}$ at site 2) (Bodinof, 2010; Bodinof et al., 2012a). The greatest factor associated with shelter establishment by reintroduced individuals was the presence of cobble and boulder substrate. However, $8 \%$ (282 of 3181) of observations during this study occurred in bank crevices and root masses (Bodinof et al., 2012b). Survival during this study was maintained at $44.4 \%$ with 16 animals alive, 13 confirmed dead, and 7 unable to be located at the end of the study (Bodinof et al., 2012c).

The ability to individually identify hellbenders effectively has also provided insight into the potential life span of this species. One specimen maintained in human care lived to an age of at least 55 years and was captured as an adult (Nickerson and Mays, 1973b), and several wild individuals have been captured and identified as being at least 25 years of age due to previous identification or growth models (Taber et al., 1975; Peterson et al., 1983).

Demographic studies of hellbenders have indicated a variety of sex ratios during surveys. Several studies have experienced nearly equal 1:1 ratios (Peterson, 1985; Humphries and Pauley, 2005). A recent study documented male-skewed ratios of 2.6:1.0 in Indiana (Burgmeier et al., 2011c), and a follow-up study of an eastern West Virginia river indicated a 10year demographic shift from 1.2:1 to 2.1:1. The follow-up surveys did document the presence 
of young age class animals at the site however (Humphries and Pauley, 2005; Horchler, 2010). Age and size structure studies of populations in recent years have also been skewed towards the observation of primarily adult hellbenders (Wheeler et al., 2003; Humphries and Pauley, 2005; Burgmeier et al., 2011a). This could potentially be indicative of poor reproduction and recruitment at study sites or a result of survey bias with techniques focused on the capture of larger individuals. A Tennessee river, a Missouri river, and a Virginia river are the only study sites that have published demographic data indicating regular observation of larval and juvenile hellbenders (Peterson, 1985; Hopkins and DuRant, 2011; Hecht-Kardasz, 2012). It is hypothesized that reduced gravel beds with poor stability at the Tennessee site provide poor cover for larvae and enhance capture rates at this site (Nickerson et al., 2003).

Population estimates for hellbenders with streams and rivers have been calculated using a variety of techniques including mass/unit of area, number of captures/unit of area, and number of captures per man hour surveyed (Nickerson and Mays, 1973a; Humphries and Pauley, 2005; Burgmeier et al., 2011c), with capture per unit effort being the most standardized and frequently used technique to compare values between sites in recent surveys. Capture per unit effort surveys conducted in Missouri, Tennessee, and West Virginia at sites where hellbender populations appear to be stable ranged from $0.25-0.65$ hellbender captures per person hour when data associated with eggs and larvae were removed from the Tennessee analyses (Nickerson and Krysko, 2003; Humphries and Pauley, 2005). Estimates for an Indiana river where age classes are skewed toward primarily adult animals, and the population is considered to be in decline, were 0.05 hellbender captures per person hour (Burgmeier et al., 2011c). 
The aforementioned data associated with shifts in hellbender age classes toward older individuals as well as a decrease in the number of sites where the hellbender still occurs as opposed to previous sites of historic occurrence have been cited as evidence of the species' decline throughout large portions of its range. Baseline historic data for this species are relatively poor outside of the Ozark hellbender's range in Arkansas and Missouri, but populations at those sites have experienced strong declines (Nickerson and Mays, 1973b; Prosen, 1999; Wheeler et al., 2003). Decreases in abundance and distribution have been cited in New York with extirpation from one site within the state (Foster et al., 2009). A decrease in distribution with extirpation from the Susquehanna drainage has been observed in Maryland (Gates et al., 1985). Significant declines in abundance and shifts in age class have been observed in Indiana (Kern, 1984; Bergmeier et al., 2011c), and declines in distribution with extirpations from $75 \%-80 \%$ of historic sites have been observed in Kentucky and Ohio (Pfingsten, 1990; Lipps and Sisson, 2008). Of the 16 states historically inhabited by the Eastern hellbender, the subspecies is believed to have been extirpated or near extirpation in three states (Alabama, Illinois, and South Carolina) (Stein and Smith, 1959; Mayasich et al., 2003; Graham et al., 2011), and Eastern hellbenders are believed to still occur in only 1-2 streams or rivers in three other states (Indiana, Maryland, and Mississippi) (Mayasich et al., 2003).

Baseline data for the presence of the hellbender in West Virginia is poor, but anecdotal data from historic surveys indicate that abundance of this species has declined dramatically. Reports of 34 animals being collected in a manner of four hours from Shavers Fork of the Cheat River in June 1934 exist, but the number of individuals participating in the survey or the length of stream that was surveyed were not recorded (Green, 1935; Mayasich et al., 2003). Regional 
surveys of historic sites in southern West Virginia during two recent surveys documented a decline in distribution at those sites with hellbenders only being detected at 7 of 18 sites (61.1\% decline) (Table 2) in both surveys combined (Makowsky, 2004; Keitzer, 2007).

The decline of the hellbender throughout its range has been attributed to multiple factors. Direct anthropogenic causes of decline have been observed historically including the collection of hellbenders for scientific study and anatomy courses; collection for the pet trade by American and Japanese collectors; bounty hunts to remove hellbenders from streams and rivers by sportsman's clubs; and intentional persecution of hellbenders by anglers who believed the species to be venomous (Green, 1934; Branch, 1935; Minton, 1972; Nickerson and Briggler, 2007).

Other anthropogenic causes of decline that have been speculated have included sedimentation due to land use practices such as development and deforestation; impoundment causing increased sedimentation and reduced gene flow; and chemical pollution from a variety of sources including but not limited to agricultural run-off and acid mine drainage (Nickerson, and Mays 1973b; Mayasich et al., 2003; Briggler et al., 2007; Quinn, 2009; Burgmeier et al., 2011c).

Natural threats to the hellbender include infection due to injury from conspecifics or predators as well as from disease. Aggression amongst hellbenders is prevalent in the wild, particularly before and during breeding season, with minor abrasions and lacerations occurring commonly. However, these injuries also can result in the loss of digits or limbs. Studies have reported injuries ranging from $25 \%$ - $90 \%$ of individuals with injuries peaking in August and 
September (Hiler et al., 2005; Miller and Miller, 2005; Burgmeier et al., 2011). Studies of the potential pathogens invading injury sites on hellbenders in Missouri identified 6 fungal and 10 bacterial agents at those sites (Nickerson et al., 2011). Studies of stress associated with aggression near and during the breeding season in Virginia indicated increased levels of corticosterone in males as opposed to females and an increased bactericidal ability of the blood in injured individuals (Hopkins and DuRant, 2011).

Larval hellbenders are prey to many predators within their habitat, with first year survival estimates approaching only 10\% (Unger et al., 2013b). The author has observed larval hellbenders and eggs preyed upon by adult hellbenders, freshwater sculpins, and crayfish. Other predators of adult and juvenile hellbenders include snapping turtles (Chelydra serpentina) (Nickerson and Mays, 1973b), North American river otters (Lontra canadensis) (Hecht et al., 2014; Pers. obs.), mink (Neovison vison) and raccoons (Procyon lotor) (Briggler et al., 2007; Greg Lipps, Pers comm.; Pers. obs.), and predatory fish species (Briggler et al., 2007). Studies have shown that hellbenders are able to detect the scent of native predators in water, but respond to introduced predators in the same manner that they respond to non-predatory native fish by continuing to move throughout an enclosure without going into a ceased state of movement (Gall and Mathis, 2010). In addition to predators, several parasitic species have been identified as potential threats to the hellbender including two leeches (Placobdella cryptobranchii and Placobdella appalachiensis) identified from Missouri and Arkansas as well as Virginia respectively (Moser et al., 2013; Hopkins et al., 2014) as well as trypanosome infections of hellbenders in Virginia (Davis and Hopkins, 2013). 
Recent studies of amphibian disease have documented the presence of the amphibian chytrid fungus, or Bd, (Batrachochytrium dendrobatidis) as well as the FV-3 ranavirus in hellbender populations in the United States as well. The amphibian chytrid fungus has been documented in museum specimens of hellbenders dating back to as early as 1969 in Missouri, and $6.3 \%$ of museum specimens (13 of 206) were positive for $B d$ (Bodinof et al., 2011). Surveys in Indiana resulted in only 1 of 88 individuals being infected with Bd (Burgmeier et al., 2011b), while surveys in Tennessee resulted in $31 \%$ of individuals testing positive for $B d$, and $24 \%$ of those individuals testing positive for FV-3 ranavirus (Souza et al., 2012). Prevalence of $B d$ on hellbenders in West Virginia was documented in 2009 (Bartkus, 2009), and prevalence studies by the author and collaborators during 2014 indicated a $52.2 \%$ ( 24 of 46 individuals) prevalence of the pathogen on hellbenders in West Virginia (unpublished data).

Due to the aforementioned declines and threats associated with hellbender populations, both subspecies have been awarded designations as rare, threatened, endangered, or of special concern in each of the states they inhabit. The Ozark hellbender is listed as a federally endangered subspecies, and the Eastern hellbender is undergoing a candidate assessment review for protection under the Endangered Species Act (Pers. comm. Jeromy Applegate, USFWS). Both subspecies were awarded protection under CITES Appendix III in 2011 (USFWS 10/05/11). The IUCN currently lists the hellbender as Near Threatened (NT), and the West Virginia Division of Natural Resources passed legislation that became effective in January 2014 that prevented the take or possession of the Eastern hellbender in West Virginia without a scientific collection permit (WVDNR, 2014). 
Several state and federal wildlife agencies in association with conservation organizations, academic institutions, and zoological facilities have initiated conservation efforts for the Eastern hellbender in recent years. These efforts have included funding and completion of many of the aforementioned surveys, production of outreach materials to educate students, sportsmen, and citizens about hellbender conservation (Jackson and Boyntan, 1994; Chudyk et al., 2014; Mullendore et al., 2014), and rearing and reproduction of hellbenders in zoos and aquaria for future reintroductions and translocations to sites where hellbender populations are declining (Ettling et al., 2013).

\section{REFERENCES CITED}

Altig, R. and R. McDiarmid. 2007. Morphological diversity and evolution of egg and clutch structure in amphibians. Herpetological Monographs. (21): 1-32. 86 pp.

Bartkus, C. 2009. The occurrence of Batrachochytrium dendrobatidis in salamander populations of West Virginia. M.S. Thesis. Marshall University. Huntington, West Virginia.

Beffa, D. 1976. Responses of Cryptobranchus alleganiensis alleganiensis to different oxygen concentrations, temperatures and photoperiod. M.S. Thesis. Southwest Missouri State University, Springfield, Missouri. 37 pp.

Behler, J. and F. King. 1998. National Audubon Society Field Guide to North American Reptiles \& Amphibians. Alfred A. Knopf, Inc. New York, New York. 743 pp.

Bishop, S. 1941. The salamanders of New York. New York State Museum Bulletin. 324: 1-365.

Blais, D. 1996. Movement, home range, and other aspects of the biology of the eastern hellbender (Cryptobranchus alleganiensis alleganiensis): a radio telemetry study. M.S. Thesis. St. Lawrence University. Canton, New York. 63 pp.

Bodinof, C. 2010. Translocation and conservation of hellbenders (Cryptobranchus alleganiensis) in Missouri. M.S. Thesis. University of Missouri. Columbia, Missouri. 152 pp. 
Bodinof, C., J. Briggler, R. Junge, J. Beringer, M. Wanner, C. Schuette, J. Ettling, R. Gitzen, and J. Millspaugh. 2011. Historic occurrence of the amphibian chytrid fungus Batrachochytrium dendrobatidis in hellbender Cryptobranchus alleganiensis populations from Missouri. Diseases of Aquatic Organisms. 96: 1-7.

Bodinof, C., J. Briggler, R. Junge, J. Beringer, M. Wanner, C. Schuette, J. Ettling, and J. Millspaugh. 2012. Postrelease movements of captive-reared Ozark hellbenders (Cryptobranchus alleganiensis bishopi). Herpetologica. 68(2): 160-173.

Bodinof, C., J. Briggler, R. Junge, T. Mong, J. Beringer, M. Wanner, C. Schuette, J. Ettling, and J. Millspaugh. 2012. Survival and body condition of captive-reared juvenile Ozark hellbenders (Cryptobranchus alleganiensis bishopi) following translocation to the wild. Copeia. 2012(1): 150-159.

Boutilier, R., D. McDonald, and D. Toews. 1980. The effects of enforced activity on ventilation, circulation, and blood acid-base balance in the aquatic gill-less urodele, Cryptobranchus alleganiensis; a comparison with the semi-terrestrial anuran, Bufo marinus. Journal of Experimental Biology. 84: 289-302.

Boutilier, R. and D. Toews. 1981. Respiratory properties of blood in a strictly aquatic and predominantly skin-breathing urodele, Cryptobranchus alleganiensis. Respiration Physiology. 46: 161-176.

Branch, H. 1935. A laboratory manual of Cryptobranchus alleganiensis Daudin. Vantage Press. Wichita, Kansas. 79 pp.

Bredehoeft, K. 2010. A re-evaluation of the Pleistocene hellbender, Cryptobranchus guildayi, and an overview of Cryptobranchus remains from caves in the Potomac River region. M.S. Thesis. East Tennessee State University. Johnson City, Tennessee. 82 pp.

Briggler, J. , J. Utrup, C. Davidson, J. Humphries, J. Groves, T. Johnson, J. Ettling, M. Wanner, K. Traylor-Holzer, D. Reed, V. Lindgren, and O. Byers (eds.). 2007. Hellbender population and habitat viability assessment. IUCN/SSC Conservation Breeding Specialist Group. Apple Valley, Minnesota. 46 pp.

Briggler, J. and K. Lohraff. 2014. Cryptobranchus alleganiensis alleganiensis (Eastern Hellbender) - Intraspecific Aggressive Behavior. Herpetological Review. 45(3): 471.

Browne, R., H. Li, Z. Wang, P. Hime, A. McMillan, M. Wu, R. Diaz, Z. Hongxing, D. McGinnity, and J. Briggler. 2012a. The giant salamanders (Cryptobranchidae): part A. palaeontology, phylogeny, genetics, and morphology. Amphibian and Reptile Conservation. 5(4): 1729. 
Browne, R., L. Hong, D. McGinnity, S. Okada, W. Zhenghuan, C. Bodinof, K. Irwin, A. McMillan, and J. Briggler. 2012b. Survey techniques for giant salamanders and other aquatic Caudata. Amphibian and Reptile Conservation. 5(4): 1-16.

Burgmeier, N., S. Unger, T. Sutton, and R. Williams. 2010. The bender board: a new design for the restraint and measurement of hellbenders. Herpetological Review. 41(3): 319-320.

Burgmeier, N., T. Sutton, and R. Williams. 2011a. Spatial ecology of the eastern hellbender (Cryptobranchus alleganiensis alleganiensis) in Indiana. Herpetologica. 67(2): 135-145.

Burgmeier, N., S. Unger, J. Meyer, T. Sutton, and R. Williams. 2011b. Health and habitat quality assessment for the eastern hellbender (Cryptobranchus alleganiensis alleganiensis) in Indiana, USA. Journal of Wildlife Diseases. 47(4): 836-848.

Burgmeier, N., S. Unger, T. Sutton, and R. Williams. 2011c. Population status of eastern hellbender (Cryptobranchus alleganiensis alleganiensis) in Indiana. Journal of Herpetology. 45(2): 195-201.

Byram, J. and M. Nickerson. 2009. The use of tricaine (MS-222) in amphibian conservation. Reptile and Amphibian Conservation Corps. Gainesville, Florida. 15pp.

Chudyk, S., A. McMillan, and C. Lange. 2014. Using the eastern hellbender in a high school genetics and ecological conservation activity. The American Biology Teacher. 76: 338344.

Coatney, C. 1982. Home range and nocturnal activity of the Ozark hellbender. M.S. Thesis. Southwest Missouri State University. Springfield, Missouri. 55pp.

Collins, J. 1981. Cryptobranchus alleganiensis (hellbender) longevity. Herpetological Review. 12(2): 69.

Conant, R. and J.T. Collins. 1998. A Field Guide to Reptiles and Amphibians of Eastern and Central North America. Houghton-Mifflin Co., Boston, MA. 616 pp.

Crowhurst, R., K. Faries, J. Collantes, J. Briggler, J. Koppelman, and L. Eggert. 2011. Genetic relationships of hellbenders in the Ozark highlands of Missouri and conservation implications for the Ozark subspecies (Cryptobranchus alleganiensis bishopi). Conservation Genetics. 12: 637-646.

Davis, A. and W. Hopkins. 2012. Widespread trypanosome infections in a population of eastern hellbenders (Cryptobranchus alleganiensis alleganiensis) in Virginia, USA. Parasitology Research. 4 pp. 
Davis, A. and T. Floyd. 2013. Evaluating levels of genotoxic stress in eastern hellbenders (Cryptobranchus alleganiensis alleganiensis) using the erythrocyte micronucleus assay. Comparative Clinical Pathology. DOI 10.1007/s00580-013-1761-1.

Deban, S. and J. O'Reilly. 2005. The ontogeny of feeding kinematics in a giant salamander Cryptobranchus alleganiensis: does current function or phylogenetic relatedness predict the scaling patterns of movement? Zoology. 108: 155-167.

Dierenfeld, E., K. McGraw, K. Fritsche, J. Briggler, and J. Ettling. 2009. Nutrient composition of whole crayfish (Orconectes and Procambarus species) consumed by hellbender (Cryptobranchus alleganiensis). Herpetological Review. 40(3): 324-330.

Duellman, W. and L. Trueb. 1994. Biology of Amphibians. Johns Hopkins University Press. Baltimore, Maryland. $670 \mathrm{pp}$.

Dundee, H. and D. Dundee. 1965. Observations on the systematic and ecology of Cryptobranchus from the Ozark Plateaus of Missouri and Arkansas. Copeia. 1965(3): 369-370.

Ettling, J., M. Wanner, C. Schuette, S. Armstrong, A. Pedigo, and J. Briggler. 2013. Captive reproduction and husbandry of adult Ozark hellbenders, Cryptobranchus alleganiensis bishop. Herpetological Review. 44: 605-610.

Feist, S., J. Briggler, J. Koppelman, and L. Eggert. 2014. Within-river gene flow in the hellbender (Cryptobranchus alleganiensis) and implications for restorative release. Conservation Genetics. DOI 10.1007/s10592-014-0591-2.

Fitch, F., Jr. 1947. A record Cryptobranchus alleganiensis. Copeia. 1947(3): 210.

Foster, R., A. McMillan, and K. Roblee. 2009. Population status of hellbender salamanders (Cryptobranchus alleganiensis) in the Allegheny River drainage of New York State. Journal of Herpetology. 43(4): 579-588.

Gall, B. and A. Mathis. 2010. Innate predator recognition and the problem of introduced trout. Ethology. 116(2010): 47-58.

Gates, J., C. Hocutt, J. Stauffer, and G. Taylor. 1985a. The distribution and status of Cryptobranchus alleganiensis in Maryland. Herpetological Review. 16(1): 17-18.

Gates, J., R. Stouffer, J. Stauffer, and C. Hocutt. 1985b. Dispersal patterns of translocated Cryptobranchus alleganiensis in a Maryland stream. Journal of Herpetology. 19(3): 436438. 
Gibbons, J. 2000. The global decline of reptiles, déjà vu amphibians. BioScience. 50: 653-666.

Gonynor, J., M. Yabsley, and J. Jensen. 2011. A preliminary survey of Batrachochytrium dendrobatidis exposure in hellbenders from a stream in Georgia, USA. Herpetological Review. 42(1): 58-59.

Graham, S., E. Soehren, G. Cline, C. Schmidt, W Sutton, J. Rayburn, S. Stiles, and J. Stiles. 2011. Conservation status of hellbenders (Cryptobranchus alleganiensis) in Alabama, USA. Herpetological Conservation and Biology. 6(2): 242-249.

Greathouse, W., C. Byrne, K. Samborsky, A. Wendt, and S. Klein. 2015. Cryptobranchus alleganiensis alleganiensis (Eastern Hellbender) - Diet. Herpetological Review. In press: Accepted 10/10/2014.

Green, N.B. 1934. Cryptobranchus alleganiensis in West Virginia. Proceedings of the West Virginia Academy of Sciences. Fairmont, WV.

Green, N.B. 1935. Further notes on the food habits of the water dog (Cryptobranchus alleganiensis Daudin). Proceedings of the West Virginia Academy of Sciences. Elkins, WV.

Green, N.B. and T. Pauley. 1987. Amphibians and Reptiles in West Virginia. University of Pittsburgh Press. Pittsburgh, PA. 241 pp.

Groves, J. and L. Williams. 2014. Cryptobranchus alleganiensis - cannibalism. Herpetological Review. 45:108-109.

Harland, R. and R. Wilkinson. 1981. The effects of progressive hypoxia and rocking activity on the blood oxygen tension for hellbenders, Cryptobranchus alleganiensis. Journal of Herpetology. 15(4): 383-387.

Hecht-Kardasz, K., M. Nickerson, M. Frake, and P. Colclough. 2012. Population structure of the hellbender (Cryptobranchus alleganiensis) in a Great Smoky Mountains stream. Bulletin of the Florida Museum of Natural History. 51(4): 227-241.

Hecht, K., M. Nickerson, and R. Vollbrecht. 2014. Cryptobranchus alleganiensis-predation. Herpetological Review. 45(3):471

Heyer, W., M. Donnelly, R. McDiarmid, L. Hayek, and M. Foster. 1994. Measuring and Monitoring Biological Diversity: Standard Methods for Amphibians. Smithsonian Institution Press. 364 pp. 
Hiler, W., B. Wheeler, and S. Trauth. 2005. Abnormalities in the Ozark hellbender (Cryptobranchus alleganiensis bishopi) in Arkansas: a comparison between two rivers with a historical perspective. Journal of Arkansas Academy of Science. 59: 88-94.

Hillis, R. and E. Bellis. 1971. Some aspects of the ecology of the hellbender, Cryptobranchus alleganiensis alleganiensis, in a Pennsylvania stream. Journal of Herpetology. 5: 121126.

Hopkins, W. and S. DuRant. 2011. Innate immunity and stress physiology of eastern hellbenders (Cryptobranchus alleganiensis) from two stream reaches with differing habitat quality. General and Comparative Endocrinology. 174(2011): 107-115.

Hopkins, W., W. Moser, D. Garst, D. Richardson, C. Hammond, E. Lazo-Wasem. 2014. Morphological and molecular characterization of a new species of leech (Glossiphoniidae, Hirudinida): implications for the health of its imperiled amphibian host (Cryptobranchus alleganiensis). ZooKeys. 378: 83-101.

Horchler, D. 2010. Long-term growth and monitoring of the eastern hellbender (Cryptobranchus a. alleganiensis) in eastern West Virginia. M.S. Thesis. Marshall University, Huntington, West Virginia. 48pp.

Humphries, W. and T. Pauley. 2000. Seasonal changes in nocturnal activity of the hellbender, Cryptobranchus alleganiensis, in West Virginia. Journal of Herpetology. 34(4): 604-607.

Humphries, W. and T. Pauley. 2005. Life history of the hellbender, Cryptobranchus alleganiensis, in a West Virginia stream. American Midland Naturalist. 154: 135-142.

Humphries, W. 2007. Diurnal seasonal activity of Cryptobranchus alleganiensis (hellbender) in North Carolina. Southeast Naturalist. 6(1): 135-140.

Hutchison, V., G. Engbretson, and D. Turney. 1973. Thermal acclimation and tolerance in the hellbender, Cryptobranchus alleganiensis. Copeia. 1973(4): 805-807.

Hutchison, V. and L. Hill. 1976. Thermal selection in the hellbender, Cryptobranchus alleganiensis, and the mudpuppy, Necturus maculosus. Herpetologica. 32(3): 327-331.

Ingersol, C. 1982. Seasonal reproductive changes in Cryptobranchus alleganiensis. M.S. Thesis. Southwest Missouri State University, Springfield, Missouri. 72 pp.

Ingersol, C., R. Wilkinson, C. Peterson, and R. Ingersol. 1991. Histology of the reproductive organs of Cryptobranchus alleganiensis (Caudata: Cryptobranchidae) in Missouri. The Southwestern Naturalist. 36(1): 60-66. 
Irwin, K., J. Briggler, and T. Crabill. 2014. Cryptobranchus alleganiensis bishop (Ozark Hellbender) - Diet. Herpetological Review. 43(3): 472.

Jackson, T. and A. Boyntan. 1994. Hellbender Cryptobranchus alleganiensis. Division of Conservation Education. N.C. Wildlife Resources Commission. 2 pp.

Keitzer, S. 2007. Habitat preferences of the eastern hellbender in West Virginia. M.S. Thesis. Marshall University. Huntington, West Virginia. 64 pp.

Keitzer, S., T. Pauley, and C. Burcher. 2013. Stream characteristics associated with site occupancy by the eastern hellbender, Cryptobranchus alleganiensis alleganiensis, in southern West Virginia. Northeastern Naturalist. 20: 666-677.

Kern, W. 1984. The hellbender, Cryptobranchus alleganiensis, in Indiana. M.S. Thesis. Indiana State University. Terre Haute, Indiana. 48 pp.

Lenfant, C. and K. Johansen. 1967. Respiratory adaptations in selected amphibians. Respiratory Physiology. 2: 247-260.

Lipps, G. and M. Sisson. 2008. Status assessment and conservation of the eastern hellbender. Kentucky Department of Fish and Wildlife Resources Annual Research Highlights. p. 51.

Lorenze Elwood, J. and D. Cundall. 1994. Morphology and behavior of the feeding apparatus in Cryptobranchus alleganiensis (Amphibia: Caudata). Journal of Morphology. 220: 47-70.

Makowsky, R. 2004. Natural history and sexual dimorphism of the eastern hellbender, Cryptobranchus alleganiensis. M.S. Thesis. Marshall University. Huntington, West Virginia. $69 \mathrm{pp}$.

Makowsky, R., L. Wilson, and T. Pauley. 2010. Sexual dimorphism in the eastern hellbender (Cryptobranchus alleganiensis alleganiensis). Herpetological Conservation and Biology. 5(1): 44-48.

Mayasich, J., D. Grandmaison, and C. Phillips. 2003. Eastern hellbender status assessment report. U.S. Fish and Wildlife Service. Ft. Snelling, Minnesota.

Merkle, D., S. Guttman, and M. Nickerson. 1977. Genetic uniformity throughout the range of the hellbender, Cryptobranchus alleganiensis. Copeia. 1977(3): 549-553.

Meszoely, C. 1966. North American fossil cryptobranchid salamanders. American Midland Naturalist. 75(2): 495-515.

Miller, B. and J. Miller. 2005. Prevalence of physical abnormalities in eastern hellbender (Cryptobranchus alleganiensis alleganiensis) populations of middle Tennessee. Southeastern Naturalist. 4(3): 513:520. 
Milner, A. 1998. The relationships and origin of living amphibians. In: M. Benton (ed.), The Phylogeny and Classification of the Tetrapods. Volume 1, Amphibians Reptiles, Birds, 59-102. Clarendon Press. Oxford, England.

Minton, S. 1972. Amphibians and Reptiles of Indiana. Indian Academy of Science Monographs. Number 3, pp. 24-27.

Moser, W., J. Briggler, D. Richardson, C. Schuette, C. Hammond, W. Hopkins, and E. LazoWasem. 2013. Redescription and molecular characterization of Placobdella cryptobranchii (Johnson \& Klemm, 1977) (Glossiphoniidae, Hirudinida). ZooKeys. 338: 110.

Mullendore, N., A. Mase, K. Mulvaney, R. Perry-Hill, A. Reimer, L. Behbehani, R. Willims, and L. Prokopy. 2014. Conserving the eastern hellbender salamander. Human Dimensions of Wildlife: An International Journal. 19:2, 166-178. DOI:10.1080/10871209.2014.853221.

Netting, M. 1929. The food of the hellbender Cryptobranchus alleganiensis (Daudin). Copeia. 1929 (170): 23-24.

Nickerson, C., C. Ott, S. Castro, V. Garcia, T. Molina, J. Briggler, A. Pitt, J. Tavano, J. Byram, J. Barrila, and M. Nickerson. 2011. Evaluation of microorganisms cultured from injured and repressed tissue regeneration sites in endangered giant aquatic Ozark hellbender salamanders. PLoS ONE 6(12):e28906.doi:10.1371/journal.pone.0028906.

Nickerson, M. and C. Mays. 1973a. A study of the Ozark hellbender Cryptobranchus alleganiensis bishopi. Ecology. 54(5): 1164-1165.

Nickerson, M. and C. Mays. 1973b. The hellbenders: North American "giant salamanders". Milwaukee Public Museum. 1:1-106.

Nickerson, M, R. Ashton, and A. Braswell. 1983. Lampreys in the diet of hellbender Cryptobranchus alleganiensis (Daudin), and the Neuse River waterdog Necturus lewisi (Brimley). Herpetological Review. 14(1):10.

Nickerson, M. and M. Tohulka. 1986. The nests and nest site selection by Ozark hellbenders, Cryptobranchus alleganiensis bishopi Grobman. Transactions of the Kansas Academy of Science. 89: 66-69.

Nickerson, M. and K. Krysko. 2003. Surveying for hellbender, Cryptobranchus alleganiensis (Daudin): a review and critique. Applied Herpetology. 1: 37-44.

Nickerson, M, K. Krysko, and R. Owen. 2003. Habitat differences affecting age class distributions of the hellbender salamander, Cryptobranchus alleganiensis. Southeastern 
Naturalist. 2(4): 619-629.

Nickerson, M. and J. Briggler. 2007. Harvesting as a factor in population decline of a long-lived salamander; the Ozark hellbender, Cryptobranchus alleganiensis bishop Grobman. Applied Herpetology. 4: 207-216.

Noble, G. 1931. The biology of the amphibian. McGraw-Hill. New York. 577 pp.

Noeske, T. and M. Nickerson. 1979. Diel activity rhythms in the hellbender, Cryptobranchus alleganiensis (Caudata: Cryptobranchidae). Copeia. 1979(1)92-95.

Oliver, P. 2008. Hellbender caught near Stratton. Steubenville Herald Star. 05/02/2008.

Olson, Z., J. Briggler, and R. Williams. 2012. An eDNA approach to detect eastern hellbenders (Cryptobranchus a. alleganiensis) using samples of water. Wildlife Research. 39: 629636.

Peterson, C., R. Wilkinson, M. Topping, and D. Metter. 1983. Age and growth of the Ozark hellbender (Cryptobranchus alleganiensis bishopi). Copeia. 1983(1): 225-231.

Peterson, C. 1985. Comparative demography of four populations of the hellbender, Cryptobranchus alleganiensis, in the Ozarks. Ph.D. Dissertation. University of Missouri. Columbia, Missouri. 158 pp.

Peterson, C., M. Topping, R. Wilkinson, and C. Taber. 1985. Examination of long-term growth of Cryptobranchus alleganiensis predicted by linear regression methods. Copeia. 1985(2): 492-496.

Peterson, C. 1987. Movement and catchability of the hellbender, Cryptobranchus alleganiensis. Journal of Herpetology. 21(3): 197-204.

Peterson, C. D. Metter, B. Miller, R. Wilkinson, and M. Topping. 1988. Demography of the hellbender Cryptobranchus alleganiensis in the Ozarks. American Midland Naturalist. 119(2): 291-303.

Peterson, C., C. Ingersol, and R. Wilkinson. 1989a. Winter breeding of Cryptobranchus alleganiensis bishopi in Arkansas. Copeia. 1989(4): 1031-1035.

Peterson, C., J. Reed, and R. Wilkinson. 1989b. Seasonal food habits of Cryptobranchus alleganiensis (Caudata: Cryptobranchidae). The Southwestern Naturalist. 34(3): 438441.

Peterson, C. and R. Wilkinson. 1996. Home range size of the hellbender (Cryptobranchus alleganiensis) in Missouri. Herpetological Review. 27(3): 126-127. 
Pfingsten, R. 1990. The status and distribution of the hellbender, Cryptobranchus alleganiensis in Ohio. Herpetological Review. 21(3): 48-51.

Phillips, C. and W. Humphries. 2005. Cryptobranchus alleganiensis (Daudin, 1803). Pp. 648651. In: Michael Lanoo, ed. Amphibian Decline: The Conservation Status of United States Species. University of California Press. 1094 pp.

Pitt, A, and M. Nickerson. 2006. Cryptobranchus alleganiensis (hellbender salamanders) larval diet. Herpetological Review. 37(1): 69.

Prosen, E. 1999. Status of the eastern hellbender (Cryptobranchus alleganiensis alleganiensis) In Missouri: a comparison of past and present populations. M.S. Thesis. Southwest Missouri State University. Springfield, Missouri. 39 pp.

Quinn, S. 2009. Factors influencing distribution of the eastern hellbender in the northern segment of its range. M.S. Thesis. State University of New York. Syracuse, New York. $49 \mathrm{pp}$.

Reese, A. 1906. Anatomy of Cryptobranchus allegheniensis. The American Naturalist. 40(472): 287-326.

Rossell, C., P. McNeal, D. Gilette, L. Williams, S. Patch, and A. Krebs. 2013. Attributes of shelters selected by Eastern hellbenders(Cryptobranchus a. alleganiensis) in the French Broad River Basin of North Carolina. Journal of Herpetology. 47(1): 66-70.

Routman, E. 1993. Mitochondrial DNA variation in Cryptobranchus alleganiensis, a salamander with extremely low allozyme diversity. Copeia. 1993(2): 407-416.

Routman, E. 1994. Parsimony, molecular, evolution, and biogeography: the case of the North American giant salamander. Evolution. 48(6): 1799-1809.

Sabatino, S. and E. Routman. 2008. Phylogeography and conservation genetics of the hellbender salamander (Cryptobranchus alleganiensis). Conservation Genetics. 10: 1235-1246.

Santas, A., T. Persaud, B. Wolfe, and J. Bauman. 2013. Noninvasive method for a statewide survey of Eastern hellbenders Cryptobranchus alleganiensis using environmental DNA. International Journal of Zoology. http://dx.doi.org/10.11155/2013/174056.

Smith, B. 1907. The life history and habits of Cryptobranchus allegheniensis. Biological Bulletin. 13(1): 5-39. 
Soule, N. and A. Lindberg. 1994. The use of leverage to facilitate the search for the hellbender. Herpetological Review. 25(1): 16.

Souza, M., M. Gray, P. Colclough, and D. Miller. 2012. Prevalence of infection by Batrachochytrium dendrobatidis and Ranavirus in eastern hellbenders (Cryptobranchus alleganiensis alleganiensis) in eastern Tennessee. Journal of Wildlife Diseases. 48(3): 560-566.

Stein, H. and P. Smith. 1959. The hellbender, Cryptobranchus alleganiensis, in Illinois. Copeia. 1959(2): 178-179.

Stouffer, R., J. Gates, C. Hocutt, and J. Stauffer. 1983. Surgical implantation of a transmitter package for radio-tracking endangered hellbenders. Wildlife Society Bulletin. 11(4): 384-386.

Taber, C., R. Wilkinson, and M. Topping. 1975. Age and growth of hellbenders in the Niangua River, Missouri. Copeia. 1975(4): 633-639.

Tonione, M., J. Johnson, and E. Routman. 2010. Microsatellite analysis supports mitochondrial phylogeography of the hellbender (Cryptobranchus alleganiensis). Genetica. 139: 209219.

Topping, M. and C. Ingersol. 1981. Fecundity in the hellbender, Cryptobranchus alleganiensis. Copeia. 1981(4): 873-876.

Townsend, C. 1882. Habits of the Menopoma. American Naturalist. 16: 139-140.

Unger, S., N. Burgmeier, and R. Williams. 2012. Genetic markers reveal high PIT tag retention rates in giant salamanders (Cryptobranchus alleganiensis). Amphibia-Reptilia. 33:313317.

Unger, S., O. Rhodes, T. Sutton, and R. Williams. 2013a. Population genetics of the eastern hellbender (Cryptobranchus alleganiensis alleganiensis). Journal for Nature Conservation. 21: 423-432.

Unger, S., T. Sutton, and R. Williams. 2013b. Projected population persistence of eastern hellbenders (Cryptobranchus alleganiensis alleganiensis). Journal for Nature Conservation. 21: 423-432.

USFWS. 10/05/2011. U.S. Fish and Wildlife Service lists the Ozark hellbender as endangered and moves to include hellbenders in Appendix III of CITES: hellbenders are among the world's largest salamanders. www.fws.gov/midwest/endangered/amphibians/ozhe/NRRFinalListingozhe.html? rid $=273$. 
Wheeler, B., E. Prosen, A. Mathis, and R. Wilkinson. 2003. Population declines of a long-lived salamander: a 20+ year study of hellbenders, Cryptobranchus alleganiensis. Biological Conservation. 109: 151-156.

Wiggs, J. 1976. Food habits, starvation, and growth in the hellbender, Cryptobranchus alleganiensis. M.S. Thesis. Southwest Missouri State University. Springfield, Missouri. $32 \mathrm{pp}$.

Wikramanayake, E. and G. Dryden. 1985. Body length of male Cryptobranchus alleganiensis at sexual maturity. Bulletin of the Maryland Herpetological Society. Pp. 76-79.

Williams, R., J. Gates, and C. Hocutt. 1981. An evaluation of known potential sampling techniques for hellbender, Cryptobranchus alleganiensis. Journal of Herpetology. 15(1): 23-27.

WVDNR. 2014. Reptile and Amphibian Regulations. West Virginia Division of Natural Resources. 8 pp. 


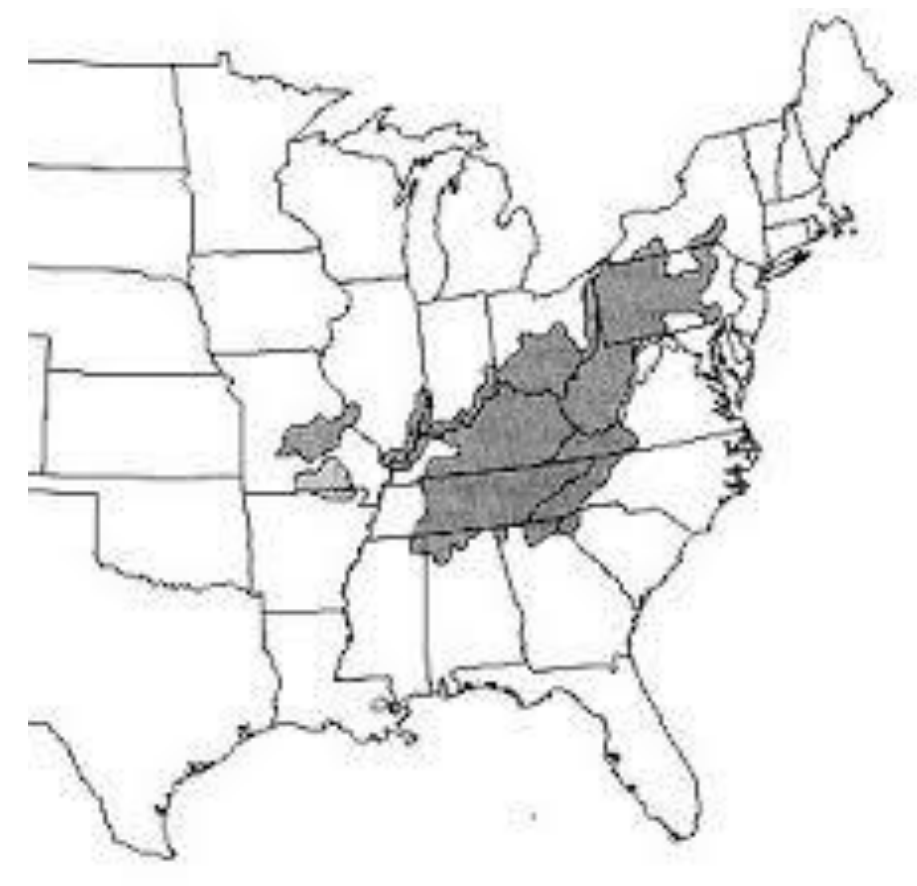

Figure 1 - Map of the range of the hellbender. Dark gray sites are the range of the Eastern hellbender, and the light gray site in northern Arkansas and southern Missouri is the range of the Ozark hellbender.

Illustration is courtesy of the Marshall University Herpetology Lab web site http://www.marshall.edu/herp/Salamanders/hellbender.htm. 


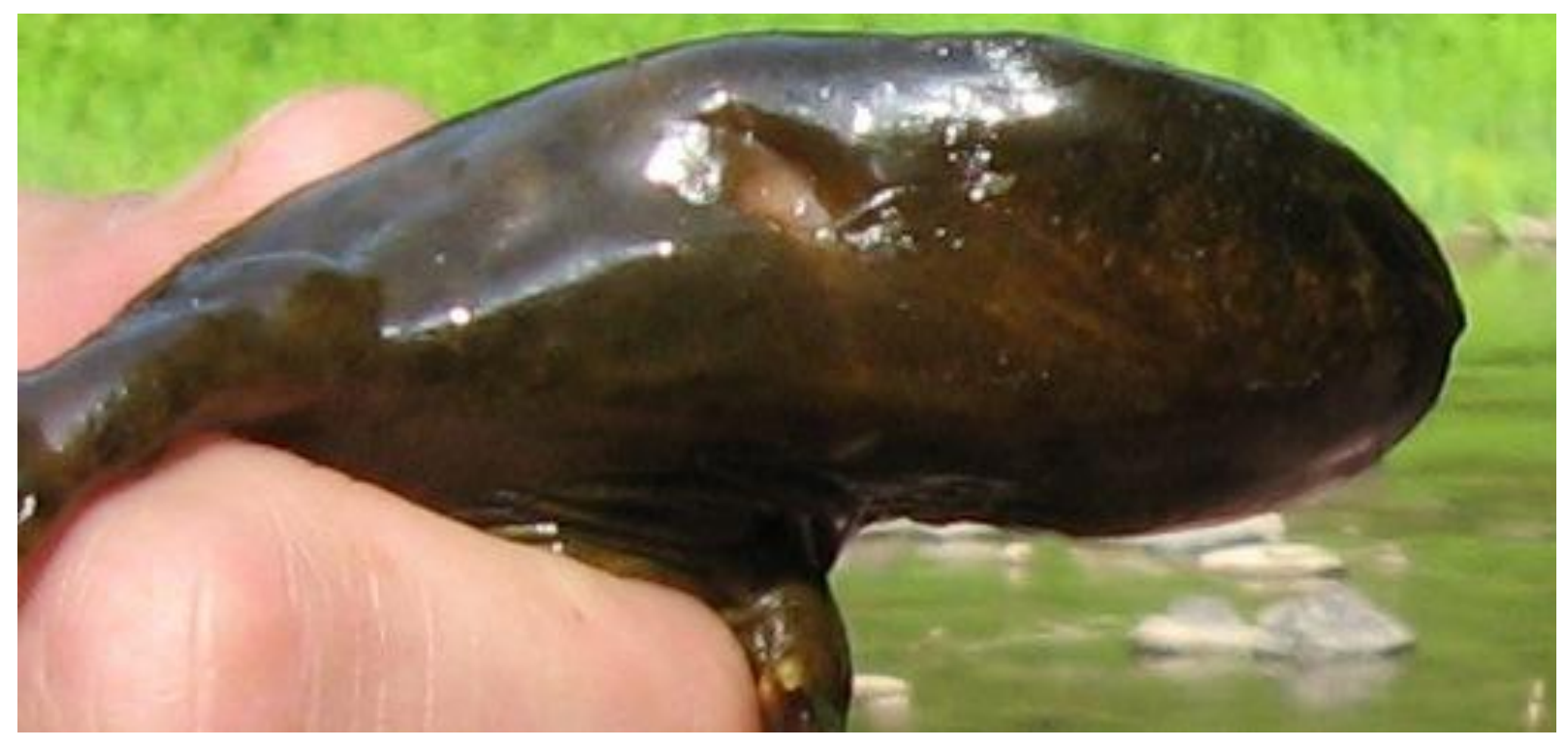

Figure 2-Gill slit opening on side of sub-adult hellbender neck at back of the jaw. This is the opening that remains on individuals after approximately 18 months of age when the gills are fully absorbed.

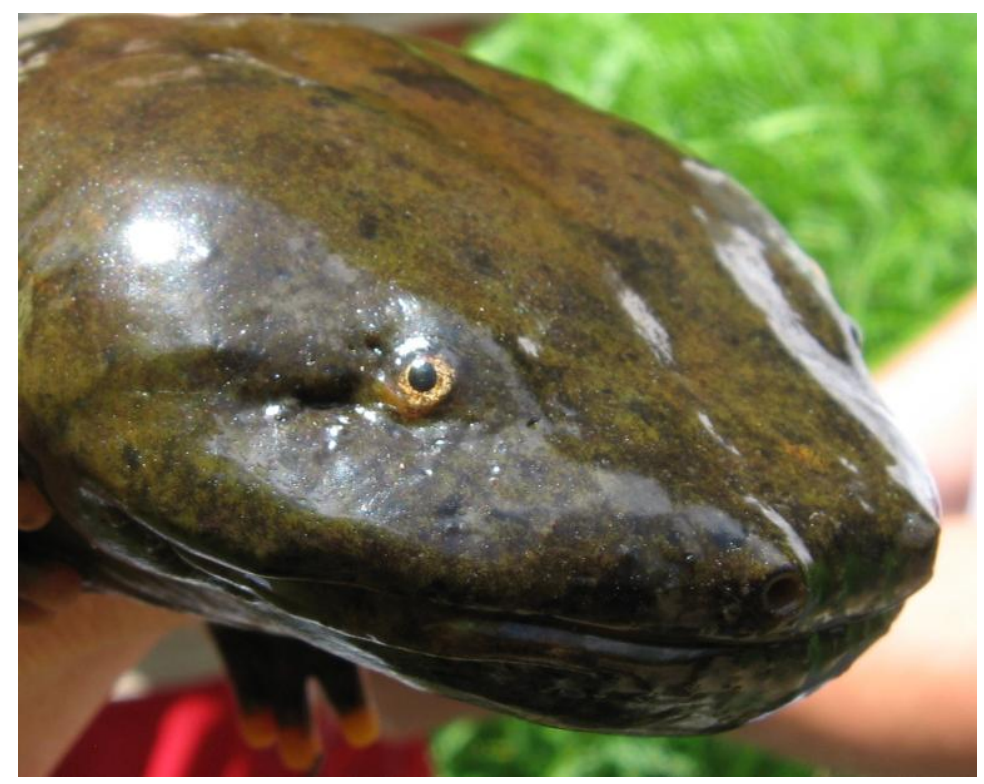

Figure 3-Head of adult hellbender showing eyes without eyelids and open anterior nostrils. 


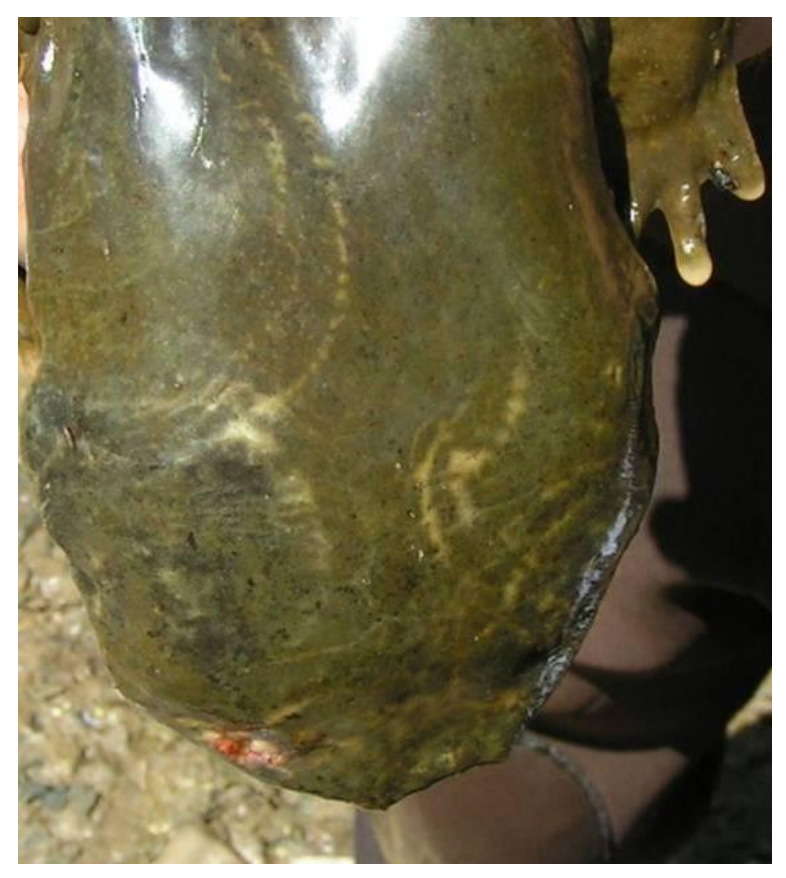

Figure 4 - Female hellbender captured during breeding season with multiple bite wounds from other adult hellbenders evidenced by the dual rows of teeth at each bite mark on the head.

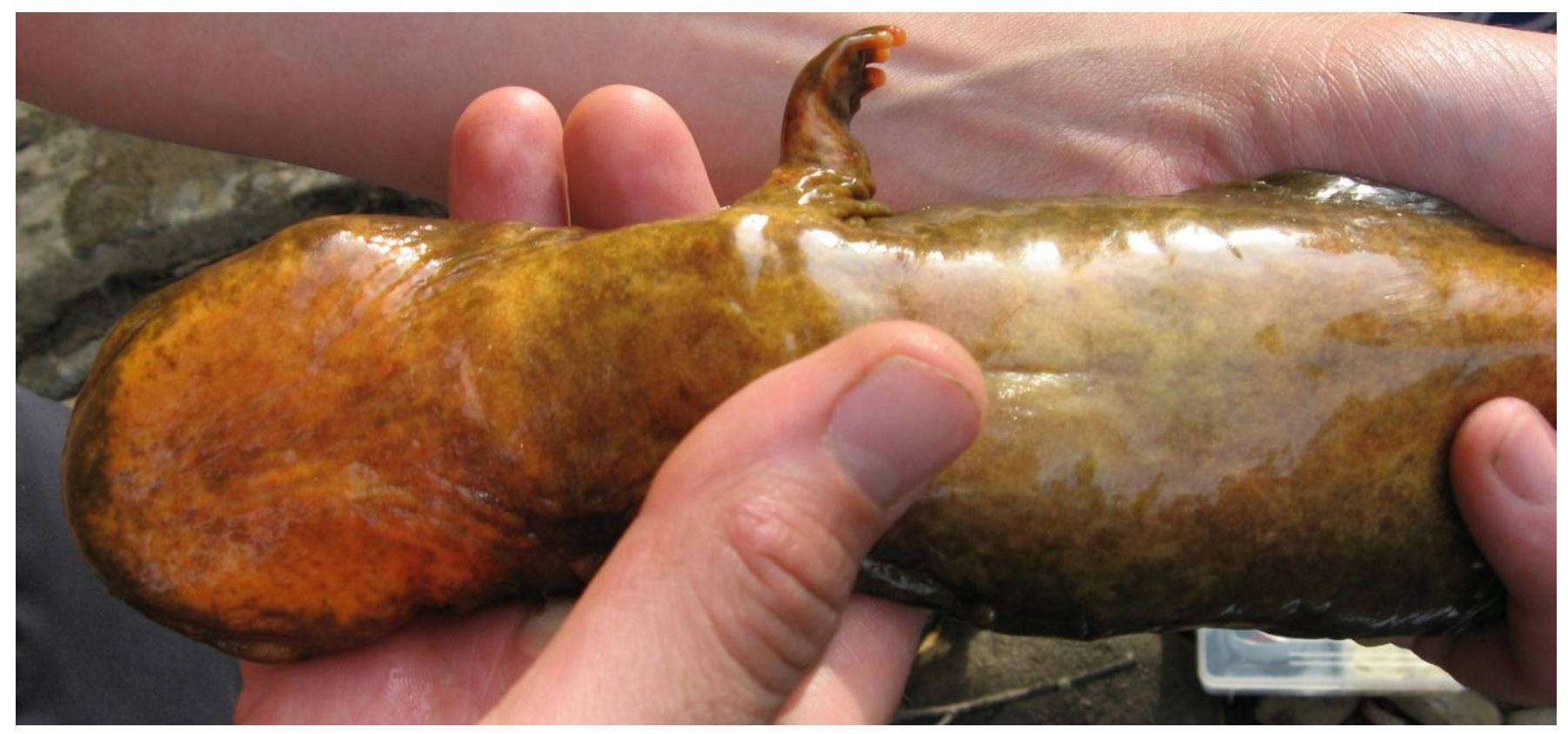

Figure 5 - Photo of adult hellbender with orange ventral pigmentation as is common in hellbenders captured at sites in and near Monongahela National Forest. 


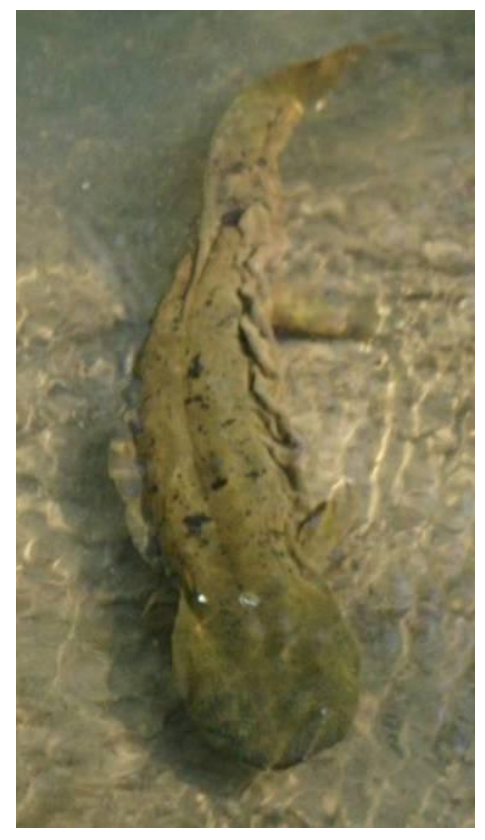

Figure 6 - Lateral folds located between the legs on each side of the hellbender facilitate cutaneous respiration by providing additional surface area for oxygen exchange.
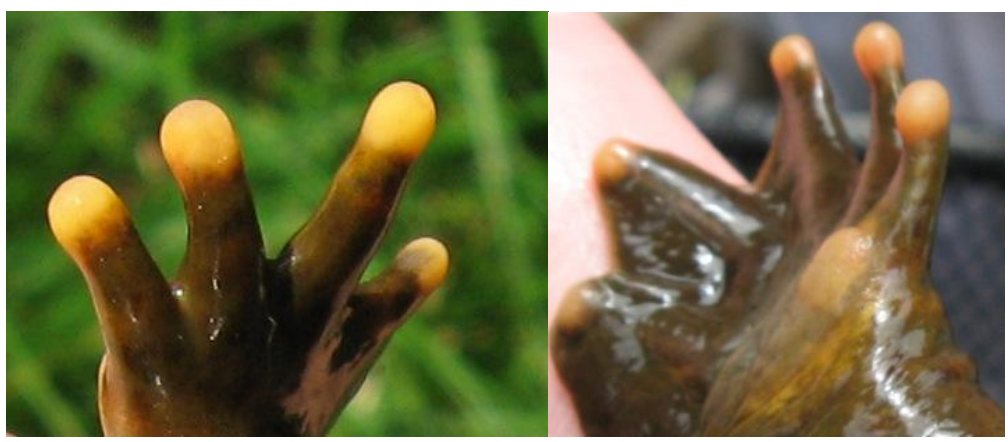

Figure 7 - Front feet of the hellbender have four toes (left), while hind feet of the hellbender have five toes (right). This is one of the diagnostic techniques utilized to distinguish young gilled hellbenders from mudpuppies. 


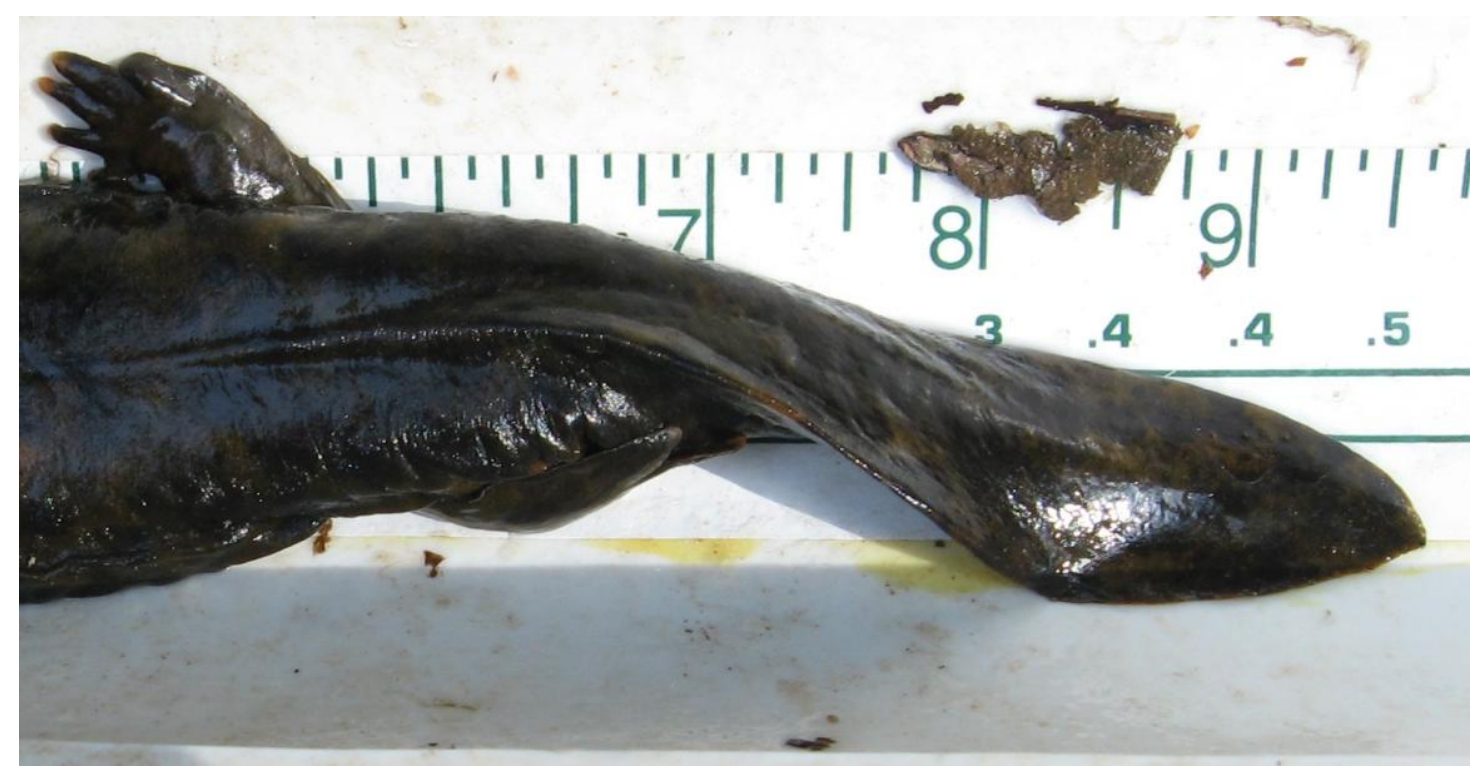

Figure 8 - The tail of the hellbender is laterally compressed to facilitate swimming.

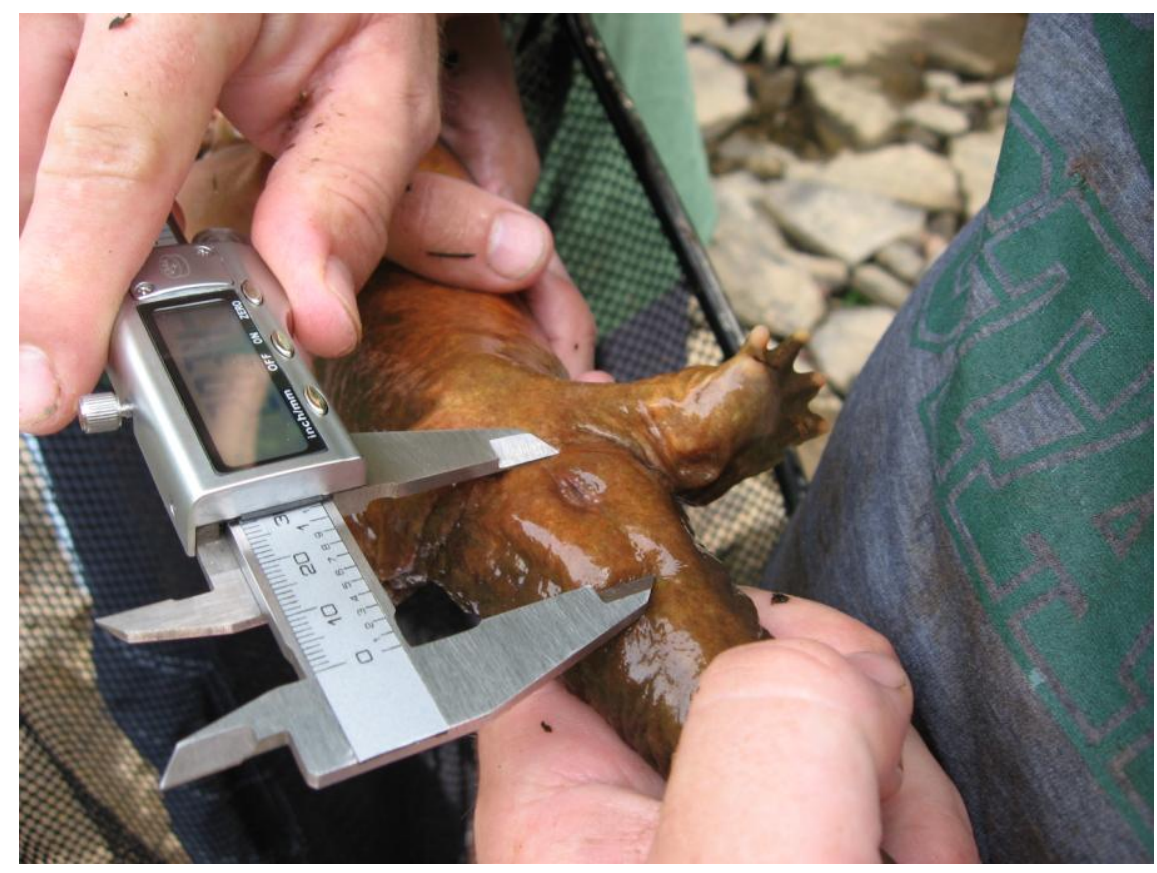

Figure 9 - Swollen cloacal glands form a swollen ring around the cloacal opening in male hellbenders in West Virginia from May - October. This is the primary technique for determining the gender of individuals captured in the field. 


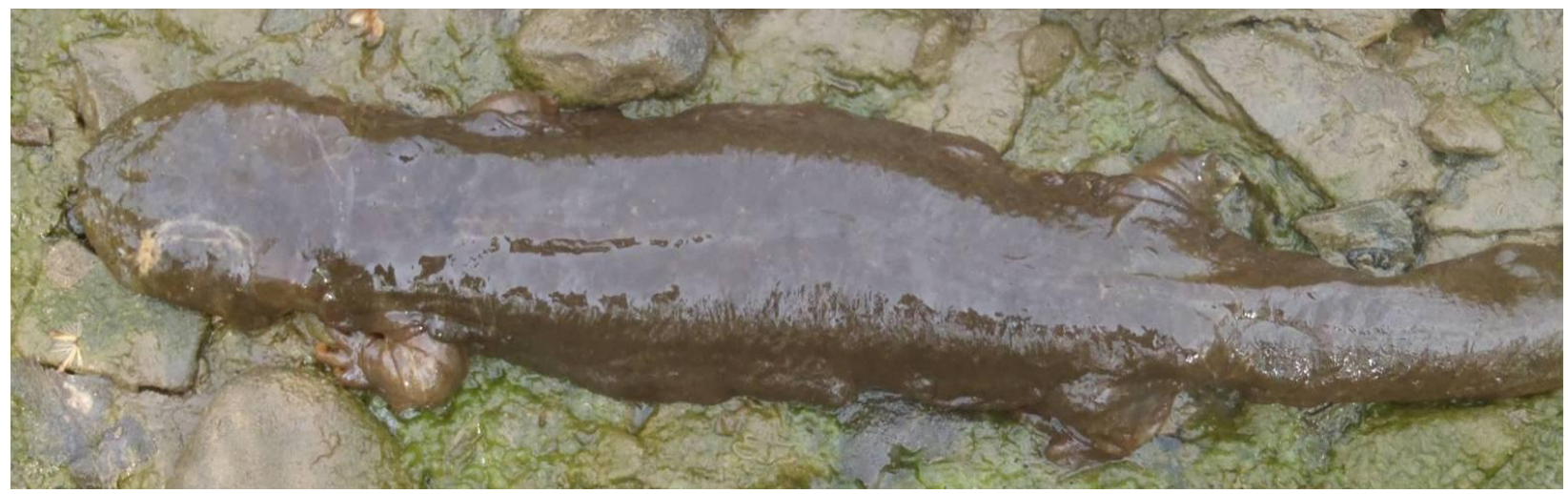

Figure 10 - Male hellbender with bite from a conspecific on the left lateral portion of the head during the breeding season. Double row of teeth in bite mark indicates bite from other hellbender.

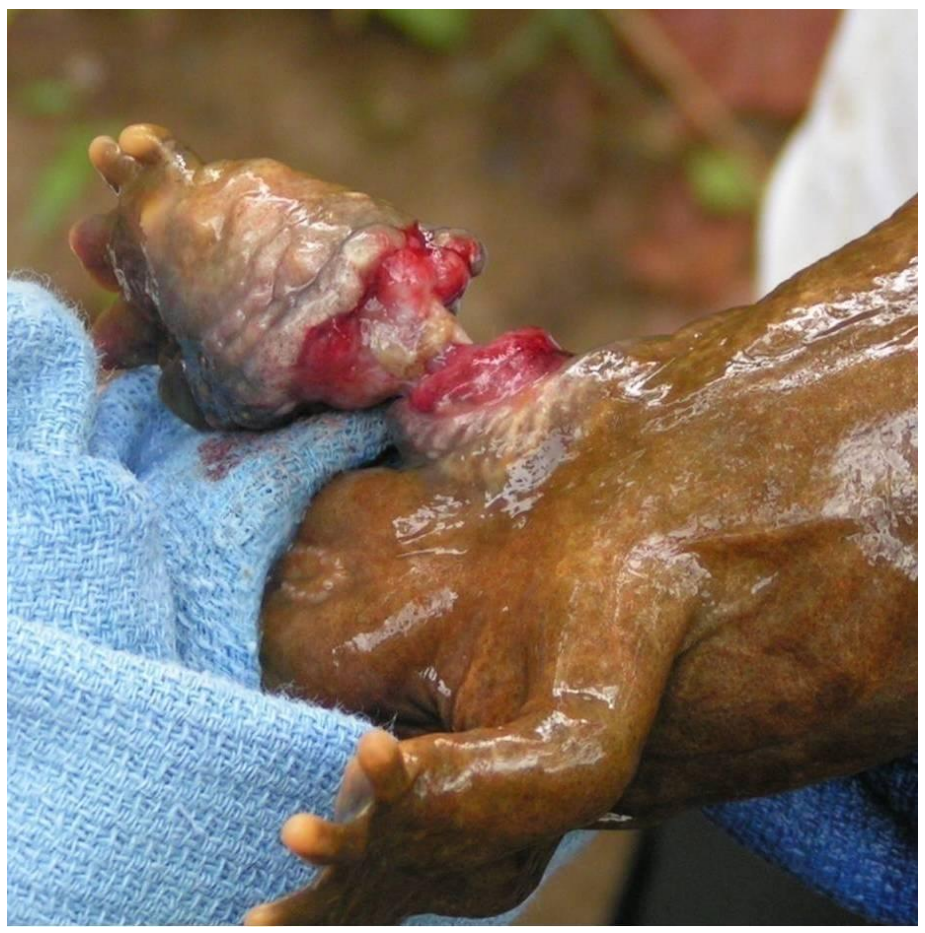

Figure 11 - Male hellbender (note swollen cloacal glands) with leg injury during breeding season. When legs, digits, or tail tips are bitten during combat, hellbenders will roll like an American alligator (Alligator mississippiensis) and sever these appendages. 


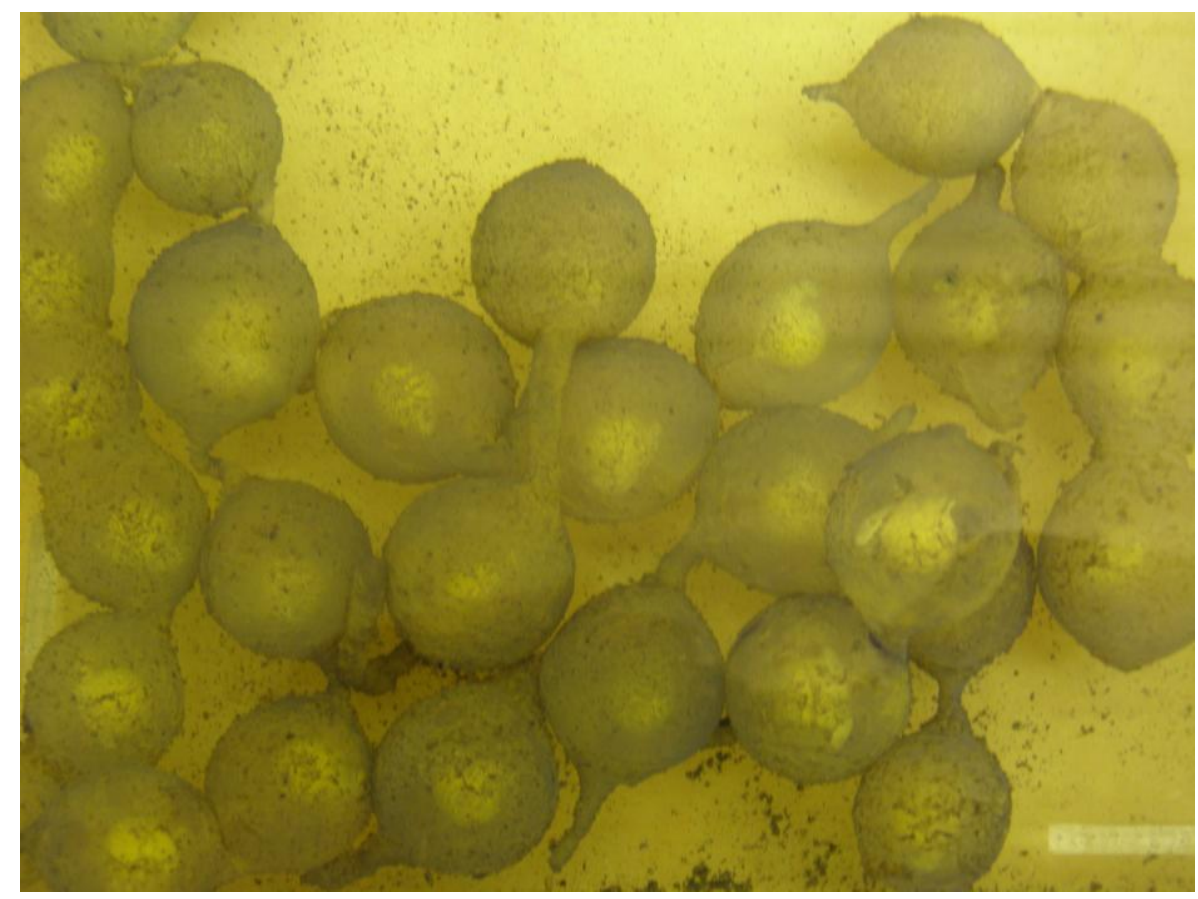

Figure 12 - Hellbender egg mass showing eggs connected in rosary-like strand.

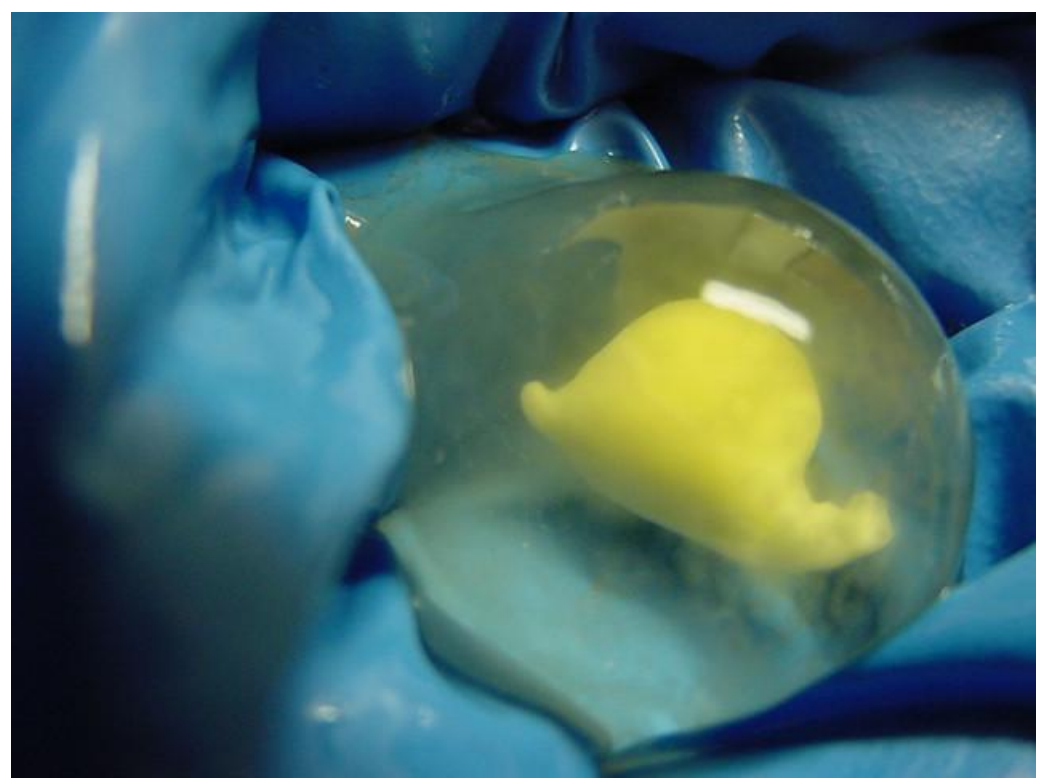

Figure 13 - Individual hellbender egg at approximately 2 weeks post-fertilization. 


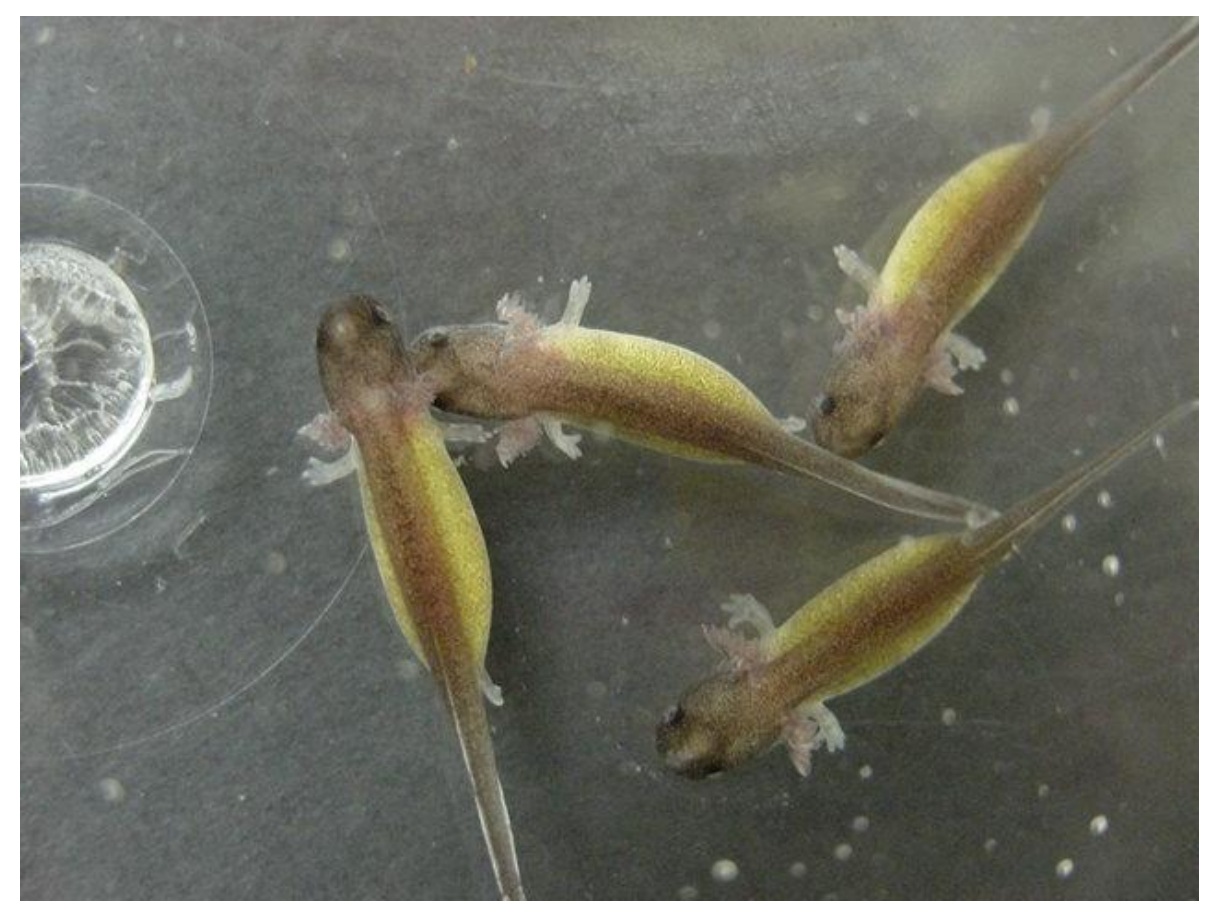

Figure 14 - Multiple hellbender larvae being reared in human care. These individuals are approximately 40 days old with gills present, front feet with four fingers, and yellow yolk sac on ventrum.

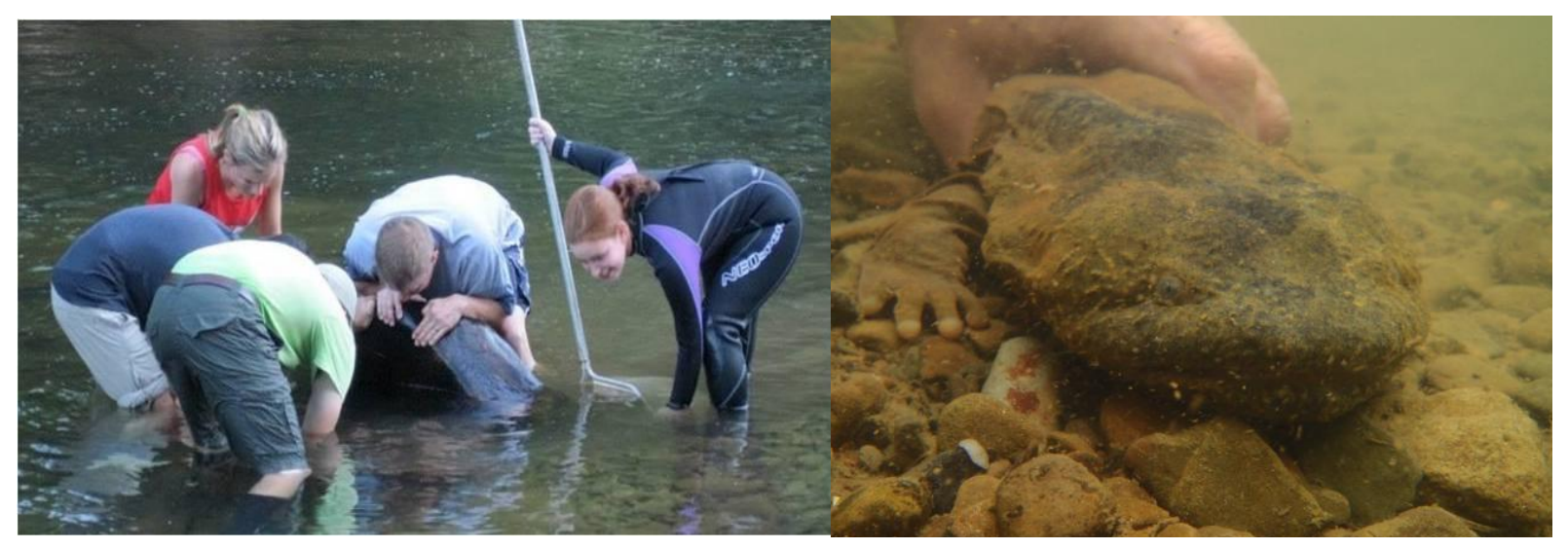

Figure 15 - Surveillance technique with shelter being lifted with nets at each corner and hellbender being captured by hand under the stone and moved to the nets. 


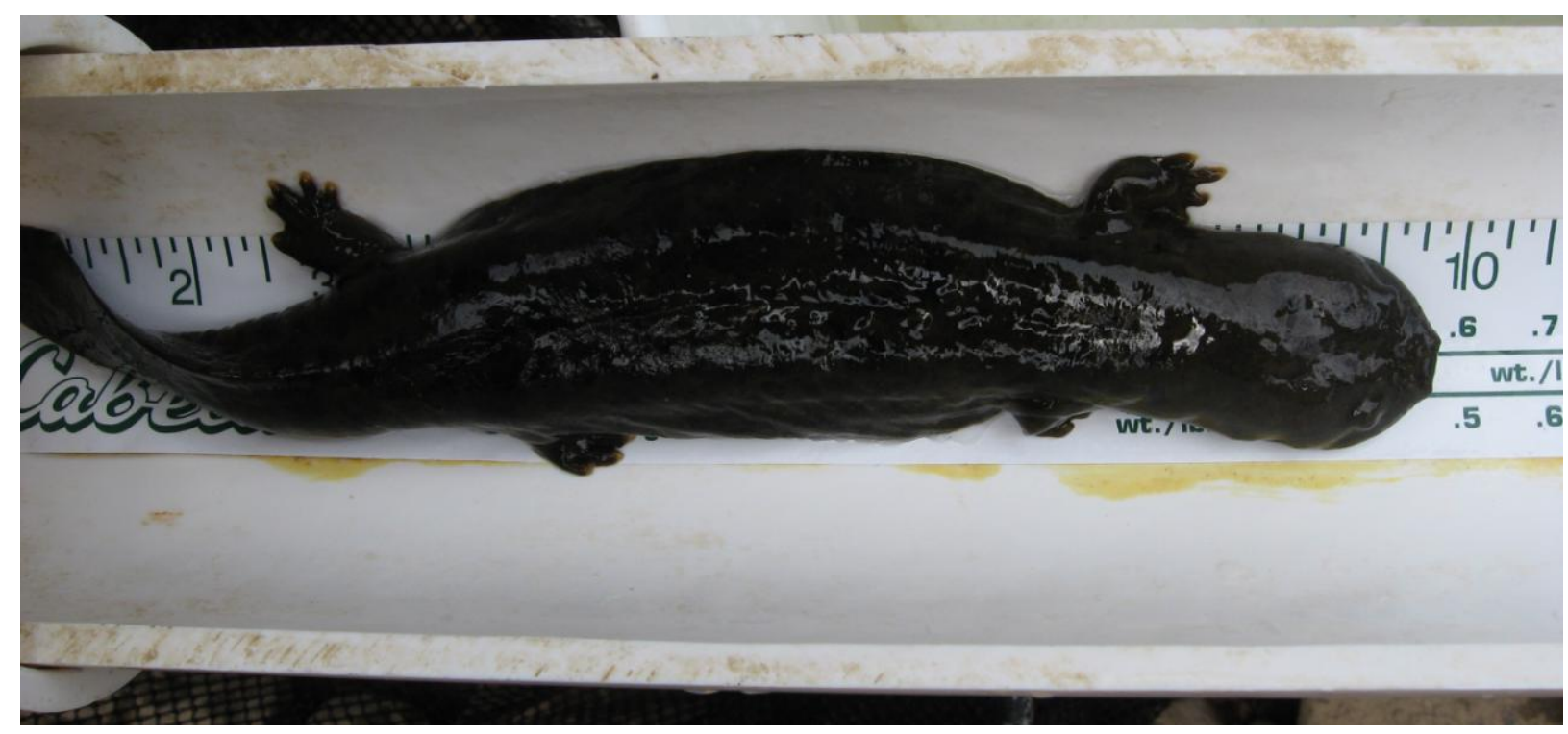

Figure 16 - Hellbender being measured in measuring tube. The measuring tube facilitates easy measurement of the individual in an extended position without stressful manual extension of the body.

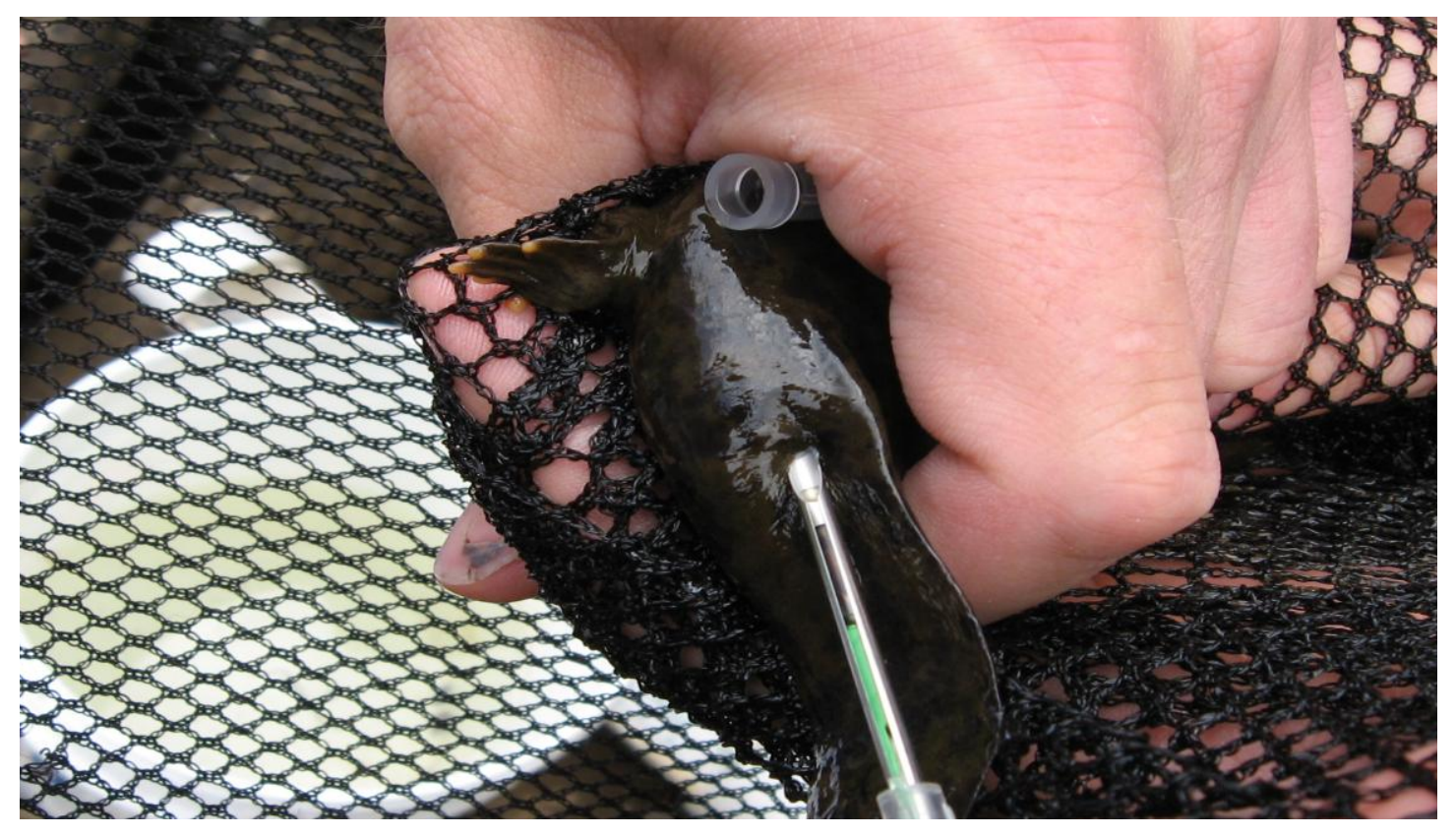

Figure 17 - Hellbender being implanted with PIT tag intramuscularly in the left lateral aspect of the tail. 


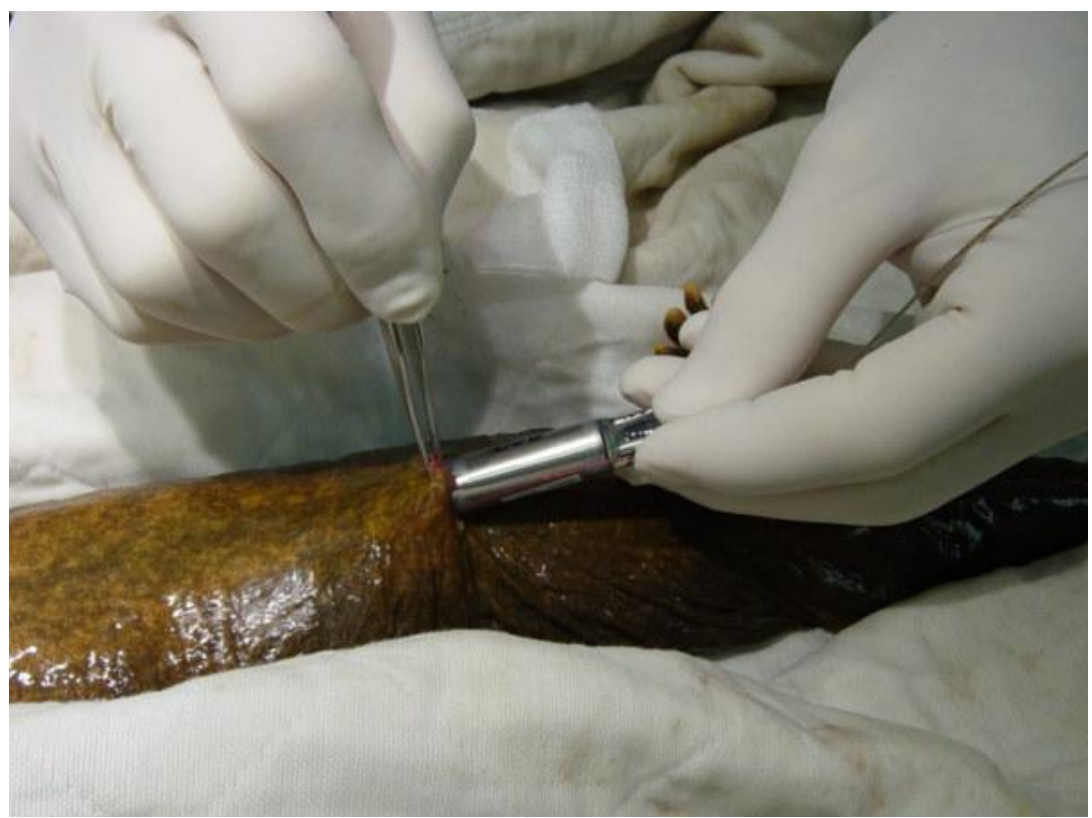

Figure 18 - Whip transmitter being implanted in adult hellbender with antenna visible on the right.

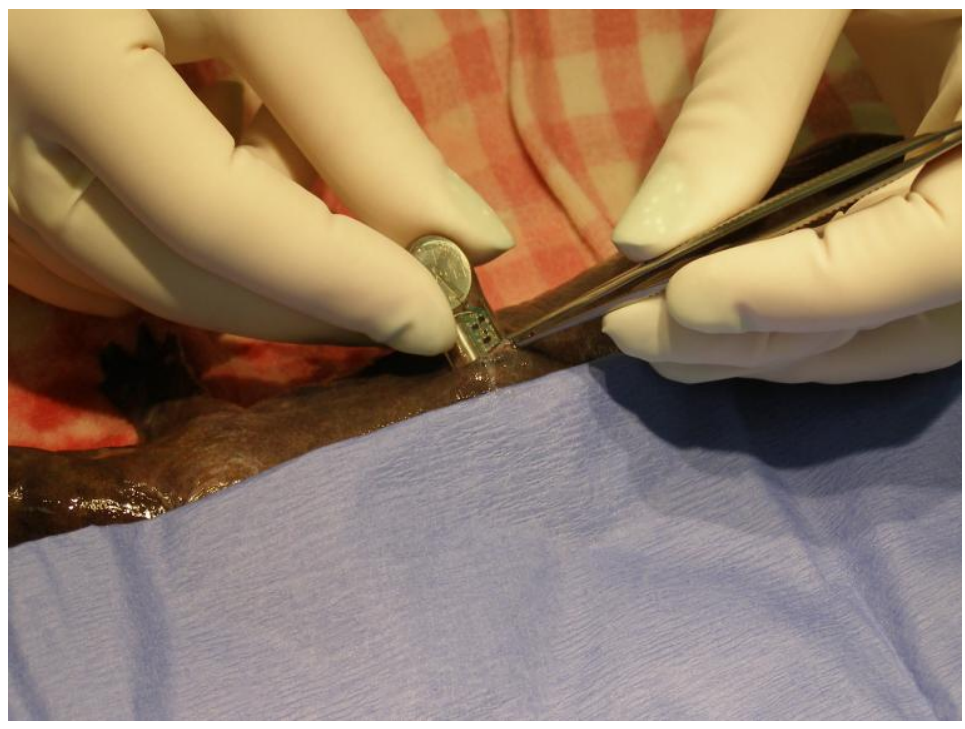

Figure 19 - Smaller loop transmitter with internal antenna being implanted in juvenile hellbender. 


\begin{tabular}{|c|c|}
\hline Stream or River & Date of Last Recorded Observation Prior to This Study \\
\hline Buffalo Creek & 2009 \\
\hline Wheeling Creek & 2009 \\
\hline Fish Creek & 2000 \\
\hline Middle Island Creek & 1968 \\
\hline North Fork Hughes River & 1998 \\
\hline South Fork Hughes River & 1969 \\
\hline Mud River & 1959 \\
\hline Twelvepole Creek & 1970 \\
\hline Cedar Creek & 1974 \\
\hline Little Kanawha River & 1983 \\
\hline Leading Creek & 1983 \\
\hline Tygart River & 1935 \\
\hline Guyandotte River & 1949 \\
\hline Ohio River & 2008 \\
\hline Kanawha River & 1951 \\
\hline Glade Creek & 1995 \\
\hline Laurel Creek & 1997 \\
\hline Second Creek & 1955 \\
\hline Greenbrier River & 1967 \\
\hline West Fork of Greenbrier River & 2006 \\
\hline East Fork of Greenbrier River & 2006 \\
\hline Cheat River & 1936 \\
\hline Shavers Fork of Cheat River & 1997 \\
\hline Dry Fork of Cheat River & Unknown date \\
\hline Williams River & 2006 \\
\hline Gauley River & 2006 \\
\hline Elk River & 1963 \\
\hline Back Fork of Elk River & 2006 \\
\hline Holly River & 2003 \\
\hline Cranberry River & 2006 \\
\hline Cherry River & 2001 \\
\hline
\end{tabular}

Table 1 - Historic sites of hellbender occurrence in West Virginia and the year of the last recorded hellbender observation prior to this study. 


\begin{tabular}{|c|c|c|}
\hline Stream or River & Makowsky 2003 & Keitzer 2005 \\
\hline Cherry River & No & No \\
\hline Cranberry River & Yes & Yes \\
\hline Elk River & No & No \\
\hline Back Fork of the Elk River & Yes & Yes \\
\hline Gauley River & No & Yes \\
\hline Glade Creek & $N / A$ & No \\
\hline Greenbrier River & $\mathrm{N} / \mathrm{A}$ & No \\
\hline East Fork of Greenbrier River & $\mathrm{N} / \mathrm{A}$ & Yes \\
\hline West Fork Greenbrier River & No & Yes \\
\hline Guyandotte River & $\mathrm{N} / \mathrm{A}$ & No \\
\hline Holly River & Yes & No \\
\hline Kanawha River & No & N/A \\
\hline Mud River & No & N/A \\
\hline Second Creek & $\mathrm{N} / \mathrm{A}$ & No \\
\hline Shavers Fork of Cheat River & No & N/A \\
\hline Twelvepole Creek & No & No \\
\hline Tygart River & No & N/A \\
\hline Williams River & No & Yes \\
\hline
\end{tabular}

Table 2 - Results of recent surveys of sites of known hellbender occurrence in West Virginia. 


\section{CHAPTER THREE}

\section{LANDSCAPE AND MICROHABITAT VARIABLES ASSOCIATED WITH THE DISTRIBUTION OF THE EASTERN HELLBENDER IN WEST VIRGINIA}

\section{PREPARED FOR SUBMISSION TO NORTHEASTERN NATURALIST}

\section{W. JOSEPH GREATHOUSE ${ }^{1,2^{*}}$ and EUGENE E. FELTON ${ }^{2}$}

${ }^{1}$ Department of Conservation Science, The Wilds, Cumberland, Ohio, USA, (304) 639-7684, jgreathouse@thewilds.org

${ }^{2}$ Department of Animal and Nutrition Science, West Virginia University, Morgantown, West Virginia, USA, (304) 293-2631, Gene.Felton@mail.wvu.edu 
Abstract - Populations of the Eastern Hellbender (Cryptobranchus alleganiensis alleganiensis) have declined throughout its range over the past 30 years. We conducted surveys at 23 sites of historic Hellbender occurrence in West Virginia from May - September, 2010 to determine the current distribution of this species in the state. We also aimed to assess which environmental variables may be associated with this species' presence and may indicate sites for potential future surveys or reintroduction efforts. Hellbenders were documented at 12 of 23 historic sites with recruitment in the form of eggs, larvae, or juveniles documented at 9 sites. Analyses of microhabitat and landscape variables indicated that dissolved oxygen concentration and percent of total forest within the watershed were the only variables significantly different between sites of Hellbender presence and sites where Hellbenders were not detected. Canonical discriminant analysis of environmental variables indicated that increased dissolved oxygen concentration, percent total forest, and percent cobble substrate in streams and rivers were strongly associated with Hellbender presence, whereas increased sand substrate was most strongly associated with sites where Hellbenders were not observed. Landscape level MaxEnt analyses of GIS data associated with sites where Hellbenders were observed indicated that the presence of open development and several well-draining sandy loam soils were the strongest indicators of predicted Hellbender distribution with open development being negatively associated and the sandy loam soils being positively associated with Hellbender presence. This study emphasizes the importance of forested riparian buffer strips to the distribution of this species in West Virginia.

\section{Introduction}

The Eastern Hellbender (Cryptobranchus alleganiensis alleganiensis) is one of the largest salamanders in the Western Hemisphere growing to a total length of up to $75 \mathrm{~cm}$ 
(Nickerson and Mays 1972). The Hellbender is considered an inhabitant of cool, clean, swiftly flowing stream and river systems in which adult individuals shelter under large boulders, within bedrock crevices, and under other in-stream materials such as large woody debris (Mayasich et al. 2003). As with other amphibian species, the Hellbender is considered an indicator species of habitat quality in the streams and rivers that it inhabits (Petranka 1998), and it is believed to be an important predator and regulator of crayfish populations in these habitats as well (Humphries and Pauley 2000).

Over the past thirty years, several studies have indicated that this species is in a state of decline in abundance and distribution throughout its historic range (Burgmeier et al. 2011a, Foster et al. 2009, Gates et al. 1985, Wheeler et al. 2003). The largest portion of the historic range of the hellbender is a contiguous region of the United States that extends from the northern reaches of the Appalachian Mountains in New York state south through northern Georgia, Alabama, and Mississippi and west to the Mississippi River. A disjunct population of the Eastern Hellbender occurs in central Missouri, and a separate subspecies, the federally threatened, Ozark hellbender (Cryptobranchus alleganiensis bishopii) inhabits a small region of southern Missouri and northern Arkansas (Briggler et al. 2007). With the well-documented decline of this species, it has been designated as a rare or endangered species in each of the states within its historic range, and it has been awarded some form of protection against active capture and take of individuals in every state except Kentucky.

The decline of this species is believed to be associated with a variety of factors throughout its range including but not limited to water pollution, sedimentation, disease, overcollection, persecution as a nuisance species, and installation of dams (Horchler 2005, Phillips and Humphries 2005). In addition to the lack of recently documented observations at historic 
sites of presence, several studies have documented a lack of recruitment in extant populations due to the lack of egg, larvae, or juvenile presence at study sites (Burgmeier et al. 2011b, Gates 1983, Peterson et al. 1983) and due to uneven sex ratios (Burgmeier et al. 2011b, Horchler 2010).

West Virginia was at one point considered to be the state with the greatest abundance of Hellbenders within the Ohio River drainage (Nickerson and Mays 1972). Historic documentations of presence of the species within the state occur from 48 locations in 33 streams or rivers located within 22 counties (Maysasich and Grandmaison 2003). The majority of these counties occur within a conterminous cluster of counties located along the western front of the Appalachian Mountain region of the state with other occurrences scattered along the stream systems of the Ohio River in the Allegheny Plateau (Green and Pauley 1987).

The purpose of this study was to document the current distribution of this species in West Virginia, to assess morphological and demographic attributes of observed Hellbenders, and to determine which microhabitat and landscape variables may be indicative of Hellbender presence in order to guide future studies and management decisions associated with this species in West Virginia.

\section{Study Area}

Twenty-three randomly selected sites from thirty-three sites of documented historic occurrence in West Virginia were utilized for physical surveys from May - September 2010 (Fig. 1). Study sites included Buffalo Creek, Wheeling Creek, Fish Creek, Middle Island Creek, the North and South Forks of the Hughes River, Little Kanawha River, Cedar Creek, Mud River, Twelvepole Creek, Shavers Fork of the Cheat River, the East and West Forks of the Greenbrier 
River, Back Fork of the Elk River, Holly River, Greenbrier River, Second Creek, Gauley River, Cranberry River, Williams River, Cherry River, Glade Creek, and Laurel Creek. Sites of surveys were based on prior documented observations or when these data were not available, sharp stream bends were selected for surveillance based upon anecdotal reports of hellbender presence being associated with these sites (Foster et al. 2009, Pfingsten 1990). The surveys in this study were conducted beginning at the end of a boulder field at the downstream portion of a stream run near a stream bend as identified from topographic maps.

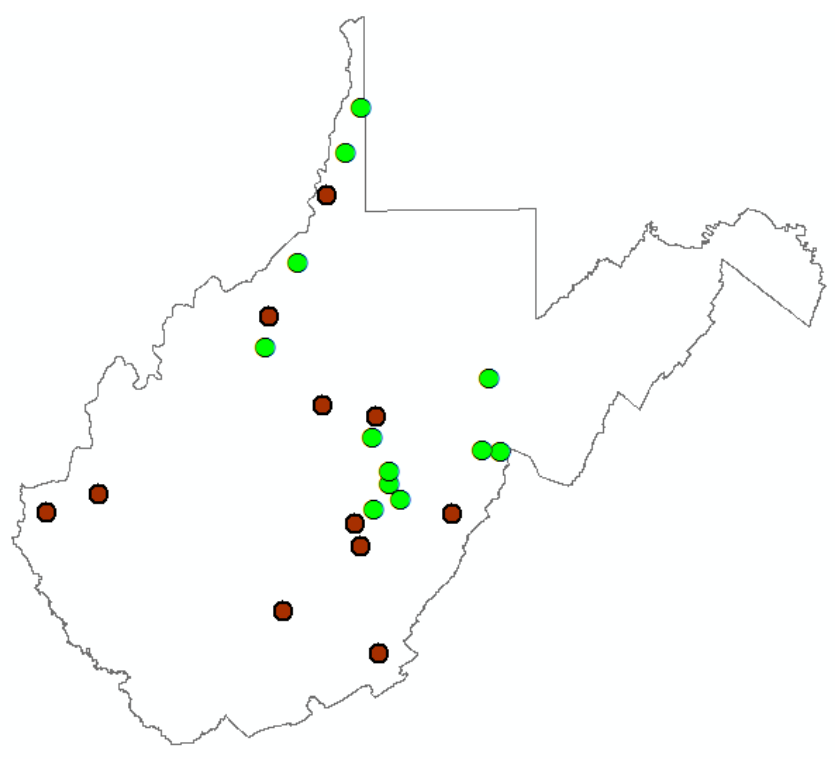

Figure 1. Map of survey sites. Green dots indicate sites where hellbenders were captured, and red dots indicate sites where hellbenders were not observed.

\section{Methods}

Two surveys were conducted at each site throughout the study period in order to improve the opportunity for surveys to occur in as optimal of conditions as possible with low water levels and reduced turbidity. Surveys commenced at the downstream portion of each site in order to minimize silt plumes in the survey site that would result from lifting boulders in those areas. When possible, boulders were lifted from the upstream side of the boulder by hand by 3-5 
individuals, and if present, Hellbenders were captured by hand beneath the rock and placed in a net (Browne et al. 2011). Upon capture, the Hellbenders were taken to the shore for data collection in order to prevent any potential escape during handling.

During processing of the Hellbender, snout-to-vent length, total length, and mass were measured. Snout-to-vent length and total length were measured by placing the hellbender in a 4" PVC pipe that had been cut in half longitudinally, capped with PVC end caps, and outfitted with a fiberglass measuring tape that was secured to the pipe with plumber's glue. Each individual was weighed in a new plastic bag with a hanging Rapala fish scale (Rapala VMC Corp., Helsinki, Finland). If the individual was approximately $23 \mathrm{~cm}$ or greater in total length, gender was determined by evaluating the presence of swollen cloacal glands in males (Smith 1906).

Each individual was then scanned with an InfoPet transponder reader (InfoPet Inc., Burnsville, Minnesota, USA) to determine if the animal had been previously captured. If the animal had been previously captured, the ten-digit alphanumeric transponder number was recorded, and if the animal had not been previously captured, a sterile transponder was implanted intramuscularly in the left lateral base of the tail approximately two centimeters distal to the cloaca. The implanted transponder was then scanned with the reader to confirm placement, and the identification number was recorded. Following this process, the individual would be rinsed in stream water and would be returned to the boulder from which it was captured and guided under the boulder until the individual was completely under cover.

Upon completion of specimen measurements, information on microhabitat variables were collected by measuring the water depth at the site with a fiberglass tape measure. Water 
chemistry and physical variables including $\mathrm{pH}$, conductivity (microseimens), dissolved oxygen (ppm), and temperature (degrees Celsius) were measured with an Extech ExStik II pH/conductivity meter and an Extech ExStik II dissolved oxygen meter (Extech Instruments, Nashua, $\mathrm{NH}$ ) respectively. Throughout the survey process, crayfish density was assessed by determining how many stones out of the first one hundred stones that were lifted were occupied by crayfish (Nickerson et al. 2003). At the conclusion of the survey, Wolman zigzag pebble counts were conducted at each survey site to quantify in-stream substrate composition (Wolman 1954).

All Hellbender surveys were timed, and capture per unit effort estimates were calculated by dividing the number of Hellbenders captured during each survey by the combined number of hours invested in the survey by each participant. For measurement of landscape level parameters at each site, data was acquired including land cover, elevation, and watershed area in ArcGIS 10.1 with spatial analyst extensions with source metadata and layers incorporated from the USGS National Map and layers from the West Virginia GIS Technical Center (Fry et al. 2011).

Comparative analyses of variables associated with sites of Hellbender presence as opposed to sites where presence were not observed were performed utilizing Mann-Whitney tests. Student's t-tests were performed to analyze morphometric data from captured individuals. A canonical discriminant analysis was performed to determine the environmental variables which most successfully differentiated sites of presence from sites where presence was not observed. We performed these statistical analyses with R 2.12.1 statistical analysis software (R Core Team 2013). Findings were considered to be statistically significant when $P<0.05$. 
The probability of potential sites of distribution in West Virginia was also determined by using the software program MaxEnt version 3.2.1 (Phillips et al. 2006). Presence data from surveys were entered into the model, and environmental layers utilized for prediction included the USGS National Land Cover 2001 data set (Homer et al. 2004), digital elevation (USGS 1999), soil (USDA 2009), geology, human population density (WV GIS Technical Center 2007),

and landscape integrity (Dougherty and Byers 2008) raster layers clipped to the processing extent of the West Virginia elevation data set in ArcGIS 10.1. Land cover, soil, and geology were classified as categorical variables, while elevation, human population, and landscape integrity were managed as continuous variables.

\section{Results}

Surveys resulted in captures of 67 Hellbenders at 12 of 23 sites (52\%) with a capture per unit effort ranging from $0.085-1.609$ captures per hour at sites of detected presence. The number of individuals captured per survey at sites of detected presence ranged from $1-14$ individuals captured per survey with a mean capture rate of 3.28 individuals per site of detected presence. Hellbenders were captured during the first survey at 11 of the 12 sites (92\%). The sex ratio for individuals large enough for sex determination was 1.3:1 (36 males and 28 females). Most individuals captured during surveys were adults (88\%) with only eight individuals captured from sub-adult size classes. Mean total length (Fig. 2) and snout-to-vent length (Table 1) of captured individuals was $45.67 \pm 8.53 \mathrm{~cm}$ and $30.09 \pm 6.03 \mathrm{~cm}$ respectively with no significant difference between either measurement for males and females. Mean mass for captured individuals was $623.7 \pm 235.5 \mathrm{~g}$, with no significant difference in mass between sexes. Recruitment was documented in the form of captures of sub-adults and juveniles or the observation of eggs at 9 of the 12 sites (75\%) where Hellbenders were captured. 


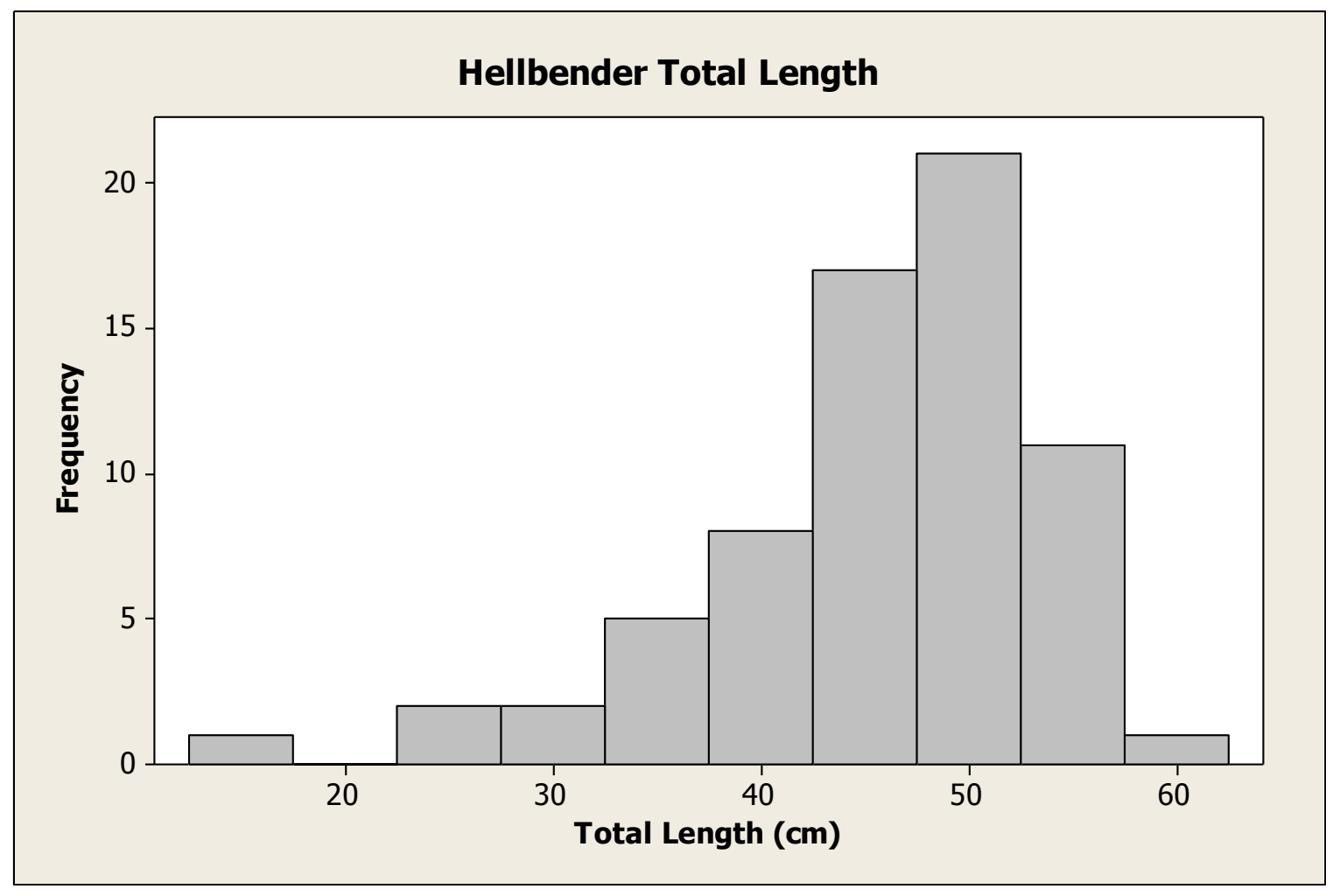

Figure 2. Frequency distribution table of number of Hellbenders captured per $5 \mathrm{~cm}$ size class.

\begin{tabular}{ccccc}
\hline & $\begin{array}{c}\text { Total } \\
(\text { Mean } \pm \text { SD) }\end{array}$ & $\begin{array}{c}\text { Male } \\
(\text { Mean } \pm \text { SD })\end{array}$ & $\begin{array}{c}\text { Female } \\
(\text { Mean } \pm \text { SD) }\end{array}$ & $\begin{array}{c}\text { Unknown } \\
(\text { Mean } \pm \text { SD })\end{array}$ \\
\hline TL $(\mathbf{c m})$ & $45.67 \pm 8.53$ & $46.04 \pm 6.14$ & $48.29 \pm 7.24$ & $27.03 \pm 10.94$ \\
SVL (cm) & $30.09 \pm 6.03$ & $30.47 \pm 3.98$ & $31.97 \pm 5.26$ & $15.75 \pm 5.93$ \\
Cranial Width & $53.24 \pm 12.55$ & $54.46 \pm 9.60$ & $56.15 \pm 11.23$ & $25.98 \pm 10.10$ \\
$\quad(\mathbf{m m})$ & & & & \\
Mass $(\mathbf{g})$ & $623.7 \pm 235.5$ & $612 \pm 178.9$ & $713 \pm 233.0$ & $178 \pm 141.3$ \\
\hline
\end{tabular}

Table 1. Mean morphological measurements of captured Hellbenders. TL: total length; SVL: snout-to-vent length; SD: standard deviation.

Analysis of microhabitat variables within the surveyed stream and river systems revealed that the only significant differences between sites where Hellbenders were captured and sites where Hellbenders were not detected were dissolved oxygen concentrations being greater at sites of Hellbender presence ( $U=27.5, P=0.02$ ) as well as percent of total forested land within the watershed being greater at sites of Hellbender presence $(U=30, P=0.03)$ (Table 2). 


\begin{tabular}{cccc}
\hline Environmental Variables & $\begin{array}{c}\text { Present } \\
(\text { Mean } \pm \text { SD })\end{array}$ & $\begin{array}{c}\text { Not Detected } \\
(\text { Mean } \pm \text { SD) }\end{array}$ & $P$-value \\
\hline Avg. Water Temperature $\left({ }^{\circ} \mathrm{C}\right)$ & $24.76 \pm 3.56$ & $26.3 \pm 2.15$ & 0.31 \\
Avg. Conductivity $(\mu \mathrm{S})$ & $293.5 \pm 97.6$ & $346.4 \pm 100.6$ & 0.26 \\
Avg. pH & $7.7 \pm 0.23$ & $7.82 \pm 0.33$ & 0.44 \\
Avg. Dissolved Oxygen $(\mathrm{ppm})$ & $6.23 \pm 0.42$ & $5.7 \pm 1.1$ & 0.02 \\
Avg. Crayfish & $48.58 \pm 16.83$ & $60.64 \pm 23.07$ & 0.12 \\
Sand \% & $5.75 \pm 8.74$ & $20.0 \pm 28.69$ & 0.11 \\
Gravel \% & $27.5 \pm 15.1$ & $28.45 \pm 19.44$ & 0.83 \\
Fine Substrate \% & $33.25 \pm 18.23$ & $48.45 \pm 30.12$ & 0.30 \\
Cobble \% & $40.92 \pm 14.86$ & $27.09 \pm 16.55$ & 0.22 \\
Boulder \% & $25.83 \pm 13.24$ & $24.45 \pm 23.11$ & 0.50 \\
Coarse Substrate \% & $65.08 \pm 17.02$ & $51.55 \pm 30.12$ & 0.23 \\
Elevation $(\mathrm{m})$ & $519 \pm 262$ & $430 \pm 256$ & 0.38 \\
Area (square km) & $123 \pm 115$ & $147.4 \pm 116.2$ & 0.74 \\
Total Forest \% & $89.58 \pm 12.48$ & $83.87 \pm 8.39$ & 0.03 \\
Total Development \% & $3.55 \pm 1.48$ & $4.2 \pm 1.85$ & 0.21 \\
\hline
\end{tabular}

Table 2.- Mean microhabitat and landscape variable values at sites where Hellbenders were observed and were not detected with Mann-Whitney test $p$-values.

The canonical discriminant analysis of sites based upon where Hellbenders were observed and were not detected in reference to the previously analyzed microhabitat and landscape variables indicated that dissolved oxygen concentration, percent total forest, and percent cobble substrate were the variables most strongly separating sites of Hellbender presence from sites where they were not observed, while percent sand substrate and crayfish abundance were the factors most associated with differentiating sites where hellbenders were not observed from sites where Hellbenders were captured $(F=27.99, \mathrm{df}=1,21, P=0.00)$ (Fig 3., Table 3). 


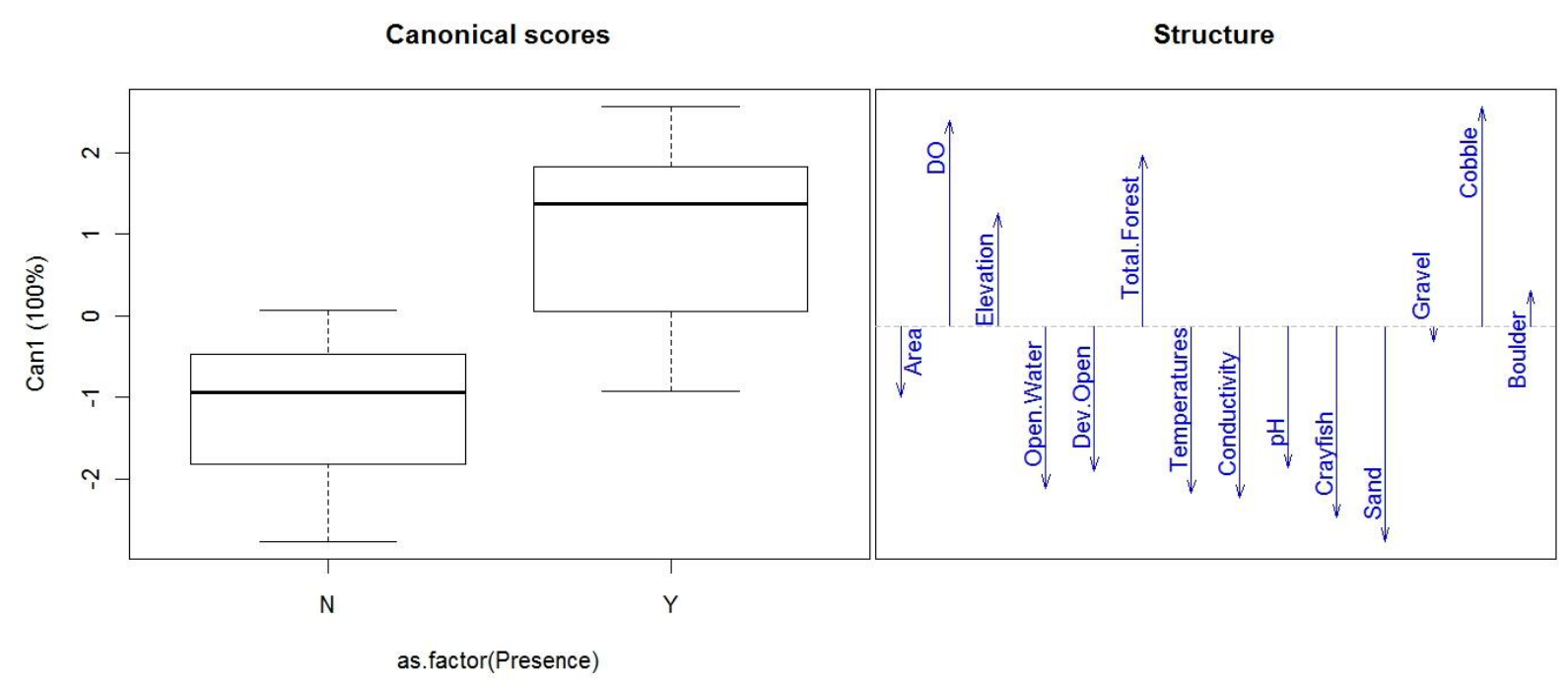

Figure 3. Box plot indicating canonical discrimant scores for sites where Hellbenders were present (Y) and not observed (N) as well as plot of vector magnitude associated with analyzed environmental variables differentiating sites of presence (above mid-line) and sites where hellbenders were not observed (below mid-line).

\begin{tabular}{cc}
\hline Canonical Correlation Value & 0.57 \\
Eigenvalue & 1.33 \\
\hline Environmental Variable & Loading \\
\hline Avg. Water Temperature $\left({ }^{\circ} \mathrm{C}\right)$ & -0.35 \\
Avg. Conductivity $(\mu \mathrm{S})$ & -0.36 \\
Avg. pH & -0.29 \\
Avg. Dissolved Oxygen $(\mathrm{ppm})$ & 0.43 \\
Avg. Crayfish & -0.40 \\
Sand \% & -0.45 \\
Gravel \% & -0.03 \\
Cobble \% & 0.46 \\
Boulder \% & 0.08 \\
Elevation $(\mathrm{m})$ & 0.23 \\
Area (square km) & -0.15 \\
Total Forest \% & 0.36 \\
Total Development \% & -0.30 \\
Total Open Water \% & -0.34 \\
\hline
\end{tabular}

Table 3. Results of canonical discriminant analysis of environmental variables associated with sites of Hellbender presence (positive values) and sites where Hellbenders were not observed (negative values). 
The MaxEnt predictive model of potential probability of occurrence exhibited an area under curve (AUC) training value of 0.97 with a test AUC of 0.53 rendering it only slightly better than predicting by random chance alone (0.50). Twenty five percent of the 12 sites of presence were utilized as random test samples. Variable importance was measured via a jackknife cross-validation of test samples. The analysis indicated that land cover and soil type were the variables most associated with prediction of Hellbender presence in this model (61.3\% and 36.9\%). A jackknife cross-validation of the AUC on the test samples indicated that geology had a strong negative impact on the model gain. A follow-up analysis was performed removing geology from the model, and this model exhibited an AUC training value of 0.98 with a test AUC of 0.85 (Fig. 4). This analysis indicated that land cover followed by soil type were the variables most associated with prediction of Hellbender presence (54.3\% and 44.9\%) (Table 4).

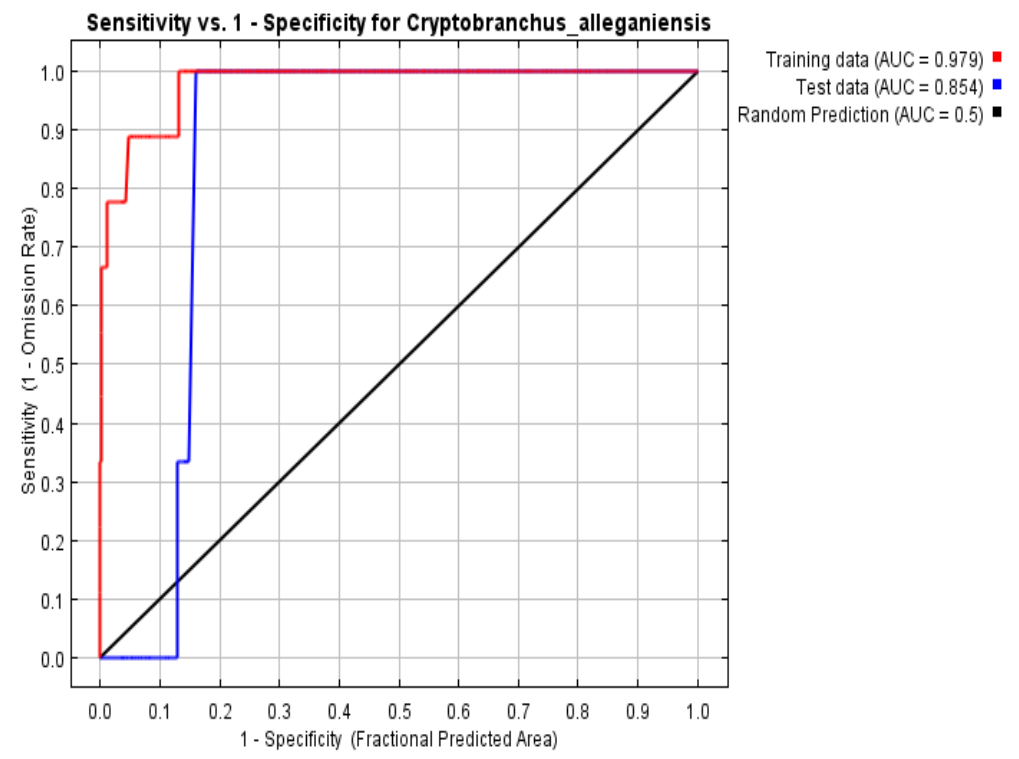

Figure 4. Plot of training and test area under curve (AUC) data of MaxEnt analysis for landscape level variables associated with prediction of Hellbender occurrence. This model built from 9 test and 3 training sites of current Hellbender presence performed well when analyzed with land use, human population density, landscape integrity, elevation, and soil classification variables with AUC values exceeding random predictions. 


\begin{tabular}{|c|c|c|}
\hline Variable & Percent Contribution & Permutation Importance \\
\hline Land Use & 54.3 & 10.2 \\
\hline Soil Type & 44.9 & 89.4 \\
\hline Human Population Density & 0.8 & 0.4 \\
\hline Landscape Integrity & 0 & 0 \\
\hline Elevation & 0 & 0 \\
\hline
\end{tabular}

Table 4. Contribution of landscape variable importance of training data to MaxEnt model as well as permutation importance of each variable to the model AUC.

The greatest land cover factors contributing to the model were the presence of water followed by the presence of open development, and the soil types that contributed most to the model were the presence of several well-draining sandy loam soils as has been seen in other predictive models for this species (Quinn 2009). Most major streams and rivers within the historic range were predicted as high probability sites of presence (Fig. 5), but large scale regional observation of the model indicated several regions in the direct Upper and Mid-Ohio River Valley as well as sites within and near the Monongahela National Forest as having the highest predicted probability of Hellbender occurrence (Fig. 6). 


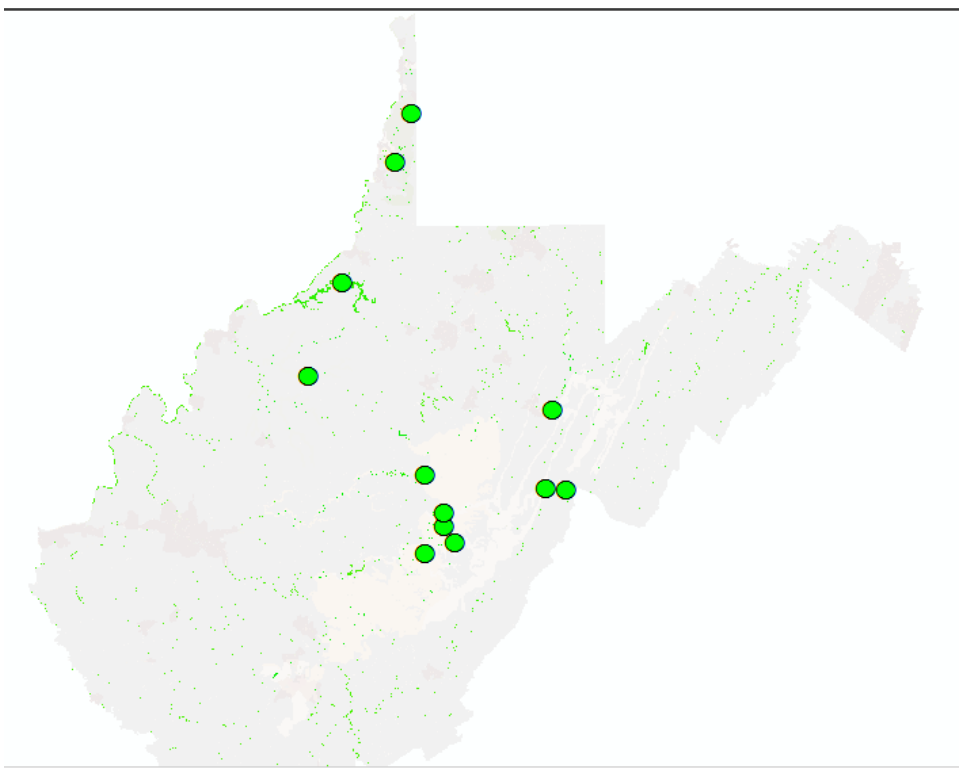

Figure 5 - Map of predicted rasters of hellbender probability greater than $73.6 \%$ are indicated by green rasters predicted in the MaxEnt prediction model with observed sites of hellbender presence represented as green dots.

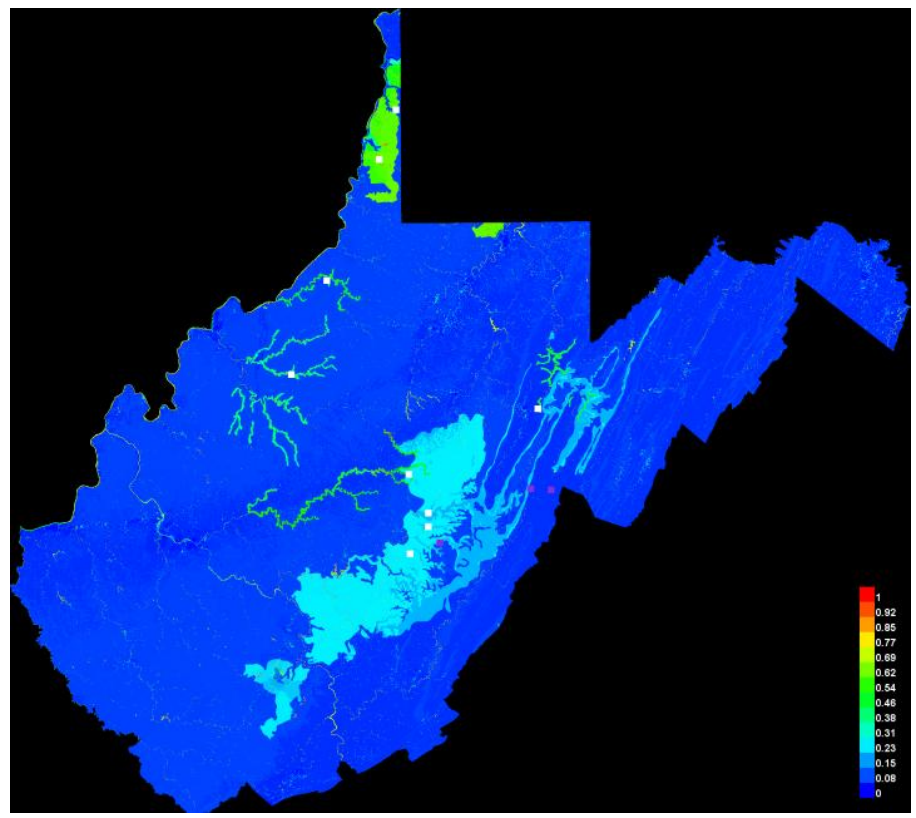

Figure 6. MaxEnt predictive map of Hellbender occurrence in West Virginia at the landscape level. This map was created from a model built from 9 test (white dots) and 3 training (purple dots) sites of current Hellbender presence with land use, human population density, landscape integrity, elevation, and soil classification variables. Predicted probability of occurrence ranges from a low of zero (dark blue - lowest probability) to 1 (red - highest probability) on the accompanying color scale. 


\section{Discussion}

Results of this study indicate that like several other states throughout the Hellbender's range, the number of streams and rivers inhabited by the Hellbender in West Virginia are potentially in decline. Hellbender presence was observed at only $48 \%$ of historic sites (12 of 23) surveyed during this study. The accuracy of survey efficacy associated with these data has been confirmed with follow-up environmental DNA (eDNA) analysis of Hellbender presence, with Hellbender DNA being amplified at all 12 of the aforementioned sites of presence as well as at only one site where hellbenders were not detected (North Fork of Hughes River) by the author (unpublished data).

These findings of decreased presence at formerly occupied sites are consistent with other recent surveys of historic sites in southern West Virginia that also documented a decline in the species' distribution in the state (Keitzer 2007, Makowsky 2004). Capture per survey estimates also appear to be much decreased from the number of individuals that were present at sites during surveys conducted by Green in the 1930's when 34 animals were captured in just four hours during one survey (Green, 1935). Capture per unit effort values are not available for that survey, and capture per unit effort values during this modern study may also be variable due to factors including the experience and skill of survey participants, boulder morphology and availability at various regions throughout the state, and turbidity at the time of survey. Similar declines in population abundance have been documented in long-term studies of this species in other states as well (Burgmeier et al. 2011a, Lipps and Sisson 2008, Wheeler et al. 2003).

Sex ratios of individuals captured throughout the study were relatively even as has been observed in other populations throughout the range (Hillis and Bellis 1971, Humphries and Pauley 2005). As opposed to several other studies, no discernible difference associated with 
mass and length, based upon gender, were observed during this study (Burgmeier et al. 2011a, Makowsky et al. 2010). Lack of observed recruitment during several studies has been associated with potentially high larval mortality rates, population declines, and surveys focusing on microhabitats that may not be as heavily utilized by younger age classes. A positive finding from this survey was that recruitment was observed at $75 \%$ of sites where presence was detected as opposed to other studies that have found a lack of recruitment at survey sites (Unger et al. 2013, Wheeler et al. 2003).

The greatest in-stream factors associated with Hellbender presence during this study were increased dissolved oxygen concentrations and increased percent cobble at sites of Hellbender presence. The greatest in-stream factor associated with sites where Hellbenders were not observed was increased percent sand substrate. Several researchers have considered sedimentation due to increased fine substrate in stream and river systems a cause of decline for this species (Gates et al. 1985, Santas et al. 2013, Trauth et al. 1992). The sediment is believed to encompass the interstitial spaces in cobble beds that could be used for shelter by larval and juvenile Hellbenders as well as prey items for these individuals (Hecht-Kardasz et al. 2012, Nickerson et al. 2003), in extreme cases, sedimentation can also impede habitat use and migration by adults.

Studies of the Spring Salamander (Gyrinophilus porphyriticus) have indicated that there is a negative relationship between adult salamander abundance in populations of this species in association with substrate embeddedness due to sedimentation from logging (Lowe et al. 2004). Sedimentation has also been observed to impede migration of larval Southern two-lined Salamanders (Eurycea cirregera) when gravel is highly embedded (Miller et al. 2007). Studies of the Pacific Giant Salamander have also indicated that increased gravel and cobble presence in 
systems that are less heavily impacted by sedimentation are the best predictors of abundant populations of this species (Welsh and Ollivier 1998).

From a landscape perspective, the greatest factor associated with Hellbender presence in West Virginia was the presence of increased proportions of percent forested land cover upstream of the study site within the watershed. A key factor associated with areas where Hellbenders were not observed in the canonical discriminant analysis as well as in the site of occurrence probability predictions from the MaxEnt model was the presence of development within watersheds. Deforestation has been considered to be detrimental to stream and river systems by increasing sedimentation due to erosion of soil (Iwata et al. 2003, Lowe and Bolger 2002). Deforestation of riparian buffer strips in the southern Appalachian region as well as in the Pacific Northwest have been implicated in the loss of fish diversity in streams where substrate particle size or in-stream habitat are impacted by increasing patches of streamside deforestation (Jones et al. 1999, Reeves et al. 1993). Increased water temperatures in streams and rivers have also been associated with loss of canopy cover due to deforestation (Kausha et al. 2010, Nelson et al. 2007). Increases in water temperature have the potential to impact the biodiversity and physiological performance of cool-water fish species in these systems (Ficke et al. 2007, Kitchell et al. 1977), and increased water temperatures are likely to influence Hellbender physiology as well, as has been observed in previous temperature acclimation studies (Hutchison et al. 1973, Hutchison and Hill 1976).

This study indicates that the distribution of the Hellbender in West Virginia has declined over the last 30 years, and the presence of intact forest in watersheds is likely the greatest predictor of Hellbender presence at historic sites of occurrence. In spite of a potential decline in distribution, several populations do appear to be actively reproducing and to be healthy, and the 
MaxEnt model indicated high probability of potential occurrence at sites where the species has not previously been documented including the Meadow River, Big Clear Creek, and Piney Creek and also indicates sites of historic occurrence that may prove successful for efforts focusing on the translocation of head-started hellbenders such as the Cherry River and the Little Kanawha River, where Hellbenders have not been detected utilizing physical or eDNA survey techniques. Future management actions for this species should emphasize the protection of forested riparian buffer zones at sites of current Hellbender presence and the restoration of forested buffer strips at sites of future reintroductions or translocations of this species in order to minimize sedimentation and increased water temperature threats.

\section{Acknowledgments}

Animals collected during this study were collected under permit WV2010.131 from the West Virginia Division of Natural Resources to William J Greathouse. Funding for this project was provided through the State Wildlife Grant (SWG) program from the West Virginia Division of Natural Resources. Animal care and use approval was granted via the Oglebay's Good Zoo Animal Care and Use Committee (ACUC\#: OGZ-09-01). We would like to thank Dr. Barbara Wolfe from the Wilds and Dr. Thomas Pauley of Marshall University for assistance with review and editing, and we would like to thank several staff and interns from Oglebay's Good Zoo with their assistance in completing this project including but not limited to Penny Miller, Susan Greathouse, Mindi White, Kala Bassa, Kate Marino, Sid Jacobs, James DeNucci, Kyle Jones, and Dan Martin.

\section{Literature Cited}

Briggler, J., J. Utrup, C. Davidson, J. Humphries, J. Groves, T. Johnson, J. Ettling, M. Wanner, K. Traylor-Holzer, D. Reed, V. Lindgren, and O. Byers (eds.). 2007. Hellbender population and habitat viability assessment. IUCN/SSC Conservation Breeding 
Specialist Group. Apple Valley, MN. 46 pp.

Browne, R., L. Hong, D. McGinnity, S. Okada, W. Zhenghuan, C. Bodinof, K. Irwin, A. McMillan, and J. Brigger. 2011. Survey techniques for giant salamanders. Amphibian and Reptile Conservation. 5(4): 1-16.

Burgmeier, N., S. Unger, T. Sutton, and R. Williams. 2011b. Population status of eastern hellbender (Cryptobranchus alleganiensis alleganiensis) in Indiana. Journal of Herpetology. 45(2): 195-201.

Burgmeier, N., S. Unger, J. Meyer, T. Sutton, and R. Williams. 2011c. Health and habitat quality assessment for the eastern hellbender (Cryptobranchus alleganiensis alleganiensis) in Indiana, USA. Journal of Wildlife Diseases. 47(4): 836-848.

Dougherty, M. and E. Byers. 2008. Preliminary calculation of landscape integrity in West Virginia based on distance from weighted disturbances. West Virginia Division of Natural Resources. Elkins, West Virginia. 5 p.

Ficke, A.D., C.A. Myrick, and L.J. Hansen. 2007. Potential impacts of global climate change on freshwater fisheries. Reviews in Fish Biology and Fisheries. 17(4): 581-613.

Foster, R., A. McMillan, and K. Roblee. 2009. Population status of hellbender salamanders (Cryptobranchus alleganiensis) in the Allegheny River drainage of New York state. Journal of Herpetology. 43(4): 579-588.

Fry, J., G. Xian, S. Jin, J. Dewitz, C. Homer, L. Yang, C. Barnes, N. Herold, and J. Wickham. 2011. Completion of the 2006 National Land Cover Database for the Conterminous United States. PE\&RS. 77(9): 858-864.

Gates, J. 1983. The distribution and status of the hellbender (Cryptobranchus alleganiensis) in Maryland: I. The distribution and status of Cryptobranchus alleganiensis in Maryland. II. Movement patterns of translocated Cryptobranchus alleganiensis in a Maryland stream. University of Maryland. Frostburg, Maryland.

Gates, J., C. Hocutt, J. Stauffer, and G. Taylor. 1985. The distribution and status of Cryptobranchus alleganiensis in Maryland. Herpetological Review. 16(1): 17-18.

Green, N.B. 1935. Further notes on the food habits of the water dog (Cryptobranchus alleganiensis Daudin). Proceedings of the West Virginia Academy of Sciences. Elkins, WV.

Green, N.B. and T. Pauley. 1987. Amphibians and Reptiles in West Virginia. University of Pittsburgh Press. Pittsburgh, PA. 241 pp.

Hecht-Kardasz, K., M. Nickerson, M. Freake, and P. Colclough. 2012. Population structure of the hellbender (Cryptobranchus alleganiensis) in a Great Smoky Mountains stream. 
Bulletin of The Florida Museum of Natural History. 51(4): 227-241.

Hillis, R. and E. Bellis. 1971. Some aspects of the ecology of the hellbender, Cryptobranchus alleganiensis alleganiensis, in a Pennsylvania stream. Journal of Herpetology. 5(3/4): 121-126.

Homer, C., C. Huang, L. Yang, B. Wylie and M. Coan, 2004. Development of a 2001 national land cover database for the United States. Photogrammetric Engineering and Remote Sensing. 70(7): 829-840.

Horchler, D. 2010. Long-term growth and monitoring of the eastern hellbender (Cryptobranchus a. alleganiensis) in eastern West Virginia. M.S. Thesis, Marshall University, Huntington, West Virginia. $48 \mathrm{pp}$.

Humphries, J. and T. Pauley. 2000. Seasonal changes in nocturnal activity of the hellbender, Cryptobranchus alleganiensis, in West Virginia. Journal of Herpetology. 34(4): 604607.

Humphries, J. and T. Pauley. 2005. Life history of the hellbender, Cryptobranchus alleganiensis, in a West Virginia stream. American Midland Naturalist 154: 135-142.

Hutchison, V., G. Engbretson, and D. Turney. 1973. Thermal acclimation and tolerance in the hellbender, Cryptobranchus alleganiensis. Copeia. 1973(4): 805-807.

Hutchison, V. and L. Hill. 1976. Thermal selection in the hellbender, Cryptobranchus alleganiensis, and the mudpuppy, Necturus maculosus. Herpetologica. 32(3): 327-331.

Iwata, T., S. Nakano, and M. Inoue. 2003. Impacts of past riparian deforestation on stream communities in a tropical rain forest in Borneo. Ecological Applications. 13: 461-473.

Jones, E. B. D., Helfman, G. S., Harper, J. O. and Bolstad, P. V. 1999. Effects of riparian forest removal on fish assemblages in Southern Appalachian streams. Conservation Biology. 13: $1454-1465$.

Kaushal, S.S., G.E. Likens, N.A. Jaworski, M.L. Pace, A.M. Sides, D. Seekell, K.T. Belt, D.H. Secor, and R.L. Wingate. Rising stream and river temperatures in the United States. Frontiers in ecology and the environment. 8(9): 461-466.

Keitzer, S. 2007. Habitat preferences of the eastern hellbender in West Virginia. M.S. Thesis. Marshall University. Huntington, West Virginia. 64 pp.

Kitchell, J.F., D.J. Stewart, and D. Weininger. 1977. Applications of a bioenergetics model to yellow perch (Perca flavescens) and walleye (Stizostedion vitreum vitreum). Journal of the Fisheries Research Board of Canada. 34: 1922-1935.

Lipps, G. and M. Sisson. 2008. Status assessment and conservation of the eastern hellbender. 
Kentucky Department of Fish and Wildlife Resources Annual Research Highlights. p. 51.

Lowe, W. H. and Bolger, D. T. 2002. Local and landscape-scale predictors of salamander abundance in New Hampshire headwater streams. Conservation Biology. 16: 183-193.

Lowe, W., K. Nislow, and D. Bolger. 2004. Stage-specific and interactive effects of sedimentation and trout on a headwater stream salamander. Ecological Applications. 14(1): 164-172.

Makowsky, R. 2004. Natural history and sexual dimorphism of the eastern hellbender, Cryptobranchus a. alleganiensis. M.S. Thesis. Marshall University. Huntington, West Virginia. $69 \mathrm{pp}$.

Makowsky, R., L. Wilson, and T. Pauley. 2010. Sexual dimorphism in the eastern hellbender (Cryptobranchus alleganiensis alleganiensis). Herpetological Conservation and Biology. 5(1): 44-48.

Mayasich, J., D. Grandmaison, and C. Phillips. 2003. Eastern hellbender status assessment report. U.S. Fish and Wildlife Service. Ft. Snelling, MN.

Miller, J., G. Hess, and C. Moorman. 2007. Southern two-lined salamanders in urbanizing watersheds. Urban Ecosystems. 10:73-85.

Nelson, K. C. and Palmer, M. A. 2007. Stream temperature surges under urbanization and climate change: data, models, and responses. Journal of the American Water Resources Association. 43: 440-452.

Nickerson, M., K. Krysko, and R. Owen. 2003. Habitat differences affecting age class distributions of the hellbender salamander, Cryptobranchus alleganiensis. Southeastern Naturalist. 2(4): 619-629.

Nickerson, M. and C. Mays. 1972. The Hellbenders. Milwaukee Public Museum. Milwaukee, WI. $106 \mathrm{pp}$.

Peterson, C., R. Wilkinson, M. Topping, and D. Metter. 1983. Age and growth of the Ozark Hellbender (Cryptobranchus alleganiensis bishop). Copeia. 1983(1): 225-231.

Petranka, J. 1998. Salamanders of the United States and Canada. Smithsonian Institution Press. Washington and London. 587 pp.

Phillips, C., and J. Humphries. 2005. Cryptobranchus alleganiensis, Hellbender. In M. Lannoo(Ed.), Amphibian declines: The conservation status of United States species (pp. 648-651). Berkeley. University of California Press.

Phillips, S., R. Anderson, and R. Schapire. 2006. Maximum entropy modeling of species 
geographic distributions. Ecological Modelling. 190: 231-259.

Pfingsten, R. 1990. The status and distribution of the hellbender, Cryptobranchus alleganiensis in Ohio. Herpetological Review. 21(3): 48-51.

Quinn, S. 2009. Factors influencing distribution of the Eastern hellbender in the northern segment of its range. M.S. Thesis. State University of New York. Syracuse, NY. 49pp.

R Core Team. 2013. R: A language and environment for statistical computing. R Foundation for Statistical Computing. Vienna, Austria. ISBN 3-900051-07-0, URL http://www.Rproject.org/.

Reeves, G.H., F.H. Everest, and J.R. Sedell. 1993. Diversity of juvenile anadromous salmonid assemblages in coastal Oregon basins with different levels of timber harvest. Transactions of the American Fisheries Society.122(3): 309-317.

Santas, A., T. Persaud, B. Wolfe, and J. Bauman. 2013. Noninvasive method for a statewide survey of Eastern hellbender (Cryptobranchus alleganiensis) using environmental DNA. International Journal of Zoology. 2013: 174056. http://dx.doi.org/10.1144/2013/174056.

Smith, B. 1907. The life history and habits of Cryptobranchus alleganiensis. Biological Bulletin. 13(1): 5-39.

Trauth, S., J. Wilhide, and P. Daniel. 1992. Status of the Ozark hellbender, Cryptobranchus bishop (Urodela: Cryptobranchidae), in the Spring River, Fulton County, Arkansas. Proceedings Arkansas Academy of Science. 46: 83-86.

Unger, S., T. Sutton, and R. Williams. 2013. Projected population persistence of eastern hellbenders (Cryptobranchus alleganiensis alleganiensis). Journal for Nature Conservation. 21: 423-432.

USDA. 2009. Soil survey geographic database. U.S. Department of Agriculture Natural Resources Conservation Service. Fort Worth, Texas.

USGS. 1999. National elevation dataset (West Virginia subset). U.S. Geological Survey EROS Data Center. Sioux Falls, South Dakota.

Welsh, H. and L. Ollivier. 1998. Stream amphibians as indicators of ecosystem stress: a case study from California's redwoods. Ecological Applications. 8(4): 1118-1132.

West Virginia GIS Technical Center. 2007. U.S. population density by census tract, 2000. Morgantown, West Virginia.

Wheeler, B., E. Prosen, A. Mathis, and R. Wilkinson. 2003. Population declines of a longLived salamander: a 20+ year study of hellbenders, Cryptobranchus alleganiensis. Biological Conservation. 109: 151-156. 
Wolman, M. 1954. A method of sampling coarse river-bed material. Transactions of the American Geophysical Union. 35: 951-956. 
CHAPTER FOUR

INCREASED WATER TEMPERATURES ASSOCIATED WITH FASTING IN THE EASTERN HELLBENDER (CRYPTOBRANCHUS ALLEGANIENSIS ALLEGANIENSIS)

\section{PREPARED FOR SUBMISSION TO HERPETOLOGICAL REVIEW}

W. JOSEPH GREATHOUSE ${ }^{1,2}$ and EUGENE E. FELTON ${ }^{2}$

${ }^{1}$ Department of Conservation Science, The Wilds, Cumberland, Ohio, USA

${ }^{2}$ Department of Animal and Nutrition Science, West Virginia University, Morgantown, West Virginia, USA 


\section{$\underline{\text { Introduction }}$}

The Eastern hellbender (Cryptobranchus alleganiensis alleganiensis) is one of the largest species of salamander in North America and is considered rare or endangered in each of the 17 states in which it inhabits (Petranka 1998). This fully aquatic species typically associated with cool, clear streams and rivers utilizes large boulders, logs, and crevices in bedrock as shelter. Many populations have been in decline over recent decades due to a variety of factors including chemical pollution, over-collection for the pet and food trade (Nickerson and Briggler 2007), impoundment of streams and rivers, sedimentation, disease (Briggler et al. 2007), bounty hunts that occurred in the early 1900's, and needless killing by anglers that believe this species to be poisonous or a predator of game fish (Grandmaison et al. 2003; Wheeler et al. 2003; Brown et al. 2005).

Hellbenders are considered primary predators of crayfish in the systems that it inhabits (Humphries and Pauley 2005). Previous diet studies conducted on this species have indicated that the primary prey item consumed is the crayfish (Green 1935). However, hellbenders have also been observed to consume a variety of other prey items including lamprey, fish eggs, hellbender eggs, other hellbenders, mudpuppies, tadpoles, toads, frogs, shed hellbender skin, stonefly and damselfly nymphs, alderfly larvae, and northern watersnakes (Nickerson and Mays 1973; Peterson et al. 1989).

From May $1^{\text {st }}, 2010$ - September $21^{\text {st }}, 2010$, we conducted surveys at 23 sites based on past records of hellbender occurrence in West Virginia to assess the current population status and distribution of this species throughout the state and to determine if any environmental variables were associated with the species' presence at those sites. If hellbenders were 
captured, morphological measurements were taken and biological samples including blood, skin swabs, choanal/cloacal swabs, and stomach contents were collected. The results from the analysis of the presence of stomach contents from the field studies were verified in a controlled setting with hellbenders reared in human-care with assigned treatments of temperature in order to document inappetence and change in body condition in these individuals in a controlled temperature setting.

\section{Methods and Materials}

\section{Field Surveys}

In 2010, 23 of 33 sites with records of past hellbender occurrence in West Virginia were randomly selected using a random number generator in Program $\mathrm{R}$ and surveyed twice each for the presence of Eastern hellbenders using standard rock flipping techniques (Browne et al. 2012; Calfee et al. 2010; Nickerson and Mays 1973).

In order to collect stomach contents from captured hellbenders, gastric lavage was performed by utilizing a pair of stainless steel hemostats to open the mouth of the hellbender by placing the hemostats at the front of the mouth just inside of the lips and spreading the mouth open. The hemostats were placed between the jaws to keep the mouth open, and an 8French flexible feeding tube was passed through the oral cavity and into the stomach (Dodd, 2010). Next, a 60cc syringe filled with stream water was attached to the feeding tube, and water was flushed into the stomach until the water could be seen coming back up into the oral cavity or passing out of the gill slits on the neck. In animals that were resistant to opening their mouths, the feeding tube was passed through the spiracle and then curved down into the stomach to prevent potential injury to the oral cavity of the hellbender. 
Once water began filling the oral cavity or began flowing out of the gill slits, the hellbender was inverted head down, and regurgitated stomach contents were passed into a plastic bag and then saved for study upon return to the laboratory. Occasionally large, solid items (primarily crayfish) that did not pass during this procedure could be palpated by hand and massaged gently to the back of the oral cavity and then removed with the hemostats.

Habitat variables potentially pertinent to presence of food items including water temperature and prey (crayfish) density estimates as well as individual morphological measurements including snout-to-vent length (SVL) in centimeters and mass in kilograms were collected from each site and from each captured individual. Water temperature was measured with an ExTech Exstik II pH, conductivity, and temperature pen, and dissolved oxygen concentration was measured with an Oakton ExTech ExStik II dissolved oxygen meter (Extech Instruments, Nashua, NH). Crayfish density estimates were determined utilizing the technique of counting the number of stones out of the first 100 stones turned that were inhabited by crayfish (Nickerson et al. 2003).

SVL was measured on each individual utilizing a PVC measuring board with a ruler attached to the bottom, and mass was measured by placing the individual in a plastic bag and attaching it to a Rapala digital fishing scale (Rapala VMC Corp., Helsinki, Finland).

Data from the field studies were analyzed in the statistical program R utilizing a Pearson's chi-square test and a classification and regression tree analysis (R Core Team 2013). 


\section{Lab Studies}

Based upon the results of the field study, 21 juvenile hellbenders reared in human care were separated into aquaria with water temperature treatments of $20^{\circ} \mathrm{C}$ and $23^{\circ} \mathrm{C}$ assigned to each aquarium. The study was conducted under these settings for a three month period, and each hellbender was offered one 0.1 gram previously frozen pinky mouse during the afternoon $(1300 \mathrm{~h}-1600 \mathrm{~h})$ every 3 days via feeding tongs. If the hellbender did not attempt to eat the offered mouse, then the mouse was discarded. At the beginning of the study, each hellbender was weighed on an Ohaus balance scale (Ohaus Corp., Newark, NJ, USA) with mass observed in grams and measured in a measuring tube constructed of PVC cut in half longitudinally with end caps and a fiberglass measuring tape secured to the tube with plumber's glue. SVL and total length were measured and recorded in centimeters with this device, and each hellbender was then weighed and measured again at the end of the study on an Ohaus balance scale and with the hellbender measuring tube described above. The data from this study was analyzed utilizing Program R.

$\underline{\text { Results }}$

Field Study

During the field studies, food was collected from 24 of 68 individuals that were captured, with only one individual having any food collected from July $8^{\text {th }}-$ September $4^{\text {th }}$. Of the 24 individuals that had food collected, 18 individuals had consumed crayfish (75\%), four had consumed fish (16.7\%), three had consumed hellbender eggs (12.5\%), and one had ingested a hellgrammite (4.2\%). A classification and regression tree analysis was performed in Program $\mathrm{R}$ to determine which, if any, habitat or morphological variables may be associated with the 
cessation of feeding in this species (De'Ath and Fabricius, 2000). The results from this analysis indicate that water temperatures exceeding $22.65^{\circ} \mathrm{C}$ are the greatest indicator of whether or not there would be food present in the captured individuals, and when the tree is read at the second recursive node, temperatures in excess of $23.0^{\circ} \mathrm{C}$ indicate even fewer prey items being consumed by hellbenders in warmer water temperatures, with a model misclassification rate of only $4.54 \%$, indicating that this model would predict similar findings $95.46 \%$ of the time (Fig. 1).

A Pearson's chi-square analysis was performed on these data with $\geq 23^{\circ} \mathrm{C}$ used as a delineating point between temperature categories, and the results showed that individuals captured in water temperatures less than $23^{\circ} \mathrm{C}$ were significantly more likely to have consumed food than individuals that were captured in water temperatures that were equal to or greater than $23^{\circ} \mathrm{C}\left(\chi^{2}=36.601, \mathrm{df}=1, \mathrm{P}<.01\right)$. Laboratory Study

Individuals housed at $20^{\circ} \mathrm{C}$ consumed pinky mice on 330 of 360 attempts, and individuals housed at $23^{\circ} \mathrm{C}$ ate on 16 of 270 attempts. A Pearson's chi-square analysis indicated that individuals housed at $20^{\circ} \mathrm{C}$ consumed offered food significantly more frequently than those individuals housed at $23^{\circ} \mathrm{C}\left(\chi^{2}=454.67, \mathrm{df}=1, \mathrm{P}<.01\right)$.

Two-sample t-tests comparing the changes in the mass and length of individuals housed in aquariums with water temperatures of $20^{\circ} \mathrm{C}(\mathrm{N}=12$, starting $\mathrm{TL} \mu=26.97 \mathrm{~cm}$, sd $=2.96)$ as opposed to those housed at $23^{\circ} \mathrm{C}(\mathrm{N}=9$, starting $\mathrm{TL} \mu=29.39 \mathrm{~cm}, \mathrm{sd}=2.52)$ indicated that individuals housed at temperatures of $20^{\circ} \mathrm{C}$ gained significantly more weight $(t=9.47, \mathrm{df}=19$, $P<0.01)$ and grew significantly longer $(t=5.2, \mathrm{df}=19, P<0.01)$ than those housed at $23^{\circ} \mathrm{C}$ (Fig. 2). 


\begin{tabular}{|c|c|c|}
\hline & $\begin{array}{c}20^{\circ} \mathrm{C} \\
(\text { Mean } \pm S D)\end{array}$ & $\begin{array}{c}23^{\circ} \mathrm{C} \\
(\text { Mean } \pm \text { SD) }\end{array}$ \\
\hline $\mathbf{N}$ & 12 & 9 \\
\hline $\mathrm{TL}(\mathrm{cm})$ & $2.29 \pm 0.99$ & $0.35 \pm 0.72$ \\
\hline Mass (g) & $21.09+9.99$ & $-15.33 \pm 6.57$ \\
\hline
\end{tabular}

Table 1.- Mean length and mass changes of hellbenders reared in human care.

\section{$\underline{\text { Discussion }}$}

The results of the field study in this project may indicate that the Eastern hellbender reduces feeding or does not eat during the summer months in West Virginia when water temperatures in streams or rivers exceed or reach $23^{\circ} \mathrm{C}$. The classification and regression tree analysis indicated that this temperature level was the most distinguishing morphological or habitat variable associated with a lack of prey items in Eastern hellbenders that were studied. When the CART tree is extended to a second node, it indicates that at $23^{\circ} \mathrm{C}$ only one surveyed animal had food in its stomach. This individual only had the small mouthpiece of a hellgrammite in its stomach contents. Due to the nature of this item, it is likely that this individual may have not eaten during the period of warmer summer stream temperatures.

The majority of diet studies or anecdotal diet notes associated with the preferred prey of the hellbender document the crayfish as the preferred food item for this species. Netting (1929) noted that in four individuals that were dissected from captures in May of that year in Pennsylvania that each hellbender that was dissected contained crayfish in its stomach, but there were also two stone rollers (Camposoma anomalum) that had been consumed by these individuals. Green recorded that in a three year study of hellbenders in West Virginia from 1931-1933 that all 27 individuals that he had captured had consumed crayfish (Green 1934), 
and in a survey resulting in the capture of 34 hellbenders on June 21,1934 in the headwaters of Shavers Fork of the Cheat River that $57 \%$ of the individuals that were captured had crayfish in their stomachs, $35 \%$ contained fish, an $21 \%$ contained parts of insect larvae, tadpoles, and worms, while one individual had an empty stomach (Green 1935). This was approximately two weeks before the temperature increase and feeding cessation that was observed in the current study.

Ozark and Eastern hellbenders captured in two studies in Arkansas and Missouri have been observed with prey items consisting primarily of crayfish present in each individual's stomach that was captured throughout every month of the year. Studies conducted by Nickerson and Mays occurred in a river where the recorded water temperatures at this site during the study never exceeded $22.5^{\circ} \mathrm{C}$, and temperatures only exceeded $20^{\circ} \mathrm{C}$ on three of seven surveys from July - September due to cool spring-fed streams at this site (Nickerson and Mays 1973, Peterson et al. 1989).

Several studies have also documented that this species becomes inactive in cold temperatures when individuals have been observed in a motionless winter torpor at water temperatures of $0^{\circ} \mathrm{C}$ (Humphries 2007; Nickerson and Mays 1972; Pfingsten 1990). Increased, vigorous activity and feeding periods immediately following the winter torpor and immediately prior to the summer temperature increases have been observed in hellbenders as well as other species of amphibians (Humphries and Pauley 2000; Nickerson and Mays 1972).

For hellbenders reared in human care, a minimum reintroduction mass of 100 grams is most favorable for implantation of a 4 gram radio telemetry transmitter (Heyer et al. 1994) that 
can be implanted in the coelomic cavity of the hellbender and last for up to 12 months of tracking. This enables the assessment of survival of head-started individuals when reintroduced to the wild. Data from both studies reported in this manuscript indicate that hellbenders that are reared in human care for reintroduction and translocation programs will reach a greater mass if they are maintained in water temperatures less than $22^{\circ} \mathrm{C}$ throughout the year. The ability to utilize telemetry to follow individuals reared in human care and released for reintroduction and translocation programs is important, since one of the greatest critiques of the success of amphibian reintroduction and translocation efforts has resulted from efforts when egg masses and larval or tadpole releases were employed with minimal or no observations of survival (Seigel and Dodd 2002). In addition, the ability to encourage growth of individuals to larger masses prior to reintroduction would likely be beneficial, because larger release sizes likely decrease potential predation in this species as has been observed in other herpetofauna (Goodyear and Lazell 1994; Sarrazin and Legendre 2000; Bradley and Gerber 2008).

In wild hellbenders living in streams and rivers with seasonal temperature fluctuations, periods of torpor and inanition may likely lead to reduced growth. Reduced growth may render juveniles more vulnerable to a greater range of predators for a longer period of their life, and extended fasting periods can lead to reduced body condition and fecundity in females (Duellman and Trueb 1986). With anticipated increases of temperatures modeled at a mean of a $5^{\circ}$ Celsius average increase over the next 80 years (EPA 2013), summer torpors of greater duration could further impede the success of wild hellbender populations. 
This could be detrimental to populations in lowland or deforested areas of West Virginia due to individuals not eating for extended periods of the year. Future restoration and reintroduction efforts for this species in West Virginia should focus on reintroduction efforts at sites that are more heavily forested in order to reduce the impact of temperature increases and sedimentation, and restoration efforts should focus on reforestation of current and historic sites of hellbender presence in the lowlands of the Allegheny Plateau to reduce increased water temperatures by providing canopy cover to the streams and rivers occupied by this species, to prevent warming of headwater streams that feed these larger order water bodies, and to reduce sedimentation of these streams (Ash and Bruce 1994; Kaushal et al. 2010; Nelson et al. 2007).

\section{ACKNOWLEDGMENTS}

Animals collected during this study were collected under permit WV2010.131 from the West Virginia Division of Natural Resources to William J Greathouse. Funding for this project was provided through the State Wildlife Grant (SWG) program from the West Virginia Division of Natural Resources. I would like to thank Dr. Barbara Wolfe from the Wilds, Dr. Thomas Pauley of Marshall University, and Dr. Todd Petty, Dr. Margaret Minch, and Dr. Roberty Dailey of West Virginia University for assistance with review and editing, and I would like to thank several staff and interns from Oglebay's Good Zoo with their assistance in completing this project including but not limited to Penny Miller, Susan Greathouse, Mindi White, Kala Bassa, Ron Shaw, and Dan Martin. 


\section{$\underline{\text { References Cited }}$}

Ash, A. and R. Bruce. 1994. Impacts of timber harvesting on salamanders.

Cons. Biol. 8: 300-301.

Briggler, J., J. Utrup, C. Davidson, J. Humphries, J. Groves, T. Johnson, J. Ettling, M. Wanner, K. Traylor-Holzer, D. Reed, V. Lindgren, and O. Byers (eds.). 2007. Hellbender population and viability assessment. IUCN/SSC Conservation Breeding Specialist Group, Apple Valley, Minnesota. $46 \mathrm{pp}$.

Brown, W.S., Kordek, W.S., Leo, K., McDonald, B., Sargent, B., and J. Wykle. 2005. West Virginia Wildlife Conservation Action Plan. Elkins, WV. 1,057 pp.

Browne, R., L. Hong, D. McGinnity, S. Okada, W. Zhenghuan, C. Bodinof, K. Irwin, A. McMillan, and J. Briggler. 2012. Survey techniques for giant salamanders and other aquatic Caudata. Amphib. Reptile Conserv. 5(4): 1-16.

Calfee, J., J. Briggler, I. Vining, and N. Murray. 2010. Protocol for monitoring Eastern (Cryptobranchus alleganiensis alleganiensis) and Ozark (Cryptobranchus alleganiensis bishopi) hellbenders in Missouri streams. Missouri Department of Conservation, Resource Science Division. 54 pp.

De'Ath, G. and K. Fabricius. 2000. Classification and regression trees: a powerful yet simple technique for ecological data analysis. Ecology 81(11):3178-3192.

Dodd, C.K. 2010. Amphibian Ecology and Conservation: A Handbook of Techniques. Oxford University Press, USA.

Duellman, W. and L. Trueb. 1994. Biology of Amphibians. Johns Hopkins University Press. Baltimore, Maryland. 670 pp. 
EPA. 11/01/2013. Climate Change. www.epa.gov/climatechange/science/future.html= Temperature.

Grandmaison, D., Mayasich, J., and C. Phillips. 2003. Eastern hellbender status assessment report. Natural Resources Research Institute. Duluth, MN. $41 \mathrm{pp}$.

Green, N.B. 1934. Cryptobranchus alleganiensis in West Virginia. Proceedings of the West Virginia Academy of Sciences. Fairmont, WV.

Green, N.B. 1935. Further notes on the food habits of the water dog, Cryptobranchus alleganiensis Daudin. Proceedings of the West Virginia Academy of Science. 9:36.

Heyer, R.W., M.A. Donnelly, R.W. McDiarmid, L.C. Hayek, and M.S. Foster. 1994. Measuring and Monitoring Biological Diversity: Standard Methods for Amphibians. Smithsonian Institution Press. USA.

Humphries, J. and T.K. Pauley. 2000. Seasonal changes in nocturnal activity of the hellbender, Cryptobranchus alleganiensis, in West Virginia. J. of Herpetol. 34(4): 604607.

Humphries, J. and T.K. Pauley. 2005. Life history of the hellbender, Cryptobranchus alleganiensis, in a West Virginia Stream. Am. Mid. Nat. 154:135-142.

Humphries, J. 2007. Diurnal seasonal activity of Cryptobranchus alleganiensis (hellbender) in North Carolina. Southeast Nat. 6(1): 135-140.

Kaushal, S.S., G.E. Likens, N.A. Jaworski, M.L. Pace, A.M. Sides, D. Seekell, K.T. Belt, D.H. Secor, and R.L. Wingate. Rising stream and river temperatures in the 
United States. Front Ecol Environ. 8(9): 461-466.

Nelson, K. C. and Palmer, M. A. 2007. Stream temperature surges under urbanization and climate change: data, models, and responses. J Am Water Res As. 43: 440-452.

Netting, G. 1929. The food of the hellbender Cryptobranchus alleganiensis (Daudin). Copeia. 170: 23-24.

Nickerson, M.A. and C.E. Mays. 1973. The Hellbenders. Milwaukee Public Museum, Milwaukee, Wisconsin. 106 pp.

Nickerson, M. K. Krysko, and R. Owen. 2003. Habitat differences affecting age class distributions of the hellbender salamander, Cryptobranchus alleganiensis. SE Nat. 2(4): 619-629.

Nickerson, M.K. and J.T. Briggler. 2007. Harvesting as a factor in population decline of a longlived salamander; the Ozark hellbender, Cryptobranchus alleganiensis bishopi Grobman. App. Herp. 4: 207-216.

Petranka, J. Salamanders of the United States and Canada. Smithsonian Institute Press, Washington and London, pp. 140-144.

Peterson, C., J. Reed, and R. Wilkinson. 1989. Seasonal food habits of Cryptobranchus alleganiensis (Caudata: Cryptobranchidae). SW Nat. 34(3): 438-441.

Pfingsten, R. 1990. The status and distribution of the hellbender, Cryptobranchus alleganiensis in Ohio. Herpetol. Rev. 21(3): 48-51.

R Core Team. 2013. R: A language and environment for statistical computing. R Foundation for Statistical Computing. Vienna, Austria. ISBN 3-900051-07-0, URL http://www.R-project.org/. 
Wheeler, B., E. Prosen, A. Mathis, and R. Wilkinson. 2003. Population declines of a long-lived salamander: a 20+ year study of hellbenders, Cryptobranchus alleganiensis. Biol. Cons. 109: 151-156.

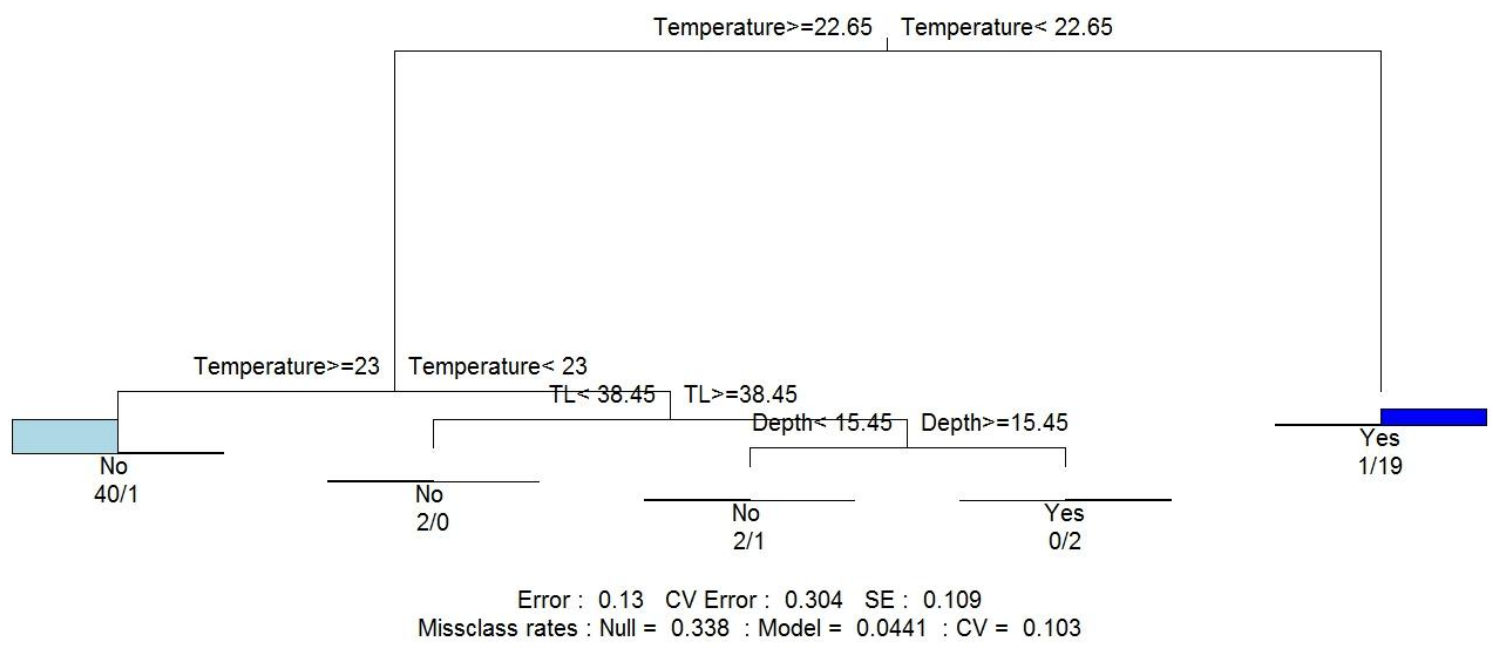

Fig. 1-Classification and regression tree indicating that water temperature is the greatest determinant as to whether or not hellbenders eat in the wild. Labels of No (light blue columns on left) indicate the number of hellbenders that had not eaten, and labels of Yes (royal blue columns on right) indicate the number of hellbenders that had food contents present in the stomach. 


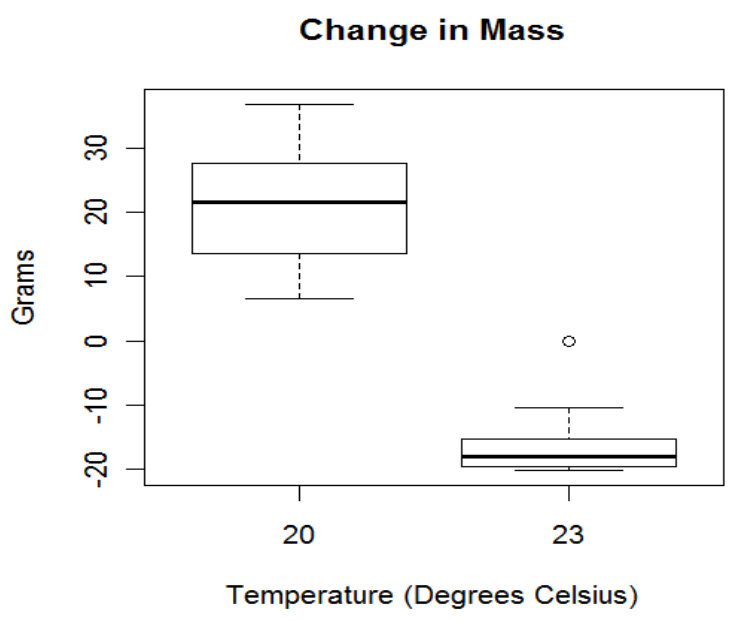

Fig. 2. - Boxplot indicating changes in mass of individuals housed at $20^{\circ} \mathrm{C}$ and $23^{\circ} \mathrm{C}$.

\section{CHAPTER 5}

Survival, Movement, and Shelter Selection of Reintroduced and Translocated Eastern

Hellbenders (Cryptobranchus alleganiensis alleganiensis) in West Virginia Following Rearing in Human Care

Prepared for Submission to Herpetological Conservation and Biology 


\section{Survival, Movement, and Shelter Selection of Reintroduced and Translocated Eastern Hellbenders (Cryptobranchus alleganiensis alleganiensis) in West Virginia Following Rearing in Human Care}

Abstract.-West Virginia was historically one of the states with the greatest distribution of Eastern Hellbenders within the species' range. However, three survey efforts of the state over the past decade have indicated the presence of the Hellbender in only 12 of 24 historic sites. We released 29 head-started Hellbenders at a reintroduction site where the head-started Hellbender eggs were collected as well as at a translocation site where Hellbenders were no longer observed to be present. Survival rates through 6 months of tracking during this study did not differ statistically between sites. Movement and home range were greater at the reintroduction site than at the translocation site, and stream bank shelters were used more frequently at the reintroduction site than at the translocation site. Increased movement and alternative shelter use are believed to be due to reduced shelter availability due to fewer boulders and the presence of adult Hellbenders at the reintroduction site as opposed to conditions at the translocation site. 
Future Hellbender conservation efforts in West Virginia should include continued reintroductions and translocations of head-started juveniles or sub-adults with long-term monitoring for detection of reproductively sustainable populations as results of releases.

Key Words.-Cryptobranchus alleganiensis; Hellbender; rearing; reintroduction; translocation; West Virginia

\section{INTRODUCTION}

The reintroduction and translocation of species raised in human care has been considered an effective wildlife conservation tool for several decades. Several high profile vertebrate species such as the American buffalo (Bison bison), black-footed ferret (Mustela nigripes), golden lion tamarin (Leontopithecus rosalia), and the California condor (Gymnogyps californianus), have avoided extinction due to reintroduction of animals raised in human care (Griffith et al. 1989; Kleiman 1989; Snyder et al. 1996; Kleiman and Mallinson 1998; and Seddon et al. 2007). The reintroduction or translocation of amphibians reared by humans has only in recent decades become a priority (Balmford et al. 1996). Literature reviews of previous wildlife reintroductions indicate a relatively small percentage of these efforts focusing on amphibians (Burke 1991; Fischer and Lindenmayer 2000; and Griffiths and Pavajeau 2008). Several programs focusing on species such as the natterjack toad, great crested newt, and Maud Island frog have proven to be successful in creating populations that are reproductively viable in the wild (Cooke and Oldham 1995; Denton et al. 1997; Tocher and Pledger 2005; Kinne 2006; and Griffiths and Pavajeau 2008).

The global decline of amphibians has been well documented over the past decade (Gascon et al. 2005; LaMarca et al. 2005; Mendelson 2006; and Norris 2007). The Eastern 
Hellbender (Cryptobranchus alleganiensis alleganiensis) is the largest salamander in North America and is considered to be a rare or endangered species in each of the states that it inhabits (Nickerson and Mays 1973; Green and Pauley 1987; Behler and King 1998; Conant and Collins 1998; Petranka 1998). Declines in the species' distribution and abundance have been documented in several states over the past thirty years (Wheeler et al. 2003; Foster et al. 2009; Burgmeier et al. 2011c ) due to a variety of suspected causes including pollution, habitat destruction, disease, and over-collection (Pfingsten 1990; Humphries and Pauley 2000; Mayasich et al. 2003; Nickerson and Briggler 2007; Horchler 2010; Burgmeier et al. 2011b ). Historically, West Virginia was considered to be a stronghold of the Hellbender (Green 1934; Nickerson and Mays 1973). However, three recent surveys of historic Hellbender streams and rivers in West Virginia have resulted in the detection of Hellbenders at only 12 of 24 sites (Makowsky 2004; Keitzer et al. 2013; Greathouse unpublished), and the WV Division of Wildlife has considered the Hellbender a species of special conservation concern (Brown et al. 2005).

On September 18, 2007, a nest of Hellbender eggs infected by a water fungus was discovered in a stream in northern West Virginia. With collaboration from the West Virginia Division of Wildlife, the eggs were taken to Oglebay's Good Zoo and head-started in human care at the zoo for future reintroduction and translocation to the wild. Since that time, several other states including Indiana, Missouri, New York, and Ohio (Bodinof 2010; Ettling et al. 2013; Rod Williams, Penny Felski, and Greg Lipps Personal Commnunication) have initiated reintroductions of head-started Hellbenders to the wild in an attempt to bolster populations in those states.

The goals of this project were to determine the efficacy of reintroducing Hellbenders reared in human care to the site where they were collected as eggs and to determine the success 
of translocating Hellbenders raised in human care to a site where Hellbenders had been documented historically but were no longer observed in recent surveys.

\section{MATERIALS AND METHODS}

Study site.-Our reintroduction site was located within a boulder field in Buffalo Creek, West Virginia where Hellbenders have been documented by the authors. This site was the boulder field where the clutch of eggs that were reared for this project was found.

Our translocation site at the Cherry River, West Virginia was selected based upon models of potential Hellbender distribution in West Virginia created from hellbender in-stream and landscape level data from surveys conducted by the authors during the summer of 2010 . Analyses were performed using the software program MaxEnt version 3.2.1 (Phillips et al. 2006) to calculate raster based distribution probability maps based upon presence of Hellbenders during the 2010 surveys; calculation of a Bray-Curtis similarity index and cluster analysis using Ward's linkage techniques; and non-metric multidimensional scaling (NMDS) ordination techniques comparing environmental and landscape continuous variables from sites where Hellbenders were not observed to the mean values of sites where Hellbenders were considered to be abundant ( 0.4 individuals captured/person-hour of surveys). Analyzed variables included stream substrate composition utilizing Wolman zigzag pebble counts, water

$\mathrm{pH}$, water temperature, conductivity, dissolved oxygen, prey availability in the form of crayfish (Nickerson et al. 2002), percent of open development, total forest, and open water in each surveyed watershed. All statistical and ordination analyses were performed in the vegan and metaMDS packages of program R. The values for each of the four analyses were ranked for 
the sites of historic occurrence where Hellbenders were no longer observed during surveys, and the site with the lowest rank sum was selected as our translocation site (Table 1).

Disease prevention and surgical procedure.-The thirty Hellbenders that were selected for this project were the largest individuals being greater than or equal to 100 grams body mass to ensure that transmitters were no greater than $4 \%$ of the total body mass of the Hellbender. Each individual in excess of 100 grams was injected with a PIT (passive integrated transponder) tag (InfoPet Inc., Burnsville, Minnesota, USA) intramuscularly at the left lateral base of the tail to ensure accurate identification of each individual. Prior to surgical implantation of transmitters, each individual was tested for the amphibian chytrid fungus (Batrachochytrium dendrobatidis) as well as the FV-3 ranavirus to prevent the potential introduction of these pathogens to the wild, since this species has been observed to be susceptible to the amphibian chytrid fungus (Cunningham 1996; Bartkus 2009; Bodinof et al. 2011; Souza et al. 2012). Chytrid fungus samples were collected by swabbing the ventral aspect of each foot as well as the abdomen five times each for a total of 25 swabs per individual with a Dacron microculturette with plastic shaft (Advantage Bundling/Medical Wire Co., Corsham, Wiltshire, England) (Boyle et al. 2004). Ranavirus samples were collected swabbing the choana and then the cloaca respectively. Each collected swab was stored in an uncapped $1.5 \mathrm{~mL}$ tube for 24 hours to air dry, and samples were then capped with an o-ring cap for shipment to the San Diego Zoo Amphibian Disease Laboratory for analysis to ensure that all individuals being utilized for the study were free from these pathogens.

Telemetry transmitter implantation was performed by anesthetizing each Hellbender in an anesthesia bath of MS-222 (tricaine methanesulfonate) at a dose of 1 gram/liter of water. The solution was oxygenated with an air pump with an air stone and was also treated with 1 
gram/liter of sodium bicarbonate to buffer the $\mathrm{pH}$ of the solution. Each individual was

maintained in the anesthesia bath until righting response was lost to ensure anesthesia efficacy. The surgical procedure was similar to the technique described by Stouffer et al. (1983), with each individual having an Advanced Telemetry Systems (ATS) F1170 4-gram loop transmitter (Advanced Telemetry Systems, Isanti, Minnesota, USA) placed in the coelomic cavity in a free-floating manner. The musculature and the skin were then closed with a row of dissolving suture material in each tissue layer respectively. Following surgery, the total length (TL), snout-to-vent length (SVL), and mass were measured, and each individual was injected with a $10 \mathrm{mg} / \mathrm{kg}$ dose of enrofloxacin subcutaneously. For recovery, each individual was placed in an enclosure with fresh water oxygenated with an air pump until the righting response was gained and the outer skin layer was shed. Each individual was then monitored daily for 4 weeks prior to release, so the surgical site could be monitored for infection or dehiscence and to prevent any potential adverse effects from MS-222 being inadvertently shed into the water system by the individuals at the release sites (Nickerson and Byram 2008).

Release and radio telemetry tracking. - Animal release locations were performed by randomly selecting 15 individuals from the group of thirty that would be released at the reintroduction site using the statistical analysis program R (R Core Team 2014). Animals that were not selected were saved for release at the translocation site. Animals were transported to each release site in coolers of water oxygenated with portable air pumps. Each individual was then placed underneath a stone within the study site that was large enough to cover the entire length of the Hellbender. Once the Hellbender was placed under the stone, the stone was measured along the longest point of the length and width of the stone in centimeters, and the GPS coordinate was collected using a Magellan eXplorist 310 (Mitac, Smyrna, Tennessee, USA) 
GPS unit. Individuals were released at the reintroduction site on December 12, 2011, while individuals were released at the translocation site on July 3, 2012 following selection of study site.

All individuals were tracked one week following release by detecting presence of telemetry transmitter signals with an ATS R410 scanning receiver with a three element folding Yagi antenna (Advanced Telemetry Systems, Isanti, Minnesota, USA). Upon location of the Hellbender, the GPS coordinate was collected, area and type of shelter selected (stone, stream bank, or other item), direction moved (upstream, downstream, or no movement), and distance moved were measured and recorded. Each site of location was then marked either by placing a plastic marking flag in the ground at a stream bank site of occurrence or under stones placed directly behind the shelter stone on the stream bottom. Each flag was marked with waterproof marker to denote the identification of the individual utilizing the shelter. Distance moved was recorded to the nearest meter by driving a rebar stake with a paper plate attached to it with plastic cable ties into the stream bottom or stream bank adjacent to the previous site of the Hellbender's location. Distance was then measured by aiming a Bushnell Yardage Pro rangefinder (Bushnell Outdoor Products, Overland Park, Kansas, USA) from the Hellbender's new shelter to the paper plate at the site of the previous shelter. At sites where there was not a straight line of measurement, measurements were collected from the straightest point of site within the stream from each bend where vision was broken, and then added to produce a straight line, in-stream distance. Stream substrate composition was assessed at the end of the study by performing Wolman zigzag pebble counts (Bevenger and King 1996) at the extreme ends of the study site utilized by reintroduced or translocated individuals and then again at 
intervals of $20 \%$ of the total study site distance throughout each site in order to determine if shelter availability was greater at either site.

Statistical analysis. - 95\% minimum convex polygon (MCP) home ranges were calculated with the adehabitatHR package within the $\mathrm{R}$ statistical analysis program. Comparisons of numbers of movements, direction of movements, survival, and shelter selection between seasons and sites were performed utilizing chi-square tests of homogeneity, and comparisons of distances moved, MCP home range size, linear home range size (LHR), stone shelter area, and survival based upon body size were analyzed using two-sample Mann-Whitney or two-sample t-tests in the R statistical analysis program.

\section{RESULTS}

Survival. - Hellbenders were tracked at the reintroduction site for a total of 373 days, encompassing 28 telemetry surveys and 178 post-release observations. Hellbenders were tracked at the translocation site for a total of 177 days, encompassing 13 telemetry surveys and 130 postrelease observations. One mortality was recorded for an individual selected for release at the reintroduction site prior to reintroduction due to undetermined causes upon necropsy and histopathology exam. Six of 14 individuals (42.9\%) were confirmed to survive the first 168 days post-release at the reintroduction site with 5 of 14 (35.7\%) individuals surviving for 373 days at this site. Of the 9 individuals that were not able to be tracked through the entirety of the study at the reintroduction site, 4 of 9 individuals (44.4\%) were unable to be accounted for, with each of these individuals being lost during the first 32 days post-release. The other five individuals that were not able to be tracked throughout the remainder of the study were confirmed deaths from 
predation by fur-bearing mammals and from burial under substrate. Raccoons (Procyon lotor), Minks (Neovison vison) and North American River Otters (Lontra canadensis canadensis) preyed upon three individuals (60\% of verified mortalities) and two individuals were buried under their shelters by sand and gravel following flooding events (40\% of verified mortalities).

At the translocation site, 9 of $15(60 \%)$ individuals were confirmed to survive for the duration of the study at this site. Of the 6 individuals that were not able to be tracked throughout the entirety of the study, only one individual was unable to be accounted for. All five confirmed deaths at this site were attributed to predation from mink (Neovison vison) and North American river otter (Lontra canadensis canadensis). Predator species at each site was hypothesized based upon presence of observed predators coming out of brush piles (mink) where transmitters were discovered or tracks and/or feces (raccoon and river otter) located near bare transmitters.

Total survival of both releases was $48.3 \%$ (14 of 29 ), with $17.2 \%$ (5 of 29 ) of individuals being unaccounted for, and 34.5\% (10 of 29) of individuals not surviving the release. The greatest cause of confirmed death during this study was predation with $80 \%$ (8 of 10) of deceased individuals being preyed upon by furbearing mammals.

Kaplan-Meier survival rate comparisons utilizing chi-square analyses of log-rank tests of the reintroduction and translocation sites through the duration of time post-release that could be compared between the two sites yielded no significant difference $\left(\chi^{2}=0.304, \mathrm{df}=1, P=0.581\right)$. Thirteen of 15 individuals $(86.7 \%)$ that were unable to be found or were confirmed to be dead occurred within the first two months post-release. No statistical difference in time post-release associated with losses was able to be determined between the sites at one week $\left(\chi^{2}=0.376\right.$, $\mathrm{df}=$ $1, P=0.540)$, one month $\left(\chi^{2}=0.007, \mathrm{df}=1, P=0.932\right)$, or two months $\left(\chi^{2}=0.837, \mathrm{df}=1, P=\right.$ 
0.360). A combined analysis of survival as a function of time since release indicated that losses were not significantly different through the first month compared to the duration of the study $\left(\chi^{2}\right.$ $=0.078, \mathrm{df}=1, P=0.781)$. However survival through the second month compared to the duration of the study at both sites was nearly statistically significant $\left(\chi^{2}=3.504, \mathrm{df}=1, P=\right.$ 0.061) (Figure 1).

Released individuals ranged from $100.3-244.3 \mathrm{~g}$ in mass $(\mu=186.96 \mathrm{~g}, \mathrm{sd}=37.68 \mathrm{~g})$ and 26.0 to $38.1 \mathrm{~cm}$ in TL $(\mu=32.35 \mathrm{~cm}, \mathrm{sd}=3.15 \mathrm{~cm})$. There was not a difference in survival at both study sites based upon mass $(t=0.332$, df $=23, P=0.743)$ or TL $(t=0.308, \mathrm{df}=23, P=$ $0.761)$.

Movement. - Hellbenders at the reintroduction site were observed to have moved 47 times (26.4\% of observations) in 373 days, with the greatest number of movements occurring during the summer (59.6\%). Hellbenders at the translocation site moved 58 times $(44.6 \%$ of observations) in 177 days, with the greatest number of movements at this site also occurring during the summer (75.9\%). Individuals at the reintroduction site moved upstream (29.8\%) more frequently than individuals at the translocation site $(6.9 \%)\left(\chi^{2}=8.9347, \mathrm{df}=1, P=0.003\right)$.

Observed movements ranged from $1-402 \mathrm{~m}(\mu=50.33 \mathrm{~m}, \mathrm{sd}=75.03 \mathrm{~m})$ amongst all individuals. Individuals at the reintroduction site were observed moving an average of $79.15 \mathrm{~m}$ per observed movement, while individuals at the translocation site were observed moving an average of $27.37 \mathrm{~m}$ per observed movement. Individuals at the translocation site were observed moving significantly shorter distances than those at the reintroduction site $(U=1875, P=$ 0.002). Long distance movements (>50 m) accounted for $42.6 \%$ of all observed movements at the reintroduction site and only $15.5 \%$ of all observed movements at the translocation site with a 
greater prevalence of long distance moves occurring at the reintroduction site $\left(\chi^{2}=7.893\right.$, df $=1$, $P=0.005)$.

Minimum convex polygon (MCP) home range spanned from $91-20,611 \mathrm{~m}^{2}(\mu=4,624.10$ $\mathrm{m}^{2}, \mathrm{sd}=6,178.68 \mathrm{~m}^{2)}$ amongst all individuals. Individuals at the reintroduction site had a mean MCP home range of $9,038.61 \mathrm{~m}^{2}$, while individuals at the translocation site had a mean MCP home range of $1,313.21 \mathrm{~m}^{2}$. Individuals at the translocation site maintained a significantly smaller MCP home range than the individuals at the reintroduction site $(U=98, P<0.001)$.

Linear home range (LHR) extended from 15.53-538.61 $\mathrm{m}(\mu=215.06 \mathrm{~m}, \mathrm{sd}=208.82 \mathrm{~m})$ amongst all released individuals. Individuals at the reintroduction site had a mean LHR of $360.08 \mathrm{~m}$, while individuals at the translocation site had a mean LHR of $106.3 \mathrm{~m}$. Individuals at the translocation site also maintained a significantly smaller LHR than the individuals at the reintroduction site $(U=95, P=0.002)$.

Shelter Selection.- - Individuals at the translocation site used boulders for shelter during 100\% (130 of 130) of observations, while individuals at the reintroduction site only used boulders for shelter during $52.8 \%$ (94 of 178) of observations. Individuals at the reintroduction site also were observed utilizing holes in stream banks during 46.6\% (83 of 178) of observations, and one individual was observed utilizing a tire as shelter during one survey. An analysis of shelter use between the two sites indicated a significant difference between shelter use at the two sites $\left(\chi^{2}=\right.$ 77.672, df $=1, P<0.001$ ), with individuals at the reintroduction site utilizing shelters other than stone more frequently than individuals at the translocation site.

Stone shelters utilized at the reintroduction site ranged from $1,030 \mathrm{~cm}^{2}-19,370 \mathrm{~cm}^{2}(\mu=$ $7,075 \mathrm{~cm}^{2}, \mathrm{sd}=448.4 \mathrm{~cm}^{2}$ ), and stone shelters utilized at the translocation site ranged from 810 
$\mathrm{cm}^{2}-114,120 \mathrm{~cm}^{2}\left(\mu=24,510.2 \mathrm{~cm}^{2}, \mathrm{sd}=2,697.7 \mathrm{~cm}^{2}\right)$. An analysis of stone shelter size at each site indicated that Hellbenders at the translocation site utilized larger boulders than those at the reintroduction site $(U=740.5, P<0.001)$, with individuals at the translocation site using boulders larger than any used at the reintroduction site during 35\% (21 of 60) of observations (Figure 2).

Stream bank shelters were chosen with greater frequency on more occasions $(64.7 \%$ of observations) and by more individuals (100\% of individuals at least once) at the reintroduction site during the summer as opposed to all other seasons. In contrast, selection of stone shelters occurred more frequently ( $74.6 \%$ of observations) and by more individuals (100\% of individuals at least once) at the reintroduction site during the winter (Figure 3). Substrate analysis at both study sites based on Wolman pebble count data indicated that the translocation site had significantly greater presence of boulders $(\mu=26.4 \%, \mathrm{sd}=14.88 \%)$ available for shelter as opposed to the reintroduction site $(\mu=7.4 \%, \mathrm{sd}=5.51 \%)(U=1.5, P=0.028)$.

\section{DISCUSSION}

Eastern Hellbenders observed in this study exhibited a 6-month survival rate of $51.7 \%$ (15 of 29), which is similar to results of a 1-year reintroduction effort associated with headstarted Hellbenders in Missouri 44.4\% (16 of 36) (Bodinof et al., 2012b). Individuals at our reintroduction site were tracked for an entire year and survival was less than what was observed in the Missouri studies with an annual survival of $35.7 \%$ (5 of 14) at this site. This study marked the first translocation effort of head-started Hellbenders to a site of historic occurrence where Hellbenders were no longer observed. Although 6-month survival was approximately 1.4 times greater at the translocation site $(60 \%)$ than the reintroduction site, 
there was not a statistically significant difference in survival between the two sites. Missing animals accounted for $28.6 \%$ of individuals that were unable to be tracked at the reintroduction site (4 of 14) and 6.7\% (1 of 15) of such individuals at the translocation site. The aforementioned Missouri study observed 19.4\% (7 of 36) of released individuals that were unable to be located amongst study sites.

Predation was believed to have accounted for $80 \%$ ( 8 of 10) of the mortalities observed by the detection of bare transmitters located on stream banks or in brush piles. Observation of fur-bearing mammals, tracks, or feces was used to hypothesize losses to mink, North American river otters, and raccoons. These observations may be indicative of increased pressure from fur-bearers on Hellbenders in West Virginia due to recovery efforts focused on increasing or repatriating these species over the past 40 years (Beck et al. 1987; Serfass et al. 1998). Bodinof et al. likewise observed the presence of bare transmitters from $61.5 \%$ of verified mortalities following release, and an Indiana radio telemetry study of adult Hellbenders observed bare transmitters on the river bank from 3 of 21 wild adult Hellbenders that were studied (Burgmeier et al. 2011a; Bodinof et al. 2012b). Several field studies have documented the predation of Hellbenders by the aforementioned fur-bearers (Nickerson and Mays 1973; Hecht et al. 2014 ). The remaining known mortalities in our study occurred when two individuals were buried underneath gravel at the reintroduction site within the stream following a flood event. One individual reared in human care during the Missouri study also had a similar fate.

Survival as a function of time following release was not statistically significant in our study $\left(\chi^{2}=3.504, \mathrm{df}=1, P=0.061\right)$. However, $86.7 \%$ (13 of 15$)$ of individuals that were unable to be tracked or were observed to have died during the study were lost during the first 
56 days following release. Although these data are not statistically significant, future release efforts may consider techniques to increase survival during initial weeks such as the utilization of soft-releases in in-stream enclosures.

Although survival rates did not vary significantly between sites, movement and utilization of shelter differed significantly between the translocation and reintroduction sites. Hellbenders at both sites were sedentary during the majority of observations as has been observed in telemetry studies of adults and head-started juveniles (Blais 1996; Gates et al. 1985; Burgmeier et al. 2011a; Bodinof et al. 2012a). When active, Hellbenders moved most frequently during the summer as has been seen in adult Hellbenders in telemetry studies in Indiana, as well as during studies of Hellbenders reared in human care and released in Missouri (Burgmeier et al. 2011a; Bodinof et al. 2012a). Individuals at the reintroduction site moved upstream significantly more frequently (36.7\% of movements) than individuals at the translocation site (6.9\% of movements). Although the individuals at the reintroduction site moved upstream somewhat regularly, net dispersal of all individuals at this site as well as at the translocation site occurred downstream from the initial site of release as was seen in Missouri head-started release studies when the majority of released individuals dispersed downstream (76.9\%) in spite of regular daily upstream movements.

Juveniles at the translocation site exhibited similar movement distances $(27.37 \mathrm{~m})$ to adults studied during telemetry studies in Indiana $(27.5 \mathrm{~m})$ and in individuals captured without the use of telemetry in Pennsylvania (19 m) and West Virginia (35.8 m) (Hillis and Bellis 1971; Humphries and Pauley 2005; Burgmeier et al. 2011a). The maximum observed distance traveled by any individual in this study was $402 \mathrm{~m}$. Ball and Blais observed movements of over 800 meters in adult Hellbenders in studies in Tennessee and New York (Blais 1996; Ball 
2001). Long distance movements (>50 m) accounted for $42.6 \%$ of movements at the reintroduction site and only $15.5 \%$ of movements at the translocation site.

Minimum convex polygon (MCP) home range in this study averaged $9,038.61 \mathrm{~m}^{2}$ at the reintroduction site and $1,313.21 \mathrm{~m}^{2}$ at the translocation site. In telemetry studies of headstarted Hellbenders in Missouri, individuals at each release site had much smaller MCP home ranges of $200.59 \mathrm{~m}^{2}$ and $235.78 \mathrm{~m}^{2}$ during the first year of tracking (Bodinof 2010). Adult individuals studied during telemetry surveys in Indiana maintained MCP home ranges greater than the translocation site but much smaller than the reintroduction site at $2,211.9 \mathrm{~m}^{2}$ (Burgmeier et al. 2011a). Both of the MCP home ranges utilizing radio telemetry in this study are much greater than observed for a population of adults that was studied in West Virginia without telemetry and averaged only $198 \mathrm{~m}^{2}$ (Humphries and Pauley 2005). Several other telemetry studies of Hellbenders have utilized linear home range (LHR) to assess movement. Average LHR's of individuals at the reintroduction site were $306.08 \mathrm{~m}$, while those at the translocation site again were smaller at $106.3 \mathrm{~m}$. When compared to other Hellbender telemetry studies, the LHR of individuals at the translocation site was similar to the LHR of adults tracked in Indiana, which had a mean LHR of $144 \mathrm{~m}$ (Burgmeier et al. 2011a). In telemetry studies of adults in New York, LHR's were analyzed seasonally, and all LHR's other than spring movement $(110.3 \mathrm{~m})$ were less than the LHR's observed at our translocation site (Blais 1996).

All observations of individuals at the translocation site occurred underneath boulders within the river. However, individuals at the reintroduction site utilized holes in stream banks during $46.6 \%$ of observations. Hellbenders have been observed utilizing holes in stream banks or stream bank areas under root mats during several studies. Individuals during the study of 
head-started juveniles in Missouri were observed using stream bank shelters or root masses during $8 \%$ of observations (Bodinof 2010). Telemetry studies of adults in New York and Indiana likewise observed the use of these shelters (Blais 1996; Burgmeier et al. 2011a), and individuals in the size class of those surveyed during our study were most commonly detected during agitation of substrate during bank searches in New York (Foster et al. 2009). Larval individuals of another cryptobranchid, the Japanese giant salamander (Andrias japonicas), have also been observed in crevices in artificial stream banks (Okada et al. 2008), and adults of this species typically utilize dens in river banks for nesting and paternal care (Okada et al. 2015).

Boulders that were selected by individuals at the translocation site during this study averaged $24,510 \mathrm{~cm}^{2}$ in size, while those utilized by individuals at the reintroduction site averaged $7,075 \mathrm{~cm}^{2}$ in size. Adult Hellbenders studied during telemetry surveys in Indiana utilized boulders in the $5,000-15,000 \mathrm{~cm}^{2}$ size range most frequently with individuals at the reintroduction site during our study utilizing boulders in the $5,000-10,000 \mathrm{~cm}^{2}$ range most frequently (Burgmeier et al. 2011a). Individuals at our translocation site utilized boulders in excess of $30,000 \mathrm{~cm}^{2}$ most frequently however. Shelter selection size by adult Hellbenders in two West Virginia studies without the use of telemetry averaged $5,535 \mathrm{~cm}^{2}$ and $10,280 \mathrm{~cm}^{2}$ (Humphries and Pauley 2005; Keitzer 2007 ), and a study of shelters utilized by hellbenders in North Carolina resulted in mean shelter size of 4,582 $\mathrm{cm}^{2}$ (Rossell et al. 2013).

Our study was the first translocation study of Hellbenders reared in human care to a site of historic Hellbender occurrence where adult Hellbenders were no longer observed during current surveys. Although not statistically significant, Hellbender survival was greater at the translocation site than at the reintroduction site utilized in this study and survival at this site 
was similar to another study of juvenile Hellbenders head-started in human care. The telemetry survey conducted by Bodinof et al. in Missouri resulted in higher first year survival rates with survival being greatest amongst the largest individuals released (Bodinof et al. 2012b). Our study did not reveal any association of size at release with survival, but none of the individuals utilized in this study were as large as the size classes that were most successful in the Missouri study (>300 g) (Bodinof et al. 2012b ).

Although Hellbenders in this study were released in winter at the reintroduction site and summer at the translocation site, movement at both sites was still greatest during summer, and the majority of mortalities or losses of individuals occurred during the first 52 days postrelease, regardless of season. Other studies of head-started and translocated individuals have led to increased long-distance movements and mortalities during the early weeks following releases as well (Gates et al. 1985; Bodinof et al. 2011a).

Individuals at the reintroduction site maintained substantially larger MCP home ranges than individuals tracked in other studies and moved greater distances between observations than has been observed in past studies. These individuals selected boulder shelters that were similar in area to shelters that have been reported for adult Hellbenders in other streams and rivers in West Virginia, but they only utilized stone shelters during 52.8\% of observations with the greatest utilization of stone shelters occurring during the winter and increased use of stream bank shelters occurring during the summer. Wolman pebble count analyses of in-stream substrate at the reintroduction and translocation sites indicated a much greater abundance of boulders at the translocation site than at the reintroduction site. Visual inspection of the sites of greatest boulder abundance within each of the study areas easily substantiates the 
disproportionate abundance of in-stream shelter availability at each release site (Figures 4 and $5)$.

The lack of available boulder shelters particularly during reduced flow periods during the summer is hypothesized to have contributed to the increased utilization of stream bank shelters near pools at the reintroduction site as well as to the increased home range size and movement observed between surveys at this site. Competition for in-stream shelters with adults at this site could lead to injury from adults defending these shelters or due to predation from adults (Miller and Miller 2005; Briggler and Lohraff 2014; Groves and Williams 2014). When instream shelter utilization increased at this site during the winter, more stones would have been available for shelter due to increased stream width and depth, and cold temperatures would have provided a thermal environment when potential predation from larger Hellbenders would have been reduced.

The utilization of home ranges at the translocation site that were similar to adult home ranges at other sites, the reduced movement distances, improved survival, and utilization of boulders as the only form of shelter at this site are hypothesized to be associated with an increased availability of shelter in the form of boulders. Bodinof et al. indicated that increased prevalence of available shelter within less than a meter and preferably within less than half a meter improved survivorship of released head-started individuals (Bodinof et al. 2012c). The greater availability of shelter at release sites would reduce competition with other Hellbenders, provide greater cover from potential predators and provide increased shelters for prey items within a reduced distance from the Hellbender. 
Our study indicated that reintroductions and translocations of head-started Hellbenders to streams and rivers in West Virginia have the potential to positively augment populations at these sites when undertaken at a large enough population density if appropriate shelter is available. Estimates of eggs from this species surviving to sub-adulthood in the wild are approximately 10\% (Unger et al. 2013), whereas egg survival to sub-adulthood in human care can be greater than $90 \%$ (Greathouse unpub. data). The greatest critiques of the success of reintroduction and translocation efforts have resulted from efforts when disease has unintentionally been released into the wild or when egg masses and larval or tadpole releases were employed with minimal or no observations of survival (Nettles et al. 1979; Thorne et al. 1988; Dodd and Seigel 1991; Cunningham 1996; Snyder et al. 1996; Seigel and Dodd 2002; Chipman et al. 2008). However, amphibians and reptiles managed in human care have the potential of being tested for pathogen presence prior to release and can be managed to a juvenile or sub-adult release size more readily than other species, because they require smaller physical facilities than many other vertebrates. In addition, the increased fecundity of amphibians as opposed to mammals or birds reduces the facility and time requirements that are essential for generating populations in a captive setting that would be large enough for reintroduction efforts (Bloxam and Tonge 1995, Burke 1991, Germano and Bishop 2008, Griffiths and Pavajeau 2008, Reinert 1991, and Trenham and Marsh 2002).

Although size at release did not impact survival in our study, larger release sizes likely decrease potential predation in this species as has been observed in other herpetofauna (Goodyear and Lazell 1994; Sarrazin and Legendre 2000; Bradley and Gerber 2008). Survival rates similar to those observed in our study have the potential to enhance current populations 
that are in decline or extirpated, particularly at sites with reduced Hellbender abundance or where individuals are no longer observed.

Our models for selection of sites to perform translocations resulted in the selection of a site that resulted in a better survival rate than a site of current Hellbender occurrence. Future translocations to enhance populations to a sustainable level at the Cherry River as well as the Little Kanawha River should be considered and sites of predicted high probability levels of Hellbender occurrence should be considered for future surveys of streams and rivers where Hellbenders have not been observed in recent years.

Juveniles at our reintroduction site frequently utilized stream bank shelters during the summer when most surveys for Hellbenders are conducted. Utilization of stream bank shelters was observed in a reduced amount in the Missouri telemetry study, and the occurrence of individuals in this size class was greatest near stream banks in New York. Several studies have suggested that Hellbender populations are or may be in decline due to the failure to detect signs of recruitment in the form of eggs, larvae, or juveniles at study sites (Pfingsten 1990; Wheeler et al. 2003; Burgmeier et al. 2011c). Most of these studies have focused on the surveillance of in-stream substrate; however the development of techniques for the surveillance of stream bank habitat as well as shelters not typically utilized by adults for juvenile individuals of this species should be considered particularly at sites with reduced boulder habitat (Nickerson et al. 2003).

Based on the results of this study and other translocation studies of Hellbenders headstarted in human care, the three primary factors that appear to be associated with survival success during these efforts include: 
1) Boulder shelter availability and its arrangement: future efforts should attempt to perform releases at sites where boulder availability is naturally adequate or provided in the form of stone slabs or artificial nest boxes at boulder percentages approximating $26 \%$ when using the Wolman zigzag pebble count as was seen at the translocation site.

2) Prevention of long-distance movements during initial weeks of release: future efforts should attempt to perform soft-releases in enclosures that would discourage initial long-distance movements and encourage time for acclimation to stream temperatures (Hutchison et al. 1973). Due to increased periods of movement during the summer months and reduced in-stream shelter availability during this time, studies should also determine the efficacy of performing releases immediately following the breeding season (October - November).

3) Reduction of predation upon released individuals - our study observed predation as the greatest cause of mortality. Predator avoidance training utilizing techniques that have been studied for Hellbenders (Crane and Mathis 2011) accompanied by negative reinforcement as has been used in reintroductions of other species such as the black-footed ferret (Biggins et al. 1999) that have been reared in human care should be considered and studied.

Acknowledgments. - Animals collected and tracked during this study were collected under permits WV2007.003, WV2010.131, and WV2011.192, and WV2012.134 from the West Virginia Division of Natural Resources to William J. Greathouse. Animal care and use approval was granted via the Oglebay's Good Zoo Animal Care and Use Committee (ACUC\#: OGZ-09- 
01). Funding for this project was provided through the State Wildlife Grant (SWG) program from the West Virginia Division of Natural Resources and the Columbus Zoo and Aquarium Conservation Grants Program. I would like to thank Dr. Barbara Wolfe from the Wilds; Dr. Robert Dailey, Dr. Margaret Minch, and Dr. Todd Petty from West Virginia University; and Dr.

Thomas Pauley of Marshall University for assistance with review and editing, and I would like to thank several staff and interns from Oglebay's Good Zoo with their assistance in completing this project including but not limited to Penny Miller, Susan Greathouse, Mindi White, and Kala Bassa.

\section{Literature Cited}

Ball, B. 2001. Habitat use and movements of Eastern Hellbenders, Cryptobranchus alleganiensis alleganiensis, a radiotelemetric study: a thesis. PhD Dissertation. Appalachian State University. Boone, North Carolina. 84 p.

Balmford, A., Mace, G., and N. Leader-Williams. 1996. Designing the ark: setting priorities for captive breeding. Conservation Biology. 10: 719-727.

Bartkus, C. 2009. The occurrence of Batrachochytrium dendrobatidis in salamander populations of West Virginia. M.S. Thesis. Marshall University. Huntington, West Virginia. 87 p.

Beck, A., S. Felser, and L. Glickman. 1987. An epizootic of rabies in Maryland, 1982-1984. American Journal of Public Health. 77(1): 42-44.

Behler, J. and F. King. 1998. National Audubon Society Field Guide to North American Reptiles \& Amphibians. Alfred A. Knopf, Inc. New York, New York. 743 p.

Bevenger, G. and R. King. 1995. A Pebble Count Procedure for Assessing Watershed Cumulative Effects. U.S. Forest Service Rocky Mount Forest and Range Experiment Station. Fort Collins, Colorado. 19 p.

Biggins, D., A. Vargas, J. Godbey, and S. Anderson. 1999. Influence of prerelease experience on reintroduced black-footed ferrets (Mustela nigripes). Biological Conservation. 89: $121-129$.

Blais, D. 1996. Movement, home range, and other aspects of the biology of the eastern Hellbender (Cryptobranchus alleganiensis alleganiensis): a radio telemetry study. M.S. Thesis. St. Lawrence University. Canton, New York. 63 p. 
Bloxam, Q. and S. Tonge. 1995. Amphibians: suitable candidates for breeding-release programmes. Biodiversity and Conservation. 4: 636-644.

Bodinof, C. 2010. Translocation and conservation of Hellbenders (Cryptobranchus alleganiensis) in Missouri. M.S. Thesis. University of Missouri. Columbia, Missouri. $152 \mathrm{p}$.

Bodinof, C., J. Briggler, R. Junge, J. Beringer, M. Wanner, C. Schuette, J. Ettling, R. Gitzen, and J. Millspaugh. 2011. Historic occurrence of the amphibian chytrid fungus Batrachochytrium dendrobatidis in Hellbender Cryptobranchus alleganiensis populations from Missouri. Diseases of Aquatic Organisms. 96: 1-7.

Bodinof, C., J. Briggler, R. Junge, J. Beringer, M. Wanner, C. Schuette, J. Ettling, and J. Millspaugh. 2012a. Postrelease movements of captive-reared Ozark Hellbenders (Cryptobranchus alleganiensis bishopi). Herpetologica. 68(2): 160-173.

Bodinof, C., J. Briggler, R. Junge, T. Mong, J. Beringer, M. Wanner, C. Schuette, J. Ettling, and J. Millspaugh. 2012b. Survival and body condition of captive-reared juvenile Ozark Hellbenders (Cryptobranchus alleganiensis bishopi) following translocation to the wild. Copeia. 2012(1): 150-159.

Bodinof, C., J. Briggler, R. Junge, J. Beringer, M. Wanner, C. Schuette, J. Ettling, and J. Millspaugh. 2012. Habitat attributes associated with short-term settlement of Ozark Hellbender (Cryptobranchus alleganiensis bishopi) salamanders following translocation to the wild. Freshwater Biology. 57:178-192.

Boyle, D., Boyle, D., Olsen, V., Morgan, J., and A. Hyatt. 2004. Rapid quantitative detection of chytridiomycosis (Batrachochytrium dendrobatidis) in amphibian samples using real-time Taqman PCR assay. Diseases of Aquatic Organisms. 60: 141-148.

Bradley, K. and G. Gerber. 2008. Headstarting the Anegada iguana, Cyclura pinguis. Proceedings of the International Wildlife Reintroduction Symposium.

Briggler, J. and K. Lohraff. 2014. Cryptobranchus alleganiensis alleganiensis (Eastern Hellbender) - Intraspecific Aggressive Behavior. Herpetological Review. 45(3): 471.

Brown, W.S., Kordek, W.S., Leo, K., McDonald, B., Sargent, B., and J. Wykle. 2005. West Virginia Wildlife Conservation Action Plan. Elkins, WV. 1,057 p.

Burgmeier, N., T. Sutton, and R. Williams. 2011a. Spatial ecology of the eastern Hellbender (Cryptobranchus alleganiensis alleganiensis) in Indiana. Herpetologica. 67(2): 135145. 
Burgmeier, N., S. Unger, J. Meyer, T. Sutton, and R. Williams. 2011b. Health and habitat quality assessment for the eastern Hellbender (Cryptobranchus alleganiensis alleganiensis) in Indiana, USA. Journal of Wildlife Diseases. 47(4): 836-848.

Burgmeier, N., S. Unger, T. Sutton, and R. Williams. 2011c. Population status of eastern Hellbender (Cryptobranchus alleganiensis alleganiensis) in Indiana. Journal of Herpetology. 45(2): 195-201.

Burke, R. 1991. Relocations, repatriations, and translocations of amphibians and reptiles: taking a broader view. Herpetologica. 47(3): 350-357.

Chipman, R., Slate, D., Rupprecht, C., and M. Mendoza. 2008. Downside risk of wildlife translocation. Developments in Biologicals. 131: 223-232.

Coatney, C. 1982. Home range and nocturnal activity of the Ozark Hellbender. M.S. Thesis. Southwest Missouri State University. Springfield, Missouri. 55 p.

Conant, R. and J.T. Collins. 1998. A Field Guide to Reptiles and Amphibians of Eastern and Central North America. Houghton-Mifflin Co., Boston, MA. 616 p.

Cooke, A. and R. Oldham. 1995. Establishment of populations of the common frog, Ranan temporaria, and common toad, Bufo bufo, in a newly created reserve following translocation. Herpetological Journal. 5: 173-180.

Crane, A. and A. Mathis. 2011. Predator-recognition training: a conservation strategy to Increase postrelease survival of Hellbenders in head-starting programs. Zoo Biology. 30: $611-622$.

Cunningham, A. 1996. Disease risk of wildlife translocations. Conservation Biology. 10: 349-353.

Denton, J., Hitchings, S., Beebee, T. and A. Gent. 1997. A recovery program for the natterjack toad (Bufo calamita) in Britain. Conservation Biology. 11(6): 13291338.

Dodd, C. Jr., and R. Seigel. 1991. Relocation, repatriation, and translocation of reptiles and amphibians: Are they conservation strategies that work? Herpetologica 47: 336-350.

Ettling, J., M. Wanner, C. Schuette, S. Armstrong, A. Pedigo, and J. Briggler. 2013. Captive reproduction and husbandry of adult Ozark Hellbenders, Cryptobranchus alleganiensis bishop. Herpetological Review. 44: 605-610. 
Fischer, J. and D. Lindenmayer. 2000. An assessment of the published results of animal relocations. Biological Conservation. 96: 1-11.

Foster, R., A. McMillan, and K. Roblee. 2009. Population status of Hellbender salamanders (Cryptobranchus alleganiensis) in the Allegheny River drainage of New York State. Journal of Herpetology. 43(4): 579-588.

Gascon, C., J. Collins, R. Moore, D. Church, J. McKay, and J. Mendelson. 2005. Amphibian Conservation Action Plan: Proceedings of the IUCN/SSC Amphibian Conservation Summit 2005. IUCN - The World Conservation Union. Gland, Switzerland.

Gates, J., R. Stouffer, J. Stauffer, and C. Hocutt. 1985. Dispersal patterns of translocated Cryptobranchus alleganiensis in a Maryland stream. Journal of Herpetology. 19(3): 436-438.

Germano, J. and P. Bishop. 2008. Suitability of amphibians and reptiles for translocation. Conservation Biology. 23(1): 7-15.

Goodyear, N. and J. Lazell. 1994. Status of a relocated population of endangered Iguana pinguis on Guana Island, British Virgin Islands. Restoration Ecology 2: $43-50$.

Green, N.B. 1934. Cryptobranchus alleganiensis in West Virginia. Proceedings of the West Virginia Academy of Sciences. Fairmont, WV.

Green, N.B. 1935. Further notes on the food habits of the water dog, Cryptobranchus alleganiensis (Daudin). Proceedings of the West Virginia Academy of Science. 9:36.

Green, N.B. and T. Pauley. 1987. Amphibians and Reptiles in West Virginia. University of Pittsburgh Press. Pittsburgh, Pennsylvania, USA.

Griffith, B., Scott, J.M., Carpenter, J.W., and C. Reed. 1989. Translocation as a species conservation tool: Status and strategy. Science. 245: 477-480.

Griffiths, R. and L. Pavajeau. 2008. Captive breeding, reintroduction, and the conservation of amphibians. Conservation Biology. 22: 852-861.

Groves, J. and L. Williams. 2014. Cryptobranchus alleganiensis-cannibalism. Herpetological Review. 45(3):108-109.

Hecht, K., M. Nickerson, and R. Vollbrecht. 2014. Cryptobranchus alleganiensis-predation. Herpetological Review. 45(3):471 
Hillis, R. and E. Bellis. 1971. Some aspects of the ecology of the Hellbender, Cryptobranchus alleganiensis alleganiensis, in a Pennsylvania stream. Journal of Herpetology. 5: 121126.

Horchler, D. 2010. Long-term growth and monitoring of the eastern Hellbender (Cryptobranchus a. alleganiensis) in eastern West Virginia. M.S. Thesis. Marshall University, Huntington, West Virginia. 48p.

Humphries, W. and T. Pauley. 2000. Seasonal changes in nocturnal activity of the Hellbender, Cryptobranchus alleganiensis, in West Virginia. Journal of Herpetology. 34(4): 604607.

Humphries, W. and T. Pauley. 2005. Life history of the Hellbender, Cryptobranchus alleganiensis, in a West Virginia stream. American Midland Naturalist. 154: 135-142.

Hutchison, V., G. Engbretson, and D. Turney. 1973. Thermal acclimation and tolerance in the Hellbender, Cryptobranchus alleganiensis. Copeia. 1973(4): 805-807.

Keitzer, S. 2007. Habitat preferences of the eastern Hellbender in West Virginia. M.S. Thesis. Marshall University. Huntington, West Virginia. 64 p.

Keitzer, S., T. Pauley, and C. Burcher. 2013. Stream characteristics associated with site occupancy by the eastern Hellbender, Cryptobranchus alleganiensis alleganiensis, in southern West Virginia. Northeastern Naturalist. 20: 666-677.

Kinne, O. 2006. Successful re-introduction of the newts Triturus cristatus and T. vulgaris. Endangered Species Research. 1: 25-40.

Kleiman, D. 1989. Reintroduction of captive mammals for conservation. BioScience. 39: $152-161$.

Kleiman, D. and J. Mallinson. 1998. Recovery and management committees for lion tamarins: partnerships in conservation planning and implementation. Conservation Biology. 12: 27-38.

LaMarca, E., K. Lips, S. Lotters, R. Puschendorf, R. Ibanez, J.V. Rueda-Almonacid, R. Schulte, C. Marty, F. Castro, J. Manzanilla-Puppo, J.E. Garcia-Perez, F. Bolanos, G. Chaves, J.A. Pounds, E. Toral, and B.E. Young. 2005. Catastrophic populations declines and extinctions in neotropical harlequin frogs (Bufonidae: Atelopus). Biotropica 37(2): 190-201.

Makowsky, R. 2004. Natural history and sexual dimorphism of the eastern Hellbender, Cryptobranchus alleganiensis. M.S. Thesis. Marshall University. Huntington, West 
Virginia. $69 \mathrm{p}$.

Mayasich, J., D. Grandmaison, and C. Phillips. 2003. Eastern Hellbender status assessment report. U.S. Fish and Wildlife Service. Ft. Snelling, Minnesota.

Mendelson, J. 2006. Confronting amphibian declines and extinctions. Science. 313: 47-48.

Miller, B. and J. Miller. 2005. Prevalence of physical abnormalities in eastern Hellbender (Cryptobranchus alleganiensis alleganiensis) populations of middle Tennessee. Southeastern Naturalist. 4(3): 513-520.

Netting, M. 1929. The food of the Hellbender Cryptobranchus alleganiensis (Daudin). Copeia. 1929(170): 23-24.

Nettles, V., Shaddock, J., Sikes, R., and C. Reyes. 1979. Rabies in translocated raccoons. American Journal of Public Health. 69: 601-602.

Nickerson, M. and C. Mays. 1973. The Hellbenders: North American "giant salamanders". Milwaukee Public Museum. 1:1-106.

Nickerson, M., Krysko, K., and R. Owen. 2002. Ecological status of the Hellbender (Cryptobranchus alleganiensis) and the mudpuppy (Necturus maculosus) salamanders in the Great Smoky Mountains National Park. Journal of the North Carolina Academy of Science. 118(1): 27-34.

Nickerson, M, K. Krysko, and R. Owen. 2003. Habitat differences affecting age class distributions of the Hellbender salamander, Cryptobranchus alleganiensis. Southeastern Naturalist. 2(4): 619-629.

Nickerson, M. and J. Briggler. 2007. Harvesting as a factor in population decline of a long-lived salamander; the Ozark Hellbender, Cryptobranchus alleganiensis bishop Grobman. Applied Herpetology. 4: 207-216.

Nickerson, M. and J. Byram. 2008. The use of tricaine (MS-222) in amphibian conservation. Reptile and Amphibian Corps Occasional Papers No.1: 1-20 pp.

Norris, S. 2007. Ghosts in our midst: coming to terms with amphibian extinctions. BioScience. 57(4): 311-316.

Okada, S., T. Utsunomiya, T. Okada, Z. Felix, and F. Ito. 2008. Characteristics of Japanese Giant Salamander (Andrias japonicus) populations in two small tributary streams in Hiroshima Prefecture, western Honshu, Japan. Herpetological Conservation and Biology. 3(2): 192-202. 
Okada, S., Y. Fukuda, and M. Takahashi. 2015. Paternal care behaviors of Japanese Giant Salamander Andrias japonicus in natural populations. Journal of Ethology. 33(1): $1-7$.

Petranka, J. Salamanders of the United States and Canada. Smithsonian Institute Press, Washington, DC, USA. 587 pp.

Pfingsten, R. 1990. The status and distribution of the Hellbender, Cryptobranchus alleganiensis in Ohio. Herpetological Review. 21(3): 48-51.

Phillips, S., R. Anderson, and R. Schapire. 2006. Maximum entropy modeling of species geographic distributions. Ecological Modelling. 190: 231-259.

Quinn, S. 2009. Factors influencing distribution of the eastern Hellbender in the northern segment of its range. M.S. Thesis. State University of New York. Syracuse, New York. $49 \mathrm{p}$.

R Core Team. 2014. R: a language and environment for statistical computing. R Foundation For Statistical Computing. Vienna, Austria.

Reinert, H. 1991. Translocation as a conservation strategy for amphibians and reptiles: some comments, concerns, and observations. Herpetologica 47: 357-363.

Rossell, C., P. McNeal, D. Gilette, L. Williams, S. Patch, and A. Krebs. 2013. Attributes of shelters selected by Eastern Hellbenders(Cryptobranchus a. alleganiensis) in the French Broad River Basin of North Carolina. Journal of Herpetology. 47(1): 66-70.

Sarrazin, F. and S. Legendre. 2000. Demographic approach to releasing adults versus young in reintroductions. Conservation Biology. 14: 488-500.

Seddon, P., Armstrong, D., and R. Maloney. 2007. Developing the science of reintroduction biology. Conservation Biology. 21: 303-312.

Seigel, R. and C. Dodd. 2002. Translocations of amphibians: proven management method or experimental technique? Conservation Biology. 16: 552-554.

Serfass, T., R. Brooks, J. Novak, P. Johns, O. Rhodes. 1998. Genetic variation among populations of river otters in North America: considerations for reintroduction projects. Journal of Mammalogy. 79(3): 736-746.

Snyder, N., Derrickson, S., Beissinger, S., Wiley, J., Smith, T., Toone, W., and B. Miller. 1996. Limitations of captive breeding in endangered species recovery. 
Conservation Biology. 10: 338-348.

Souza, M., M. Gray, P. Colclough, and D. Miller. 2012. Prevalence of infection by Batrachochytrium dendrobatidis and Ranavirus in eastern Hellbenders (Cryptobranchus alleganiensis alleganiensis) in eastern Tennessee. Journal of Wildlife Diseases. 48(3): 560-566.

Stouffer, R., J. Gates, C. Hocutt, and J. Stauffer. 1983. Surgical implantation of a transmitter package for radio-tracking endangered Hellbenders. Wildlife Society Bulletin. 11(4): 384-386.

Thorne, E. and E. Williams. 1988. Disease and endangered species: the black-footed ferret as an example. Conservation Biology. 2: 66-74.

Tocher, M. and S. Pledger. 2005. The inter-island translocation of the New Zealand frog Leiopelma hamiltoni. Applied Herpetology. 2: 401-413.

Trenham, P. and D. Marsh. 2002. Amphibian translocation programs: reply to Seigel and Dodd. Conservation Biology. 16: 555-556.

Unger, S., T. Sutton, and R. Williams. 2013. Projected population persistence of Eastern Hellbenders (Cryptobranchus alleganiensis alleganiensis). Journal for Nature Conservation. 21:423-432.

Wheeler, B., E. Prosen, A. Mathis, and R. Wilkinson. 2003. Population declines of a long-lived salamander: a 20+ year study of Hellbenders, Cryptobranchus alleganiensis. Biological Conservation. 109: 151-156. 
TABLES

\begin{tabular}{|c|c|c|c|c|c|c|}
\hline Site & $\begin{array}{l}\text { Similarity } \\
\text { Index } \\
\text { Ranking }\end{array}$ & $\begin{array}{c}\text { Cluster } \\
\text { Analysis } \\
\text { Ranking }\end{array}$ & $\begin{array}{l}\text { NMDS } \\
\text { Ranking }\end{array}$ & $\begin{array}{c}\text { MaxEnt } \\
\text { Probability } \\
\text { Ranking }\end{array}$ & $\begin{array}{c}\text { Sum of } \\
\text { Rankings }\end{array}$ & $\begin{array}{l}\text { Translocation } \\
\text { Site Ranking }\end{array}$ \\
\hline $\begin{array}{l}\text { Cedar } \\
\text { Creek }\end{array}$ & 7 & 4 & 7 & 11 & 29 & 9 \\
\hline $\begin{array}{l}\text { Cherry } \\
\text { River }\end{array}$ & 1 & 1 & 1 & 5 & 8 & 1 \\
\hline Fish Creek & 9 & 5 & 3 & 10 & 24 & $\mathrm{~T}-7$ \\
\hline $\begin{array}{l}\text { Glade } \\
\text { Creek }\end{array}$ & 3 & 3 & 11 & 4 & 21 & 6 \\
\hline $\begin{array}{l}\text { Greenbrier } \\
\text { River }\end{array}$ & 6 & 2 & 5 & 3 & 13 & 3 \\
\hline $\begin{array}{l}\text { Laurel } \\
\text { Creek }\end{array}$ & 5 & 2 & 8 & 9 & 24 & $\mathrm{~T}-7$ \\
\hline $\begin{array}{l}\text { Little } \\
\text { Kanawha } \\
\text { River }\end{array}$ & 4 & 3 & 2 & 1 & 9 & 2 \\
\hline Mud River & 10 & 6 & 10 & 8 & 34 & 11 \\
\hline $\begin{array}{l}\text { North Fork } \\
\text { Hughes } \\
\text { River }\end{array}$ & 8 & 4 & 6 & 2 & 20 & 5 \\
\hline $\begin{array}{l}\text { Second } \\
\text { Creek }\end{array}$ & 2 & 1 & 4 & 10 & 17 & 4 \\
\hline $\begin{array}{l}\text { Twelvepole } \\
\text { Creek }\end{array}$ & 11 & 6 & 9 & 6 & 32 & 10 \\
\hline
\end{tabular}

Table 1-Ranking of similarity index, cluster analysis, and NMDS model values of in-stream and landscape variables for each site of historic occurrence where Hellbenders were not observed during recent surveys in association to sites of Hellbender abundance ( $\geq 0.4$ captures per person hour) during recent surveys (most similar $=1$ ) and ranking of MaxEnt model prediction of probability occurrence for each site of historic occurrence where Hellbenders were not observed during recent surveys (highest predicted probability of occurrence $=1$ ). The lowest sum value of rankings was utilized to select the translocation site. 


\section{FIGURE LEGENDS}

Figure 1-Kaplan-Meier survival estimates for Hellbenders released at the reintroduction and translocation sites as a function of days post-release.

Figure 2-Chart of boulder shelter area $\left(\mathrm{cm}^{2}\right)$ occupied by Hellbenders at the reintroduction and translocation sites.

Figure 3-Chart of shelters selected during each season by individuals at the reintroduction site.

Figure 4-Photo of most boulder dense region of the translocation site.

Figure 5-Photo of most boulder dense region of the reintroduction site. 


\section{FIGURES}

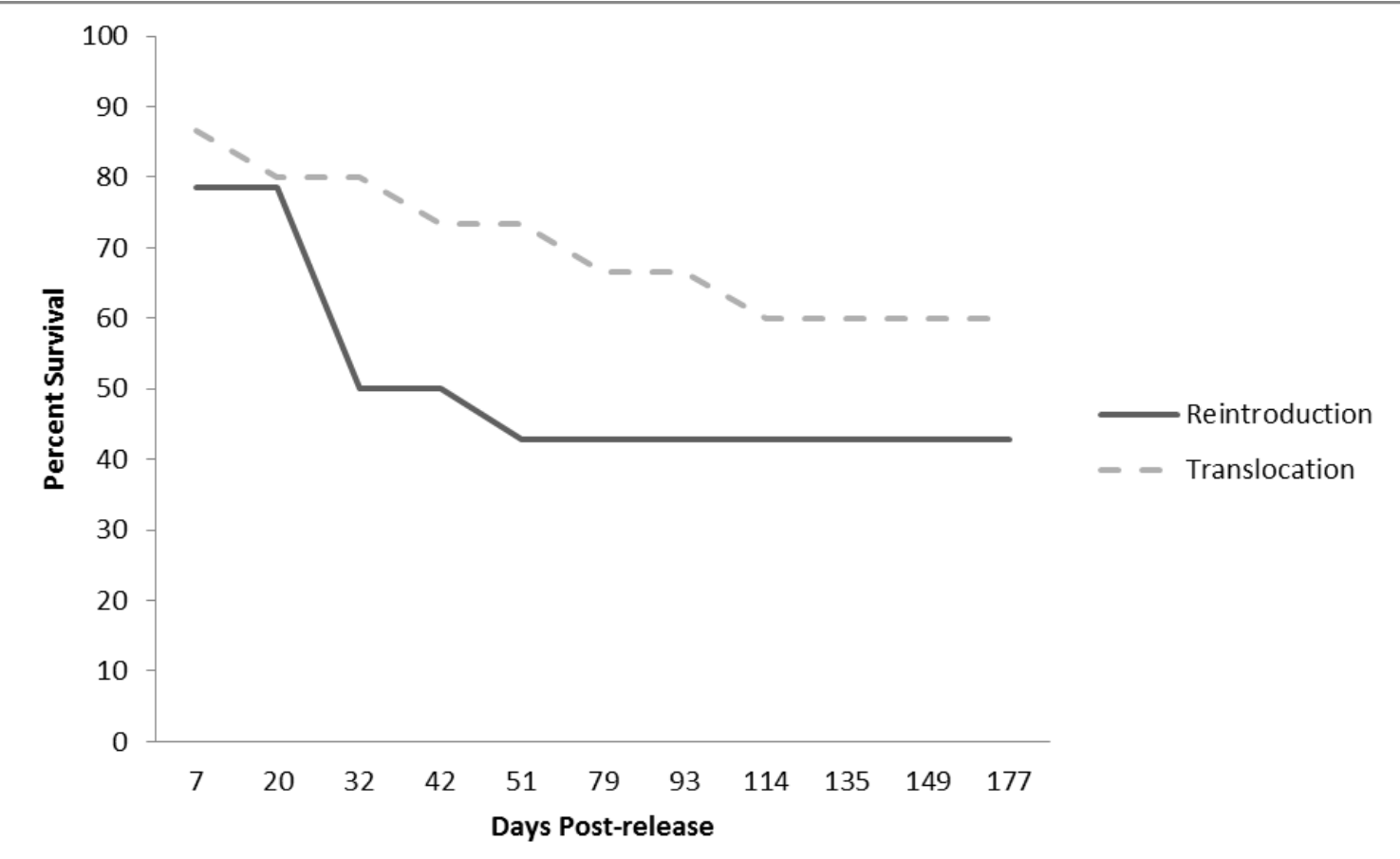

Figure 1 


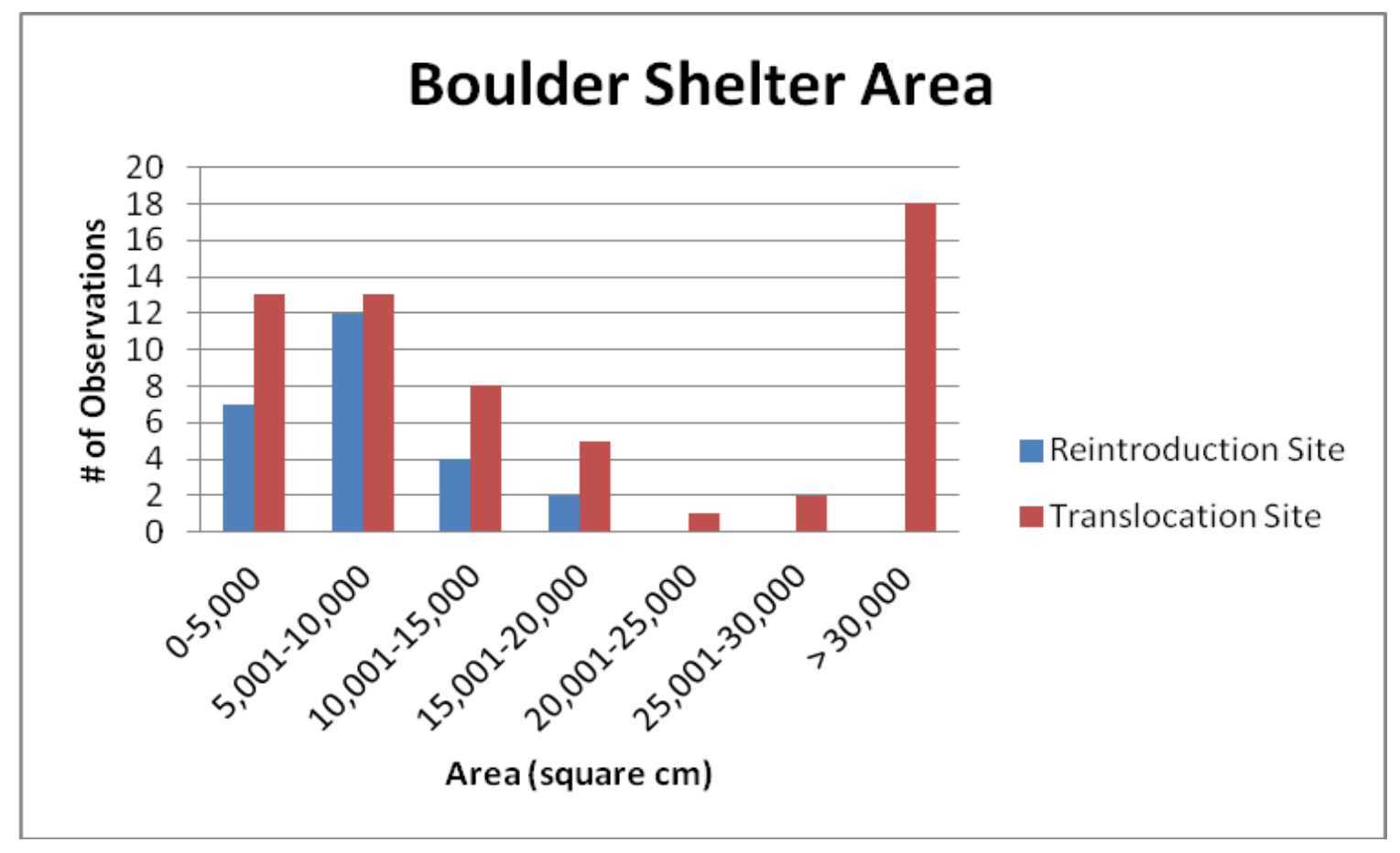

Figure 2

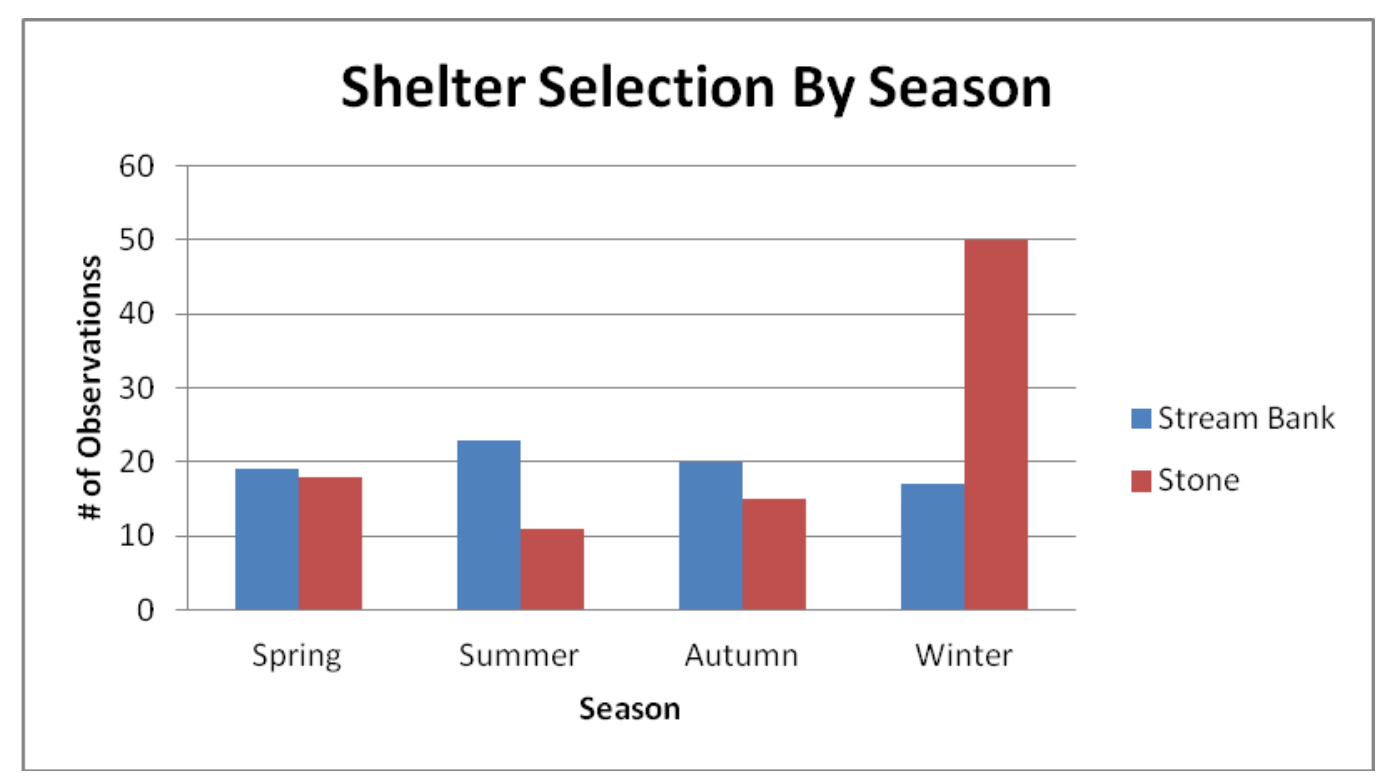

Figure 3 


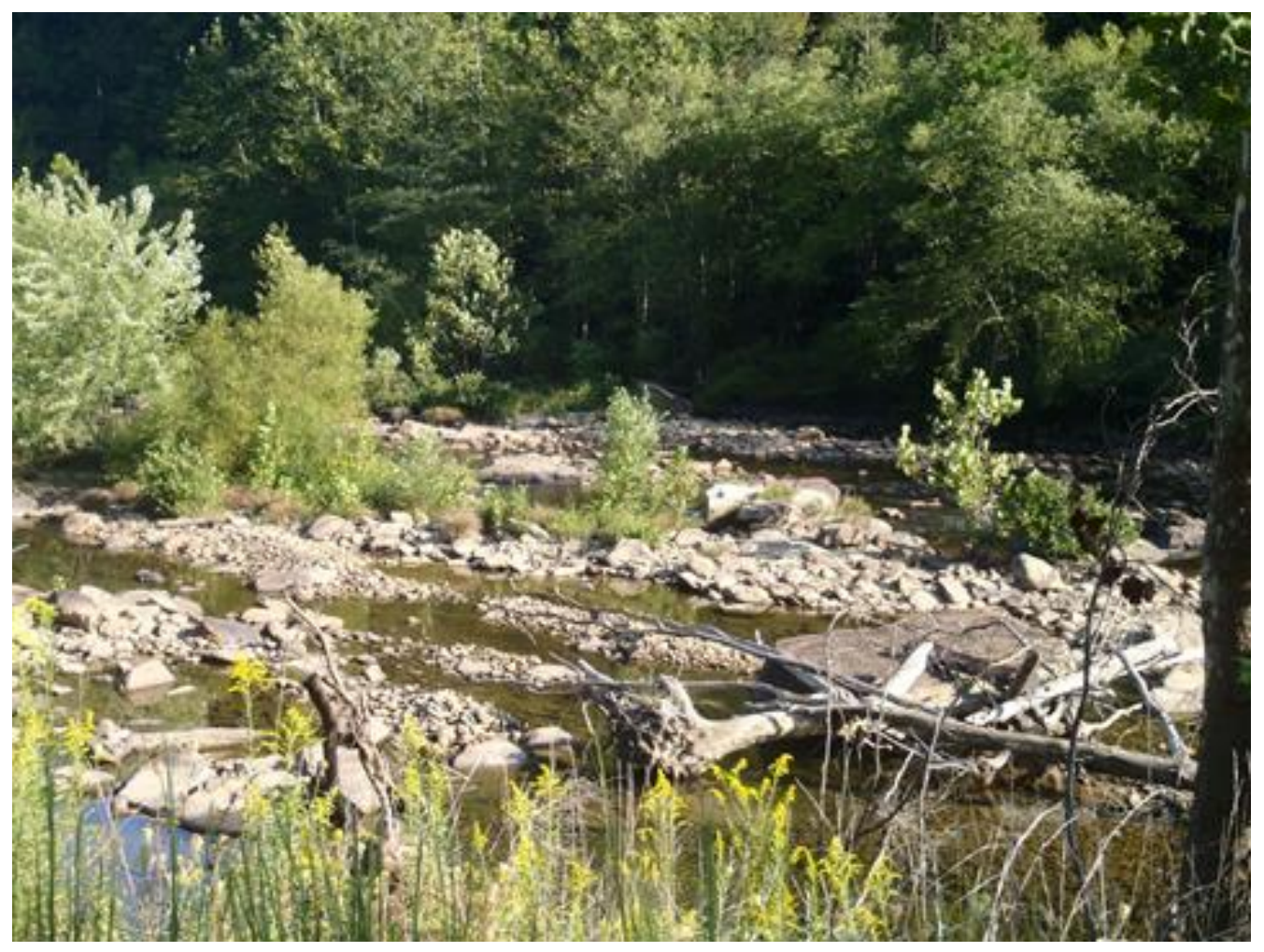

Figure 4

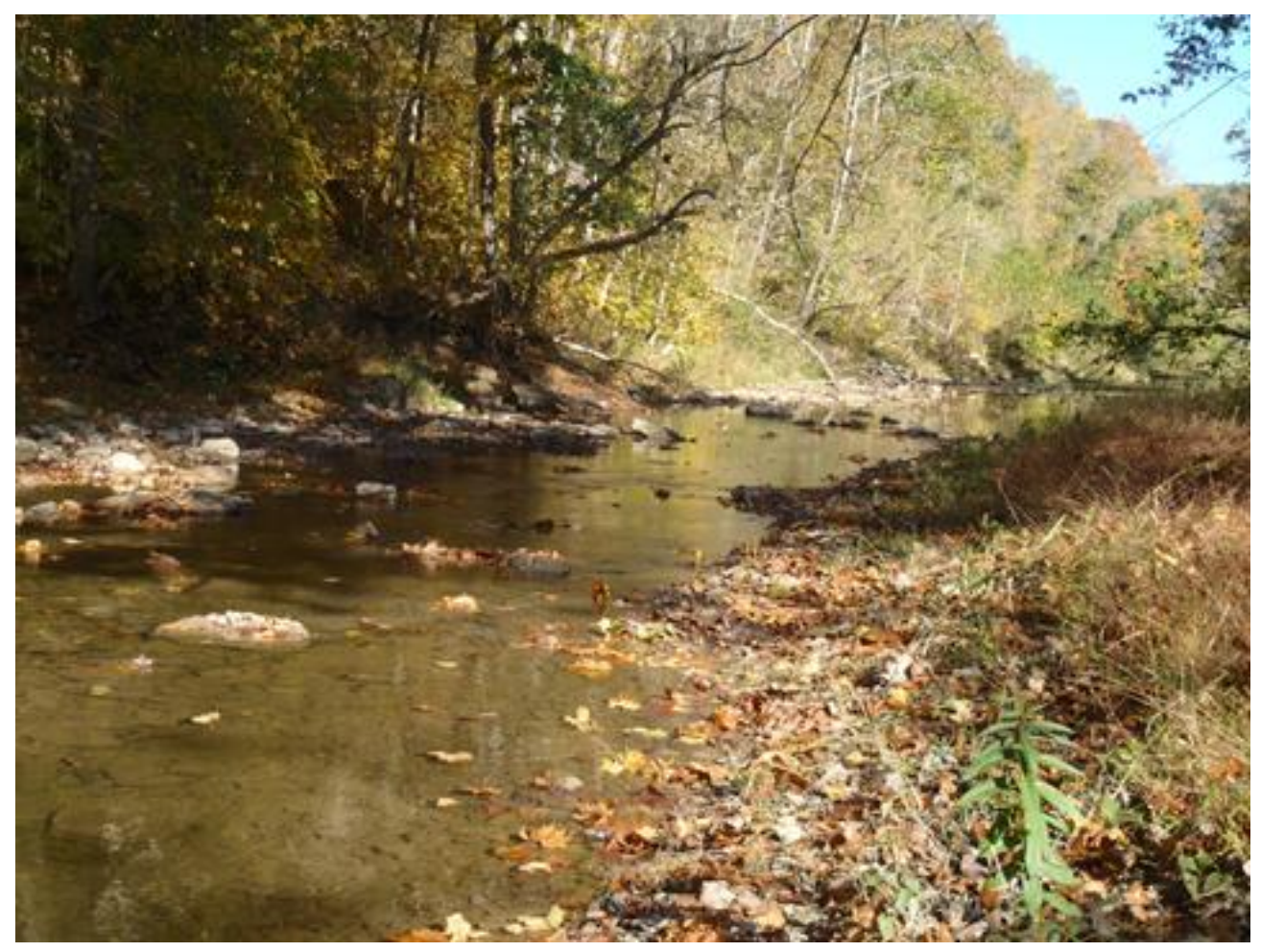

Figure 5 


\section{AUTHOR BIOGRAPHIES}

WiLLIAM J. “JOE” GREATHOUSE began his career as an Animal Keeper for Oglebay's Good Zoo in Wheeling, West Virginia, USA. He received his Bachelor of Arts in Biology from West Virginia University, and his Masters of Science in Wildlife and Fisheries Management was bestowed from West Virginia University as well. Greathouse was the Curator of Animals at Oglebay's Good Zoo for 12 years before becoming the Director of Conservation and Science at the Wilds in Cumberland, Ohio. Greathouse and keepers at the Good Zoo were the first to successfully hatch and rear Eastern hellbenders collected as wild eggs in a zoo or aquarium setting in 2007, and he has studied Eastern hellbenders in West Virginia in collaboration with the West Virginia Division of Natural Resources since 2004. He currently performs field ecology research and training of college interns and entry level ecologists in field studies and at the Hellbender Conservation Center at the Wilds.

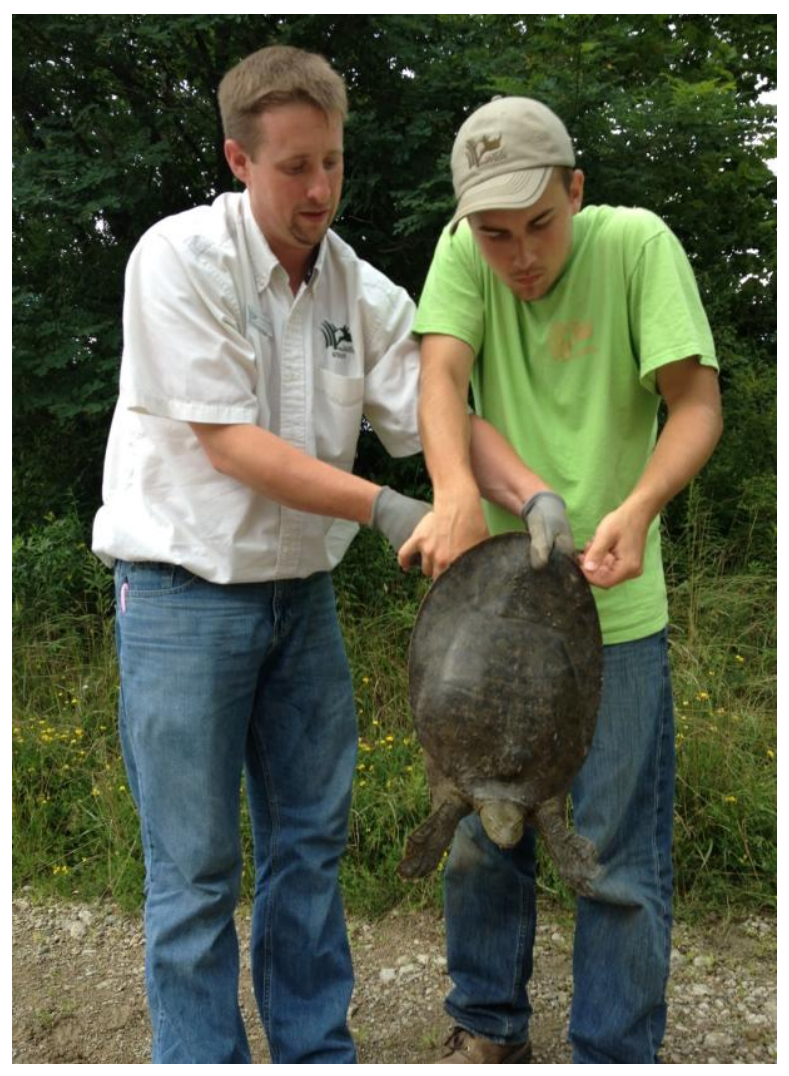




\section{CHAPTER 6}

\section{Conclusions and Future Directions}

The goals of this project were to: 1) identify the distribution of current populations of hellbenders based upon surveillance of historic sites of occurrence; 2 ) identify habitat variables that may be most associated with hellbender presence; 3) collect data on the natural history of the hellbender throughout West Virginia including morphologic, demographic, and diet intake data; 4) identify appropriate sites based on habitat suitability models where hellbenders once occurred but were no longer able to be detected for translocation of hellbenders raised in human care; and 5) to assess the viability of reintroductions and translocations of hellbenders raised in human care.

The physical surveys conducted during this project resulted in the capture of hellbenders at 12 of 23 (52.2\%) historic sites of occurrence. Based on a variety of inferential statistical techniques as well as ordination models, several key variables that were measured during these surveys or ascertained from landscape data associated with the study sites via GIS analysis techniques including: forest cover within watersheds, increased dissolved oxygen saturations, as well as increased coarse in-stream substrate availability in the form of cobble were associated with the presence of current hellbender populations.

Sites that currently have hellbender populations and these environmental conditions present should be targeted for land acquisition or easement purposes to preserve populations at these sites. Sites that currently have hellbender populations but lack these environmental variables should be prioritized for future conservation efforts including planting of forested 
riparian buffers as well as installation of in-stream shelter in the form of boulders or artificial nestboxes. Sites of historic hellbender occurrence that lack current hellbender populations but have these key environmental variables present should be considered for future translocation efforts.

Natural history data observed during this study indicated that sex ratios of individuals captured during surveys were nearly equal. Adult hellbenders were the age class of individuals most regularly encountered during this study, but juvenile hellbenders as well as eggs were observed at 9 of $12(75 \%)$ sites of documented occurrence. Crayfish were the most prevalent prey items observed during our study, followed by fish, but it was determined that hellbenders in West Virginia do not consume prey when water temperatures near $23^{\circ} \mathrm{C}$ in July and August.

Predictive models of the probability of hellbender occurrence in West Virginia based upon in-stream and landscape level habitat attributes prioritized several sites of historic hellbender occurrence that would be most appropriate to attempt translocations of hellbenders raised in human care. Translocations were conducted at the Cherry River with sites on the Little Kanawha River as well as the North Fork of the Hughes River also producing model results that would be favorable for future translocation efforts with individuals from Ohio River tributaries, while the Greenbrier River and Second Creek produced model results that were favorable for translocations of individuals potentially head-started from the forks of the Greenbrier River due to potential genetic differences between tributaries from the Ohio and New River drainages suggested from previous studies (Sabatino and Routman, 2008). Sites that were projected to have a high probability of hellbender presence in each of these rivers should 
also be surveyed physically to determine if populations are still present at previously unsurveyed sites from the 2010 surveys. In addition, sites that were projected to have a high probability of hellbender presence in streams without documented historic occurrence, such as the Meadow River, Big Clear Creek, and Piney Creek should be surveyed utilizing physical and environmental DNA techniques to determine if hellbender populations are present at these sites.

The reintroduction and translocation of hellbenders raised in human care proved to be more successful over a 6-12 month period than reintroductions of other amphibian species that have been studied, but the findings of this study should be utilized to enhance survival rates during these efforts. In addition, long-term monitoring of reintroduced and translocated populations should be conducted to determine the efficacy of these efforts in creating reproductively viable populations. Due to the greatest identified cause of mortality during release efforts being predation from fur-bearing mammals, predator avoidance training should be considered for release candidates. Sites with abundant boulder substrate for shelter should also be prioritized in order to reduce home ranges and the potential exposure of individuals to predators.

Releases of head-started individuals at a translocation site during various seasons of the year should be considered to determine if a particular time of year is most successful in increasing survival, particularly after this study's findings of inappetence in this species during July and August in West Virginia. Soft releases in enclosures such as artificial nest boxes should also be considered in order to determine if this technique would increase initial survival over 
the first weeks following release. Based upon the frequent utilization of stream banks as shelter by juveniles at Buffalo Creek, alternative survey techniques to capture individuals of larval and juvenile age classes at sites of historic occurrence should be studied and developed at sites with reduced boulder shelter abundance and substantial stream bank habitat such as the lowland tributaries of the Ohio River.

Finally, a coordinated conservation program involving stakeholders from academia, nonprofit conservation organizations, and government agencies should be developed for the conservation of this species in West Virginia. A potential framework for such a program has been prepared in Appendix 1 of this chapter. 
PROPOSED CONSERVATION ACTION PLAN FOR THE HELLBENDER IN WEST VIRGINIA

\begin{tabular}{|c|c|}
\hline Statewide Actions & Recommended Action Steps \\
\hline \multicolumn{2}{|l|}{ Coordination } \\
\hline $\begin{array}{l}\text { Initiate Hellbender Conservation } \\
\text { Working Group in West Virginia }\end{array}$ & $\begin{array}{l}\text { - Identify stakeholders with interests or experience with } \\
\text { hellbenders in WV including but not limited to: WV DNR, WV } \\
\text { DEP, USFWS, US EPA, USDA NRCS, West Virginia University, } \\
\text { Marshall University, The Wilds, Oglebay's Good Zoo, The } \\
\text { Nature Conservancy, West Virginia Land Trust, etc. } \\
\text { - Initiate stakeholders meeting with explanation of challenges } \\
\text { facing hellbenders in WV; the actions that have currently } \\
\text { been taken in WV and other states; and elicit ideas for } \\
\text { further conservation of the species. } \\
\text { - Integrate appropriate individuals from pertinent resource } \\
\text { extraction industries including timber, natural gas, and coal } \\
\text { into working group in a cooperative manner to discuss } \\
\text { sustainable synergies for hellbender conservation. } \\
\text { Coordinate additional actions within working group based } \\
\text { upon abilities and expertise and assign group and topic- } \\
\text { based coordinators for: 1) program coordination 2) fund- } \\
\text { raising, 3) land management and restoration, 4) surveillance } \\
\text { and monitoring, 5) conservation medicine, 6) management } \\
\text { in human care, and 7) conservation outreach programs. }\end{array}$ \\
\hline $\begin{array}{l}\text { Conduct twice annual meetings } \\
\text { to discuss progress, } \\
\text { modifications to conservation } \\
\text { actions, and evaluation of } \\
\text { conservation efforts }\end{array}$ & $\begin{array}{l}\text { - Meet to report progress } \\
\text { - Determine necessary continuing actions } \\
\text { - Determine short-term and long-term goals for evaluation of } \\
\text { efforts }\end{array}$ \\
\hline \multicolumn{2}{|l|}{ Surveillance } \\
\hline $\begin{array}{l}\text { Utilize historic and current } \\
\text { presence data to model } \\
\text { predicted distribution of the } \\
\text { species within the state. }\end{array}$ & 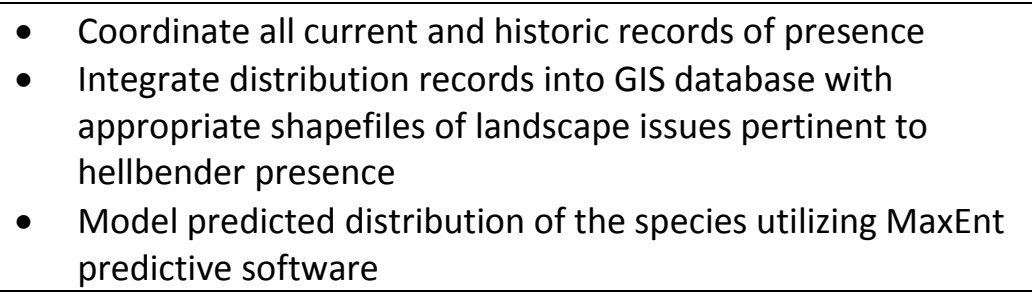 \\
\hline $\begin{array}{l}\text { Conduct eDNA surveys at sites of } \\
\text { current and historic records as } \\
\text { well as at sites of predicted } \\
\text { occurrence. }\end{array}$ & $\begin{array}{l}\text { - } \quad \text { Collect and filter water samples from appropriate sites } \\
\text { - } \quad \text { Extract DNA and perform PCR analysis } \\
\text { - Enter presence data from molecular surveys into } \\
\text { aforementioned modeling package and predict distribution } \\
\text { and further identify key landscape variables impacting } \\
\text { hellbender presence. }\end{array}$ \\
\hline $\begin{array}{l}\text { Conduct physical surveys at sites } \\
\text { of eDNA presence. }\end{array}$ & $\begin{array}{l}\text { Develop schedule for physical surveillance of sites where } \\
\text { eDNA presence was identified. Sites should be surveyed }\end{array}$ \\
\hline
\end{tabular}




\begin{tabular}{|c|c|}
\hline & $\begin{array}{l}\text { once every three years to prevent habitat disruption but to } \\
\text { maintain regular physical documentation of status. For } \\
\text { example, of the four identified sites on Buffalo Creek, no } \\
\text { one site should be surveyed physically with rock-turning } \\
\text { more than once per year. New surveyors should be trained } \\
\text { by biologists with experience surveying in the state, such as } \\
\text { Greathouse, Humphries, Pauley, Wykle, etc., in order to } \\
\text { improve efficiency. }\end{array}$ \\
\hline $\begin{array}{l}\text { Develop standardized data } \\
\text { collection form. }\end{array}$ & $\begin{array}{l}\text { A standardized data collection form should be developed } \\
\text { with minimum pertinent data that is to be shared with the } \\
\text { West Virginia DNR. }\end{array}$ \\
\hline $\begin{array}{l}\text { Develop catchability index to } \\
\text { improve quantification of } \\
\text { physical capture abundance. }\end{array}$ & $\begin{array}{l}\text { - Standardize catch per unit effort data at sites by integrating } \\
\text { key variables impacting hellbender capture including but not } \\
\text { limited to: researcher experience, stone geomorphology, } \\
\text { stone density, water depth, turbidity, etc. in order to more } \\
\text { accurately assess quantitative status of species within state. }\end{array}$ \\
\hline $\begin{array}{l}\text { Conduct fine-scale surveys of } \\
\text { small substrate at sites of known } \\
\text { recent recruitment to assess } \\
\text { larval and juvenile habitat at } \\
\text { these sites. }\end{array}$ & $\begin{array}{l}\text { - Conduct intense fine cobble and gravel surveys for larval } \\
\text { and juvenile hellbenders at the following sites to assess } \\
\text { habitat use throughout the state: Buffalo Creek, Wheeling } \\
\text { Creek, Holly River, Shavers Fork of Cheat River, Back Fork of } \\
\text { Elk River, East and West Fork Greenbrier Rivers, Gauley } \\
\text { River, and Williams River. }\end{array}$ \\
\hline \multicolumn{2}{|l|}{$\underline{\text { Health }}$} \\
\hline $\begin{array}{l}\text { Develop minimum standards for } \\
\text { health sample collection and } \\
\text { assessment per capture. }\end{array}$ & $\begin{array}{l}\text { Researchers should be trained by veterinarians or } \\
\text { researchers experienced in these techniques to collect } \\
\text { baseline health samples including: observation of } \\
\text { abnormalities or injury; body condition index calculations; } \\
\text { collection of skin and choanal/cloacal swabs for } B d \text {, } \\
\text { ranavirus, and potential emerging disease surveillance; } \\
\text { blood collection for DNA, serology, WBC differential, and } \\
\text { whole blood samples (total } 1 \% \text { body weight in volume). }\end{array}$ \\
\hline $\begin{array}{l}\text { Development of a rapid } \\
\text { response group. }\end{array}$ & $\begin{array}{l}\text { A rapid response group should be developed to react to } \\
\text { hellbender disease outbreaks, hellbender mortalities, } \\
\text { disease outbreaks or mortalities in other ectotherms at sites } \\
\text { of hellbender occurrence, and to potential environmental } \\
\text { contamination at sites of hellbender occurrence. Potential } \\
\text { holding facilities with appropriate veterinary ability and } \\
\text { quarantine or isolation facilities should be identified for this } \\
\text { group. }\end{array}$ \\
\hline $\begin{array}{l}\text { Develop health sample storage } \\
\text { facility and database. }\end{array}$ & $\begin{array}{l}\text { - A working group partner with adequate veterinary ability on } \\
\text { staff should serve as a repository for health sample storage, } \\
\text { analysis, and epidemiological reporting. }\end{array}$ \\
\hline \multicolumn{2}{|l|}{ Land Management } \\
\hline Identify and prioritize key areas & - $\quad$ Create GIS maps identifying key habitats for preservation \\
\hline
\end{tabular}




\begin{tabular}{|c|c|}
\hline $\begin{array}{l}\text { of preservation for acquisition of } \\
\text { land or conservation easements }\end{array}$ & $\begin{array}{l}\text { that are currently adjacent to or upstream of documented } \\
\text { sites of hellbender presence (please see example below). } \\
\text { Prioritize sites with GIS based upon stream buffer distance, } \\
\text { forest cover, current land ownership, and parcel size. } \\
\text { - Prioritize sites for acquisition of property or easements for } \\
\text { event that mitigation funds are available. }\end{array}$ \\
\hline $\begin{array}{l}\text { Identify key areas of active } \\
\text { conservation for acquisition of } \\
\text { land or conservation easements }\end{array}$ & $\begin{array}{l}\text { - Create GIS maps identifying key habitats for conservation } \\
\text { that are currently adjacent to or upstream of documented } \\
\text { sites of hellbender presence or sites of predicted hellbender } \\
\text { presence. } \\
\text { - Prioritize sites with GIS based upon stream buffer distance, } \\
\text { lack of forest cover, current land ownership, and parcel size. } \\
\text { Prioritize sites for acquisition of property or easements for } \\
\text { event that mitigation funds are available. }\end{array}$ \\
\hline \multicolumn{2}{|l|}{$\underline{\text { Restoration }}$} \\
\hline $\begin{array}{l}\text { Identify key land units for } \\
\text { streamside and/or in-stream } \\
\text { restoration }\end{array}$ & $\begin{array}{l}\text { - Based on aforementioned GIS maps, identify and prioritize } \\
\text { land units based upon preservation need first, then } \\
\text { conservation need. The goal would be to maintain what is } \\
\text { still strong and likely most affordable first and then move on } \\
\text { to the more challenging areas unless site selection is } \\
\text { mandated by mitigation rules. }\end{array}$ \\
\hline $\begin{array}{l}\text { Identify applicable restoration } \\
\text { techniques at identified sites } \\
\text { based upon need }\end{array}$ & $\begin{array}{l}\text { Determine most applicable technique for restoration at each } \\
\text { prioritized site. Action will likely be site-dependent and } \\
\text { potentially include activities such as reforestation of } \\
\text { streamside buffer zones, restoration or augmentation of in- } \\
\text { stream shelter, reintroduction or translocation of individuals } \\
\text { reared in human care, water treatment, etc. }\end{array}$ \\
\hline $\begin{array}{l}\text { Identify potential restoration } \\
\text { partners }\end{array}$ & $\begin{array}{l}\text { Identify private, industry, and external agency (WVDOT, WV } \\
\text { Division of Corrections, U.S.F.S.) partners that could assist } \\
\text { with acquisition of materials or manpower to assist with } \\
\text { restoration activities. }\end{array}$ \\
\hline $\begin{array}{l}\text { Determine genetic status of } \\
\text { species within watersheds }\end{array}$ & $\begin{array}{l}\text { - Seek funding to continue to investigate the in-stream and in- } \\
\text { state genetic diversity of the hellbender. } \\
\text { - Emphasize genetic challenges such as inbreeding at sites } \\
\text { with isolated populations in the Ohio River Valley Region. }\end{array}$ \\
\hline $\begin{array}{l}\text { Develop restocking plan from } \\
\text { genetic data in order to prevent } \\
\text { over-representation of genes } \\
\text { from human-reared nests for } \\
\text { translocations and } \\
\text { reintroductions. }\end{array}$ & $\begin{array}{l}\text { - Identify sites that would be most appropriate and would } \\
\text { benefit the most from reintroduction and translocation } \\
\text { efforts. } \\
\text { - Identify sites for annual egg collection for rearing in human } \\
\text { care and partial reintroduction and translocation } \\
\text { throughout the state based upon genetic diversity. }\end{array}$ \\
\hline $\begin{array}{l}\text { Create } \\
\text { translocation/reintroduction and } \\
\text { monitoring plan. }\end{array}$ & $\begin{array}{l}\text { Utilizing aforementioned data, create a } 10 \text {-year restocking } \\
\text { plan for the state with follow-up monitoring and evaluation } \\
\text { of success in developing reproducing populations as a }\end{array}$ \\
\hline
\end{tabular}




\begin{tabular}{|c|c|}
\hline & primary goal of the program. \\
\hline $\begin{array}{l}\text { Identify partners to assist with } \\
\text { head-starting hellbenders for } \\
\text { translocation/reintroduction. }\end{array}$ & $\begin{array}{l}\text { - Identify local zoos, aquariums, hatcheries, and universities } \\
\text { with appropriate staffing and veterinary care to initiate } \\
\text { head-start program. }\end{array}$ \\
\hline $\begin{array}{l}\text { Develop husbandry manual for } \\
\text { head-starting and reintroducing } \\
\text { hellbenders and training course } \\
\text { for partners without experience. }\end{array}$ & $\begin{array}{l}\text { Create husbandry manual focusing on incubation, larval } \\
\text { rearing, daily care and maintenance, biosecurity, and } \\
\text { veterinary care and provide to head-starting institutions. }\end{array}$ \\
\hline \multicolumn{2}{|l|}{ Outreach } \\
\hline $\begin{array}{l}\text { Develop outreach plans and } \\
\text { actions for key stakeholders and } \\
\text { target groups. }\end{array}$ & $\begin{array}{l}\text { - Identify key stakeholders for outreach such as anglers, } \\
\text { businesses, schools, and design curriculum and conservation } \\
\text { messaging that is appropriate for each group. } \\
\text { - Identify funding or partners that are able to assist in the } \\
\text { production and dissemination of outreach materials. }\end{array}$ \\
\hline \multicolumn{2}{|l|}{$\frac{\text { Conservation and Research }}{\text { Funding }}$} \\
\hline $\begin{array}{l}\text { Develop funding plans for } \\
\text { prioritized subjects and actions. }\end{array}$ & $\begin{array}{l}\text { - Determine budgets for aforementioned priorities. } \\
\text { - Identify appropriate sources of funding for each type of } \\
\text { priority. } \\
\text { - Develop grant-writing, philanthropy, and sponsorship plans } \\
\text { for acquisition of funds to implement actions. }\end{array}$ \\
\hline
\end{tabular}


APPENDIX 2

Morphometric measurements of hellbenders captured during 2010 surveys.

\begin{tabular}{|c|c|c|c|c|}
\hline PIT Tag \# & Gender & Total Length $(\mathrm{cm})$ & SVL $(\mathrm{cm})$ & Mass (g) \\
\hline 00-068D-9E7B & Female & 48.9 & 32.7 & 770 \\
\hline 00-0676-B942 & Female & 52.1 & 30.5 & 890 \\
\hline 00-068D-A592 & Unknown & 38.1 & 20 & 330 \\
\hline 00-0676-DB52 & Male & 49.5 & 31.8 & 830 \\
\hline 00-068D-BFB9 & Male & 48.3 & 30.2 & 630 \\
\hline 00-068D-A7F1 & Unknown & 24.8 & 13.7 & 120 \\
\hline 00-068D-AAE3 & Male & 43.8 & 27.9 & 590 \\
\hline 00-068D-AC9E & Unknown & 32.4 & 21 & 250 \\
\hline 00-068D-BC3E & Male & 43.2 & 31.1 & 680 \\
\hline 00-06FB-8629 & Male & 41.3 & 27.3 & 570 \\
\hline 00-06FB-A651 & Female & 48.9 & 30.5 & 920 \\
\hline 00-06FB-8D5D & Female & 43.8 & 28.6 & 580 \\
\hline 00-06FB-8F7C & Female & 43.8 & 30.5 & 530 \\
\hline 00-06FB-A4D8 & Female & 45.7 & 27.9 & 490 \\
\hline 00-06FB-8C39 & Female & 43.2 & 31.8 & 620 \\
\hline 00-06FB-9DF2 & Male & 48.9 & 31.8 & 730 \\
\hline 00-06FB-9CDA & Male & 55.9 & 38.7 & 1,000 \\
\hline 00-06FB-A000 & Female & 55.9 & 36.8 & 990 \\
\hline 00-06FB-8E76 & Male & 49.5 & 32.4 & 520 \\
\hline 00-06FB-7F92 & Male & 43.8 & 32.4 & 640 \\
\hline 00-06FB-A4DE & Female & 40.6 & 27.9 & 420 \\
\hline 00-06FB-AEBC & Male & 44.5 & 31.8 & 550 \\
\hline 00-06FB-A2C3 & Female & 25.4 & 17.2 & 110 \\
\hline 00-06FB-8E5A & Female & 50.2 & 40 & 920 \\
\hline 00-06FB-7926 & Male & 41.6 & 30.5 & 480 \\
\hline 00-06FB-8CD8 & Female & 57.2 & 38.7 & 1,080 \\
\hline 00-06E7-627C & Male & 45.7 & 30.5 & 550 \\
\hline 00-06FB-7F10 & Male & 38.1 & 24.8 & 330 \\
\hline 00-06F1-C6D2 & Female & 50.8 & 34.3 & 670 \\
\hline 00-06FB-AA41 & Female & 49.5 & 35.6 & 740 \\
\hline 00-06E7-5DD3 & Male & 48.3 & 33 & 600 \\
\hline 00-06E7-5F5A & Male & 46.4 & 31.1 & 490 \\
\hline
\end{tabular}




\begin{tabular}{|c|c|c|c|c|}
\hline 00-06FB-A9C5 & Male & 53.3 & 33.7 & 590 \\
\hline 00-06FB-8194 & Male & 50.8 & 35.6 & 770 \\
\hline 00-06FB-8D48 & Male & 49.5 & 32.4 & 740 \\
\hline 00-06FB-8CC3 & Male & 50.8 & 31.1 & 690 \\
\hline 00-0676-С38E & Female & 54.6 & 34.3 & 880 \\
\hline 00-06FB-8E74 & Male & 47.6 & 27.3 & 630 \\
\hline 00-06E7-5441 & Female & 46.4 & 29.9 & 630 \\
\hline 00-06FD-21CD & Male & 47 & 29.2 & 620 \\
\hline 00-06FB-806F & Female & 54.6 & 36.2 & 960 \\
\hline 00-06Е7-7B0A & Male & 41.6 & 27.3 & 410 \\
\hline Too small & Unknown & 12.8 & 8.3 & 10 \\
\hline 00-0697-D839 & Male & 54.6 & 34.9 & 870 \\
\hline 00-06FB-AAB5 & Male & 34.9 & 24.8 & 300 \\
\hline 00-06FB-952E & Female & 48.9 & 31.1 & 730 \\
\hline 00-06FB-94C3 & Male & 54.9 & 36.2 & 870 \\
\hline 00-06E7-797A & Male & 35.6 & 31.1 & 590 \\
\hline 00-06FB-98E6 & Female & 44.5 & 26.7 & 650 \\
\hline 00-0676-C7F0 & Female & 50.8 & 34.3 & 760 \\
\hline 00-06E7-67C6 & Female & 59.7 & 40.6 & 960 \\
\hline 00-068D-9591 & Male & 48.3 & 31.8 & 770 \\
\hline 00-06FB-95B7 & Male & 36.2 & 22.2 & 300 \\
\hline 00-0697-E643 & Male & 52.7 & 31.4 & 640 \\
\hline 00-0676-D8BC & Female & 50.8 & 33 & 640 \\
\hline 00-068D-A097 & Male & 50.8 & 33.7 & 710 \\
\hline 00-06FB-7FOE & Male & 31.4 & 19.7 & 210 \\
\hline 00-06E7-509F & Female & 38.1 & 23.5 & 310 \\
\hline 00-06E7-74A5 & Female & 54.6 & 34.6 & 870 \\
\hline 00-06FB-8723 & Male & 44.5 & 27.3 & 690 \\
\hline
\end{tabular}

Table 1 - Morphometrics table with individual identification numbers from PIT tags implanted into hellbenders captured during this study, gender, total length in centimeters (cm), snout-vent length (SVL) in centimeters, and mass in grams (g). 
APPENDIX 3

Environmental Variables Measured from 2010 Survey Sites and Associated Analysis Values

\begin{tabular}{|c|c|c|c|c|c|c|}
\hline Site & Dates & $\begin{array}{c}\text { Water } \\
\text { Temperature }\left({ }^{\circ} \mathrm{C}\right)\end{array}$ & $\mathrm{pH}$ & $\begin{array}{c}\text { Conductivity } \\
(\mu \mathrm{S})\end{array}$ & $\begin{array}{c}\text { Dissolved } \\
\text { Oxygen (ppm) }\end{array}$ & $\begin{array}{l}\text { Crayfish } \\
\text { Presence }\end{array}$ \\
\hline Fish Creek & $\begin{array}{l}07 / 03 \\
07 / 21\end{array}$ & 28.4 & 8.14 & 533 & 5.9 & 51 \\
\hline E. Fork Greenbrier & $\begin{array}{l}06 / 17 \\
07 / 22\end{array}$ & 25.8 & 7.38 & 365 & 5.91 & 46 \\
\hline W. Fork Greenbrier & $\begin{array}{l}06 / 12 \\
07 / 22\end{array}$ & 27.1 & 8.01 & 386 & 6.88 & 32 \\
\hline Williams River & $\begin{array}{l}07 / 24 \\
08 / 29\end{array}$ & 25.5 & 7.56 & 197.6 & 5.96 & 33 \\
\hline Middle Island Creek & $\begin{array}{l}07 / 03 \\
07 / 26\end{array}$ & 28.3 & 7.87 & 360 & 6.37 & 70 \\
\hline $\begin{array}{l}\text { Shavers Fork of Cheat } \\
\text { River }\end{array}$ & $\begin{array}{l}06 / 17 \\
07 / 31 \\
\end{array}$ & 23.3 & 7.77 & 390 & 6.4 & 45.5 \\
\hline Second Creek & $\begin{array}{l}06 / 24 \\
08 / 05\end{array}$ & 28.3 & 8.21 & 248 & 6.07 & 80 \\
\hline Greenbrier River & $\begin{array}{l}06 / 26 \\
08 / 05 \\
\end{array}$ & 27.3 & 8.15 & 377 & 5.87 & 76 \\
\hline $\begin{array}{l}\text { South Fork Hughes } \\
\text { River }\end{array}$ & $\begin{array}{l}07 / 08 \\
08 / 06 \\
\end{array}$ & 29.1 & 7.71 & 242 & 5.48 & 84.5 \\
\hline $\begin{array}{l}\text { North Fork Hughes } \\
\text { River }\end{array}$ & $\begin{array}{l}07 / 08 \\
08 / 06 \\
\end{array}$ & 28.5 & 7.45 & 315 & 4.57 & 74 \\
\hline Mud River & $\begin{array}{l}07 / 28 \\
08 / 10 \\
\end{array}$ & 27.8 & 7.61 & 457 & 4.03 & 82 \\
\hline Twelvepole Creek & $\begin{array}{l}07 / 28 \\
08 / 10\end{array}$ & 28.1 & 7.67 & 465 & 5.17 & 75.5 \\
\hline Laurel Creek & $\begin{array}{l}06 / 26 \\
08 / 14\end{array}$ & 23 & 7.42 & 273 & 5.3 & 35 \\
\hline Glade Creek & $\begin{array}{l}06 / 24 \\
08 / 14\end{array}$ & 23.7 & 8.17 & 355 & 8.33 & 13.5 \\
\hline Cedar Creek & $\begin{array}{l}08 / 17 \\
08 / 19\end{array}$ & 24.1 & 7.51 & 292.5 & 5.46 & 60 \\
\hline Holly River & $\begin{array}{l}08 / 19 \\
08 / 29 \\
\end{array}$ & 25.4 & 7.77 & 121.3 & 6.8 & 45 \\
\hline Little Kanawha River & $\begin{array}{l}05 / 27 \\
08 / 17\end{array}$ & 25.7 & 8.08 & 263.9 & 6.32 & 81 \\
\hline Cherry River & $\begin{array}{l}07 / 07 \\
08 / 21 \\
\end{array}$ & 24.4 & 7.59 & 231 & 5.63 & 39 \\
\hline Cranberry River & $\begin{array}{l}07 / 01 \\
08 / 21\end{array}$ & 22.3 & 7.38 & 218.8 & 5.92 & 29.5 \\
\hline Buffalo Creek & $\begin{array}{l}05 / 01 \\
08 / 28 \\
\end{array}$ & 26.4 & 8.1 & 417 & 5.97 & 50.5 \\
\hline Wheeling Creek & $\begin{array}{l}05 / 27 \\
07 / 29 \\
\end{array}$ & 27.3 & 7.53 & 371 & 6.04 & 34 \\
\hline Gauley River & $\begin{array}{l}07 / 01 \\
09 / 04 \\
\end{array}$ & 18.2 & 7.66 & 237.6 & 6.7 & 64 \\
\hline Back Fork of Elk River & $\begin{array}{l}07 / 07 \\
09 / 04\end{array}$ & 18.4 & 7.63 & 216.2 & 6.32 & 49 \\
\hline
\end{tabular}

Table 1 - In-stream habitat characteristics for each study site including water temperature in degrees Celsius $\left({ }^{\circ} \mathrm{C}\right), \mathrm{pH}$, conductivity in microsiemens $(\mu \mathrm{S})$, dissolved oxygen in parts per million (ppm), and average number of crayfish encountered under the first 100 rocks surveyed at each site. 


\begin{tabular}{|l|c|c|c|c|}
\hline \multicolumn{1}{|c|}{ Site } & \% Sand & \% Gravel & \% Cobble & \% Boulder \\
\hline Fish Creek & 2 & 39 & 39 & 20 \\
\hline E. Fork Greenbrier & 0 & 16 & 60 & 24 \\
\hline W. Fork Greenbrier & 1 & 17 & 63 & 19 \\
\hline Williams River & 0 & 12 & 54 & 34 \\
\hline Middle Island Creek & 4 & 53 & 32 & 11 \\
\hline Shavers Fork of Cheat River & 9 & 18 & 47 & 26 \\
\hline Second Creek & 4 & 11 & 48 & 37 \\
\hline Greenbrier River & 0 & 32 & 48 & 20 \\
\hline South Fork Hughes River & 31 & 39 & 19 & 11 \\
\hline North Fork Hughes River & 23 & 51 & 11 & 15 \\
\hline Mud River & 90 & 2 & 4 & 4 \\
\hline Twelvepole Creek & 59 & 31 & 4 & 6 \\
\hline Laurel Creek & 10 & 33 & 43 & 76 \\
\hline Glade Creek & 3 & 3 & 18 & 2 \\
\hline Cedar Creek & 17 & 57 & 24 & 33 \\
\hline Holly River & 3 & 38 & 26 & 19 \\
\hline Little Kanawha River & 2 & 45 & 34 & 56 \\
\hline Cherry River & 10 & 9 & 25 & 35 \\
\hline Cranberry River & 12 & 11 & 42 & 11 \\
\hline Buffalo Creek & 2 & 41 & 46 & 20 \\
\hline Wheeling Creek & 2 & 48 & 30 & 29 \\
\hline Gauley River & 4 & 20 & 50 & 57 \\
\hline Back Fork of Elk River & 17 & 22 & \\
\hline Table $-W o l m a n ~$ & 31 & 5 & \\
\hline
\end{tabular}

Table 2 - Wolman pebble count data for substrate composition at each study site. 


\begin{tabular}{|l|c|c|c|c|c|}
\hline \multicolumn{1}{|c|}{ Site } & $\begin{array}{c}\text { Area } \\
\left(\mathbf{k m}^{\mathbf{2}} \mathbf{)}\right.\end{array}$ & $\begin{array}{c}\text { Elevation } \\
\text { (feet) }\end{array}$ & $\begin{array}{c}\text { \% Open } \\
\text { Water }\end{array}$ & $\begin{array}{c}\text { \% Total } \\
\text { Development }\end{array}$ & $\begin{array}{c}\text { \% Total } \\
\text { Forest }\end{array}$ \\
\hline Fish Creek & 227.72 & 739 & 0.20 & 6.05 & 86.45 \\
\hline E. Fork Greenbrier & 32.63 & 2827 & 0.01 & 2.80 & 94.82 \\
\hline W. Fork Greenbrier & 49.93 & 2843 & 0.12 & 2.51 & 96.86 \\
\hline Williams River & 71.08 & 2471 & 0.08 & 2.24 & 95.85 \\
\hline Middle Island Creek & 445.28 & 642 & 0.17 & 4.19 & 88.72 \\
\hline Shavers Fork of Cheat River & 151.44 & 2138 & 0.78 & 2.56 & 95.74 \\
\hline Second Creek & 45.81 & 2073 & 0.48 & 4.57 & 70.86 \\
\hline Greenbrier River & 344.79 & 2831 & 0.38 & 3.61 & 90.76 \\
\hline South Fork Hughes River & 170.50 & 692 & 0.12 & 4.71 & 86.08 \\
\hline North Fork Hughes River & 93.30 & 733 & 0.10 & 5.80 & 80.31 \\
\hline Mud River & 250.40 & 652 & 0.16 & 5.18 & 82.15 \\
\hline Twelvepole Creek & 312.34 & 623 & 0.60 & 4.63 & 83.48 \\
\hline Laurel Creek & 20.84 & 2661 & 0.02 & 1.18 & 87.82 \\
\hline Glade Creek & 63.33 & 1217 & 1.29 & 3.71 & 66.96 \\
\hline Cedar Creek & 34.22 & 837 & 0.05 & 3.96 & 91.60 \\
\hline Holly River & 54.71 & 1020 & 0.01 & 3.44 & 95.26 \\
\hline Little Kanawha River & 98.03 & 1059 & 0.02 & 5.09 & 90.49 \\
\hline Cherry River & 130.65 & 2072 & 0.11 & 2.41 & 91.64 \\
\hline Cranberry River & 71.14 & 2331 & 0.02 & 2.18 & 97.74 \\
\hline Buffalo Creek & 112.53 & 847 & 0.14 & 6.69 & 55.78 \\
\hline Wheeling Creek & 201.23 & 772 & 0.33 & 5.73 & 75.21 \\
\hline Gauley River & 49.34 & 2317 & 0.05 & 3.14 & 95.97 \\
\hline Back Fork of Elk River & 65.80 & 1533 & 0.05 & 2.39 & 96.97 \\
\hline Table 3 Landscape & & & & & \\
\hline
\end{tabular}

Table 3 - Landscape level characteristics of study sites with total area of the study site watershed and

upstream watersheds in square kilometers $\left(\mathrm{km}^{2}\right)$, elevation of the study site in feet, and percent open water, percent total development, and percent total forest within the study site watershed and upstream watersheds. 


\begin{tabular}{|c|c|c|}
\hline Variable & Test Statistic & P-value \\
\hline Water Temperature $\left({ }^{\circ} \mathrm{C}\right)$ & 83.0 & 0.310 \\
\hline Conductivity $(\mu \mathrm{S})$ & 85.0 & 0.260 \\
\hline $\mathrm{pH}$ & 79.0 & 0.442 \\
\hline Dissolved Oxygen $(\mathrm{ppm})$ & 27.5 & 0.019 \\
\hline Crayfish & 92.0 & 0.118 \\
\hline Sand \% & 92.5 & 0.106 \\
\hline Gravel \% & 70.0 & 0.828 \\
\hline Fine Substrate \% & 83.5 & 0.294 \\
\hline Cobble \% & 45.5 & 0.218 \\
\hline Boulder \% & 54.5 & 0.498 \\
\hline Coarse Substrate \% & 46.0 & 0.229 \\
\hline Elevation $(\mathrm{m})$ & 51.0 & 0.379 \\
\hline Area (km $\left.{ }^{2}\right)$ & 72.0 & 0.740 \\
\hline Total Forest \% & 30.0 & 0.027 \\
\hline Total Open Development \% & 87.0 & 0.212 \\
\hline
\end{tabular}

Table 4 - Mann-Whitney test results of statistical comparisons of in-stream and landscape environmental variables at sites where hellbender presence was documented as opposed to sites where hellbenders were not observed. 


\section{APPENDIX 4}

Capture Per Unit Effort Abundance Data from 2010 Surveys and Associated Analyses

\begin{tabular}{|c|c|c|c|}
\hline Site & $\begin{array}{l}\text { Hellbender } \\
\text { Presence }\end{array}$ & $\begin{array}{l}\text { Hellbender Captures Per } \\
\text { Person Hour }\end{array}$ & Abundance Category \\
\hline Fish Creek & No & 0.00 & $\mathrm{~N}$ \\
\hline E. Fork Greenbrier & Yes & 0.641 & $A$ \\
\hline W. Fork Greenbrier & Yes & 0.607 & A \\
\hline Williams River & Yes & 0.110 & $\mathrm{~L}$ \\
\hline Middle Island Creek & Yes & 0.164 & $\bar{L}$ \\
\hline $\begin{array}{l}\text { Shavers Fork of Cheat } \\
\text { River }\end{array}$ & Yes & 0.769 & $A$ \\
\hline Second Creek & No & 0.00 & $\mathrm{~N}$ \\
\hline Greenbrier River & No & 0.00 & $\mathrm{~N}$ \\
\hline South Fork Hughes River & Yes & 0.194 & $\mathrm{~L}$ \\
\hline North Fork Hughes River & No & 0.00 & $\mathrm{~N}$ \\
\hline Mud River & No & 0.00 & $\mathrm{~N}$ \\
\hline Twelvepole Creek & No & 0.00 & $\mathrm{~N}$ \\
\hline Laurel Creek & No & 0.00 & $\mathrm{~N}$ \\
\hline Glade Creek & No & 0.00 & $\mathrm{~N}$ \\
\hline Cedar Creek & No & 0.00 & $\mathrm{~N}$ \\
\hline Holly River & Yes & 0.667 & A \\
\hline Little Kanawha River & No & 0.000 & $\mathrm{~N}$ \\
\hline Cherry River & No & 0.000 & $\mathrm{~N}$ \\
\hline Cranberry River & Yes & 0.127 & $\mathrm{~L}$ \\
\hline Buffalo Creek & Yes & 1.609 & $A$ \\
\hline Wheeling Creek & Yes & 0.677 & A \\
\hline Gauley River & Yes & 0.085 & $\mathrm{~L}$ \\
\hline Back Fork of Elk River & Yes & 0.414 & $A$ \\
\hline
\end{tabular}

Table 1 - Hellbender distribution and density table listing survey sites where hellbenders were found,

the number of individuals captured at each site per person hour of searching, and the abundance

category assigned to sites for ordination analyses. Sites were considered to have abundant (A)

populations if captures per person hour were $\geq 0.4$ captures per hour, to have less abundant $(L)$

populations if captures per person hour were $<0.4$ captures per hour but $>0.00$ captures per hour, and

to be not present $(\mathrm{N})$ if no captures were made at the site. 


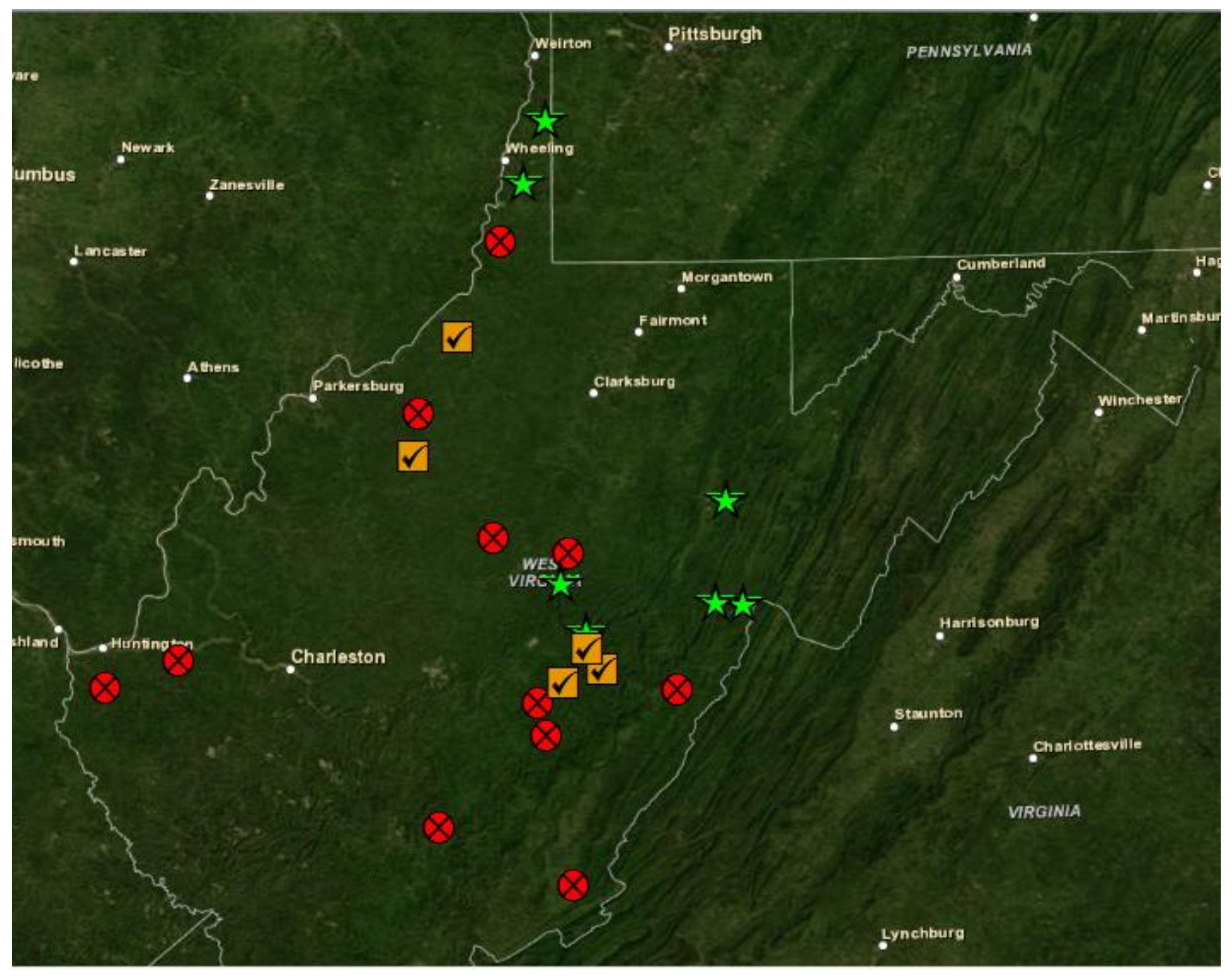

Figure 1 - Map of survey sites: sites of abundance are denoted by green stars; sites of less abundant populations are denoted by orange check boxes; and sites where hellbenders were not detected are denoted by red $\mathrm{X}$ circles. 


\begin{tabular}{|c|c|c|c|}
\hline Variable & $\begin{array}{l}\text { Abundant Presence ( } \geq 0.4 \\
\text { captures/hour) }\end{array}$ & $\begin{array}{l}\text { Less Abundant } \\
\text { Presence }(<0.4 \\
\text { captures/hour) }\end{array}$ & No Presence Detected \\
\hline DO & $\mathbf{6 . 3 3 1}$ & $\mathbf{6 . 0 8 6}$ & 7.818 \\
\hline pH & 7.741 & 7.636 & 346.4 \\
\hline Conductivity & 323.8 & 251.2 & 26.30 \\
\hline Temperature & 24.81 & 24.68 & 60.64 \\
\hline Crayfish & 43.14 & 56.2 & $\mathbf{2 0}$ \\
\hline Sand & $\mathbf{3 . 1 4 3}$ & $\mathbf{9 . 8}$ & 7.364 \\
\hline Gravel & 5.857 & 8.8 & $\mathbf{4 2 . 3 6}$ \\
\hline Cobble & $\mathbf{5 8 . 7 1}$ & $\mathbf{5 0 . 2}$ & $\mathbf{3 0 . 2 7}$ \\
\hline Boulder & $\mathbf{3 3 . 1 4}$ & $\mathbf{3 1 . 2}$ & \\
\hline
\end{tabular}

Table 2 - Average in-stream environmental variables at sites of abundant, less abundant, and no presence. 


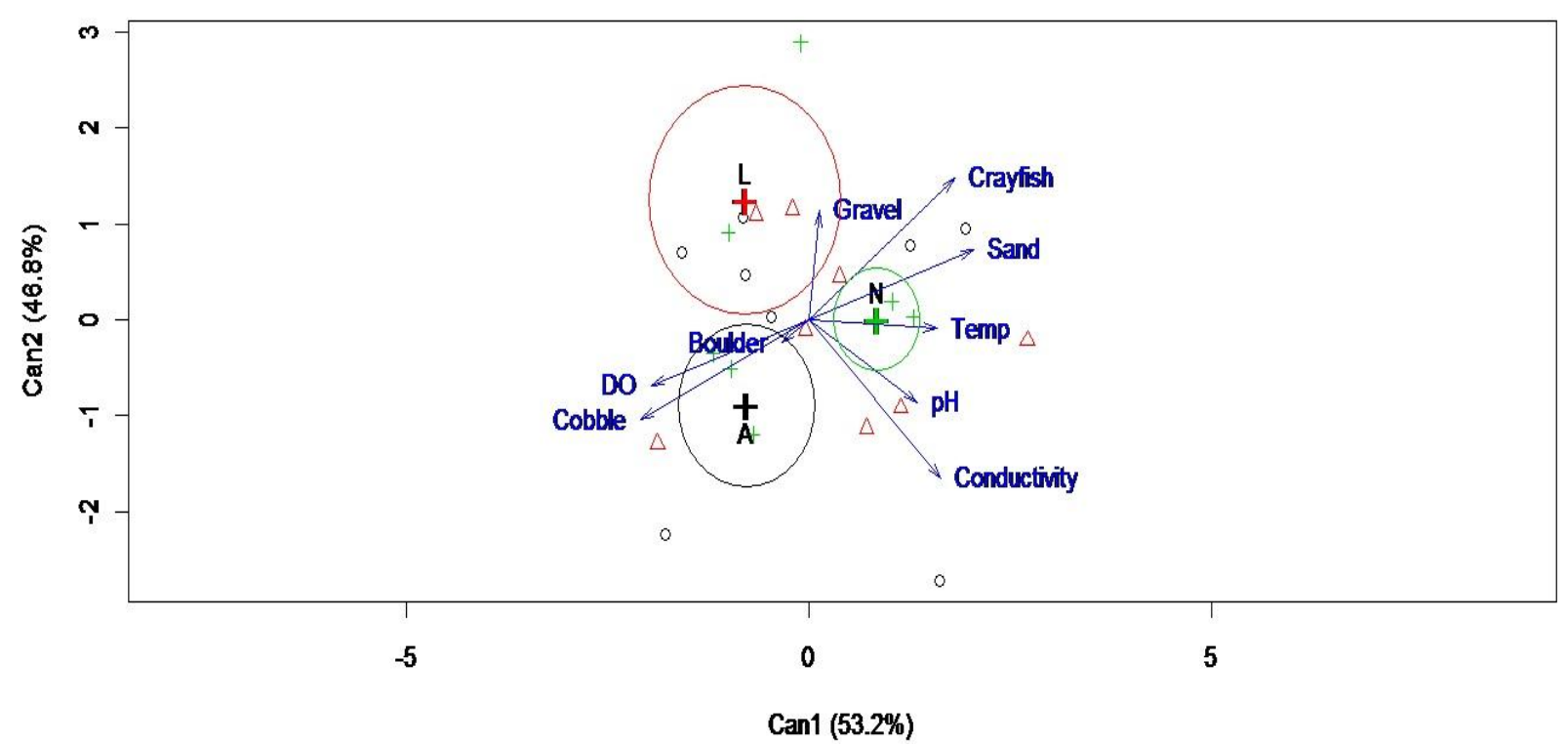

Figure 2 - Canonical discriminant analysis biplot of in-stream environmental variables at each site as a function of abundance ( $\geq 0.4$ captures per person hour) $-A$; less abundance $(<0.4$ captures per person hour) $-L$; and no captures $-N$. Sites of abundance $(A)$ are associated most strongly with increasing percent cobble and boulder substrate as well as dissolved oxygen, while sites of less abundance are associated with increasing fine substrate in the form of percent gravel. Sites of no captures are associated most strongly with increasing water temperatures and percent sand substrate. 


\begin{tabular}{|c|c|c|c|}
\hline Canonical Variable & Adjusted $\mathrm{R}^{2}$ & $\operatorname{Pr}(>\mathrm{F})$ & a-value \\
\hline CV1 & 0.43147 & 0.0003248 & 0.00 \\
\hline CV2 & 0.40009 & 0.0015841 & 0.00 \\
\hline
\end{tabular}

\begin{tabular}{|c|c|c|}
\hline & CV1 & CV2 \\
\hline DO & -0.4906 & - \\
\hline Temperature & - & - \\
\hline Conductivity & 0.4117 & -0.4130 \\
\hline pH & - & - \\
\hline Crayfish & 0.4542 & - \\
\hline Sand & 0.5122 & - \\
\hline Gravel & - & - \\
\hline Cobble & -0.5223 & - \\
\hline Boulder & - & - \\
\hline
\end{tabular}

Table 3 - Table of eigenvectors $(\geq|0.4|)$ associated with canonical discriminant analysis of in-stream environmental variables as a function of abundance ( $\geq 0.4$ captures per person hour) $-A$; less abundance $(<0.4$ captures per person hour $)-L$; and no captures $-N$. Based on eigenvector values, percent cobble and dissolved oxygen concentration are the greatest in-stream environmental variables associated with sites of abundance captures per hour during this survey. 


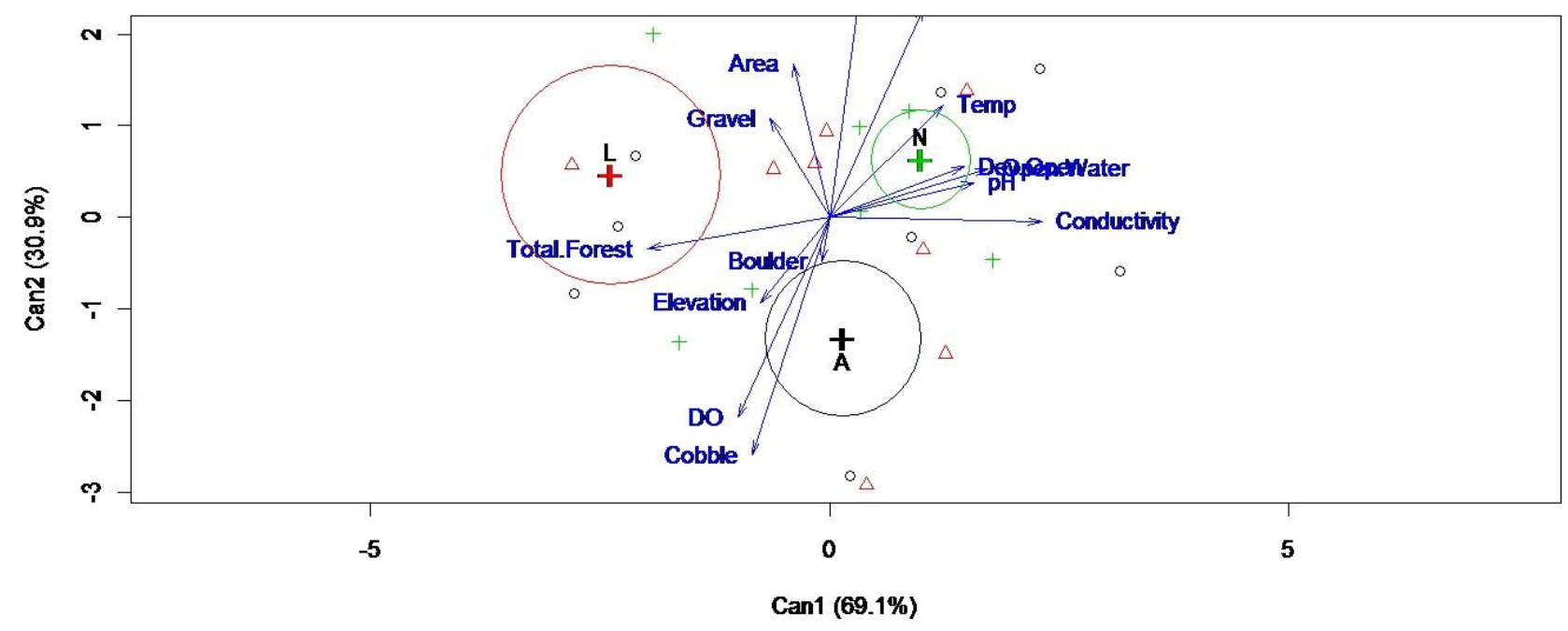

Figure 3-Canonical discriminant analysis biplot of in-stream and landscape variables at each site as a function of abundance ( $\geq 0.4$ captures per person hour) $-A$; less abundance $(<0.4$ captures per person hour) $-L$; and no captures $-N$. Sites of abundance $(A)$ are associated most strongly with increasing percent cobble and boulder substrate as well as dissolved oxygen concentration and elevation, while sites of presence as a total are associated with increasing percent total forest within the watershed. Sites of no captures are associated most strongly with increasing water temperatures and $\mathrm{pH}$ as well as percent open water and open development within the watershed. 


\begin{tabular}{|c|c|c|c|}
\hline Canonical Variable & Adjusted $\mathbf{R}^{2}$ & $\operatorname{Pr}(>\mathrm{F})$ & $\alpha$-value \\
\hline CV1 & 0.66369 & $9.466-10^{-7}$ & 0.00 \\
\hline \multirow[t]{2}{*}{ CV2 } & 0.46826 & 0.0004442 & 0.00 \\
\hline & \multicolumn{2}{|r|}{ CV1 } & CV2 \\
\hline DO & \multicolumn{2}{|r|}{-} & -0.4367 \\
\hline Elevation & \multicolumn{2}{|r|}{-} & - \\
\hline Open Water & \multicolumn{2}{|r|}{-} & - \\
\hline Open Development & \multicolumn{2}{|r|}{-} & - \\
\hline Total Forest & \multicolumn{2}{|r|}{-} & - \\
\hline Temperature & \multicolumn{2}{|r|}{-} & - \\
\hline Conductivity & \multicolumn{2}{|r|}{0.4615} & - \\
\hline $\mathrm{pH}$ & \multicolumn{2}{|r|}{-} & - \\
\hline Crayfish & \multicolumn{2}{|r|}{-} & - \\
\hline Sand & \multicolumn{2}{|r|}{-} & 0.5471 \\
\hline Gravel & \multicolumn{2}{|r|}{-} & - \\
\hline Cobble & \multicolumn{2}{|r|}{-} & -0.5189 \\
\hline Boulder & \multicolumn{2}{|r|}{-} & - \\
\hline
\end{tabular}

Table 4 - Table of eigenvectors $(\geq|0.4|)$ associated with canonical discriminant analysis of in-stream and landscape variables as a function of abundance ( $\geq 0.4$ captures per person hour $)-A$; less abundance $(<$ 0.4 captures per person hour) $-L$; and no captures $-N$. Based on eigenvector values, percent cobble and dissolved oxygen concentration are the greatest variables associated with sites of abundance captures per hour during this survey, and increased percent sand substrate is most strongly associated with sites of less abundance and no presence. 


\begin{tabular}{|c|c|c|}
\hline Environmental Variable & Test Statistic $\left(\chi^{2}\right)$ & $P$-value \\
\hline Water Temperature $\left({ }^{\circ} \mathrm{C}\right)$ & 1.1916 & 0.551 \\
\hline Conductivity $(\mu S)$ & 4.0818 & 0.130 \\
\hline $\mathrm{pH}$ & 0.9169 & 0.632 \\
\hline Dissolved Oxygen (ppm) & 6.2270 & 0.045 \\
\hline Crayfish & 3.4353 & 0.180 \\
\hline Sand \% & 3.3286 & 0.189 \\
\hline Gravel \% & 0.5095 & 0.775 \\
\hline Fine Substrate \% & 1.9582 & 0.376 \\
\hline Cobble \% & 3.1727 & 0.205 \\
\hline Boulder \% & 0.5254 & 0.769 \\
\hline Coarse Substrate \% & 2.6594 & 0.265 \\
\hline Elevation (m) & 1.1434 & 0.565 \\
\hline Area $\left(\mathrm{km}^{2}\right)$ & 0.6749 & 0.714 \\
\hline Total Forest \% & 5.1774 & 0.075 \\
\hline Total Development \% & 1.9616 & 0.375 \\
\hline
\end{tabular}

Table 5 - Kruskall-Wallis test results of statistical comparisons of in-stream and landscape environmental variables at sites as a function of hellbender capture density categories where $\geq 0.4$ captures per person hour were considered abundant; $<0.4$ captures per person hour and captures documented were considered less abundant; and no captures were considered not observed. The only significant finding in this analysis was the increased dissolved oxygen concentration at sites of hellbender abundance as opposed to sites where hellbenders were not observed. 


\section{APPENDIX 5}

Hellbender Growth as a Function of Water Temperature

\begin{tabular}{|c|c|c|c|c|c|c|c|}
\hline Transponder ID & $\begin{array}{c}\text { Treatment } \\
\text { Temperature } \\
\left({ }^{\circ} \mathrm{C}\right)\end{array}$ & $\begin{array}{l}\text { Mass (g) } \\
04 / 22 / 11\end{array}$ & $\begin{array}{l}\text { Mass (g) } \\
07 / 17 / 11\end{array}$ & $\begin{array}{c}\text { Mass } \\
\text { Change } \\
\text { (g) }\end{array}$ & $\begin{array}{c}\text { Total } \\
\text { Length } \\
(\mathrm{cm}) \\
04 / 22 / 11\end{array}$ & $\begin{array}{c}\text { Total } \\
\text { Length } \\
(\mathrm{cm}) \\
07 / 17 / 11\end{array}$ & $\begin{array}{l}\text { Total } \\
\text { Length } \\
\text { Change } \\
(\mathrm{cm})\end{array}$ \\
\hline 00-06FB-7BDE & 20 & 134.5 & 161 & 26.5 & 30.5 & 31.8 & 1.3 \\
\hline 00-06FB-7CBC & 20 & 101.5 & 125.4 & 23.9 & 26.8 & 28.9 & 2.1 \\
\hline 00-06FB-8729 & 20 & 128 & 156.5 & 28.5 & 29.2 & 32.4 & 3.2 \\
\hline 00-06FB-9977 & 20 & 128 & 147.3 & 19.3 & 29.9 & 31.1 & 1.2 \\
\hline 00-06FB-7CDD & 20 & 93 & 106.5 & 13.5 & 25.7 & 30.2 & 4.5 \\
\hline 00-06FB-A43B & 20 & 106 & 115 & 9.0 & 27.0 & 29.2 & 2.2 \\
\hline 00-06FB-9D4C & 20 & 70 & 83.6 & 13.6 & 25.4 & 27.9 & 2.5 \\
\hline 00-06FB-8D5E & 20 & 60 & 85.7 & 25.7 & 20.6 & 24.1 & 3.5 \\
\hline 00-06FB-A3D0 & 20 & 89 & 103.1 & 14.1 & 23.5 & 24.8 & 1.3 \\
\hline 00-06FB-B2B0 & 20 & 101.5 & 108 & 6.5 & 26.0 & 27.9 & 1.9 \\
\hline 00-06FB-8C36 & 20 & 111 & 147.8 & 36.8 & 28.9 & 30.5 & 1.6 \\
\hline 00-06FB-98E9 & 20 & 140 & 175.7 & 35.7 & 30.2 & 32.4 & 2.2 \\
\hline 00-06FB-9A1C & 23 & 116 & 100.5 & -15.5 & 29.8 & 31.1 & 1.3 \\
\hline 00-06FB-9A91 & 23 & 107 & 96.7 & -10.3 & 29.8 & 29.8 & 0 \\
\hline 00-06FB-8123 & 23 & 119.5 & 99.5 & -20.0 & 30.2 & 30.2 & 0 \\
\hline 00-06FB-ACA8 & 23 & 163 & 145 & -18.0 & 33.7 & 33.7 & 0 \\
\hline 00-06FB-A868 & 23 & 115 & 95.8 & -19.2 & 29.2 & 29.2 & 0 \\
\hline 00-06FB-AE03 & 23 & 116.5 & 101.2 & -15.3 & 25.7 & 25.7 & 0 \\
\hline 00-06FB-A945 & 23 & 132 & 112.5 & -19.5 & 29.9 & 29.9 & 0 \\
\hline 00-06FB-7AA5 & 23 & 140.5 & 119.3 & -21.2 & 30.8 & 30.8 & 0 \\
\hline $00-06 \mathrm{FB}-8 \mathrm{CD} 5$ & 23 & 83 & 83 & 0.0 & 25.4 & 27.3 & 1.9 \\
\hline
\end{tabular}

Table 1 - Original and final masses $(\mathrm{g})$ and total lengths $(\mathrm{cm})$ as well as the changes in each individual observed during the lab portion of this study. 


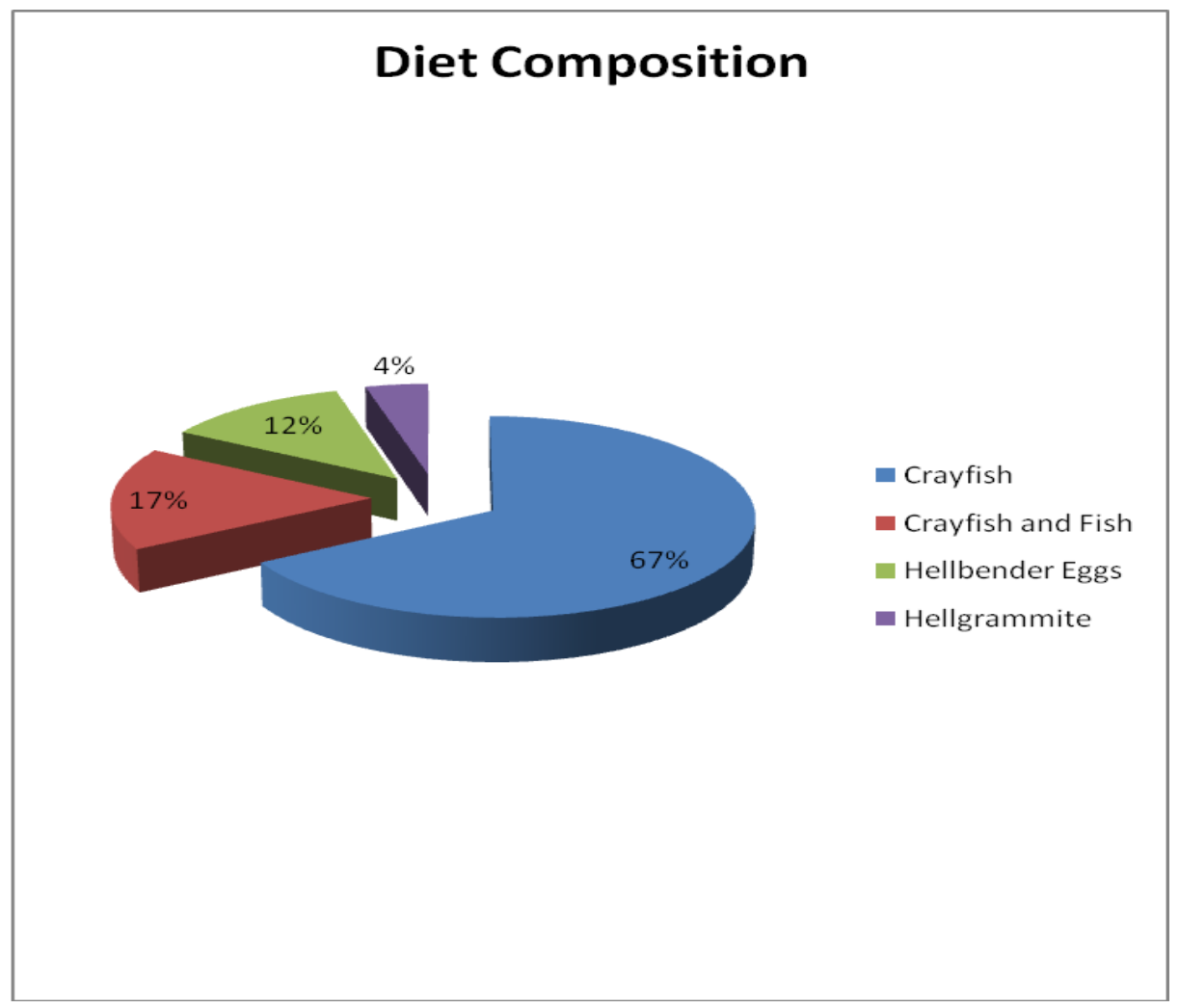

Figure 1 - Pie graph of food items consumed by percent of individuals studied in the wild that were observed to have consumed prey. 


\begin{tabular}{|c|c|c|c|c|}
\hline Date & PIT Tag ID\# & Site & Sex & Prey Items Observed \\
\hline $5 / 1 / 2010$ & 00-068D-9E7B & Buffalo Creek & Female & Crayfish and Fish \\
\hline $5 / 1 / 2010$ & 00-0676-B942 & Buffalo Creek & Female & Crayfish \\
\hline $5 / 1 / 2010$ & 00-068D-A592 & Buffalo Creek & Unknown & Crayfish \\
\hline $5 / 1 / 2010$ & 00-0676-DB52 & Buffalo Creek & Male & Crayfish and Fish \\
\hline $5 / 27 / 2010$ & 00-068D-BFBD & Wheeling Creek & Male & Crayfish and Fish \\
\hline $6 / 12 / 2010$ & 00-068D-A7F1 & W. Fork Greenbrier & Unknown & Crayfish \\
\hline $6 / 12 / 2010$ & 00-068D-AAE3 & W. Fork Greenbrier & Male & Crayfish \\
\hline $6 / 12 / 2010$ & 00-068D-AC9E & W. Fork Greenbrier & Unknown & Crayfish \\
\hline $6 / 17 / 2010$ & 00-068D-BC3E & E. Fork Greenbrier & Male & Crayfish \\
\hline $6 / 17 / 2010$ & 00-06FB-8629 & E. Fork Greenbrier & Male & Crayfish \\
\hline $6 / 17 / 2010$ & 00-06FB-A651 & E. Fork Greenbrier & Female & Traces of Crayfish \\
\hline $6 / 17 / 2010$ & 00-06FB-8D5D & Shavers Fork of Cheat River & Female & Crayfish \\
\hline $6 / 17 / 2010$ & 00-06FB-8F7C & Shavers Fork of Cheat River & Female & Crayfish \\
\hline $7 / 1 / 2010$ & 00-06FB-A4D8 & Cranberry River & Female & Crayfish \\
\hline $7 / 3 / 2010$ & 00-06FB-8C39 & Middle Island Creek & Female & Nothing \\
\hline $7 / 7 / 2010$ & 00-06FB-9DF2 & Back Fork of Elk River & Male & Crayfish \\
\hline $7 / 7 / 2010$ & 00-06FB-9CDA & Back Fork of Elk River & Male & Crayfish \\
\hline $7 / 8 / 2010$ & 00-06FB-A000 & South Fork Hughes River & Female & Nothing \\
\hline $7 / 8 / 2010$ & 00-06FB-8E76 & South Fork Hughes River & Male & Nothing \\
\hline $7 / 22 / 2010$ & 00-06FB-7F92 & E. Fork Greenbrier & Male & Nothing \\
\hline $7 / 22 / 2010$ & 00-06FB-A4DE & E. Fork Greenbrier & Female & Nothing \\
\hline $7 / 22 / 2010$ & 00-06FB-AEBC & E. Fork Greenbrier & Male & Nothing \\
\hline $7 / 22 / 2010$ & 00-06FB-A2C3 & W. Fork Greenbrier & Female & Nothing \\
\hline $7 / 22 / 2010$ & 00-06FB-8E5A & W. Fork Greenbrier & Female & Nothing \\
\hline $7 / 22 / 2010$ & 00-06FB-7926 & W. Fork Greenbrier & Male & Nothing \\
\hline $7 / 22 / 2010$ & 00-06FB-8CD8 & W. Fork Greenbrier & Female & Nothing \\
\hline $7 / 24 / 2010$ & $00-06 \mathrm{E} 7-627 \mathrm{C}$ & Williams River & Male & Nothing \\
\hline $7 / 29 / 2010$ & 00-06FB-7F10 & Wheeling Creek & Male & Nothing \\
\hline $7 / 29 / 2010$ & 00-06F1-C6D2 & Wheeling Creek & Female & Nothing \\
\hline $7 / 29 / 2010$ & 00-06FB-AA41 & Wheeling Creek & Female & Nothing \\
\hline $7 / 31 / 2010$ & 00-06E7-5DD3 & Shavers Fork of Cheat River & Male & Nothing \\
\hline $7 / 31 / 2010$ & 00-06E7-5F5A & Shavers Fork of Cheat River & Male & Nothing \\
\hline $7 / 31 / 2010$ & 00-06FB-A9C5 & Shavers Fork of Cheat River & Male & Nothing \\
\hline $7 / 31 / 2010$ & 00-06FB-8194 & Shavers Fork of Cheat River & Male & Nothing \\
\hline $8 / 19 / 2010$ & 00-06FB-8D48 & Holly River & Male & Nothing \\
\hline $8 / 19 / 2010$ & $00-06 F B-8 C C 3$ & Holly River & Male & Nothing \\
\hline $8 / 28 / 2010$ & 00-0676-С38E & Buffalo Creek & Female & $\begin{array}{l}\text { Helgrammite mouth } \\
\text { piece }\end{array}$ \\
\hline $8 / 28 / 2010$ & 00-06FB-8E74 & Buffalo Creek & Male & Nothing \\
\hline $8 / 28 / 2010$ & 00-06E7-5441 & Buffalo Creek & Female & Nothing \\
\hline $8 / 28 / 2010$ & 00-06FD-21CD & Buffalo Creek & Male & Nothing \\
\hline $8 / 28 / 2010$ & 00-06FB-806F & Buffalo Creek & Female & Nothing \\
\hline $8 / 28 / 2010$ & 00-06E7-7B0A & Buffalo Creek & Male & Nothing \\
\hline $8 / 28 / 2010$ & Too small & Buffalo Creek & Unknown & Did not try \\
\hline
\end{tabular}




\begin{tabular}{|c|c|c|c|c|}
\hline $8 / 28 / 2010$ & 00-0697-D839 & Buffalo Creek & Male & Nothing \\
\hline $8 / 28 / 2010$ & 00-06FB-AAB5 & Buffalo Creek & Male & Nothing \\
\hline $8 / 28 / 2010$ & 00-06FB-952E & Buffalo Creek & Female & Nothing \\
\hline $8 / 28 / 2010$ & 00-06FB-94C3 & Buffalo Creek & Male & Nothing \\
\hline $8 / 28 / 2010$ & 00-06E7-797A & Buffalo Creek & Male & Nothing \\
\hline $8 / 28 / 2010$ & 00-06FB-98E6 & Buffalo Creek & Female & Nothing \\
\hline $8 / 28 / 2010$ & 00-0676-C7F0 & Buffalo Creek & Female & Nothing \\
\hline $8 / 29 / 2010$ & 00-06E7-67C6 & Wheeling Creek & Female & Nothing \\
\hline $8 / 29 / 2010$ & 00-068D-9591 & Wheeling Creek & Male & Nothing \\
\hline $8 / 29 / 2010$ & 00-06FB-95B7 & Wheeling Creek & Male & Nothing \\
\hline $8 / 29 / 2010$ & 00-0697-E643 & Wheeling Creek & Male & Nothing \\
\hline $8 / 29 / 2010$ & 00-0676-D8BC & Wheeling Creek & Female & Nothing \\
\hline $8 / 29 / 2010$ & 00-068D-A097 & Wheeling Creek & Male & Nothing \\
\hline $8 / 29 / 2010$ & 00-06FB-7F0E & Wheeling Creek & Male & Nothing \\
\hline $9 / 4 / 2010$ & 00-06E7-509F & Gauley River & Female & Crayfish \\
\hline $9 / 4 / 2010$ & 00-06E7-74A5 & Gauley River & Female & Nothing \\
\hline $9 / 4 / 2010$ & $00-06 F B-8723$ & Back Fork of Elk River & Male & Hellbender Eggs \\
\hline
\end{tabular}

Table 2 - Table of prey items observed in captured wild hellbenders during this study.

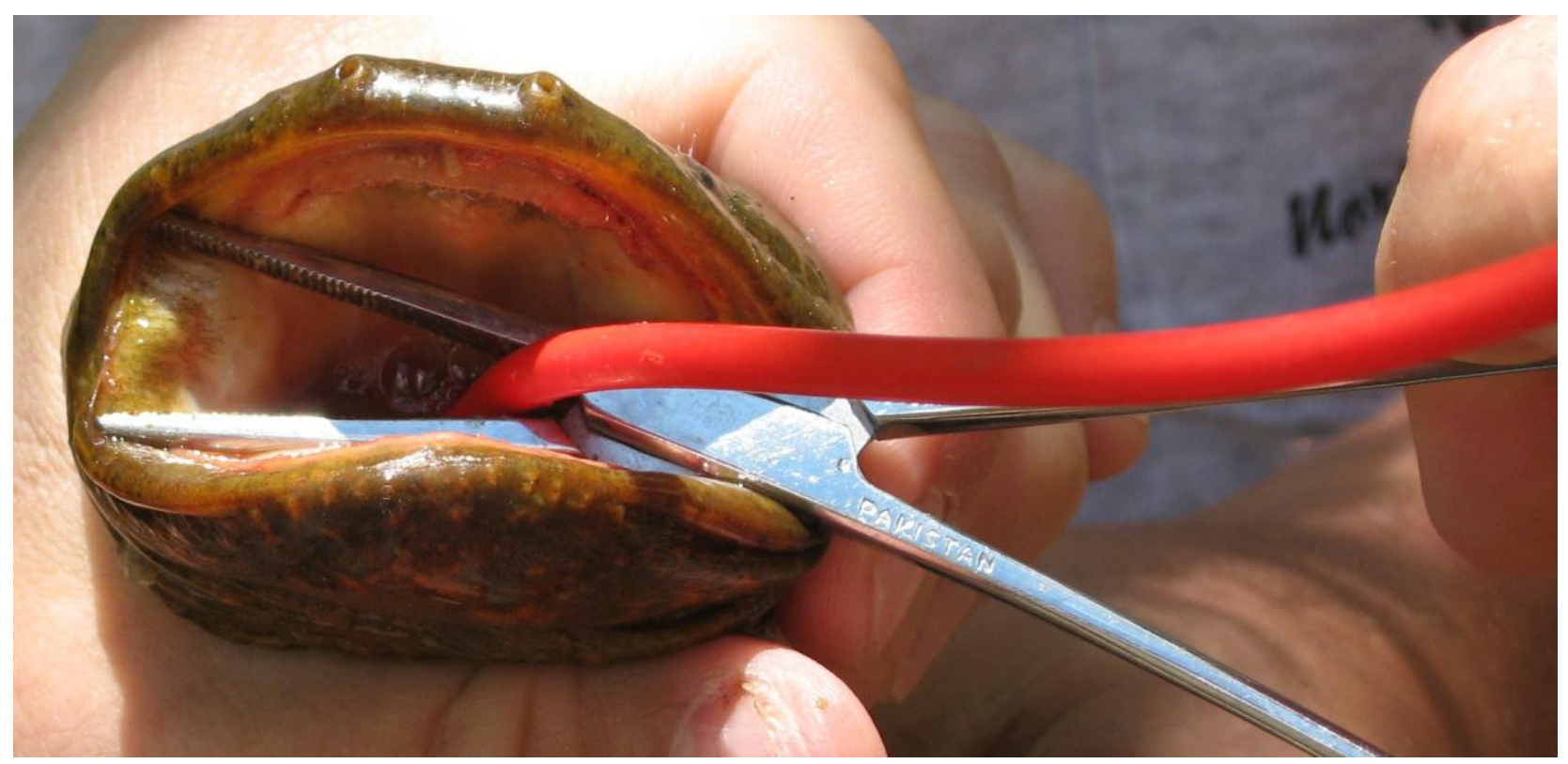

Figure 2 - Gastric lavage technique being utilized on adult hellbender. 


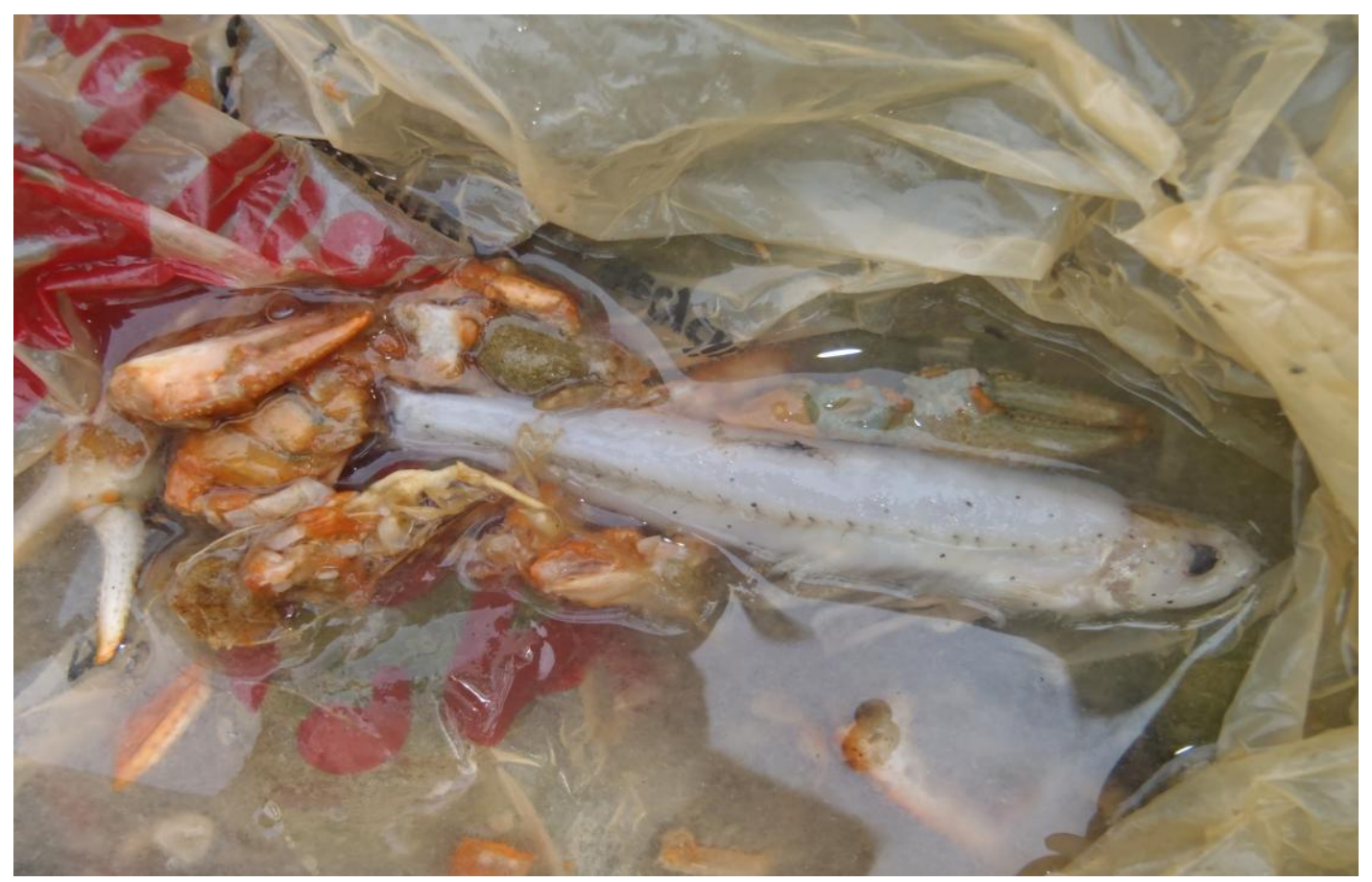

Figure 3 - Stomach contents collected from adult female hellbender ID \#: 00-068D-9E7B at Buffalo Creek on May $1^{\text {st }}, 2010$.

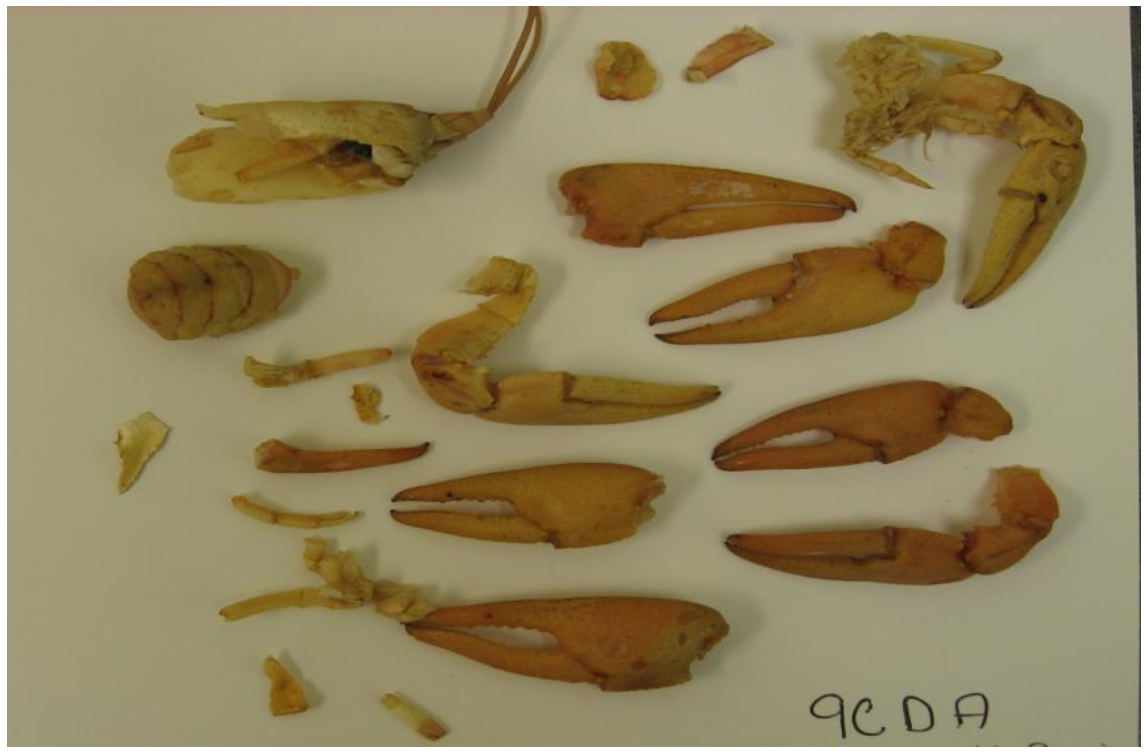

Figure 4 - Stomach contents collected from adult male ID\#: 00-06FB-9CDA from the Back Fork of the Elk River on July $7^{\text {th }}, 2010$. 


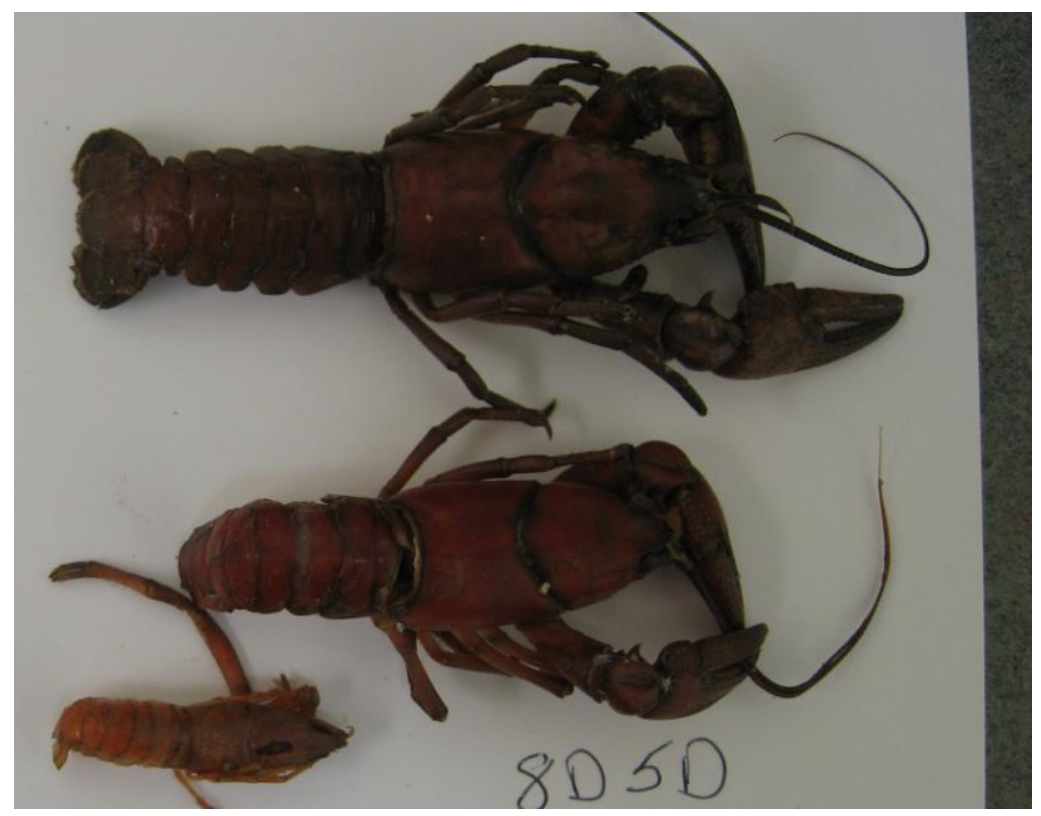

Figure 5 - Stomach contents collected from adult female ID\#: 00-06FB-8D5D from the Shavers Fork of the Cheat River on June $17^{\text {th }}, 2010$.

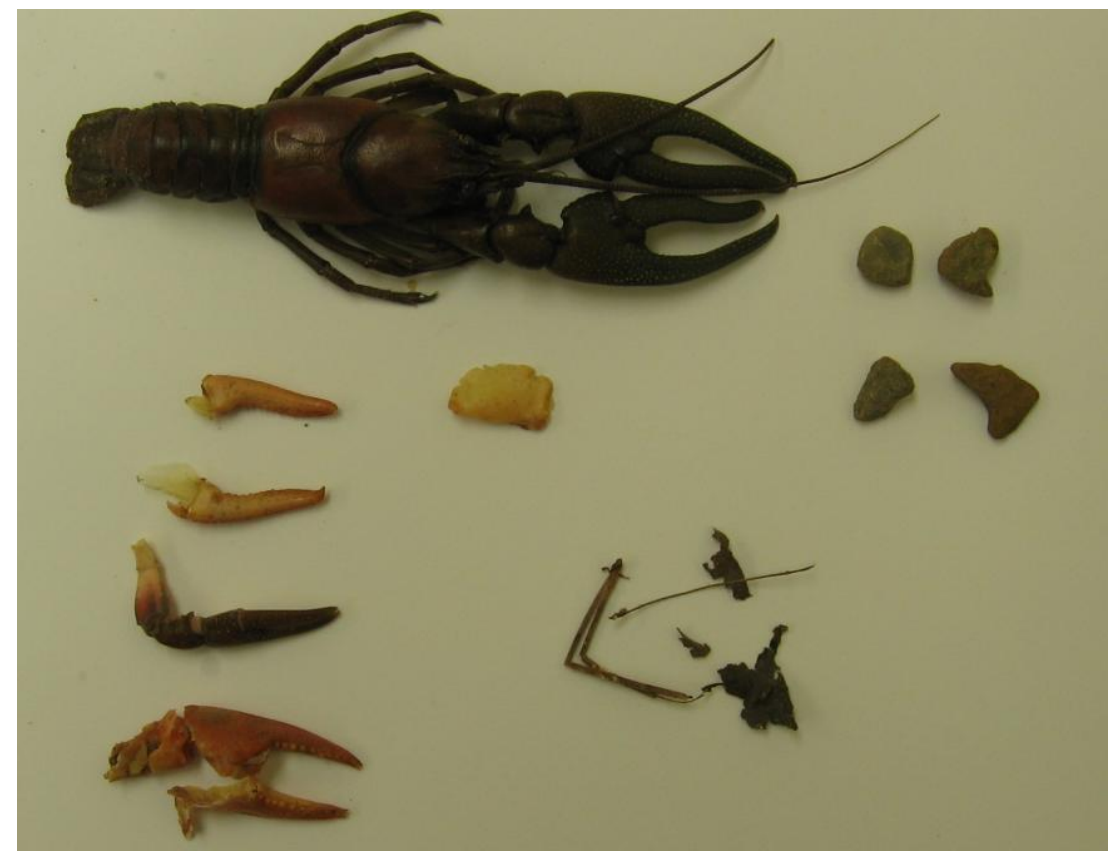

Figure 6 - Stomach contents collected from adult male ID\#: 00-068D-AAE3 from the West Fork of the Greenbrier River on June 12 $2^{\text {th }}, 2010$. 


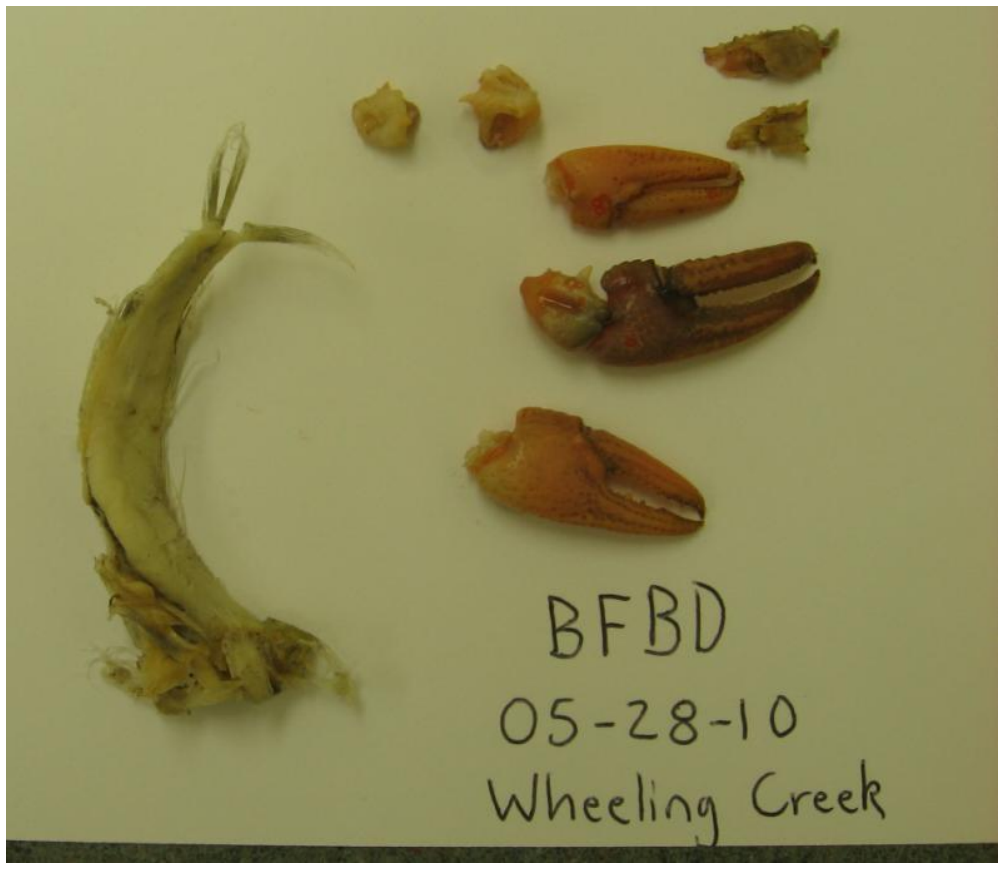

Figure 7 - Stomach contents collected from adult male ID\#: 00-068D-BFBD from the Wheeling Creek on May 28th, 2010. 


\section{APPENDIX 5}

Models and Maps Utilized for Determination of Translocation Site

\begin{tabular}{|c|c|}
\hline Site & Similarity Index \\
\hline Mean Sites of Abundance & 1.000 \\
\hline Little Kanawha River & 0.814 \\
\hline Cherry River & 0.888 \\
\hline Greenbrier River & 0.765 \\
\hline SecondCreek & 0.884 \\
\hline FishCreek & 0.678 \\
\hline North Fork Hughes River & 0.713 \\
\hline Mud River & 0.614 \\
\hline TwelvepoleCreek & 0.608 \\
\hline LaurelCreek & 0.802 \\
\hline GladeCreek & 0.835 \\
\hline Cedar Creek & 0.731 \\
\hline
\end{tabular}

Table 1-Calculated Bray-Curtis similarity index values of environmental variable values at sites of historic Hellbender occurrence where Hellbenders had not been observed during recent surveys in relation mean environmental variable values at sites of current Hellbender survey abundance ( $\geq 0.4$ captures per person hour). 


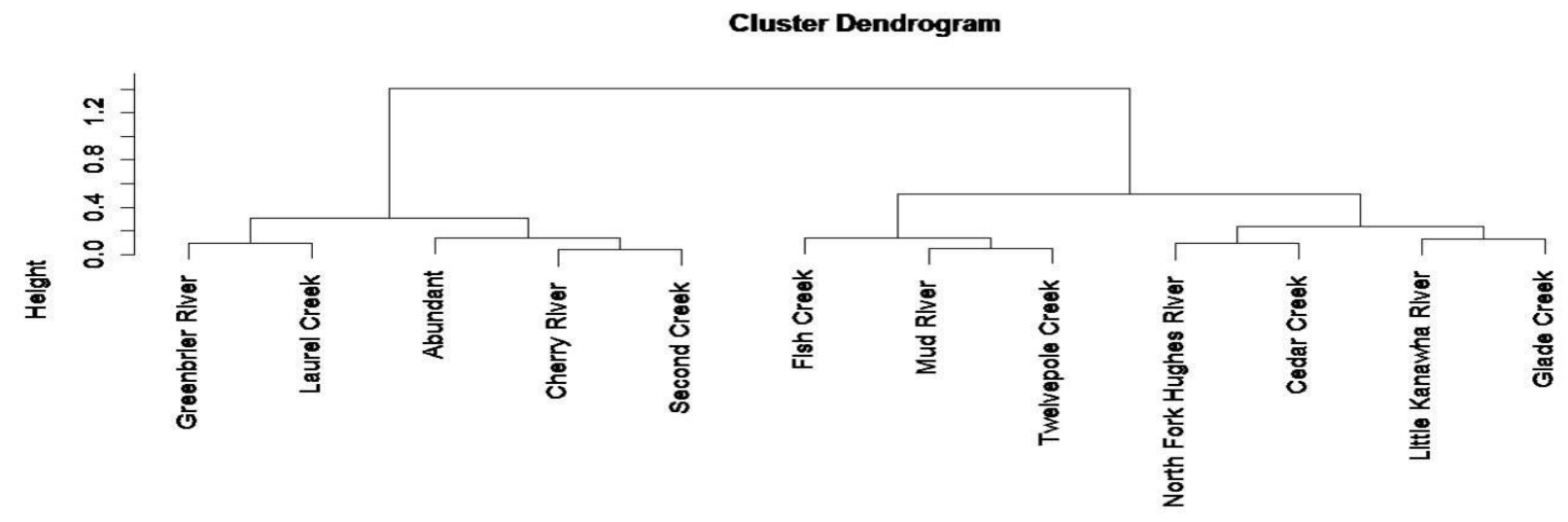

Figure 1-Cluster dendrogram with Ward linkage from Bray-Curtis similarity index showing relationship of environmental variables at sites of historic occurrence where Hellbenders were not observed recently to sites of current observed Hellbender abundance $(\geq 0.4$ Hellbender captures per person hour). 


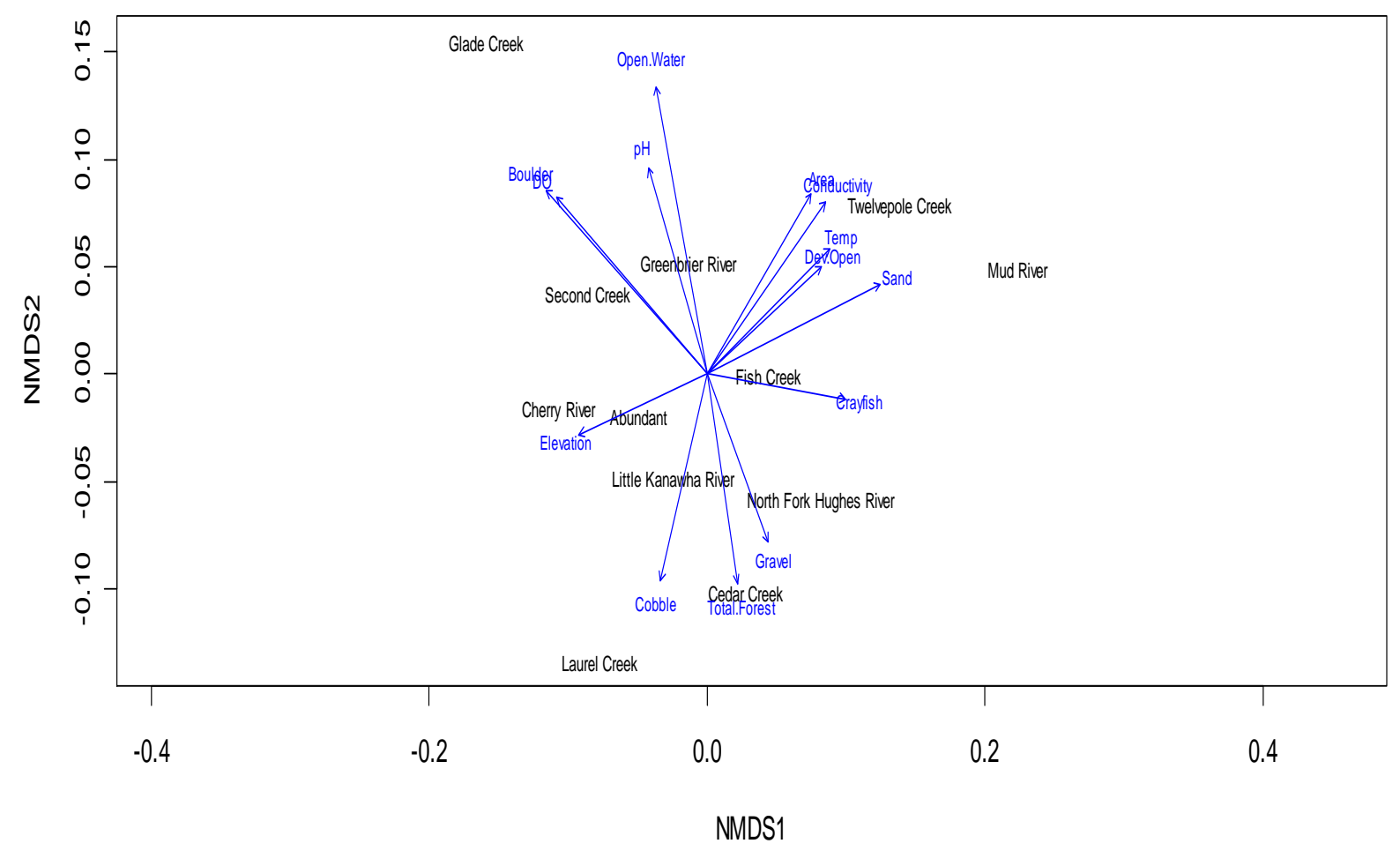

Figure 2-NMDS biplot based upon Bray-Curtis similarity index of environmental variables at sites of historic occurrence where Hellbenders were not observed recently to sites of current observed Hellbender abundance ( $\geq 0.4$ Hellbender captures per person hour). Environmental variables are fit to the model sites with elevation, dissolved oxygen, and abundance of coarse substrate (cobble and boulder) being most closely associated with the chosen translocation site and sites of abundance on NMDS axis 1 . 


\begin{tabular}{|c|c|c|c|c|c|}
\hline Variable & Description & NMDS1 & NMDS2 & $\mathrm{R}^{2}$ & $\alpha$ level \\
\hline Area & $\begin{array}{l}\text { Area of watershed at survey site } \\
\text { and contributing upstream bodies }\end{array}$ & 0.66546 & 0.74643 & 0.5465 & 0.05 \\
\hline DO & Dissolved oxygen at survey sites & -0.79590 & 0.60542 & 0.7949 & 0.00 \\
\hline Elevation & Elevation of survey sites & -0.95644 & -0.29192 & 0.3995 & - \\
\hline Open Water & $\begin{array}{l}\text { Percent open water land coverage } \\
\text { in watershed areaassociated with } \\
\text { survey sites }\end{array}$ & -0.26429 & 0.96444 & 0.8304 & 0.00 \\
\hline $\begin{array}{l}\text { Open } \\
\text { Development }\end{array}$ & $\begin{array}{l}\text { Percent open development land } \\
\text { coverage in watershed area } \\
\text { associated with survey sites }\end{array}$ & 0.85264 & 0.52251 & 0.4001 & - \\
\hline Total Forest & $\begin{array}{l}\text { Percent total forest land coverage } \\
\text { in watershed areaassociated with } \\
\text { survey sites }\end{array}$ & 0.21836 & -0.97587 & 0.4304 & - \\
\hline Temperature & Water temperature at survey sites & 0.83312 & 0.55309 & 0.4805 & 0.05 \\
\hline Conductivity & Water conductivity at survey sites & 0.72760 & 0.68600 & 0.5907 & 0.05 \\
\hline $\mathrm{pH}$ & Water pH at survey sites & -0.40218 & 0.91556 & 0.4755 & 0.05 \\
\hline Crayfish & $\begin{array}{l}\text { Number of stonesoccupied with } \\
\text { crayfish out of first } 100 \text { stones } \\
\text { lifted at survey sites }\end{array}$ & 0.99336 & -0.11509 & 0.4314 & - \\
\hline
\end{tabular}

Table 2-Relation between two dimensional nonmetric multidimensional scaling (NMDS) axes and in-stream and landscape variables at 23 survey sites of historic Hellbender occurrence in West Virginia, summer 2010. 


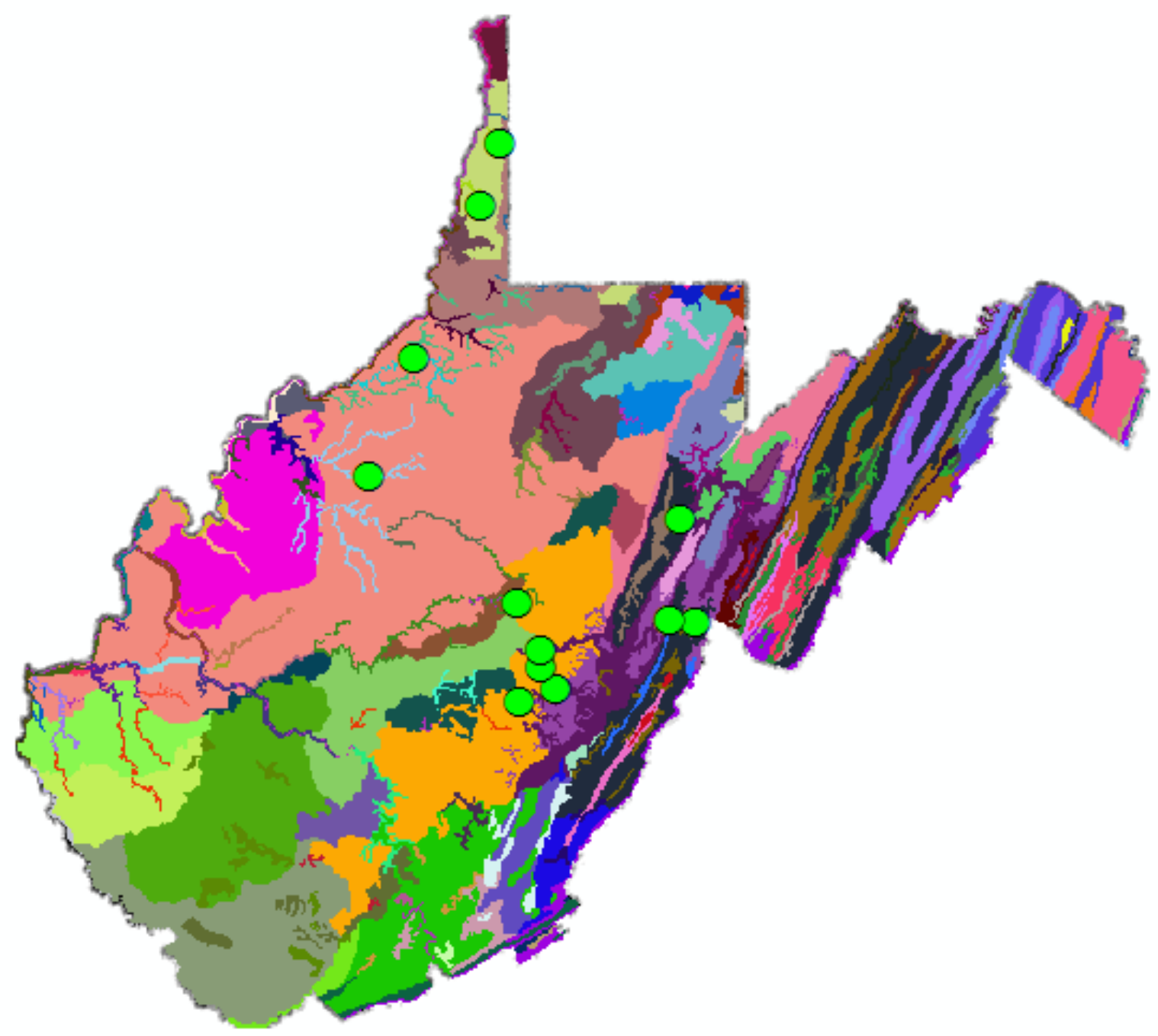

Figure 3 - Map of soil rasters utilized in MaxEnt prediction model with observed sites of hellbender presence represented as green dots. 


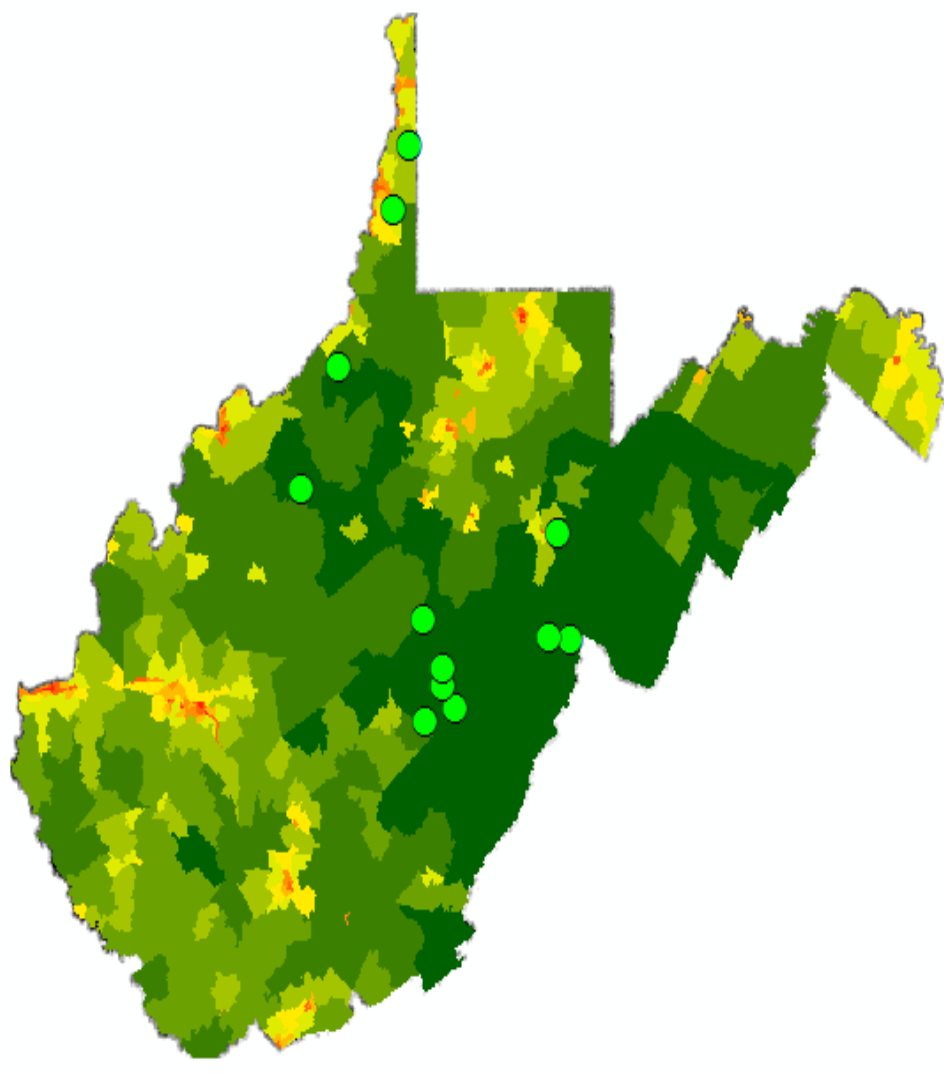

$8.314889908-22.1303997$

$22.13039971-42.20420074$

$42.20420075-73.42479706$

$73.42479707-150.8099976$

$150.8099977-288.5889893$

$288.5889894-577.3560181$

$577.3560182-1,131.030029$

$1,131.03003-2,073.139893$

$2,073.139894-4,405.669922$

$4,405.669923-9,936.629883$

Figure 4 - Map of population density rasters per square mile utilized in MaxEnt prediction model with observed sites of hellbender presence represented as green dots. 


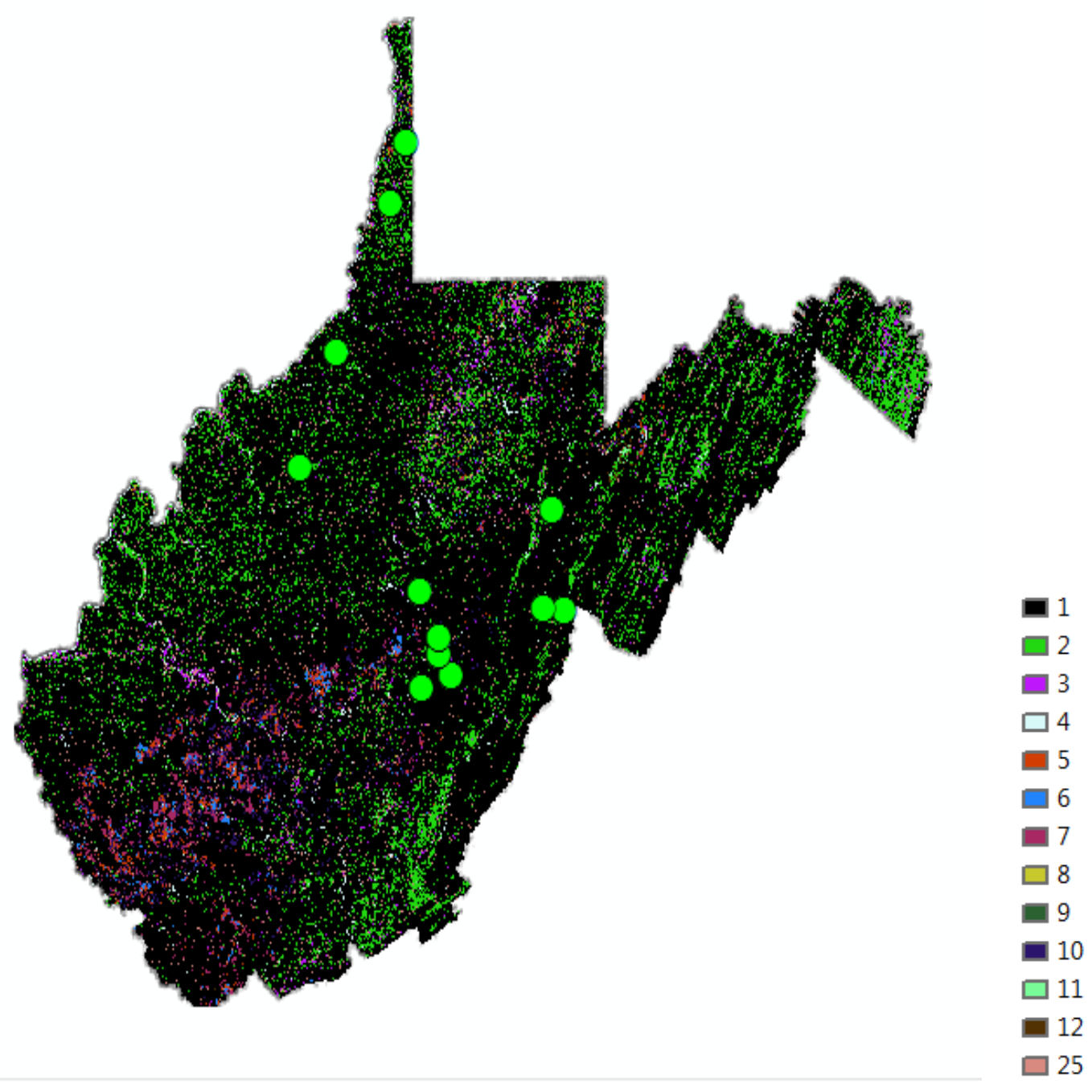

Figure 5 - Map of land cover rasters utilized in MaxEnt prediction model with observed sites of hellbender presence represented as green dots. Categorical descriptions of numeric values are:

$1=$ Forested cover; 2 = Grasslands/Pasture/Agriculture cover; 3 = Barren/Developed; $4=$ Open

Water; 5 = Mined Grassland; $6=$ Barren Mine Land; 7 = Forested SMCRA lands; $8=$ Pre-

SMCRA Grasslands; $9=$ Pre-SMCRA Barren Lands; $10=$ Pre-SMCRA Forested Lands; $11=$

Herbaceous Wetlands; 12 = Woody Wetlands; 25 = Roads. 


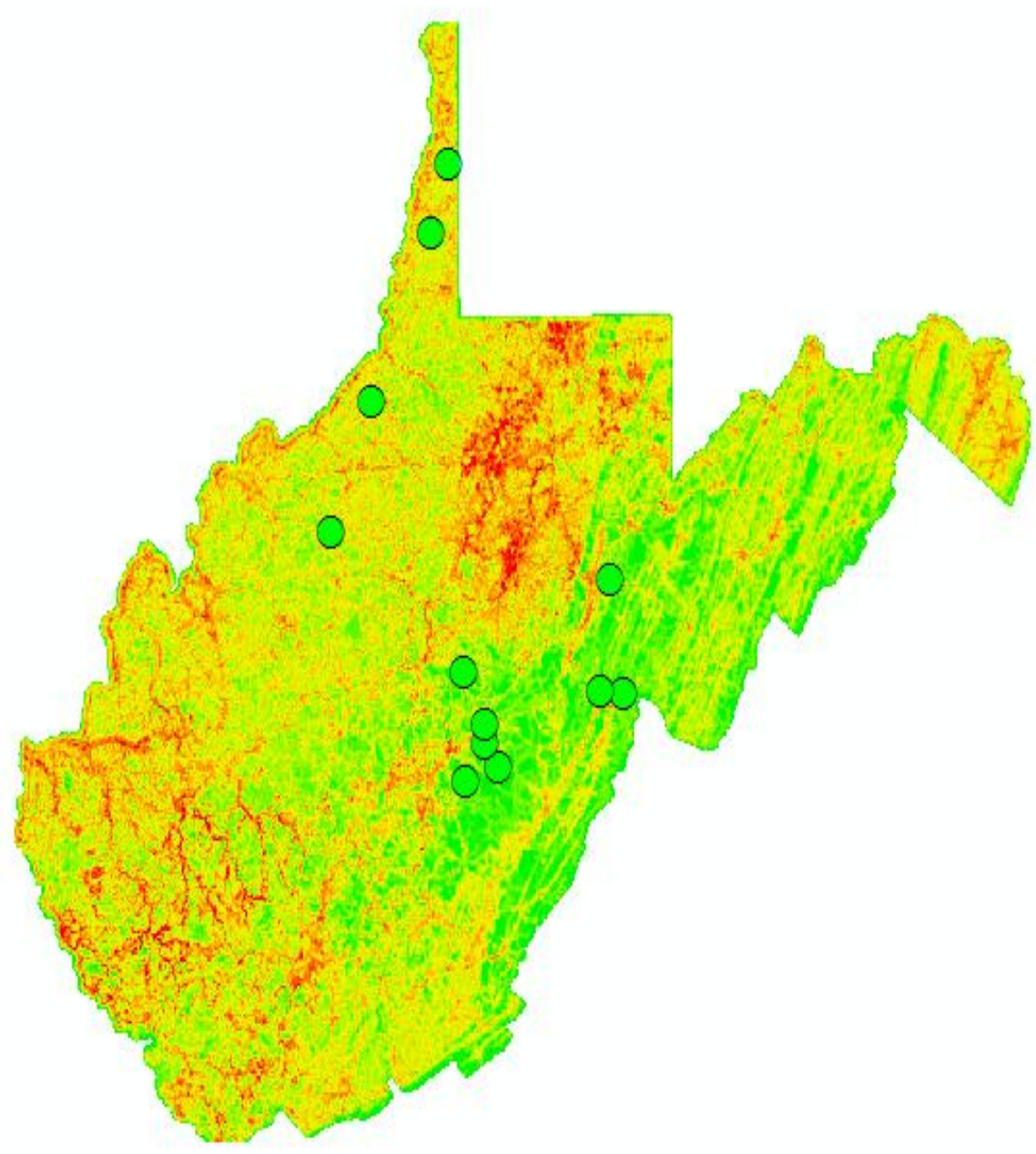

Value

High : 880

Low : 226

Figure 6 - Map of landscape integrity rasters utilized in MaxEnt prediction model with observed sites of hellbender presence represented as green dots. Values indicate landscape integrity scores based upon distances from landscape disturbances including mining and other industries, residential and urban development, transportation corridors, and agriculture. 


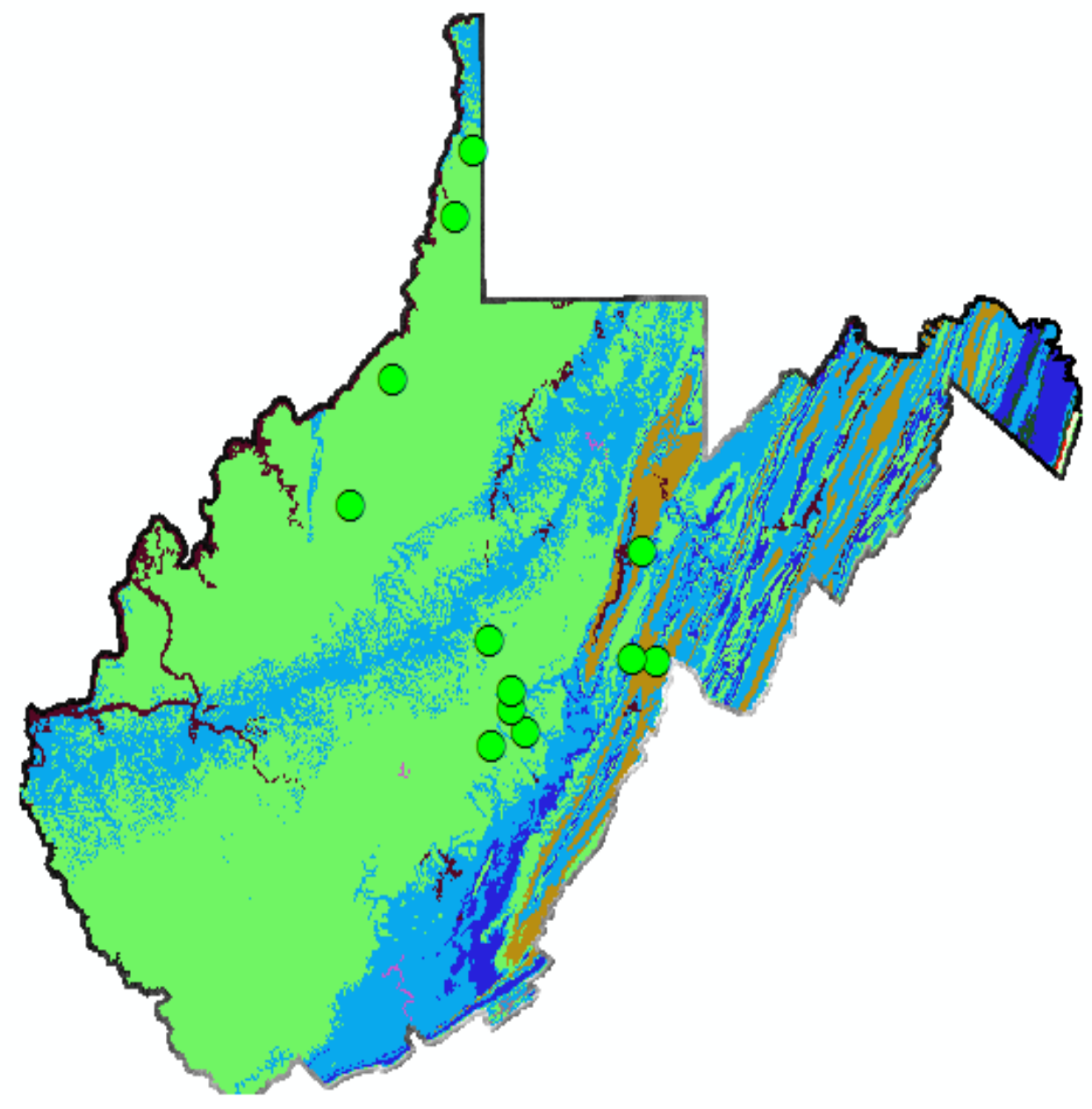

Figure 7 - Map of geology rasters removed from MaxEnt prediction model after poor performance in model with observed sites of hellbender presence represented as green dots. 


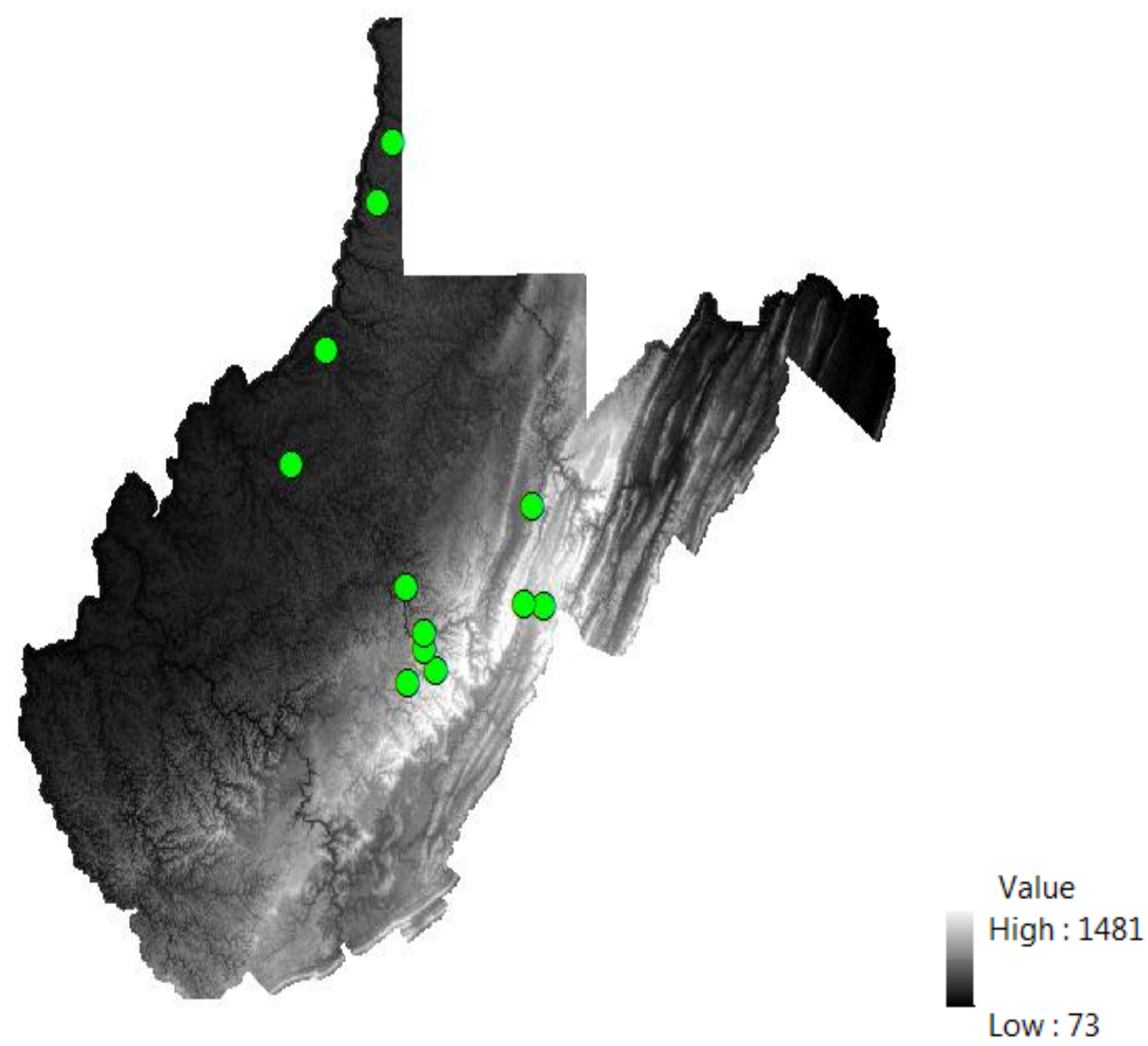

Figure 8 - Map of elevation rasters utilized in MaxEnt prediction model with observed sites of hellbender presence represented as green dots. Continuous scale of elevation in meters in legend ranges from black in low elevations to white in high elevation sites. 


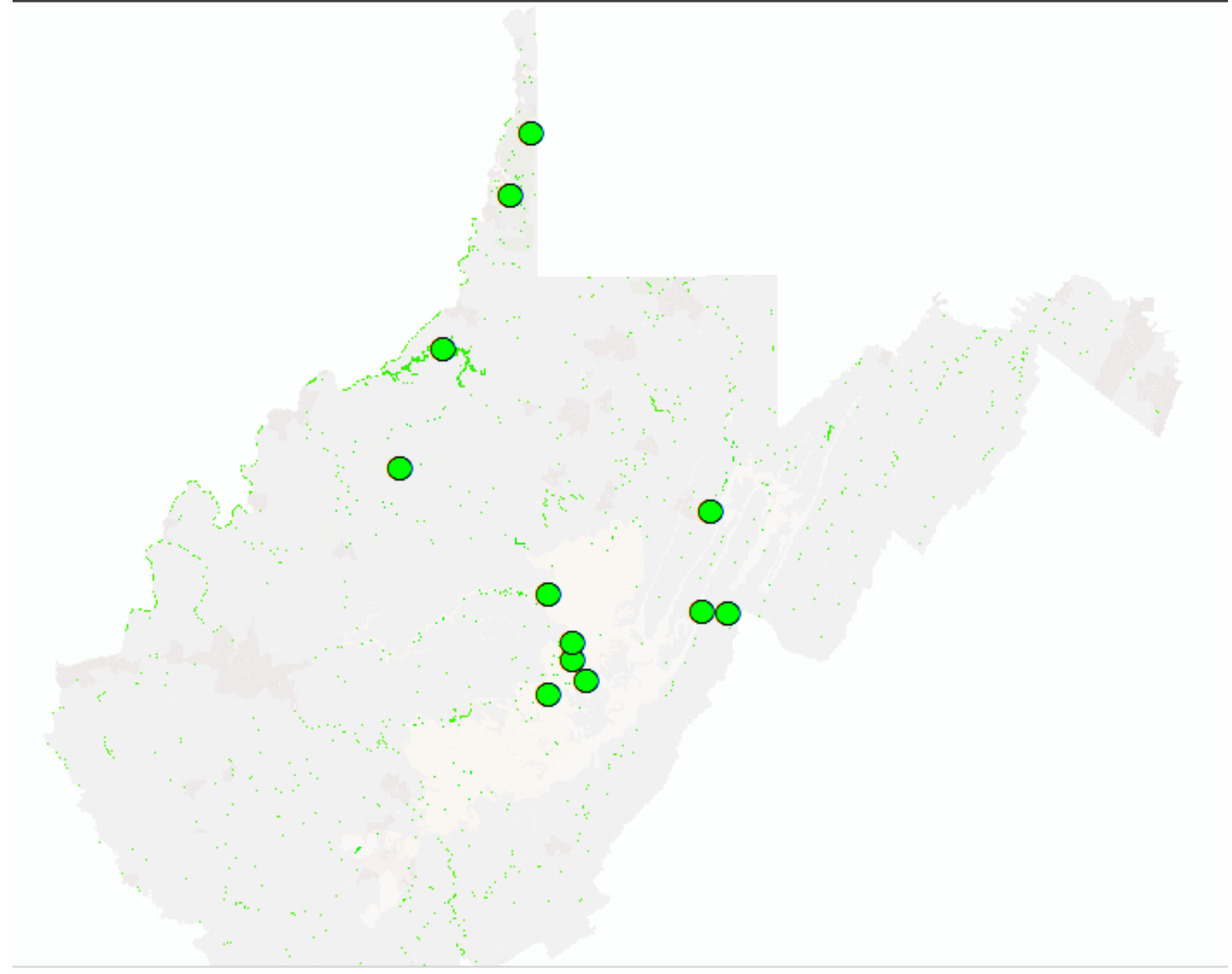

Figure 9 - Map of predicted rasters of hellbender probability greater than $73.6 \%$ are indicated by green rasters predicted in the MaxEnt prediction model with observed sites of hellbender presence represented as green dots. 


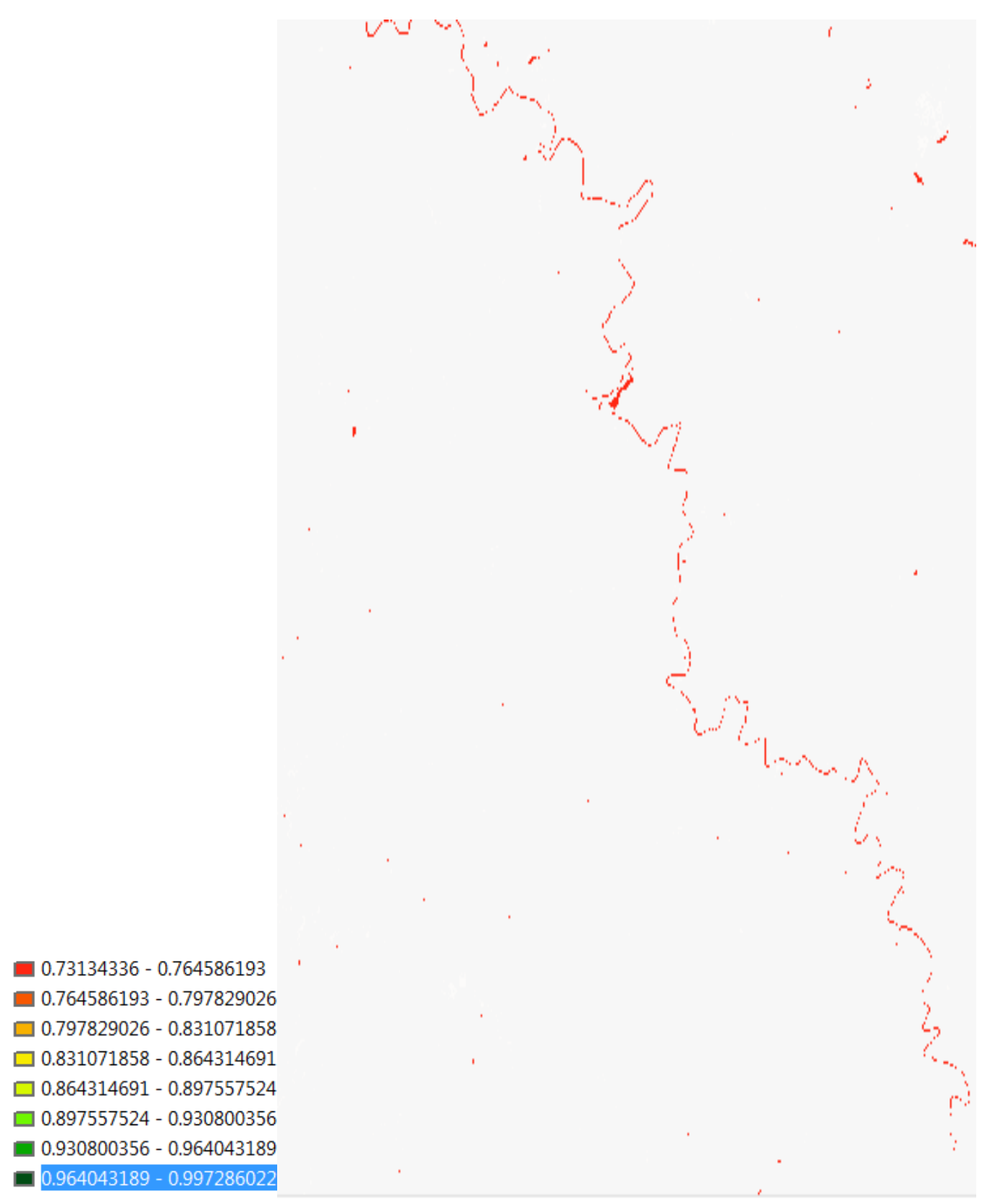

Figure 10 - Cedar Creek MaxEnt probability projection. Predicted probability of occurrence coincides with scale in legend. Areas with no color have predicted probabilities less than $73.1 \%$. 


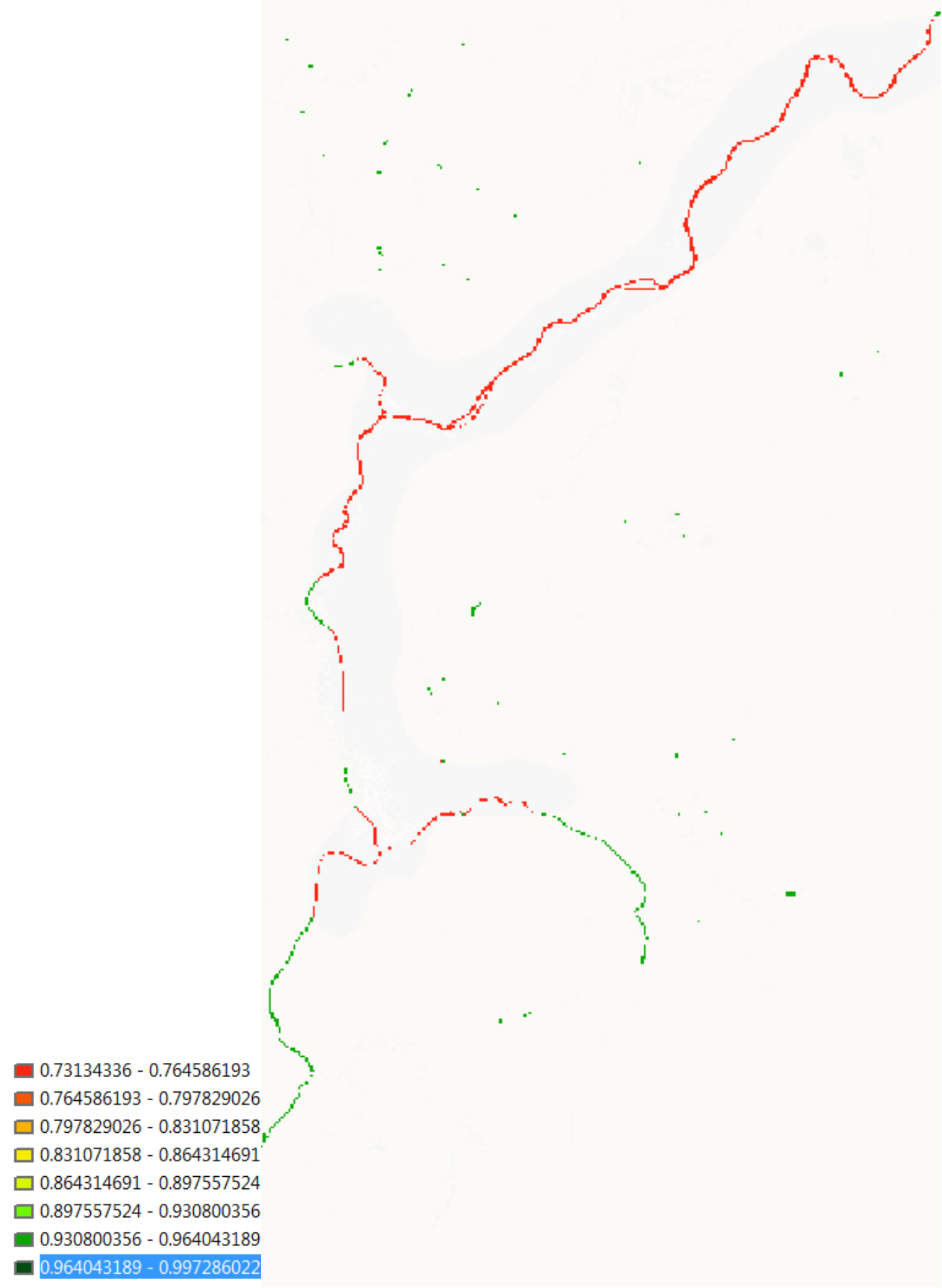

Figure 11 - Cherry River MaxEnt probability projection. Predicted probability of occurrence coincides with scale in legend. Areas with no color have predicted probabilities less than $73.1 \%$. 


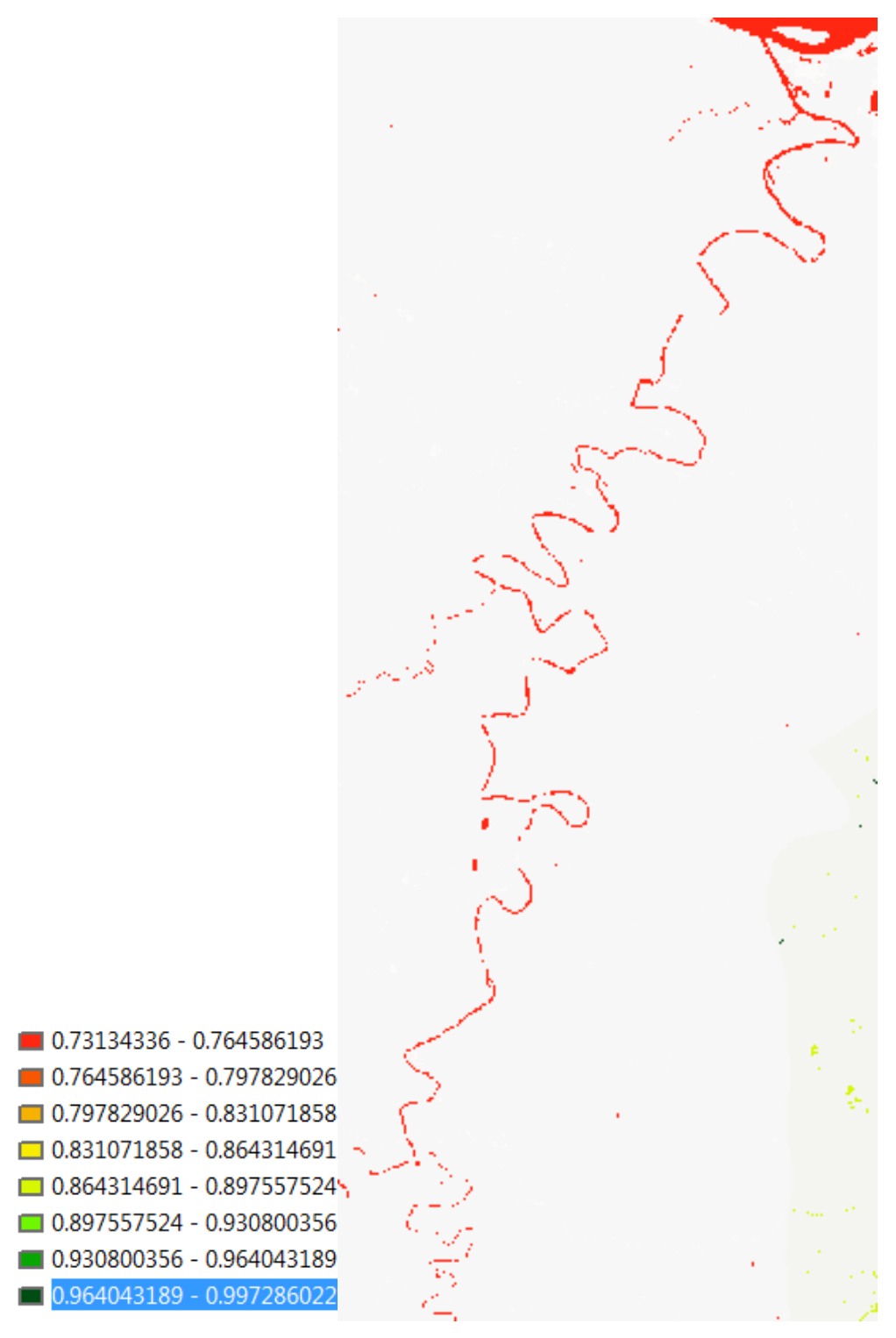

Figure 12 - Fish Creek MaxEnt probability projection. Predicted probability of occurrence coincides with scale in legend. Areas with no color have predicted probabilities less than $73.1 \%$. 


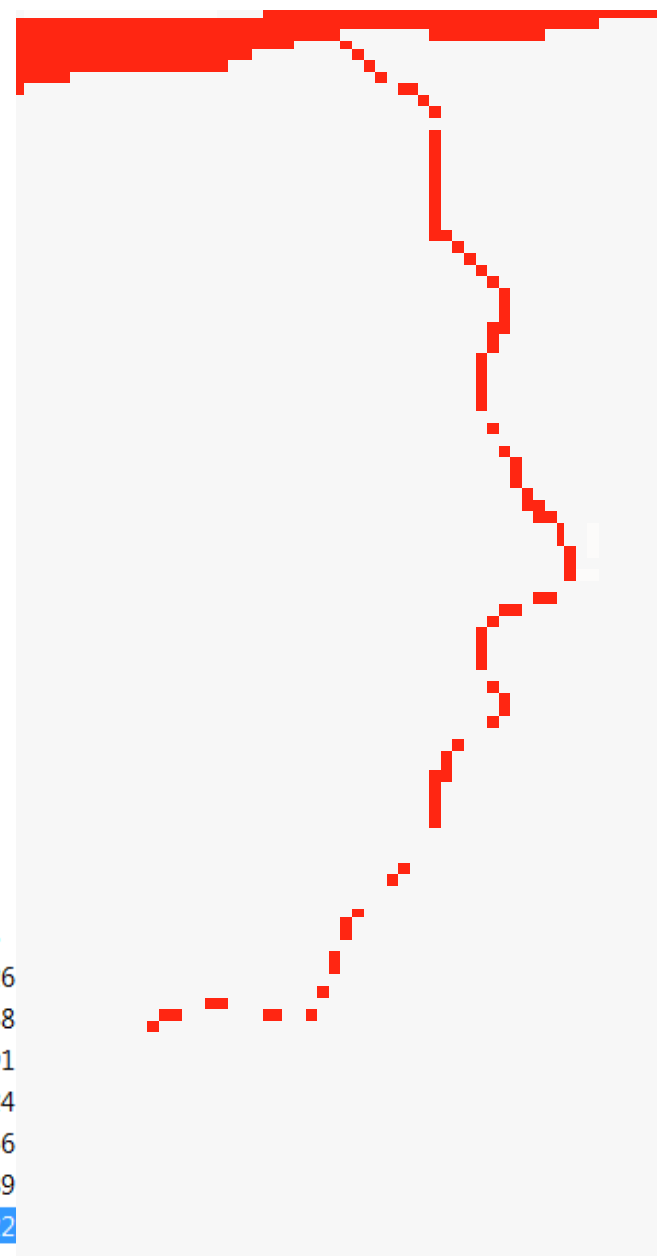

Figure 13 - Glade Creek MaxEnt probability projection. Predicted probability of occurrence coincides with scale in legend. Areas with no color have predicted probabilities less than $73.1 \%$. 


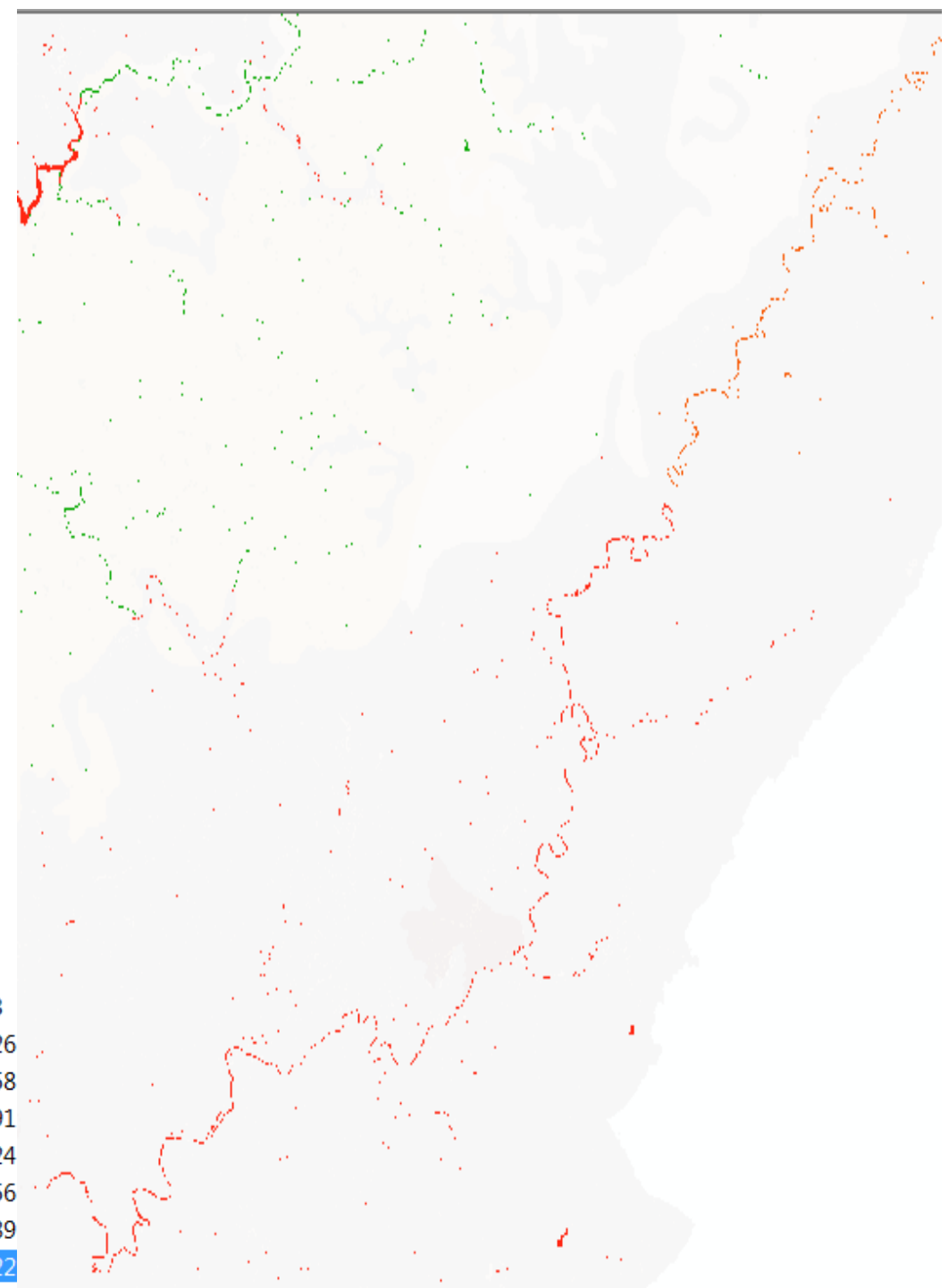

Figure 14 - Greenbrier River MaxEnt probability projection (Right and bottom of map). Predicted probability of occurrence coincides with scale in legend. Areas with no color have predicted probabilities less than $73.1 \%$. 
$0.73134336-0.764586193$

$0.764586193-0.797829026$

$\square 0.797829026-0.831071858$

$\square 0.831071858-0.864314691$

$\square 0.864314691-0.897557524$

$\square 0.897557524-0.930800356$

$0.930800356-0.964043189$

므 $0.964043189-0.997286022$

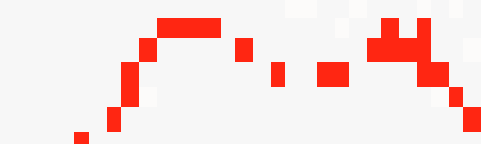

Figure 15 - Laurel Creek MaxEnt probability projection (Right and bottom of map). Predicted probability of occurrence coincides with scale in legend. Areas with no color have predicted probabilities less than $73.1 \%$ 


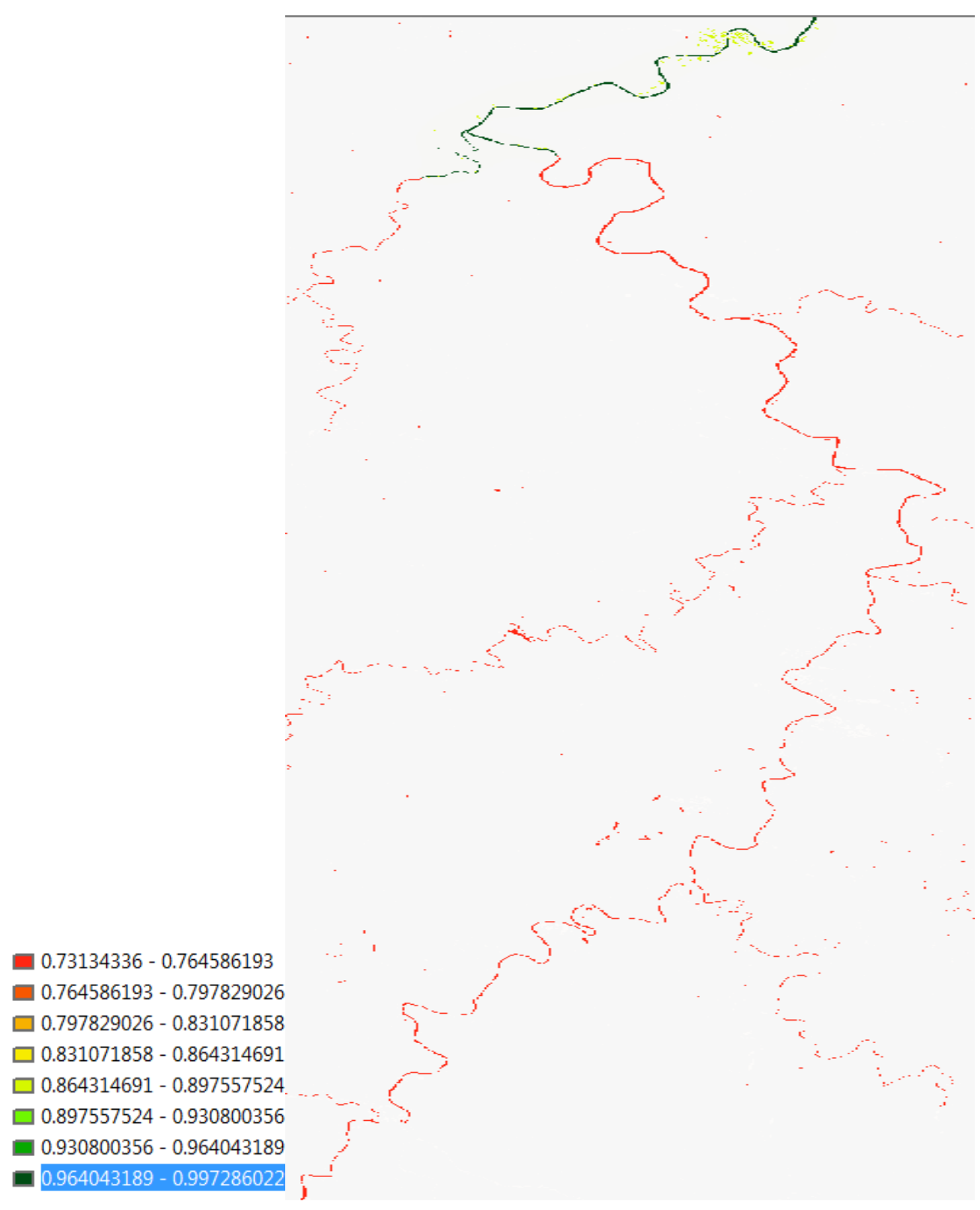

Figure 16 - Little Kanawha River MaxEnt probability projection (main branch running from bottom left to middle right through top of map). Predicted probability of occurrence coincides with scale in legend. Areas with no color have predicted probabilities less than $73.1 \%$. 
$0.73134336-0.764586193$

$0.764586193-0.797829026$

$\square 0.797829026-0.831071858$

$\square 0.831071858-0.864314691$

$\square 0.864314691-0.897557524$

$\square 0.897557524-0.930800356$

$0.930800356-0.964043189$

[0.964043189- 0.997286022

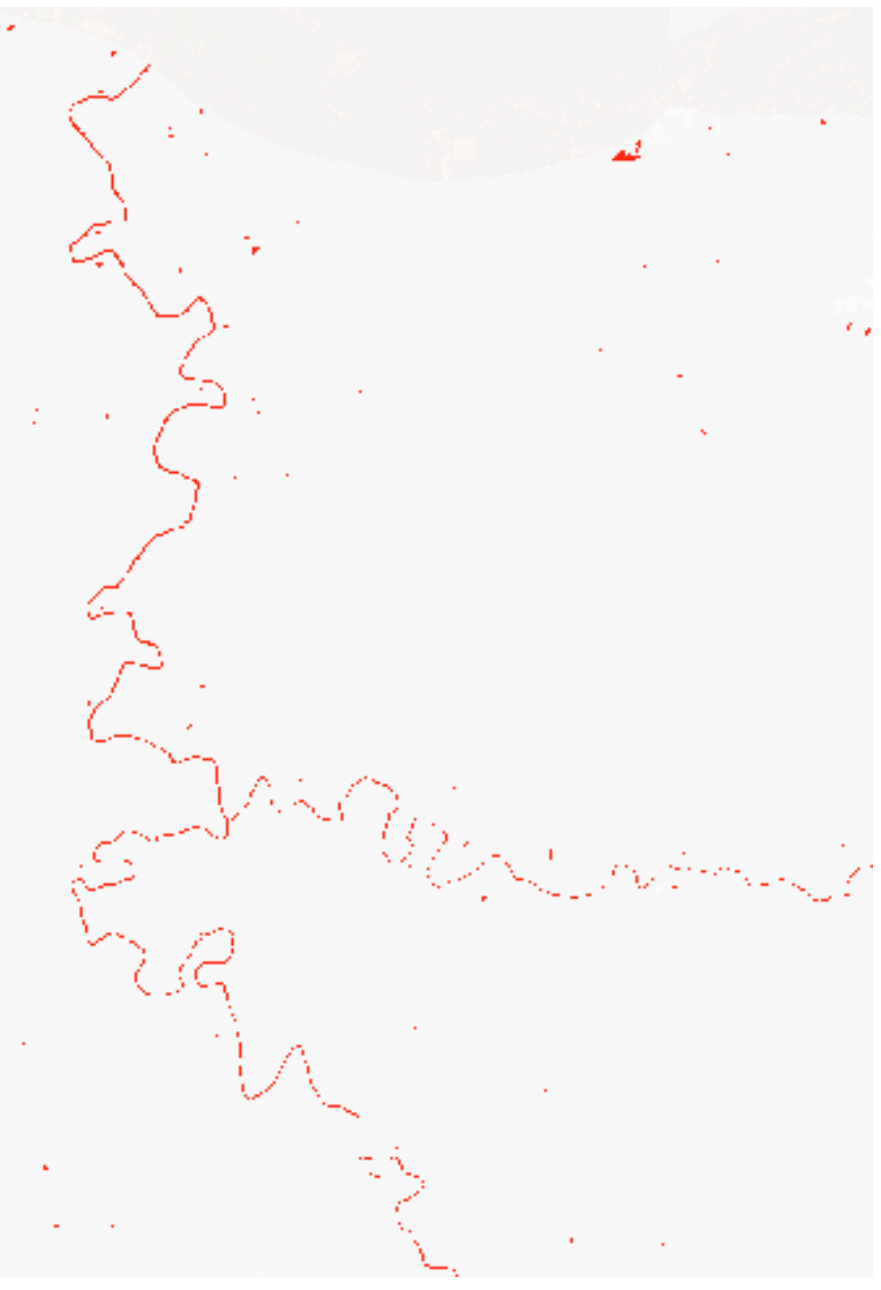

Figure 17 - Mud River MaxEnt probability projection. Predicted probability of occurrence coincides with scale in legend. Areas with no color have predicted probabilities less than $73.1 \%$. 


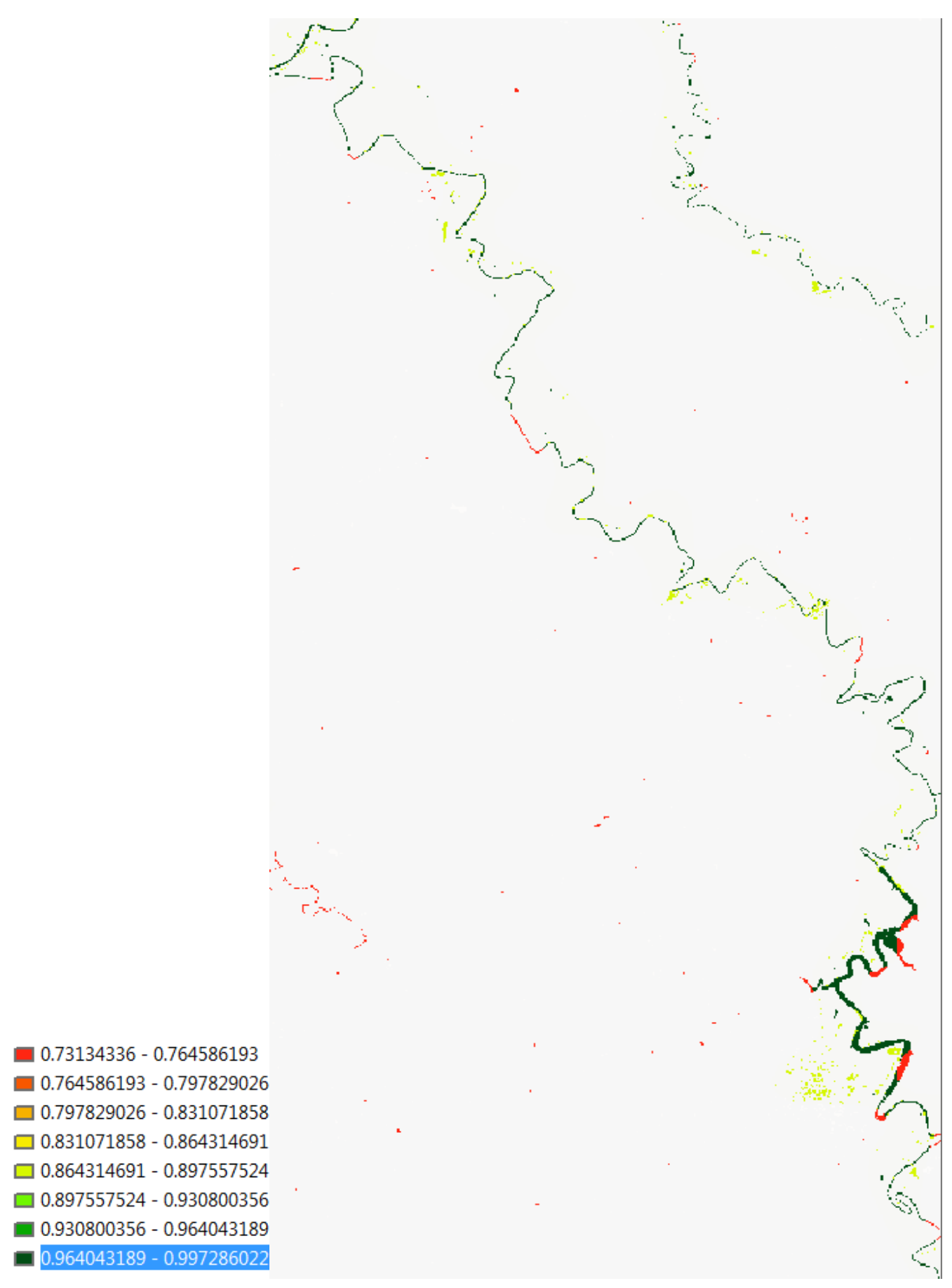

Figure 18 - North Fork Hughes River MaxEnt probability projection (bottom right to upper left of map). Predicted probability of occurrence coincides with scale in legend. Areas with no color have predicted probabilities less than $73.1 \%$. 


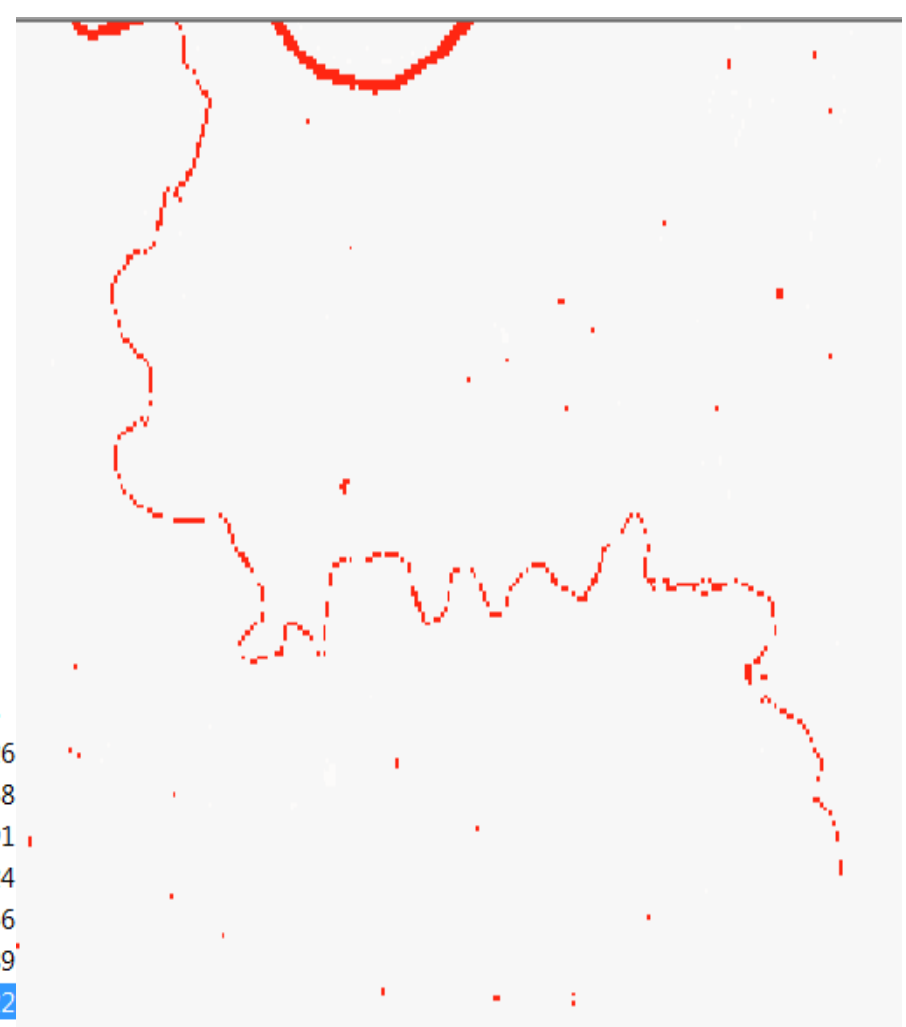

Figure 19 - Second Creek MaxEnt probability projection. Predicted probability of occurrence coincides with scale in legend. Areas with no color have predicted probabilities less than $73.1 \%$. 


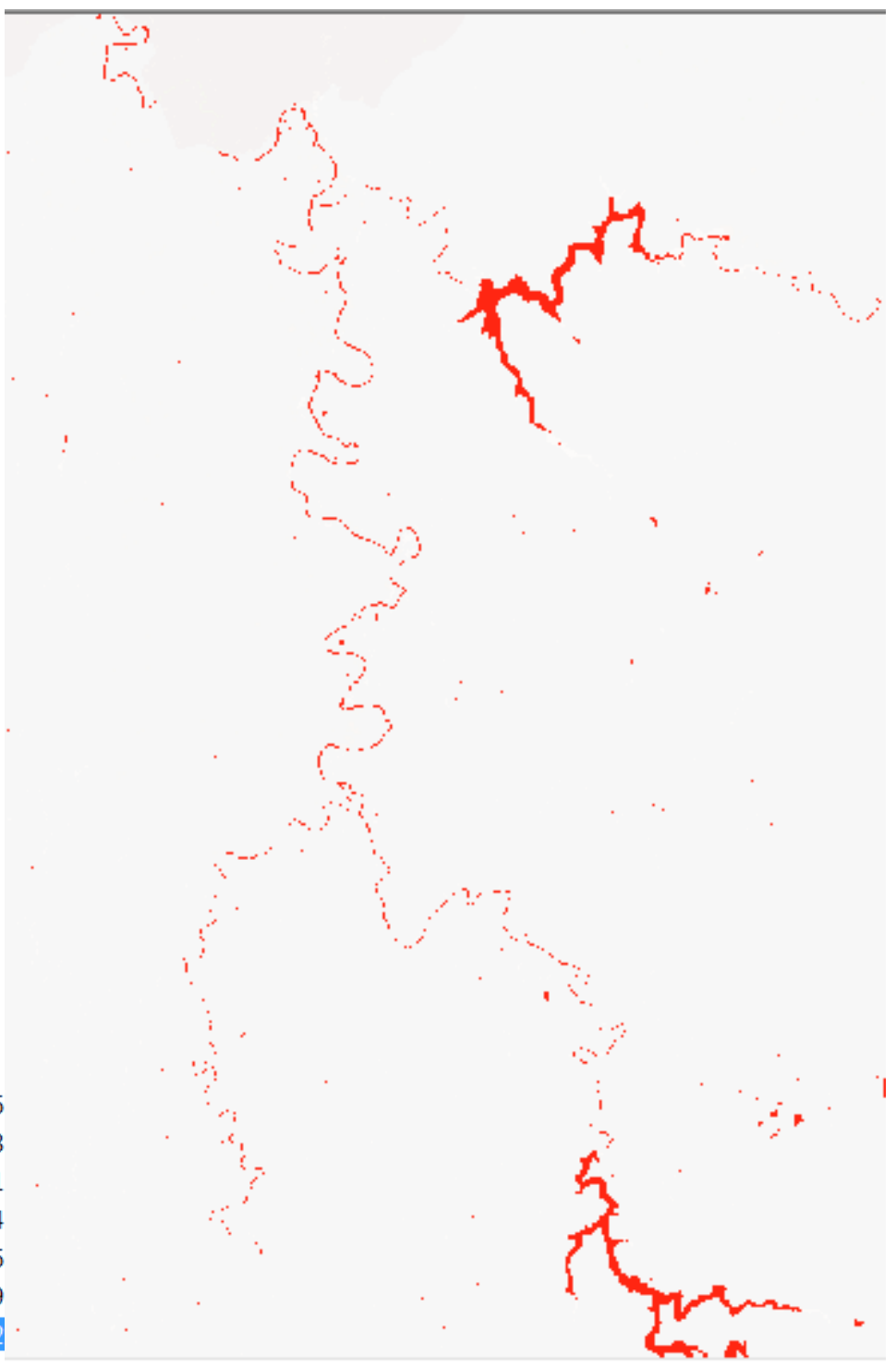

Figure 20 - Twelvepole Creek MaxEnt probability projection. Predicted probability of occurrence coincides with scale in legend. Areas with no color have predicted probabilities less than $73.1 \%$. 
APPENDIX 7

Radio Telemetry Survival, Shelter, and Movement Tables and Figures

\begin{tabular}{|c|c|c|c|c|c|}
\hline Site & $\begin{array}{l}\text { Telemetry } \\
\text { ID\# }\end{array}$ & Mass (g) & $\begin{array}{l}\text { SVL } \\
(\mathrm{cm})\end{array}$ & Result & Day of Final Observation \\
\hline Buffalo & 164.012 & 127.5 & 17.46 & Death (Buried) & 32 \\
\hline Buffalo & 164.024 & 229.6 & 20.64 & Death (Predation) & 32 \\
\hline Buffalo & 164.053 & 205.6 & 21.59 & Survived & 373 \\
\hline Buffalo & 164.063 & 194.3 & 20.96 & Missing & 0 (Day of Release) \\
\hline Buffalo & 164.093 & 163.1 & 19.37 & Death (Predation) & 42 \\
\hline Buffalo & 164.122 & 185.9 & 19.37 & Death (Buried) & 32 \\
\hline Buffalo & 164.145 & 170.0 & 17.94 & Missing & 0 (Day of Release) \\
\hline Buffalo & 164.192 & 122.8 & 16.83 & Survived & 373 \\
\hline Buffalo & 164.203 & 100.3 & 16.20 & Survived & 373 \\
\hline Buffalo & 164.243 & 194.8 & 20.64 & Missing & 0 (Day of Release) \\
\hline Buffalo & 164.255 & 225.4 & 22.23 & Survived & 373 \\
\hline Buffalo & 164.263 & 232.7 & 20.96 & Death (Predation) & 317 \\
\hline Buffalo & 164.283 & 232.4 & 20.96 & Missing & 32 \\
\hline Buffalo & 164.304 & 185.8 & 16.51 & Survived & 373 \\
\hline Cherry & 164.032 & 176.7 & 18.73 & Survived & 177 \\
\hline Cherry & 164.043 & 110.8 & 18.73 & Survived & 177 \\
\hline Cherry & 164.083 & 222.1 & 20.32 & Survived & 177 \\
\hline Cherry & 164.102 & 174.1 & 20.32 & Survived & 177 \\
\hline Cherry & 164.114 & 186.1 & 20.32 & Survived & 177 \\
\hline Cherry & 164.133 & 156.0 & 19.69 & Death (Predation) & 7 \\
\hline Cherry & 164.153 & 244.3 & 21.91 & Survived & 177 \\
\hline Cherry & 164.162 & 177.9 & 19.05 & Death (Predation) & 93 \\
\hline Cherry & 164.172 & 208.5 & 21.59 & Death (Predation) & 0 (Day of Release) \\
\hline Cherry & 164.183 & 226.2 & 20.96 & Death (Predation) & 37 \\
\hline Cherry & 164.214 & 197.4 & 20.32 & Survived & 177 \\
\hline Cherry & 164.222 & 217.1 & 22.54 & Survived & 177 \\
\hline Cherry & 164.232 & 163.3 & 19.37 & Missing & 51 \\
\hline Cherry & 164.272 & 207.3 & 21.91 & Survived & 177 \\
\hline Cherry & 164.291 & 185.5 & 18.42 & Death (Predation) & 20 \\
\hline
\end{tabular}

Table 1-Individual Hellbender transmitter numbers, telemetry transmitter frequency number, mass in grams $(\mathrm{g})$, snout-to-vent length $(\mathrm{SVL})$ in centimeters $(\mathrm{cm})$, result of individual during study, and days observed following release. 


\begin{tabular}{|c|c|c|c|c|c|}
\hline Site & $\begin{array}{l}\text { Telemetry } \\
\text { ID\# }\end{array}$ & $\begin{array}{l}\mathrm{MCP} \\
\left(\mathrm{m}^{2}\right)\end{array}$ & LHR (m) & Result & Day of Final Observation \\
\hline Buffalo & 164.012 & $7,574.0$ & 631.5 & Death (Buried) & 32 \\
\hline Buffalo & 164.024 & 647.5 & 386.67 & Death (Predation) & 32 \\
\hline Buffalo & 164.053 & $4,185.5$ & 142.38 & Survived & 373 \\
\hline Buffalo & 164.093 & $12,140.0$ & 269.62 & Death (Predation) & 42 \\
\hline Buffalo & 164.192 & $15,786.0$ & 538.61 & Survived & 373 \\
\hline Buffalo & 164.203 & $15,134.0$ & 142.28 & Survived & 373 \\
\hline Buffalo & 164.255 & 797.5 & 80.59 & Survived & 373 \\
\hline Buffalo & 164.263 & $20,611.0$ & 537.36 & Death (Predation) & 317 \\
\hline Buffalo & 164.304 & $4,472.0$ & 511.69 & Survived & 373 \\
\hline Cherry & 164.032 & 99.0 & 35.46 & Survived & 177 \\
\hline Cherry & 164.043 & 505.5 & 19.69 & Survived & 177 \\
\hline Cherry & 164.083 & 759.0 & 462.47 & Survived & 177 \\
\hline Cherry & 164.102 & 163.0 & 263.52 & Survived & 177 \\
\hline Cherry & 164.114 & 757.5 & 36.13 & Survived & 177 \\
\hline Cherry & 164.153 & 279.0 & 97.62 & Survived & 177 \\
\hline Cherry & 164.162 & $3,356.5$ & 30.14 & Death (Predation) & 93 \\
\hline Cherry & 164.183 & $6,995.0$ & 84.21 & Death (Predation) & 37 \\
\hline Cherry & 164.214 & 91.0 & 169.07 & Survived & 177 \\
\hline Cherry & 164.222 & 399.0 & 15.53 & Survived & 177 \\
\hline Cherry & 164.232 & $2,051.0$ & 21.61 & Missing & 51 \\
\hline Cherry & 164.272 & 303.0 & 40.14 & Survived & 177 \\
\hline
\end{tabular}

Table 2-Individual Hellbender transmitter numbers, telemetry transmitter frequency number, minimum convex polygon (MCP) home range in square meters $\left(\mathrm{m}^{2}\right)$, linear home range (LHR) in meters $(\mathrm{m})$, result of individual during study, and days observed following release. 

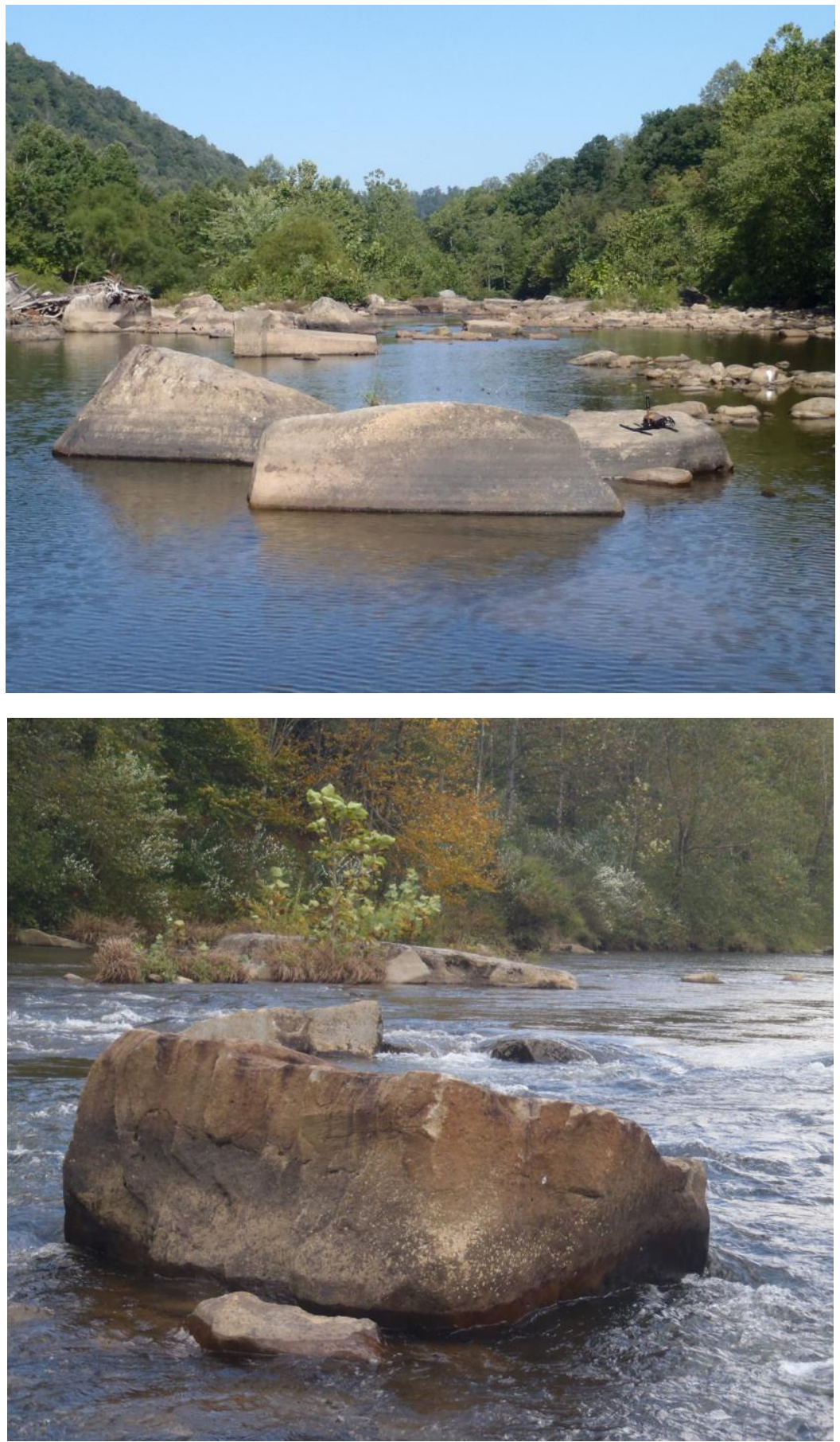

Figure 1 - Large boulders utilized by released hellbenders in this study at the Cherry River translocation site. Large boulder in center of top photo was and large boulder in foreground of bottom picture was inhabited regularly by released individuals. 


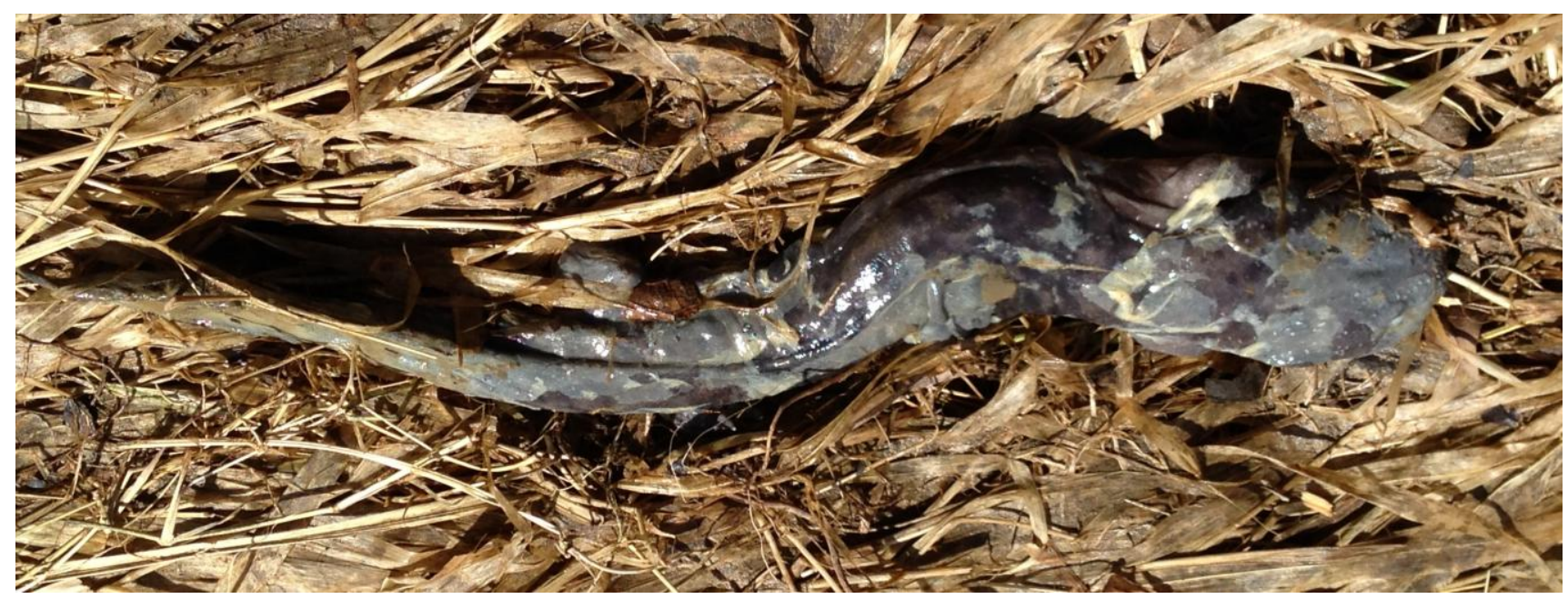

Figure 2 - Photo of deceased hellbender that was buried and removed from deep gravel bed after high water event. Animal appeared to be in normal body condition but exhibited gross signs of dysecdysis.

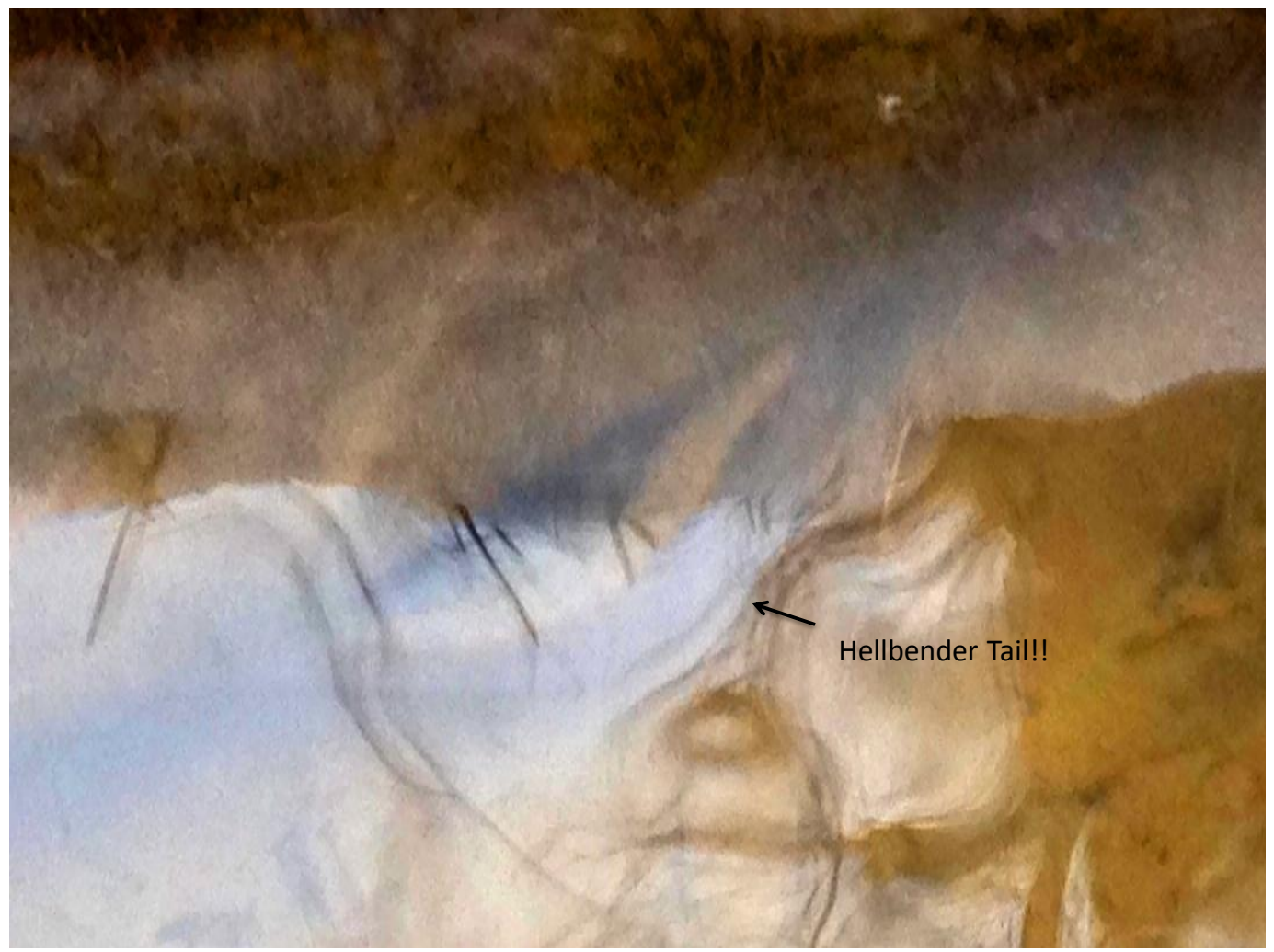

Figure 3 - Hellbender tail observed coming out of crevice in stream bank during telemetry study. 


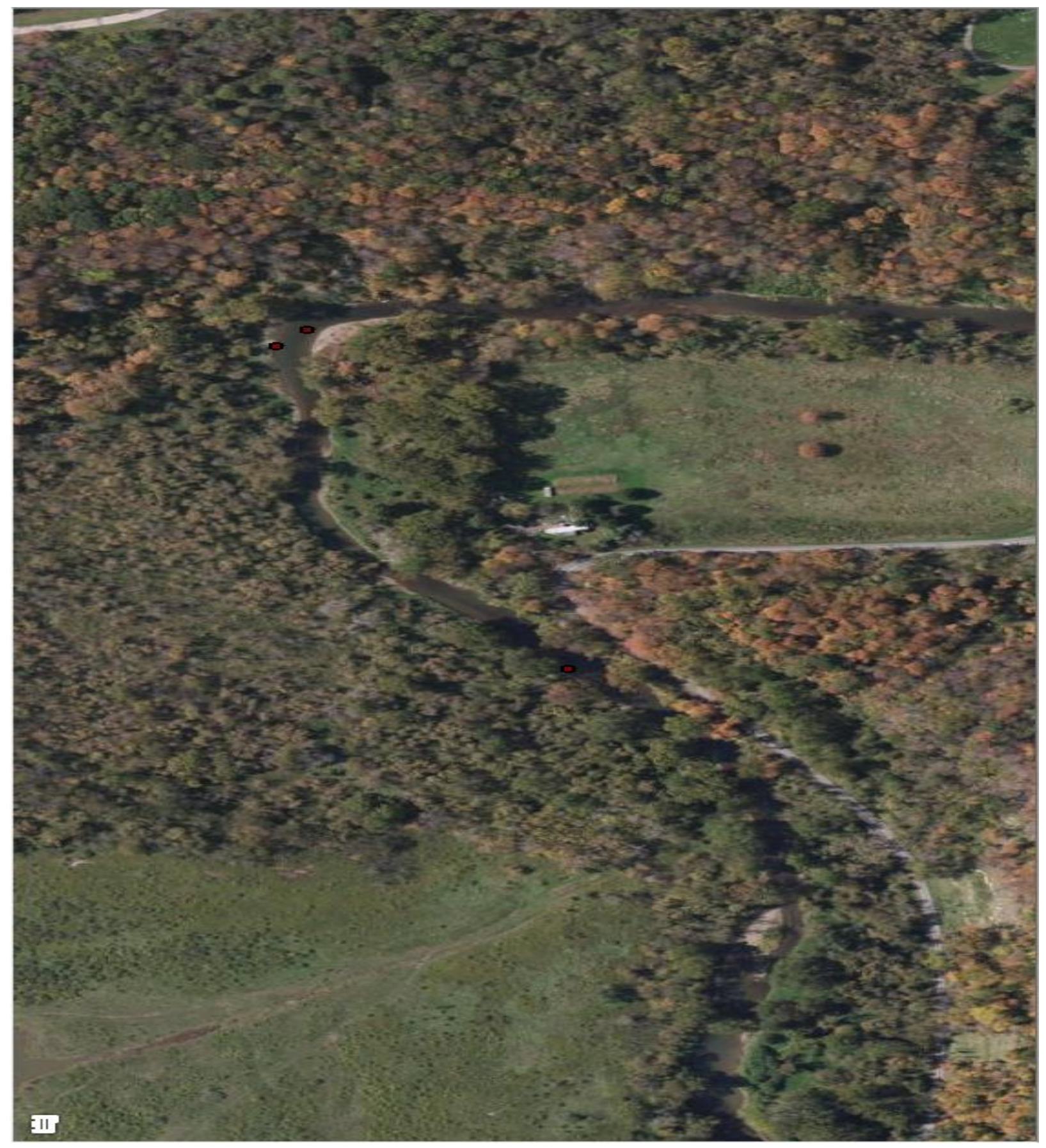

Figure 4 - Buffalo Creek 164.012 observed locations (red dots) during study. 


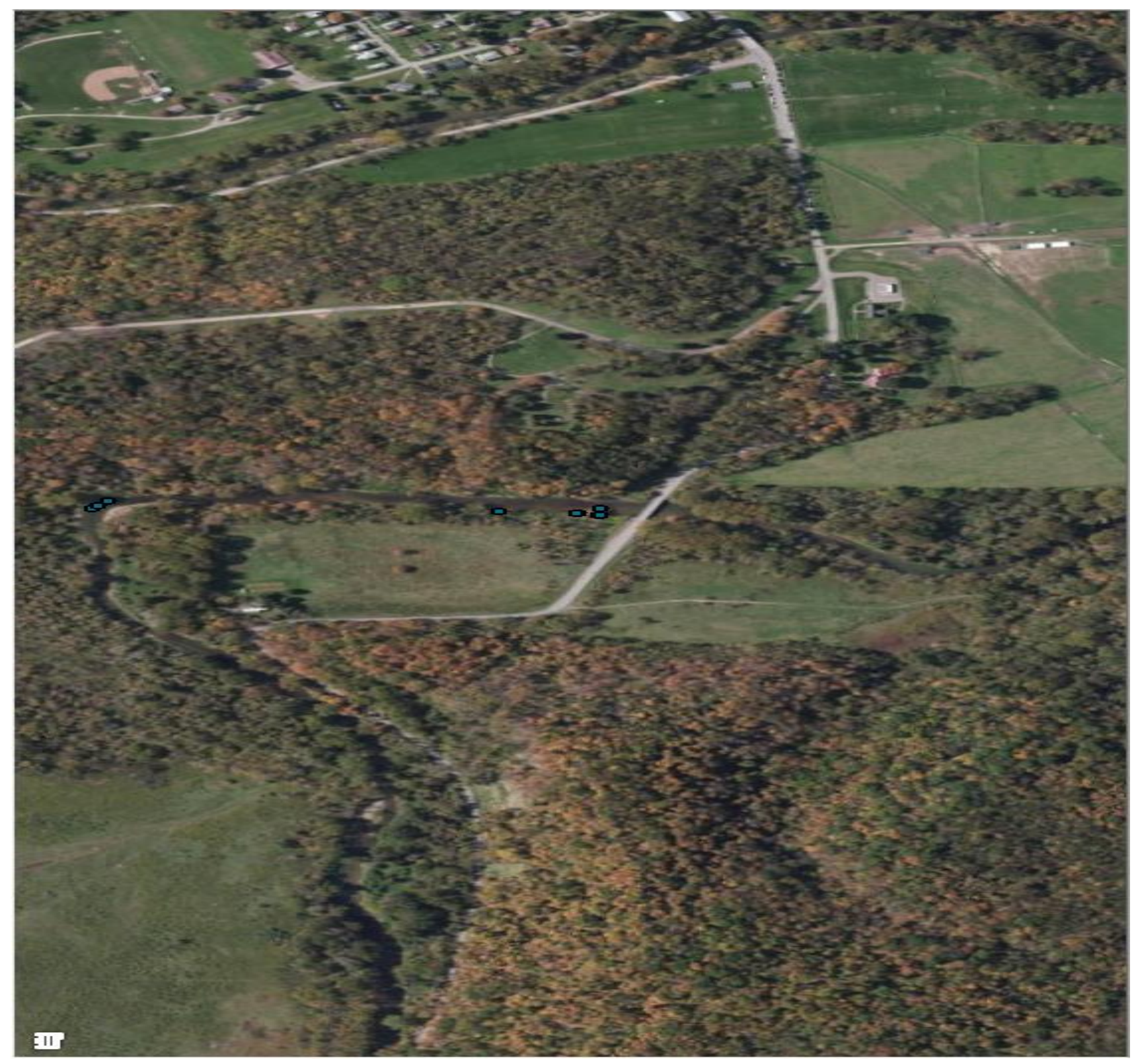

Figure 5 - Buffalo Creek 164.053 observed locations (blue dots) during study. 


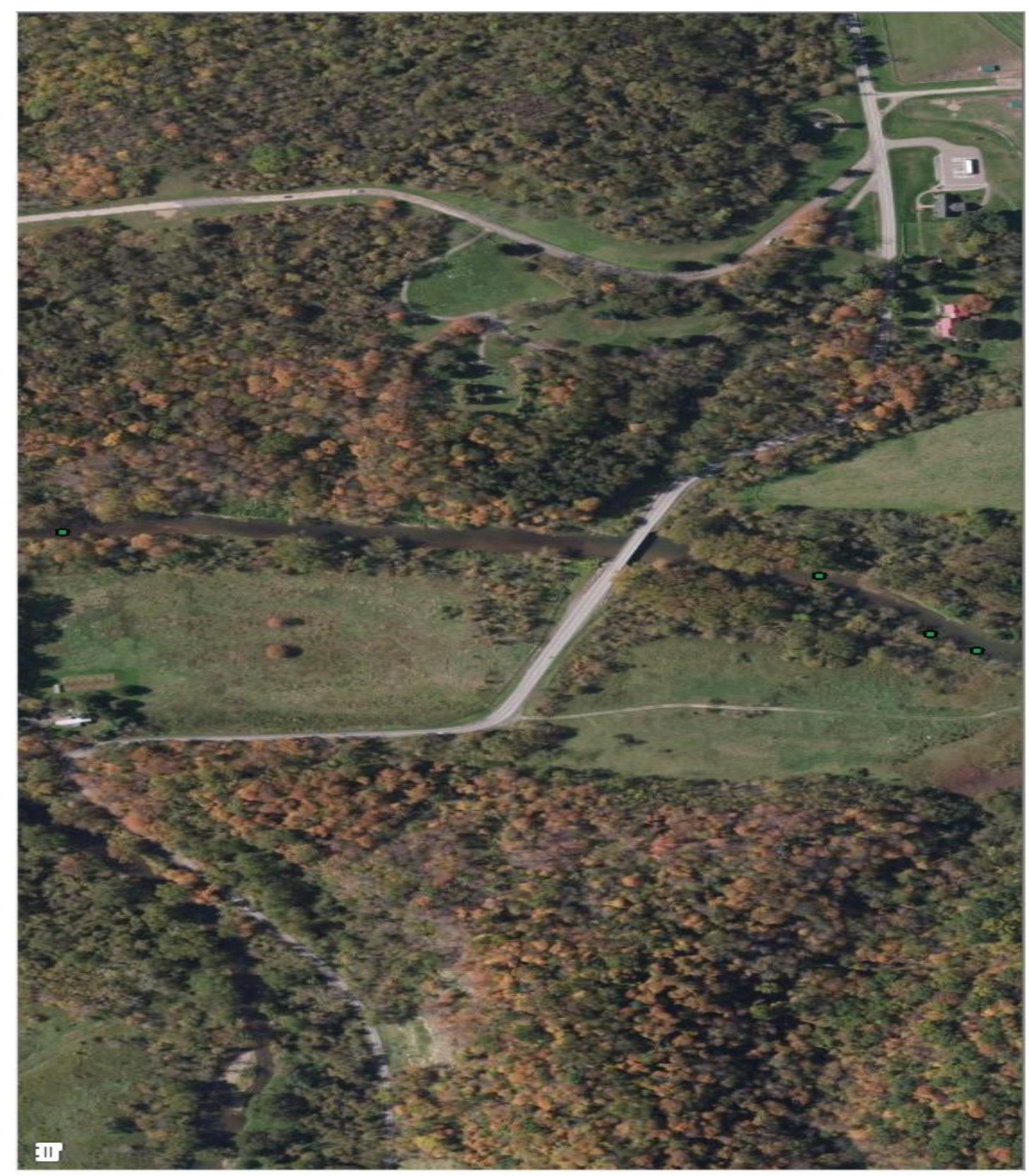

Figure 6 - Buffalo Creek 164.093 observed locations (green dots) during study. 


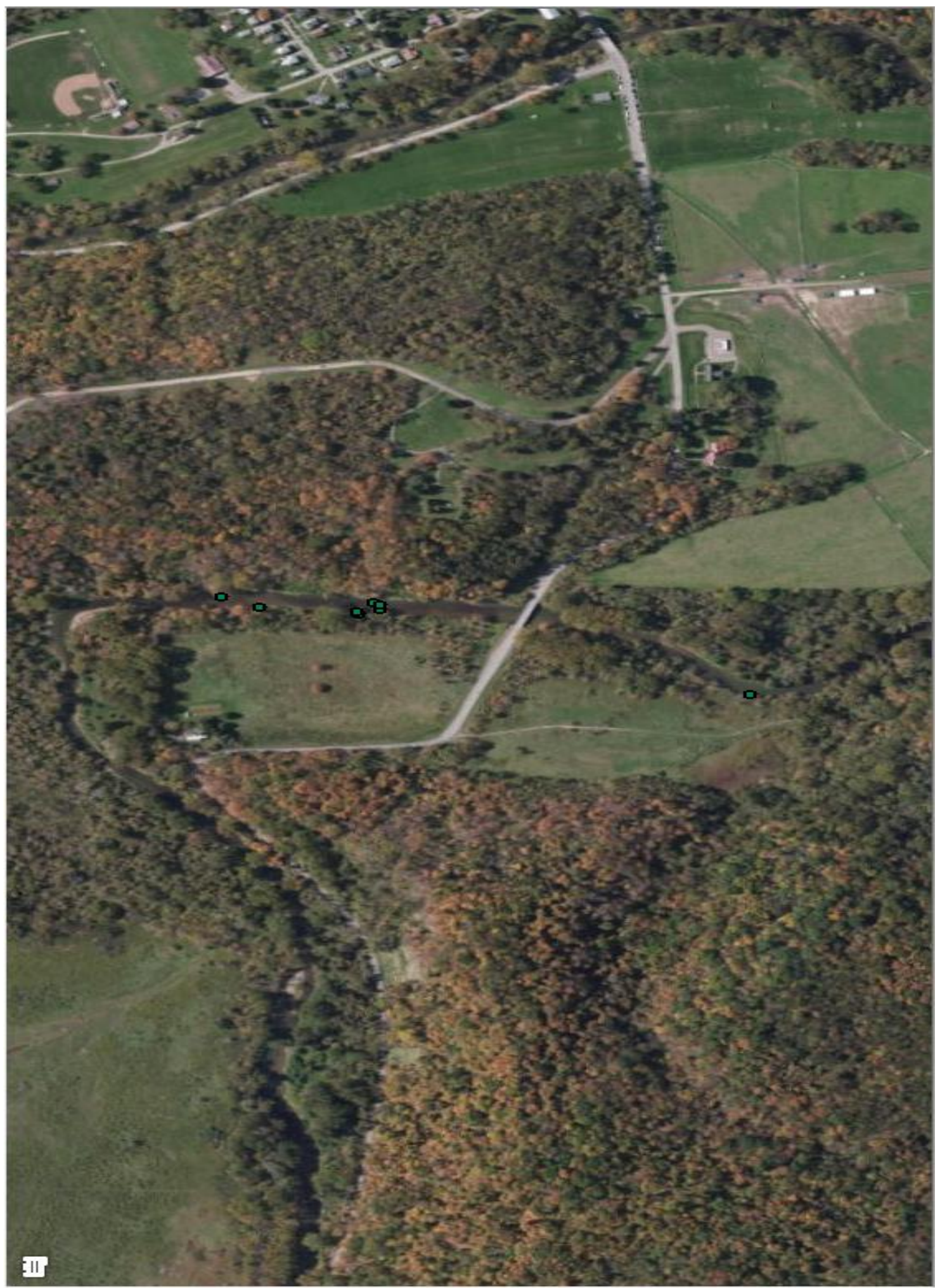

Figure 7 - Buffalo Creek 164.255 observed locations (green dots) during study. 


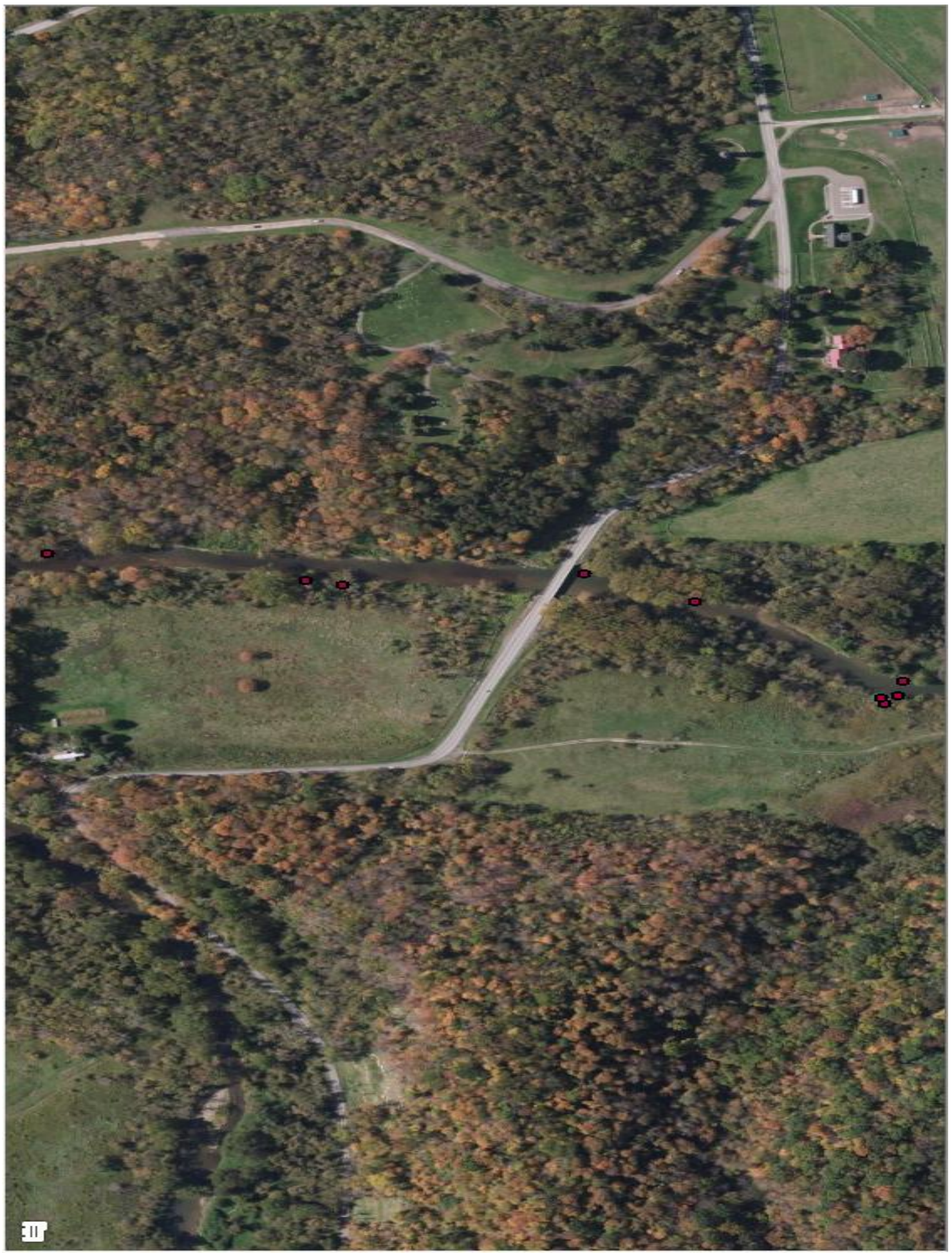

Figure 8 - Buffalo Creek 164.263 observed locations (red dots) during study. 


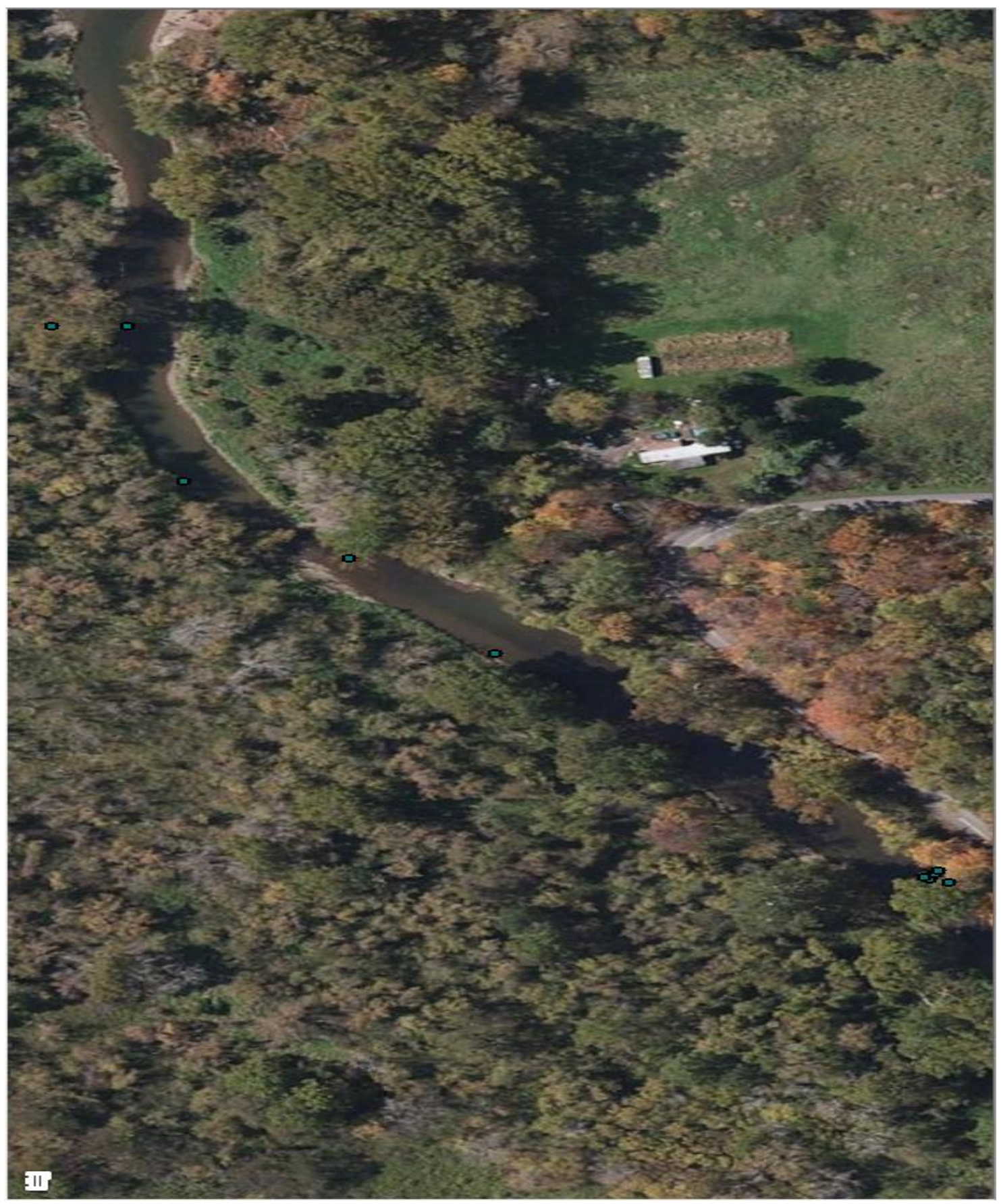

Figure 9 - Buffalo Creek 164.304 observed locations (blue dots) during study. 


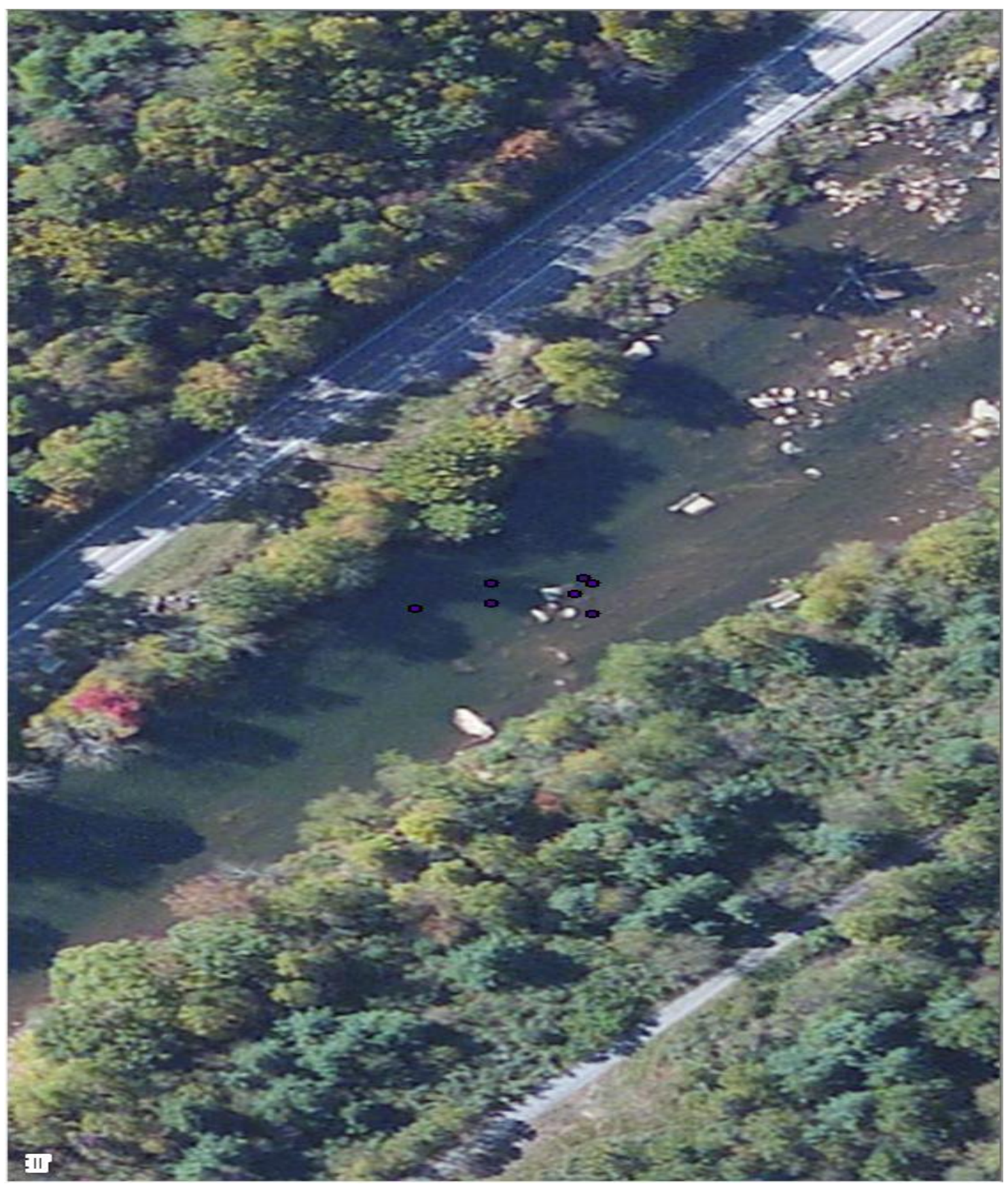

Figure 10 - Cherry River 164.032 observed locations (purple dots) during study. 


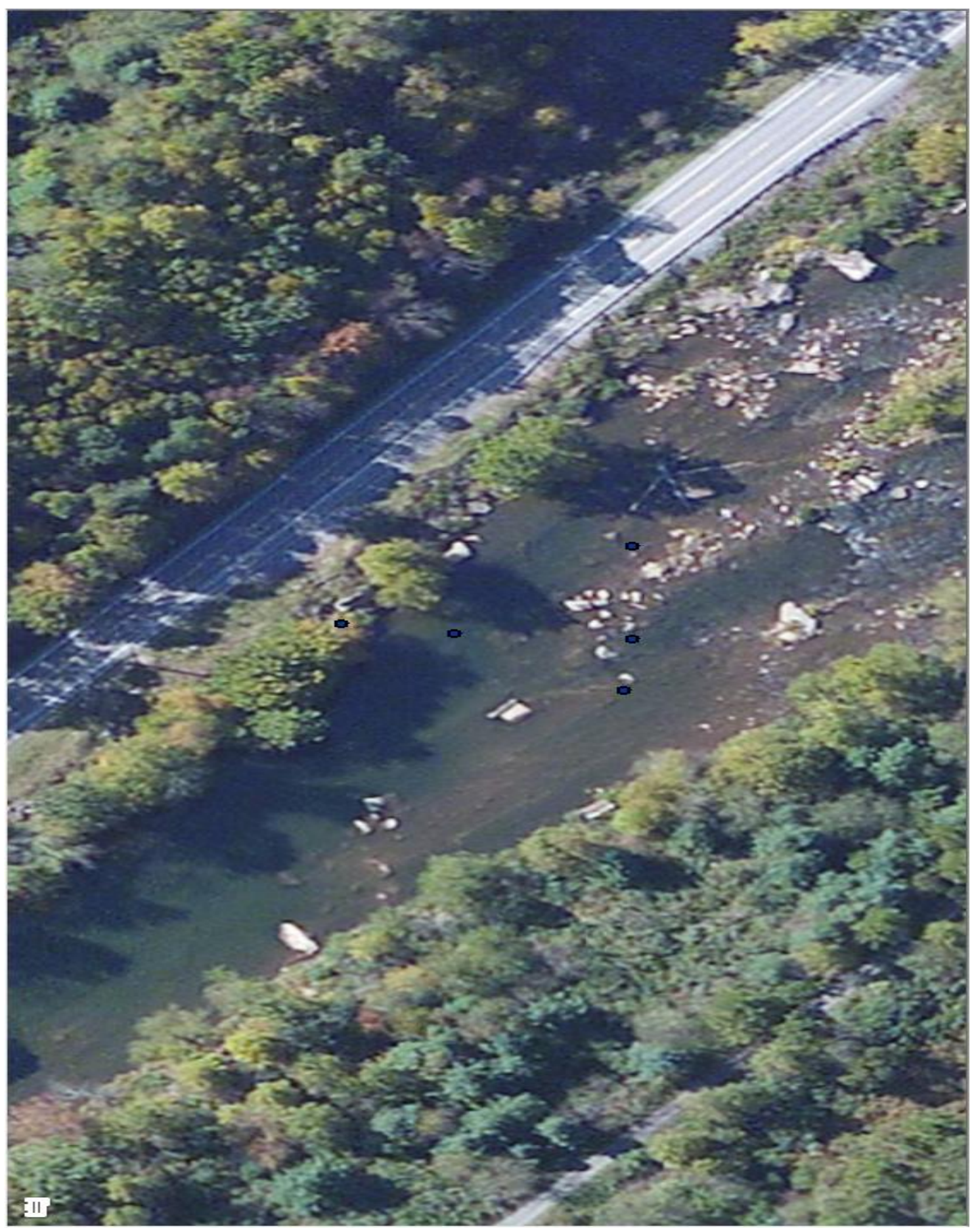

Figure 11 - Cherry River 164.043 observed locations (blue dots) during study. 


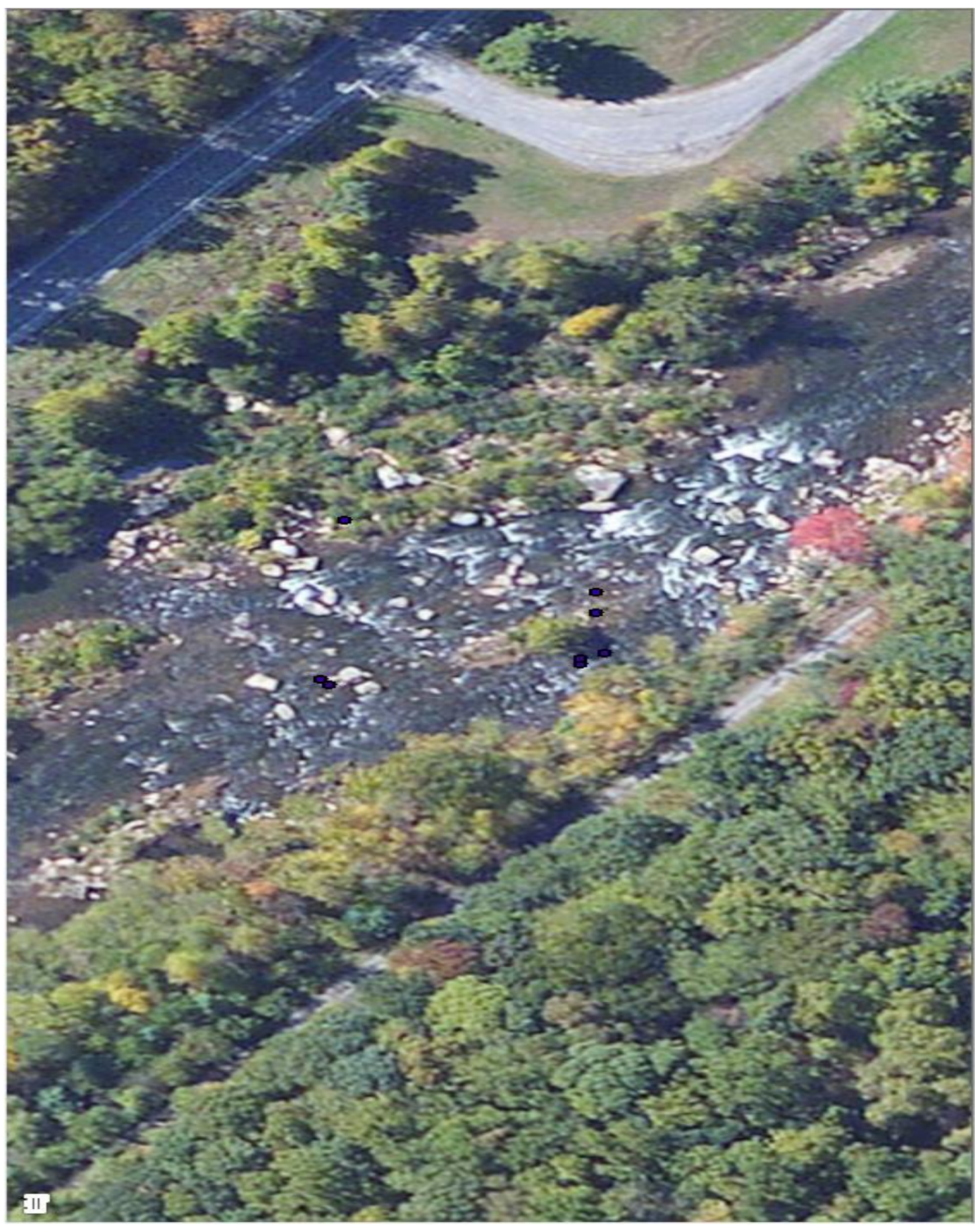

Figure 12 - Cherry River 164.083 observed locations (purple dots) during study. 


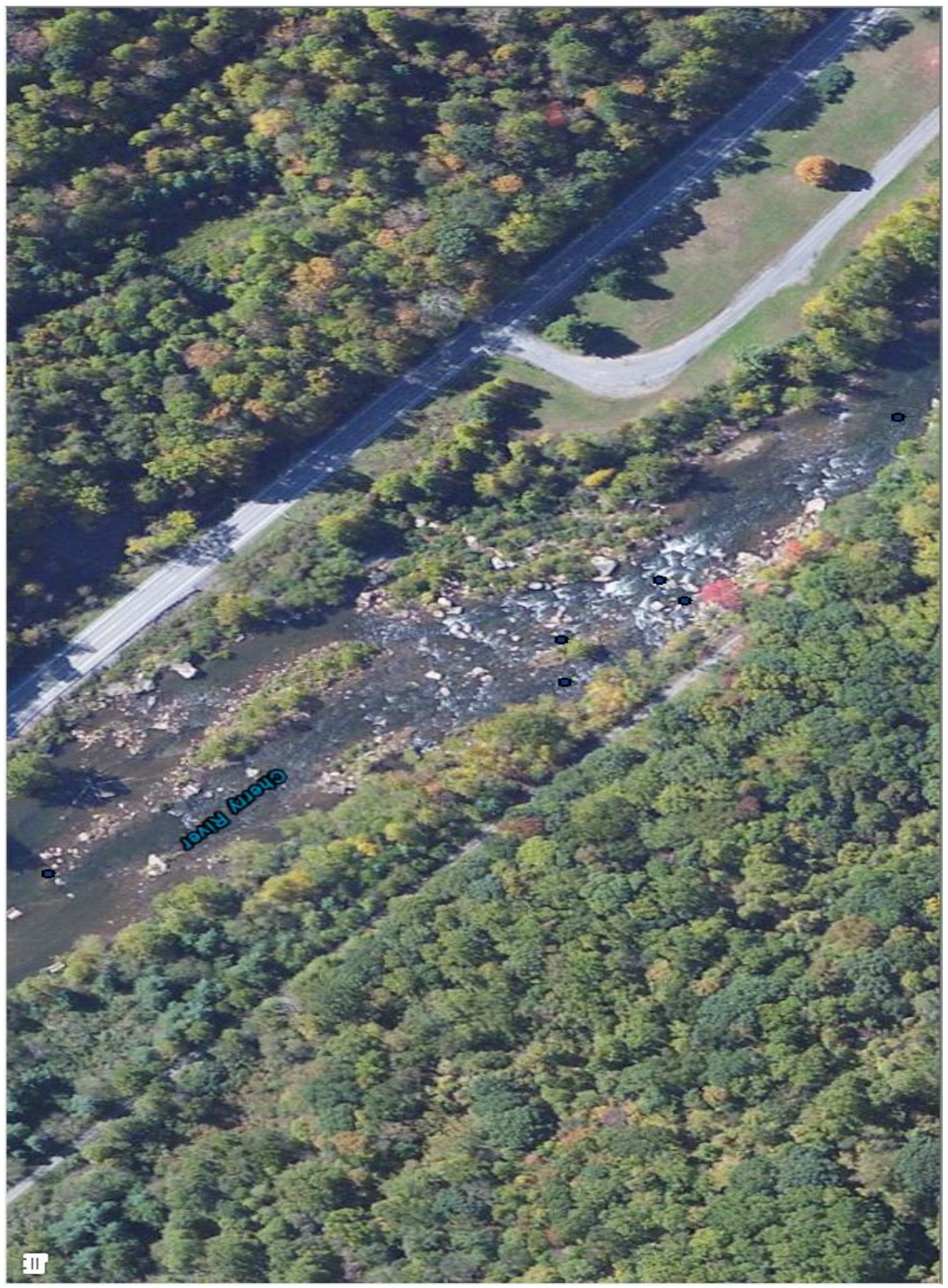

Figure 13 - Cherry River 164.162 observed locations (blue dots) during study. 


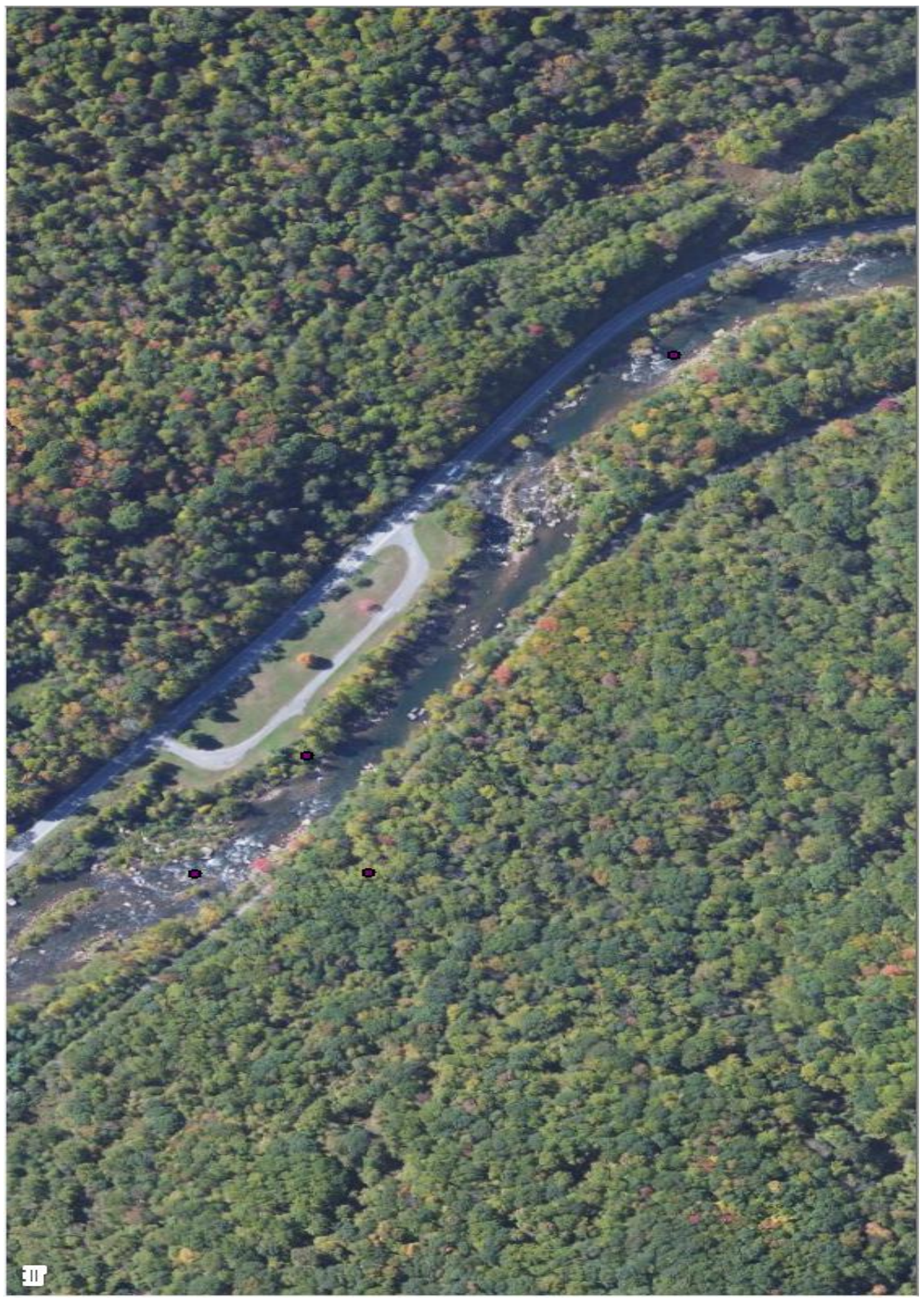

Figure 14 - Cherry River 164.183 observed locations (red dots) during study. 


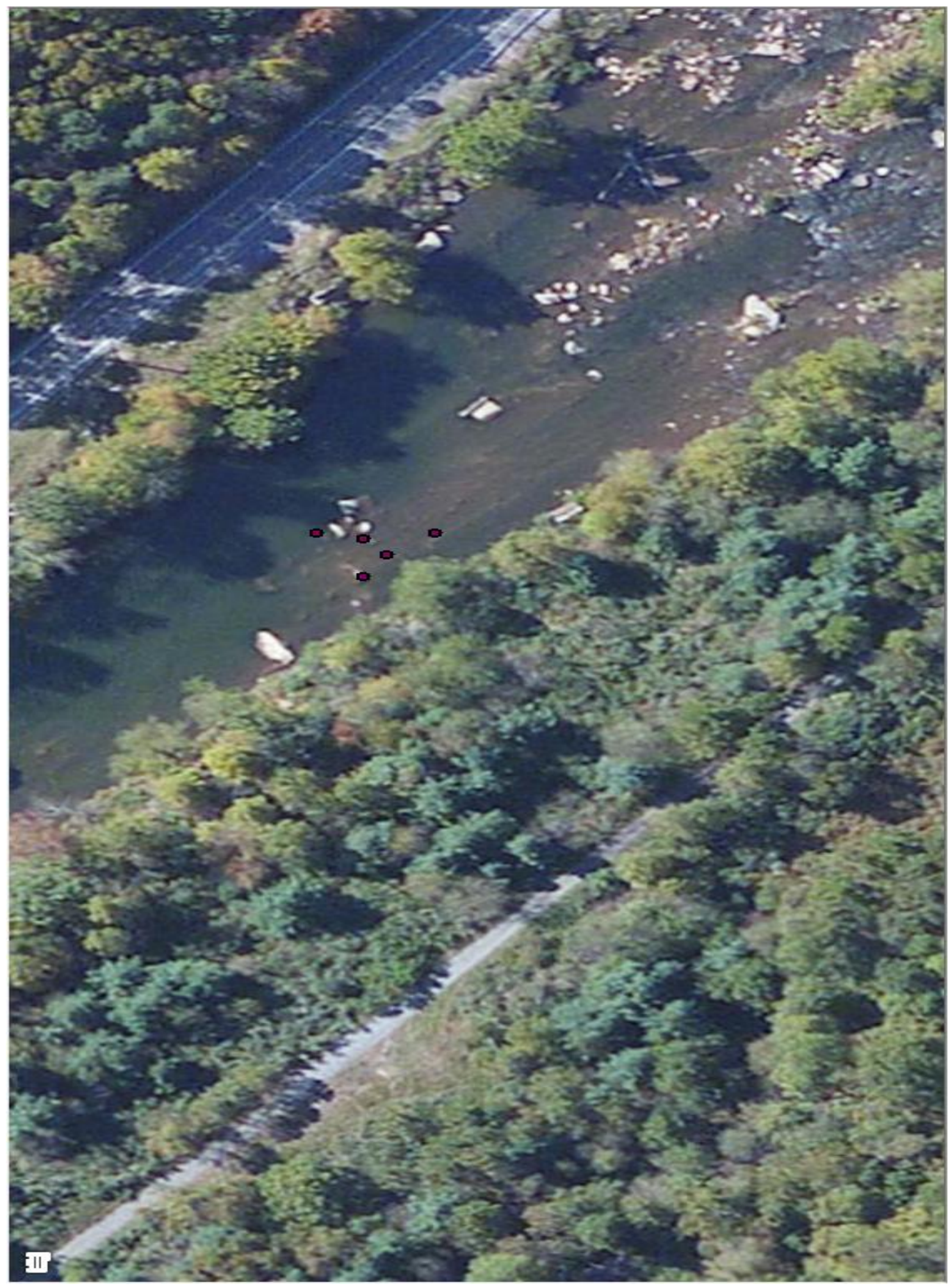

Figure 15 - Cherry River 164.214 observed locations (red dots) during study. 


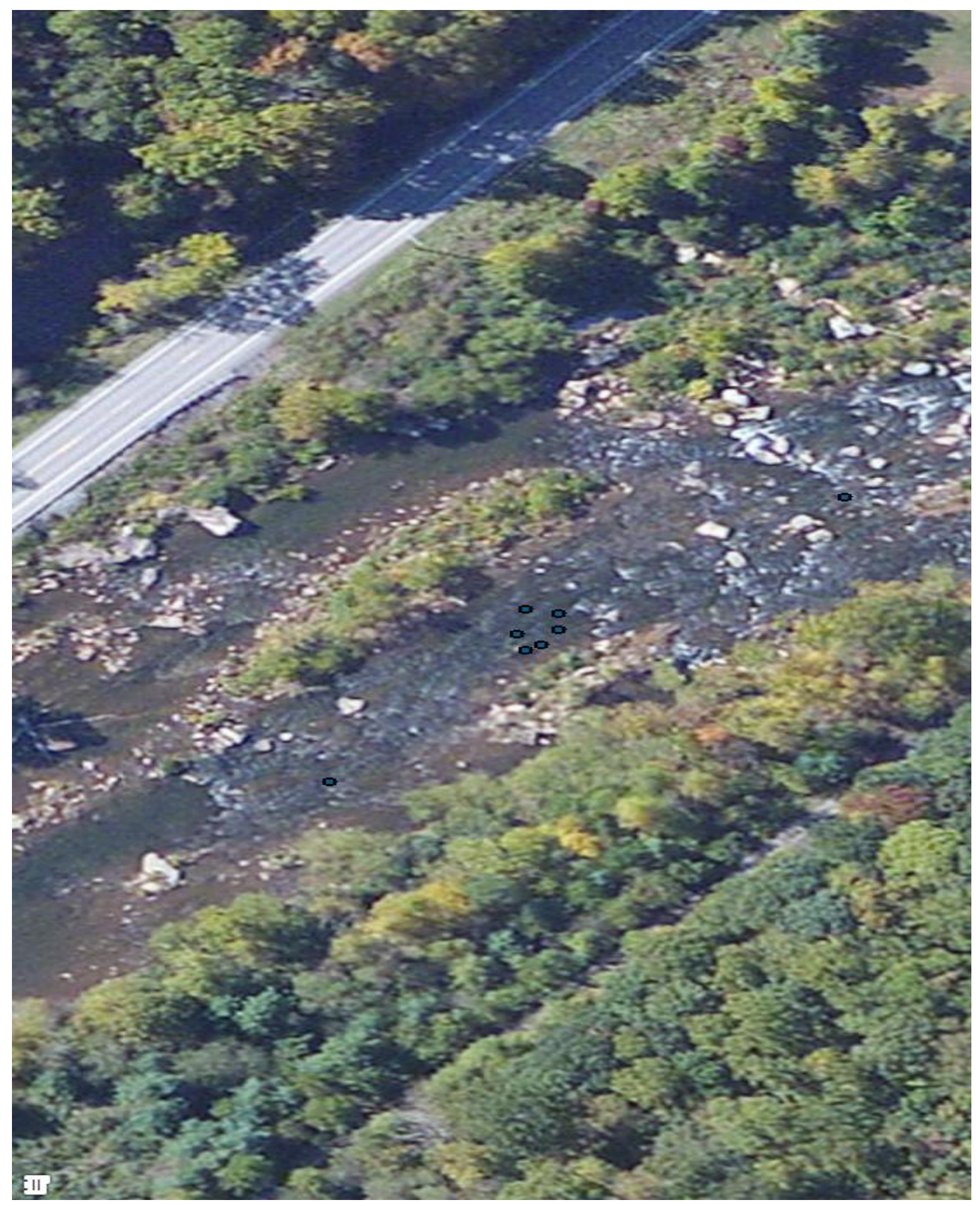

Figure 16 - Cherry River 164.222 observed locations (red dots) during study. 


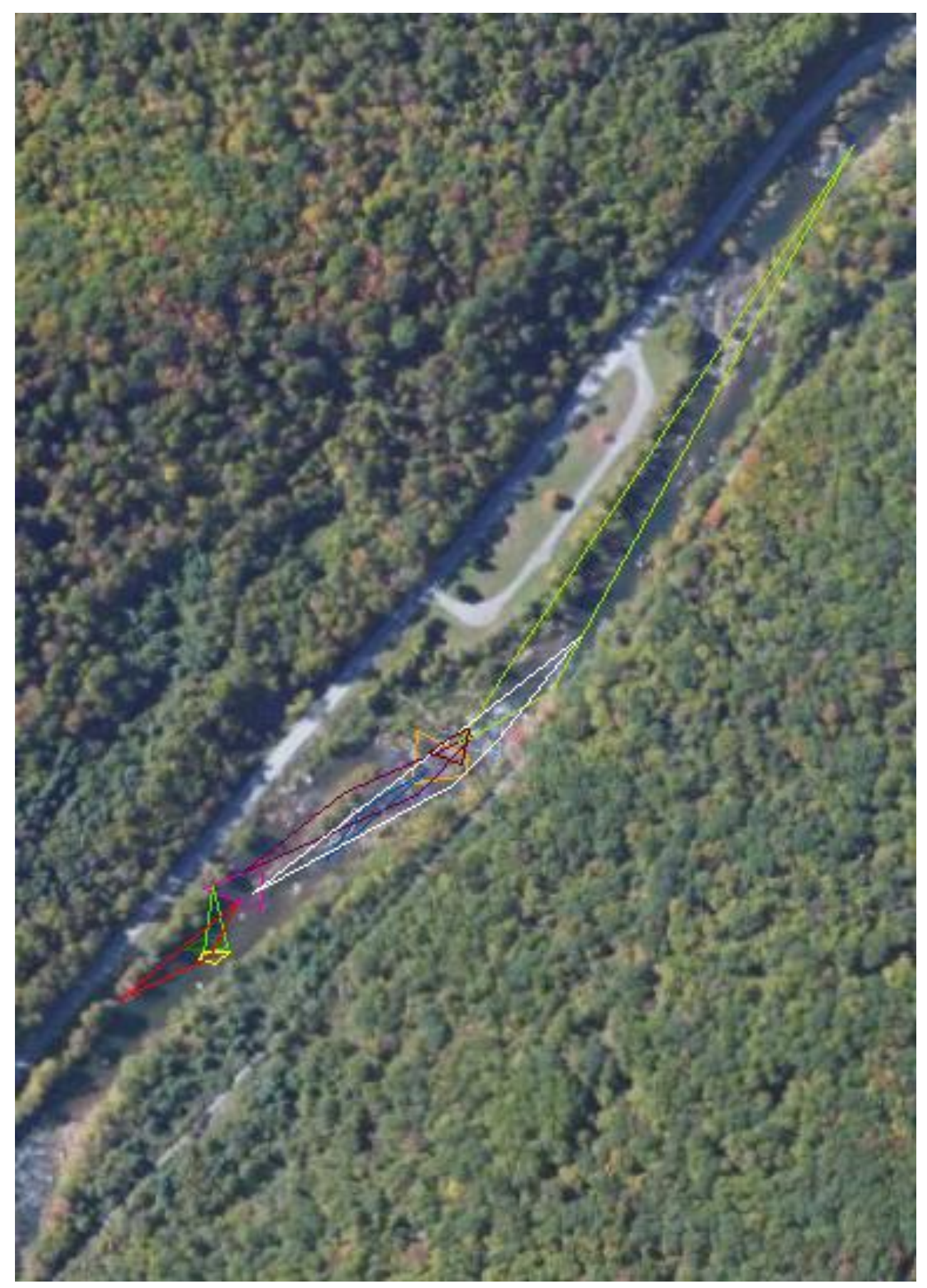

Figure 17 - Cherry River 95\% MCP's of translocated individuals tracked during study. 


\section{WILLIAM JOSEPH GREATHOUSE \\ Curriculum vitae}

Address: 11 Deerhaven Drive, Wheeling, WV 26003

Telephone and e-mail: (304)639-7684 jgreathouse@thewilds.org

\section{EDUCATION}

West Virginia University

Morgantown, West Virginia

August 2010-Present

- PhD Candidate

- Dissertation Research: Development of a Conservation Action Plan for the Eastern Hellbender (Cryptobranchus alleganiensis alleganiensis) in West Virginia

- Animal Science Major - Ph.D. Program

AZA Conservation Academy

Orlando, Florida

October 2006

- Developing an Institutional In-situ Conservation Strategy

AZA Conservation Academy

Wheeling, West Virginia

February 2002

- Managing For Success: Organizational Development

AZA Conservation Academy

Wheeling, West Virginia

February 2001

- Managing For Success: Career Development

AZA Central Regional Conference

May 2000

- Institutional Collection Planning Workshop

AZA Conservation Academy

Wheeling, West Virginia

February 2000

- Institutional Records Keeping Course

West Virginia University

August 1998-December 1999

Morgantown, West Virginia

- Masters of Science Degree

- Wildlife and Fisheries Resource Management Major

- Grade Average: $3.78 / 4.00$

AZA Conservation Academy

Wheeling, West Virginia

February 1999

- Applied Zoo and Aquarium Biology Course 
West Virginia University

Morgantown, West Virginia

August 1997-May 1998

- Bachelor of Arts Degree

- Biological Sciences Major

- Grade Average: 3.46/4.00

\section{EXPERIENCE}

the Wilds

Cumberland, Ohio

Director of Conservation Science

November 2012-Present

- Manage field ecology projects

- Manage Hellbender Conservation Center and Research Animal Collections

- Manage Conservation Science Training Center programs

- Manage Wilds Intern Scholar and Apprenticeship programs - ( 40 participants per year)

- Manage Conservation Science Program budgets

- Coordinate collaborative relationships with colleges and universities

- Acquire and renew state and federal permits

- Taxon manager for the Eastern Hellbender through the AZA Amphibian Taxon Advisory Group

Oglebay's Good Zoo

Wheeling, West Virginia

Curator of Animals

February 2002-November 2012

- Manage animal care, building cleanup, and zoo horticulture and grounds staffs

- Create and manage animal care, animal purchase, veterinary care, zoo conservation programs, and zoo horticulture and grounds budgets

- Manage all animal records

- Manage raptor rehabilitation program

- Develop husbandry policies and procedures

- Acquire and renew state, federal, and international permits

- Manage institutional collection plan

- Manage animal transactions

- Serve as liaison with AZA conservation program representatives

- Coordinate veterinary procedures with zoo veterinarians

- Supervise and evaluate college interns (approximately 20 students per summer)

- Instructor for West Virginia Master Naturalist Program (Herpetology and Mammalogy)

- Taxon manager for the Eastern Hellbender through the AZA Amphibian Taxon Advisory Group

West Virginia University

Morgantown, West Virginia

Instructor

May 2012

- Co-taught Exotic Animal Medicine Course (2 credit hours)

- Co-taught lecture course and field sections focusing on preventative medicine, animal training, and capture and restraint to 5 students

- Created syllabus, lectures, and exams

- Graded assignments and exams 
West Virginia University

Morgantown, West Virginia

Instructor

January 2011 - May 2011; January 2012 - May 2012

- Taught Principles of Zoo Science Course (2 credit hours)

- Taught lecture course to 28 students

- Created syllabus, lectures, and exams

- Grade written assignments and exams

Oglebay's Good Zoo

Wheeling, West Virginia

Registrar and Manager of Animal Husbandry

January 2000-February 2002

- Manage animal records

- Manage and create animal purchase budget

- Develop husbandry policies and procedures

- Acquire and renew state, federal, and international permits

- Supervise and evaluate all college interns

- Organize species transactions

Oglebay's Good Zoo

Wheeling, West Virginia

Animal Keeper I

May 1999-January 2000

- Worked as swing keeper (responsible for animals in all sections of zoo)

- Cleaned exhibits and prepared diets

- Provided behavioral enrichment to animals

- Conducted research on terrestrial salamander monitoring project

- Performed minor exhibit maintenance

West Virginia University

Morgantown, West Virginia

Graduate Teaching Assistant

August 1998-May 1999

- Taught General Biology Laboratory Sections

- Taught 7 classes of 24 students

- Created quizzes and graded assignments, quizzes, reports, and debates

\section{PREVIOUS GRANTS AWARDED}

Cultivating Future Field Scientists Through Amphibian Conservation - West Virginia Wildlife Diversity Program Cooperative Project Grant - 2002

Habitat Preference and Winter Ecology of the Eastern Hellbender, Cryptobranchus alleganiensis alleganiensis, at Buffalo Creek, Bethany, West Virginia - West Virginia Wildlife Diversity Program Research Grant - 2004

West Virginia Northern Panhandle Herpetological Survey (Collaborative Research Grant with Oglebay Institute's Schrader Environmental Education Center - Dr. Zac Loughman) - West Virginia Wildlife Diversity Program Research Grant - 2005 
Surveillance and Monitoring of the Eastern Hellbender, Cryptobranchus alleganiensis alleganiensis, in five Ohio River tributary streams in the Northern Panhandle of West Virginia - West Virginia Wildlife Diversity Program Research Grant -2005

Surveillance, Public Outreach, and Captive Reproduction of the Eastern hellbender (Cryptobranchus alleganiensis alleganiensis) in Ohio (Collaborative Research Grant with The Wilds, Columbus Zoo and Aquarium, and Pittsburgh Zoo \& PPG Aquarium) - Ohio Wildlife Diversity Program Research Grant - 2005

Development of Surveillance and Monitoring Techniques for the Eastern hellbender (Cryptobranchus alleganiensis alleganiensis) in the Ohio River Valley of West Virginia - West Virginia Wildlife Diversity Program Grant - 2006

Development of a Surveillance and Response Plan for the Amphibian Chytrid Fungus in West Virginia (Collaborative Research Grant with Dr. Thomas K. Pauley, Marshall University) - West Virginia Wildlife Diversity Program Grant - 2007

Development of a Translocation Program for Eastern Hellbenders (Cryptobranchus allegnaniensis alleganiensis) in West Virginia with Captive-reared Hellbenders - West Virginia Wildlife Diversity Program Grant - Funded 2010 2012

Development of a Translocation Program for Eastern Hellbenders (Cryptobranchus allegnaniensis alleganiensis) in West Virginia with Captive-reared Hellbenders - Columbus Zoo and Aquarium Conservation Fund - 2011

Development of Integrated Conservation Techniques for the Eastern Hellbender in West Virginia - West Virginia Wildlife Diversity Program Grant - Funded - 2013

ESRI Conservation GIS Grant - Funded - 2013

Developing a Coordinated Research Approach for Hellbender Conservation in the Northeast with benefits to Wild Mudpuppy Populations (Collaborative Research Grant with Smithsonian Conservation Biology Institute, Buffalo State University, Maryland Division of Wildlife, and Western Pennsylvania Conservancy)- Northeast Association of Fish and Wildlife Agencies - Regional Conservation Needs Grant - Funded 2014

State-wide surveillance of the Eastern hellbender (Cryptobranchus alleganiensis alleganiensis) in Ohio Utilizing Environmental DNA (eDNA) Techniques - Ohio Division of Wildlife - Funded 2014

\section{PUBLICATIONS}

Gratwicke, B., Evans, M., Grant, E.H.C., Greathouse, J, McShea, W., Rotzel, N., and Fleischer, R. 2010. Low prevalence of Batrachochytrium dendrobatidis detected in aquatic Appalachian salamanders from Warren County, Virginia, USA. Herpetological Review. 42(2): 217-219.

Greathouse, J., C. Byrne, K. Samborsky, S. Klein, and A. Wendt. 2015 (In Press). Natural History Note Hellbender - Predation. Herpetological Review.

Greathouse, J. 2007. Collaborative partnerships for hellbender conservation. Proceedings of the AZA Annual Conference. Philadelphia, PA.

Greathouse, J. 2011. Natural History Notes on the Eastern hellbender (Cryptobranchus alleganiensis alleganiensis) in West Virginia. Proceedings of the $5^{\text {th }}$ Hellbender Symposium. Ligonier, PA.

Greathouse, J. 2007. Population status of the Eastern hellbender (Cryptobranchus alleganiensis alleganiensis) in the northern panhandle of West Virginia. Proceedings of the $3^{\text {rd }}$ Hellbender Symposium. Wheeling, WV. 
Greathouse, J. 2010. Surveillance of the amphibian chytrid fungus (Batrachochytridium dendrobatidis) in West Virginia amphibians. Proceedings of the West Virginia Academy of Sciences. Morgantown, WV.

Greathouse, J. 2011. Surveillance of the Eastern hellbender (Cryptobranchus alleganiensis alleganiensis) in West Virginia. Proceedings of the $5^{\text {th }}$ Hellbender Symposium. Ligonier, PA.

Greathouse, J. 2007. Winter activity of the Eastern hellbender (Cryptobranchus alleganiensis alleganiensis) in a creek in northern West Virginia. Proceedings of the $3^{\text {rd }}$ Hellbender Symposium. Wheeling, WV.

Seeley, K., M. D'Angelo, C. Gowins, and J. Greathouse. 2015. Prevalence of the amphibian chytrid fungus in Eastern hellbenders (Cryptobranchus alleganiensis alleganiensis) in West Virginia. Journal of Wildlife Diseases. (In Review). 